\title{
WestVirginiaUniversity
}

THE RESEARCH REPOSITORY @ WVU

Graduate Theses, Dissertations, and Problem Reports

2020

\section{Three Essays in Law and Economics}

Daniel Bonneau

ddb0013@mix.wvu.edu

Follow this and additional works at: https://researchrepository.wvu.edu/etd

Part of the Other Economics Commons, and the Public Economics Commons

\section{Recommended Citation}

Bonneau, Daniel, "Three Essays in Law and Economics" (2020). Graduate Theses, Dissertations, and Problem Reports. 7746.

https://researchrepository.wvu.edu/etd/7746

This Dissertation is protected by copyright and/or related rights. It has been brought to you by the The Research Repository @ WVU with permission from the rights-holder(s). You are free to use this Dissertation in any way that is permitted by the copyright and related rights legislation that applies to your use. For other uses you must obtain permission from the rights-holder(s) directly, unless additional rights are indicated by a Creative Commons license in the record and/ or on the work itself. This Dissertation has been accepted for inclusion in WVU Graduate Theses, Dissertations, and Problem Reports collection by an authorized administrator of The Research Repository @ WVU.

For more information, please contact researchrepository@mail.wvu.edu. 
Graduate Theses, Dissertations, and Problem Reports

2020

Three Essays in Law and Economics

Daniel Bonneau

Follow this and additional works at: https://researchrepository.wvu.edu/etd

Part of the Other Economics Commons, and the Public Economics Commons 


\title{
THREE ESSAYS IN LAW AND ECONOMICS
}

\author{
Daniel David Bonneau
}

\author{
Dissertation submitted to the \\ John Chambers College of Business and Economics \\ at West Virginia University \\ in partial fulfillment of the requirements for the degree of \\ Doctor of Philosophy \\ in \\ Economics
}

Joshua C. Hall, Ph.D., Committee Chairperson

Bryan C. McCannon, Ph.D.

Alexander L. Lundberg, Ph.D.

Jack A. Dorminey, Ph.D.

Department of Economics

Morgantown, West Virginia

2020

Keywords: Crime Policy, Policing, Plea Bargaining, Prison Construction, Extra-Legal
Factors

Copyright (C) 2020 Daniel D. Bonneau 


\title{
ABSTRACT
}

\section{Three Essays in Law and Economics}

\author{
by Daniel David Bonneau
}

This dissertation investigates three relevant topics in law and economics literature. The first chapter explores the effectiveness of a crime prevention policy in Detroit, Project Green Light. The second chapter empirically evaluates the dominant theory of plea bargaining in economics, using police officer deaths as plausibly exogenous variation to the sentencing process. The final chapter examines the impact of new public prison openings in the state of Florida.

The first chapter, "Does Increased Surveillance Deter or Displace Crime? An Evaluation of Detroit's Project Green Light" considers the direct and indirect effects of Detroit's Project Green Light. This initiative began in 2016 and was aimed at reducing crime around high-risk businesses. The approach to combating crime is through the installation of CCTV camera systems with a direct feed into a real-time crime center for rapid notification of crimes. Additionally, all calls from these participating businesses were designated priority 1 , the highest designation for the police department, with the intention of decreasing response times to these suspected crimes. To evaluate this program, geo-located crime and calls for service data are utilized. Additionally, the effects were considered at the business-block level, as well as throughout traditional buffer zones. Reductions in crime can be found in the business block that housed the green light, with a potential diffusion of benefits to their immediate neighbors. Using calls for service produces mixed results and suggest that there may be an increase in proactive policing within these areas. Lastly, response times do appear to decrease significantly.

In the second chapter, "Bargaining in the Shadow of the Trial? Deaths of Law Enforcement Officials and the Plea Bargaining Process" Dr. Bryan McCannon and I empirically test the dominant theory of plea bargaining in the economics literature. This theory is difficult to test, however, due to the endogeneity of reforms and the private information that may be driving the bargaining process. We contribute by using plausibly exogenous variation using deaths of law enforcement officials on a data set of all felonies processed from 2004-2017 within the state of Florida. We argue that deaths of law enforcement officials are salient to the potential voter base, thus increasing the probability of conviction at trial, funneling back into the plea bargaining process through harsher plea bargained sentence agreements. If this is the case, it would be evidence in support that plea bargaining occurs in the shadow of the trial. This is found. Considering only cases that were already in process at the time of a death, and located within the same county as the death, we find a $13 \%$ increase in plea bargaining sentences on average. Numerous alternative specifications were conducted to evaluate heterogeneous effects, in which we find more salient (gunfire deaths, expansive newspaper coverage, and public dedications) produce stronger effects. Lastly, to verify this occurs through the jury and not solely through changes in the attitudes of prosecutors or judges, we find that results are only present in reference to jury trials, with no effect for bench trials. These results provide suggestive evidence of the validity of a widely used framework with which economists evaluate the criminal justice system.

The third chapter, "If You Build It, We Will Make Them Come: The Impact of New Prison Construction on the Likelihood of Incarceration" evaluates the opening of new public prison facilities in Florida on the likelihood defendants face incarceration. Exploiting spatial and temporal variation in each case, I find a nine-month window of increased incarceration rates for those defendants most likely to face incarceration at the new prison. This effect is more pronounced in plea bargained cases, suggesting that prosecutors may be shifting their behavior during this time. This contributes to a growing literature that is investigating the mechanism through judges. 
To my parents, David and Nancy; and my brother, Derek. Your influence as role models, and your unwavering support of my aspirations have made this possible. 


\section{Acknowledgments}

I would like to thank those individuals that have been influential to my development both as a scholar, and a person throughout my time at West Virginia University. To my advisor, Dr. Joshua Hall, thank you for the many encouraging conversations in your office, and the opportunities you offered me to grow as a researcher, instructor, and person. The countless conversations we had provided me with some of the most valuable insights I have received during my time here.

To my committee members, thank you for always pushing me to dig deeper into my research questions. To Dr. Bryan McCannon, you have been influential in providing me with the knowledge and tools to join you as a researcher in the field of law and economics. To Dr. Alexander Lundberg, our relationship began to develop as my time here came to a close, but the insight you were able to provide me with in that short period will stay with me as a researcher. To Dr. Jack Dorminey, thank you for the feedback you provided in regards to the completion of this dissertation. In addition to my committee, I am grateful for the resources available at WVU in particular the support from the Center for Free Enterprise throughout my graduate education. Additionally, Karen Smith provided me with friendship through our many conversations in her office. On some of the toughest days, you turned my mood around just by being you.

To the teachers and professors that guided me prior to graduate school, thank you for the dedication you provided to me and other students. My high school mathematics teacher, Mr. Donald Blodgett, was influential in my discovery that math was fun. Without that, my entire professional path would be different. To Dr. Sean Mulholland, you were a mentor throughout my time as an undergraduate. I am certain that if I did not have you in my corner, I never would have pursued a Ph.D. To Dr. Norah Esty, just because I liked math, did not mean it was easy. Your courses challenged me in ways I never thought possible. That challenge provided me with confidence in myself to explore difficult ideas, and has been incredibly beneficial throughout graduate school.

The efforts of my friends along the way cannot go unacknowledged. I am grateful for the community created by my fellow graduate students at WVU. To my friends from college and back home, thank you for providing me a respite from the challenges of completing a Ph.D. To Jacob Raymond, I cannot express enough gratitude. Our many conversations have helped me through difficult times, and have assisted me in finding the person I want to become.

Last, but surely not least, my family has been my crutch through it all. To my father, David, thank you for fostering my interest in the criminal justice system. As a curious child, and now adult, you have always been willing to share your knowledge and expertise with me. You have been instrumental in the discovery of my passion. To my mother, Nancy, your enthusiasm and optimism with everything I do is infectious. The compassion you have always displayed for your family, friends, and strangers provided me with a vision of what it means to be a good person. I am grateful for the support you both have offered me throughout the program, and throughout my life. To my brother, Derek, you have always been an excellent role model. Your hard work is something I strive to compete with, and your accomplishments have pushed me to become the best version of myself. To Alicia, thank you for your unconditional support. To Luna, thank you for being the best cheerleader an uncle could ask for. To Laura, thank you for everything.

I would be remiss if I didn't mention the companionship of my pets. To my childhood dog, Skippy, you were my best friend. I miss you every day. To my cats, Coach and Fenway, you two came into my life in graduate school and the snuggles you offer are always the warmest. 


\section{Contents}

$\begin{array}{ll}\text { Abstract } & \text { ii }\end{array}$

Acknowledgments $\quad$ iv

List of Figures $\quad$ vii

List of Tables $\quad$ viii

1 Does Increased Surveillance Deter or Displace Crime? An Evaluation of Detroit's Project Green Light $\quad 1$

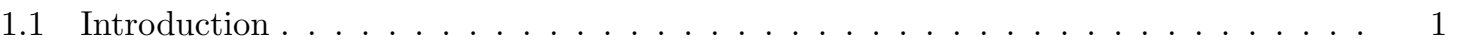

1.2 Detroit's Green Light Project . . . . . . . . . . . . . . . . . . . 4

1.3 Data . . . . . . . . . . . . . . . . . . . . 5

$1.3 .1 \quad$ Parcel Data . . . . . . . . . . . . . . . . . . . 6

1.3 .2 Crime Data . . . . . . . . . . . . . . . . . . . 8

1.3 .3 Calls for Service . . . . . . . . . . . . . . . . . . . . 10

1.4 Methodology . . . . . . . . . . . . . . . . . . . . . . . 11

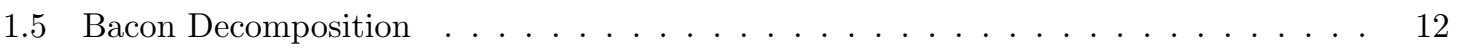

1.6 Results . . . . . . . . . . . . . . . . . . . . . . . . . . . 13

1.6.1 Monthly Crime in Business Blocks . . . . . . . . . . . . . . . . . . . 13

1.6.2 Weekly Crime in Business Blocks . . . . . . . . . . . . . . . . . . . 14

1.7 Buffer Zone Results . . . . . . . . . . . . . . . . . . . . . . . . 15

1.7.1 Monthly Crime in Buffer Zones . . . . . . . . . . . . . . . . . . 15

1.8 Results Using Calls for Service in Buffer Zones . . . . . . . . . . . . . . . . . . . 24

1.8.1 Calls for Service - $150 \mathrm{ft}$. Interior - $350 \mathrm{ft}$. Exterior . . . . . . . . . . . . 25

1.8.2 Calls for Service - $250 \mathrm{ft}$. Interior - $250 \mathrm{ft}$. Exterior . . . . . . . . . . . . 28

1.8.3 Calls for Service - $350 \mathrm{ft}$. Interior - $150 \mathrm{ft}$. Exterior . . . . . . . . . . . . . . 32

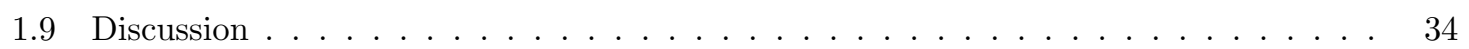

2 Bargaining in the Shadow of the Trial? Deaths of Law Enforcement Officials and the Plea Bargaining Process $\quad 36$

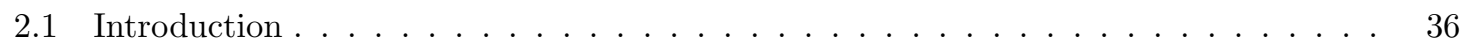

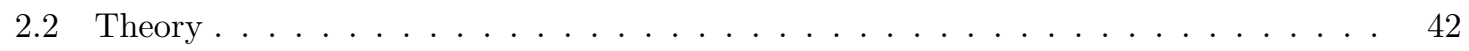

2.3 Data . . . . . . . . . . . . . . . . . . . . . . 43

2.3 .1 Police Deaths . . . . . . . . . . . . . . . . . . . . . . 43 
2.3.2 Charging and Prosecution in Florida . . . . . . . . . . . . . . . . . . . 44

2.4 Sentencing and the Plea Discount . . . . . . . . . . . . . . . . . . . . . . . 48

2.4 .1 Estimation Strategy . . . . . . . . . . . . . . . . . 49

2.4.2 Identification Concerns . . . . . . . . . . . . . . . . 51

2.4 .3 Main Result . . . . . . . . . . . . . . . . . . . . . . 54

2.4.4 Heterogeneous Treatment Effects . . . . . . . . . . . . . . 65

2.5 Going to Court . . . . . . . . . . . . . . . . . . . . . . . 69

2.6 Is it Really the Jurors? . . . . . . . . . . . . . . . . . . . . . . . . . . . . . . . . . . . 72

2.6.1 Separating Jury Trials from Bench Trials . . . . . . . . . . . . . . . . 72

2.6.2 Convictions versus Acquittals . . . . . . . . . . . . . . . . . . 74

2.7 Conclusion ............................ 76

2.8 Appendix ............................. 77

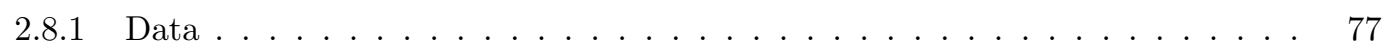

2.8.2 Additional Results ...................... 83

2.8.3 Breakdown By Crime Type . . . . . . . . . . . . . . . . 109

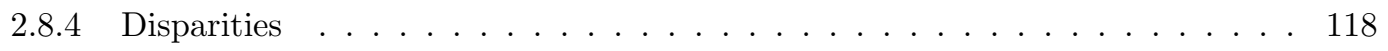

2.8.5 Charge Stacking . . . . . . . . . . . . . . . . . . 121

3 If You Build It, We Will Make Them Come: The Impact of New Prison Con$\begin{array}{lr}\text { struction on the Likelihood of Incarceration } & 123\end{array}$

3.1 Introduction . . . . . . . . . . . . . . . . . . . . . . . . 123

3.2 Florida's Criminal Justice System . . . . . . . . . . . . . . . . . . . . . . . . . . 125

3.3 Data . . . . . . . . . . . . . . . . . . . . . . 127

3.4 Where are Prisoners Sentenced? . . . . . . . . . . . . . . . . . . . . . . 131

3.5 Methodology ............................. 136

3.6 Results . . . . . . . . . . . . . . . . . . . . . . . . 137

3.6.1 Statewide Analysis . . . . . . . . . . . . . . . . . . . . 137

3.6 .2 Regional Analysis . . . . . . . . . . . . . . . . . . . 140

3.6.3 Removing Dismissed Cases ... . . . . . . . . . . . . . . 145

3.7 Discussion . . . . . . . . . . . . . . . . . . . . . . . 146 


\section{List of Figures}

1.1 Green Light Locations in Detroit . . . . . . . . . . . . . . . . . . 5

1.2 Detroit Business Parcels . . . . . . . . . . . . . . . . . . 7

1.3 Greenlights in Business Parcels $\ldots \ldots \ldots \ldots \ldots \ldots \ldots \ldots$

2.1 Does Sentencing Severity Correspond to Law Enforcement Officials' Deaths? . . . . 48

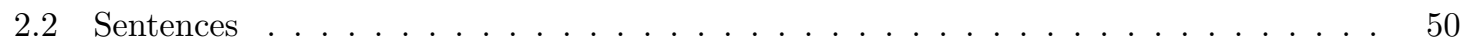

2.3 Test of Parallel Trends . . . . . . . . . . . . . . . . . . . . . . 55

2.4 Quantile Regression: Sentence Reduction for Pleading Guilty . . . . . . . . . . . . 62

2.5 DiD Coefficient from 1000 Permutations . . . . . . . . . . . . . . . . 63

2.6 Relationship between Trial Rate and Plea Discount . . . . . . . . . . . . . 66

2.7 Does LEO Death Correspond to Trials? _ . . . . . . . . . . . . . . . . . 70

2.8 LEO Deaths in Florida . . . . . . . . . . . . . . . . . . . . . 78

2.9 LEO Deaths Across the State . . . . . . . . . . . . . . . . . . . 79

2.10 Does Trial Convictions Correspond to LEO Deaths? . . . . . . . . . . . . . . . . . 85

2.11 Death Coefficient from 1000 Permutations: Serious Crimes Only . . . . . . . . . 89

2.12 Test of Parallel Trends: Trial Rate . . . . . . . . . . . . . . . . . . . . . . . . 90

2.13 Relationship between Trial Rate and Plea Discount . . . . . . . . . . . . . . . 115

2.14 Relationship between Change in the Trial Rate and Change in the Plea Discount . . 117

3.1 Florida Circuits . . . . . . . . . . . . . . . . . . . . . . . 126

3.2 Florida Department of Corrections Regions . . . . . . . . . . . . . . . . . . . . 132 


\section{List of Tables}

1.1 Summary Statistics - Monthly Blocks _. . . . . . . . . . . . . . . . 9

1.2 Crime in Business Blocks - Monthly . . . . . . . . . . . . . . . . . . 13

1.3 Business Blocks Regressions - Live Only . . . . . . . . . . . . . . . . . . 14

1.4 Summary Stats - $150 \mathrm{ft}$. Interior Buffer - $350 \mathrm{ft}$. Exterior . . . . . . . . . . . . 16

1.5 Crime in Buffers - $150 \mathrm{ft}$. Interior - $350 \mathrm{ft}$. Exterior . . . . . . . . . . . . . . 17

1.6 Total Crime Bacon Decomposition - 150ft Interior \& $350 \mathrm{ft}$. Exterior . . . . . . . . . 18

1.7 Violent Crime Bacon Decomposition - 150ft Interior \& $350 \mathrm{ft}$. Exterior . . . . . . . 18

1.8 Property Crime Bacon Decomposition - 150ft Interior \& $350 \mathrm{ft}$. Exterior . . . . . . . 18

1.9 Summary Stats - $250 \mathrm{ft}$. Interior Buffer - $250 \mathrm{ft}$. Exterior . . . . . . . . . . . . 19

1.10 Crime in Buffers - $250 \mathrm{ft}$. Interior - $250 \mathrm{ft}$. Exterior . . . . . . . . . . . . . 20

1.11 Total Crime Bacon Decomposition - 250ft Interior \& $250 \mathrm{ft}$. Exterior . . . . . . . . 20

1.12 Violent Crime Bacon Decomposition - 250ft Interior \& $250 \mathrm{ft}$. Exterior . . . . . . . . 21

1.13 Property Crime Bacon Decomposition - 250ft Interior \& $250 \mathrm{ft}$. Exterior . . . . . . . 21

1.14 Summary Stats - $350 \mathrm{ft}$. Interior Buffer - $150 \mathrm{ft}$. Exterior . . . . . . . . . . . . . 21

1.15 Crime in Buffers - $350 \mathrm{ft}$. Interior - $150 \mathrm{ft}$. Exterior . . . . . . . . . . . . . . 22

1.16 Total Crime Bacon Decomposition - 350ft Interior \& $150 \mathrm{ft}$. Exterior . . . . . . . . . 23

1.17 Violent Crime Bacon Decomposition - 350ft Interior \& $150 \mathrm{ft}$. Exterior . . . . . . . . 23

1.18 Property Crime Bacon Decomposition - 350ft Interior \& $150 \mathrm{ft}$. Exterior . . . . . . . 23

1.19 Summary Statistics - All Calls - $150 \mathrm{ft}$. Interior - $350 \mathrm{ft}$. Exterior . . . . . . . . . . . 25

1.20 Summary Statistics - 911 Calls $-150 \mathrm{ft}$. Interior - $350 \mathrm{ft}$. Exterior . . . . . . . . 26

1.21 Summary Statistics - Non-Calls - $150 \mathrm{ft}$. Interior - $350 \mathrm{ft}$. Exterior . . . . . . . . . 26

1.22 Calls for Service - $150 \mathrm{ft}$. Interior - $350 \mathrm{ft}$. Exterior . . . . . . . . . . . . . . 27

1.23 Calls for Service W/ Buffer Live - $150 \mathrm{ft}$. Interior - $350 \mathrm{ft}$. Exterior . . . . . . . . . 28

1.24 Summary Statistics - $250 \mathrm{ft}$. Interior - $250 \mathrm{ft}$. Exterior . . . . . . . . . . . . . . 29

1.25 Calls for Service $-250 \mathrm{ft}$. Interior - $250 \mathrm{ft}$. Exterior . . . . . . . . . . . . . 30

1.26 Calls for Service W/ Buffer Live - $250 \mathrm{ft}$. Interior - $250 \mathrm{ft}$. Exterior . . . . . . . . . . 31

1.27 Summary Statistics - $350 \mathrm{ft}$. Interior - $150 \mathrm{ft}$. Exterior . . . . . . . . . . . . . . 32

1.28 Calls for Service - $350 \mathrm{ft}$. Interior - $150 \mathrm{ft}$. Exterior . . . . . . . . . . . . . . 33

1.29 Calls for Service W/ Buffer Live - $350 \mathrm{ft}$. Interior - $150 \mathrm{ft}$. Exterior . . . . . . . . . 34

2.1 Law Enforcement Official Deaths . . . . . . . . . . . . . . . . . . . . . . 44

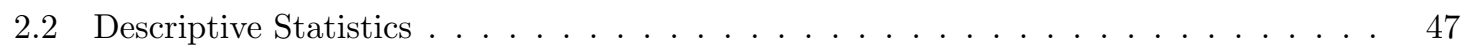

2.3 Randomness Check . . . . . . . . . . . . . . . . . . . . 51 
2.4 Test of Parallel Trends . . . . . . . . . . . . . . . . . . . . . . . 53

2.5 Bargaining in the Shadow of the Trial? . . . . . . . . . . . . . . . 56

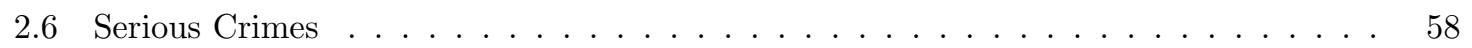

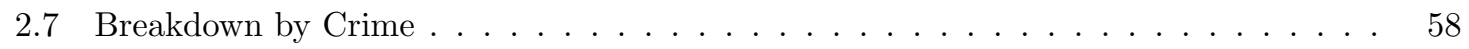

2.8 Hurdle Model . . . . . . . . . . . . . . . . . . . . . . . . . . . . . . . . . . . 60

2.9 Permutation Test: Plea Discount . . . . . . . . . . . . . . . . . . . 62

2.10 Heterogeneous Treatment Effects . . . . . . . . . . . . . . . . . 67

2.11 Trial Rate . . . . . . . . . . . . . . . . . . . . . . . . . 70

2.12 Trial Rate: Heterogeneous Treatment Effects . . . . . . . . . . . . . . . . . 71

2.13 Is it Really Affecting Jurors? Plea Discount . . . . . . . . . . . . . . . . . . . . . 73

2.14 Is it Really Affecting Jurors? Trial Rate . . . . . . . . . . . . . . . . . . . 74

2.15 Acquittal Rate . . . . . . . . . . . . . . . . . . . 75

2.16 Treatment Time Series . . . . . . . . . . . . . . . . . . . . . 79

2.17 Less-Serious Crimes _ . . . . . . . . . . . . . . . . . . . . 84

2.18 Quantile Regression . . . . . . . . . . . . . . . . . . . . . 86

2.19 Treatment Effect . . . . . . . . . . . . . . . . . . . . 86

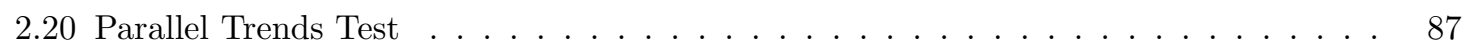

2.21 Permutation Test: Trial Rate . . . . . . . . . . . . . . . . . . . . . 88

2.22 Parallel Trends Test: Trial Rate . . . . . . . . . . . . . . . . . . . . . . . . 90

2.23 Test of Parallel Trends: Trial Rate . . . . . . . . . . . . . . . . . . . . . 90

2.24 Alternative Adjustments to the Dependent Variable . . . . . . . . . . . . . . . 91

2.25 County Fixed Effects and Clusters _ . . . . . . . . . . . . . . . . . 92

2.26 Circuit Fixed Effects and Clusters _ . . . . . . . . . . . . . . . . 93

2.27 A Further Refining of the Fixed Effects and Clusters . . . . . . . . . . . . . . . 94

2.28 Dropping Arrests Immediately after the Death . . . . . . . . . . . . . . . . . . . . . . . .

2.29 Dropping Counties without a Death . . . . . . . . . . . . . . . 96

2.30 Heterogeneous Treatment Effects: All Felonies . . . . . . . . . . . . . . . . . 97

2.31 Plea Discount: Heterogeneous Treatment Effects: All Felonies . . . . . . . . . . . . . 98

2.32 Plea Discount: Heterogeneous Treatment Effects: Serious Crimes Only . . . . . . . . 99

2.33 Breakdown by Crime . . . . . . . . . . . . . . . . . . . . . . . 100

2.34 A Long Time Since Arrest . . . . . . . . . . . . . . . . . . . . . . . . . . 101

2.35 Dedications . . . . . . . . . . . . . . . . . . . . 102

2.36 Spatial Effects _. . . . . . . . . . . . . . . . . . . 104

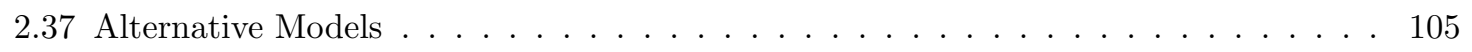

2.38 Dropping Arrests Immediately After the Death: Trial Rate . . . . . . . . . . . . 105

2.39 Dropping Counties without a Death: Trial Rate . . . . . . . . . . . . . . 106

2.40 Less-Serious Crimes: Trial Rate . . . . . . . . . . . . . . . . . . . . . . 107

2.41 A Further Refining of the Fixed Effects and Clusters: Trial Rate . . . . . . . . . . . 107

2.42 Trial Rate: Heterogeneous Treatment Effects: Serious Crimes Only . . . . . . . . . 108

2.43 Time Since Arrest: Trial Rate . . . . . . . . . . . . . . . . . . . . . . . 108

2.44 Trial Rate Broke Down by Crime . . . . . . . . . . . . . . . . . . . . . 109

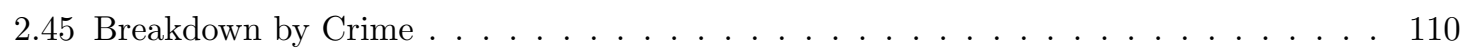

2.46 Pleas or Trials? . . . . . . . . . . . . . . . . . . . . . . . . 111 
2.47 Crimes with at Least 2500 Observations . . . . . . . . . . . . . . . . . . . . . . . . 112

2.48 Main Specification on Different Subsamples . . . . . . . . . . . . . . . . . . . . 113

2.49 Trial Rate Specification on Different Subsamples . . . . . . . . . . . . . . . . . 116

2.50 Disparities: Plea Discount . . . . . . . . . . . . . . . . . . . . . . . . . 119

2.51 Disparities: Trial Rate . . . . . . . . . . . . . . . . . . . . . . . . . 120

2.52 Charge Stacking . . . . . . . . . . . . . . . . . . . . . . 122

3.1 Summary Statistics - Including Dismissed Cases . . . . . . . . . . . . . . . . . . . . 128

3.2 List of New Prison Openings . . . . . . . . . . . . . . . . . . . . . . . . 130

3.3 Home and Crime Locations . . . . . . . . . . . . . . . . . . . . . . . . . . . . . 132

3.4 Home and Prison Locations . . . . . . . . . . . . . . . . . . . . . . . . . . . . . . . 132

3.5 Crime and Prison Locations . . . . . . . . . . . . . . . . . . . . . . . . . 133

3.6 Percent Sentenced within Region . . . . . . . . . . . . . . . . . . . . . . 134

3.7 Home and Prison Region Percentages . . . . . . . . . . . . . . . . . . . . . . . 135

3.8 Statewide Results - Disposal Type . . . . . . . . . . . . . . . . . . . . . . . . . . 138

3.9 Statewide Results - Case Outcome . . . . . . . . . . . . . . . . . . . . . . . . . 139

3.10 Regional Results - Disposal Type . . . . . . . . . . . . . . . . . . . . . . . . . . . . 141

3.11 Regional Results - Case Outcome . . . . . . . . . . . . . . . . . . . . . . . . . . . . 142

3.12 Regional Results - Case Outcome by Disposal Type . . . . . . . . . . . . . . . . . . 144

3.13 Summary Statistics - w/o Dismissed . . . . . . . . . . . . . . . . . . . . . . . . . 145

3.14 Statewide Results - Case Outcome w/o Dismissed . . . . . . . . . . . . . . . . . . . 147

3.15 Regional Results - Case Outcome w/o Dismissed . . . . . . . . . . . . . . . . . . . . 148

3.16 Regional Results - Case Outcome by Disposal Type w/o Dismissed . . . . . . . . . . 149 


\section{Chapter 1}

\section{Does Increased Surveillance Deter or Displace Crime? An Evaluation of Detroit's Project Green Light}

\subsection{Introduction}

Technology has been slowly integrating into the criminal justice system in the United States. As high-quality technology becomes available as lower prices, some departments have created unique programs to approach crime reduction through different means. In 2016, Detroit implemented Project Green Light, a public-private partnership between the police departments and local businesses. This program is just one development the city of Detroit has undertaken in an attempt to combat the high-levels of crime within the city. Findings suggest that there may be an increase in the number of crime events, and total charges levied against criminals in the area immediately surrounding these green lights.

The investigation will utilize all green light locations present through the $15^{\text {th }}$ week of 2019 , which totals 554 businesses that have gone live within the program. The primary analysis will use parcels files from the city of Detroit for lots that were zoned for business. The classification used allowed for the inclusion of strictly business usage, mixed usage, and industrial usage. These businesses will then be grouped into block-street parcels that will allow us to aggregate the area and investigate potential displacement effects. Importantly, residential parcels are included from the analysis. Further checks will be conducted using buffer zones of 500 feet around the locations. These 500 foot buffer zones will be broken down into "interior" and "exterior" areas. Interior areas will be 150 feet, 250 feet, and 350 feet, with the exterior areas as the remaining distance to fill the 500 foot buffer. In cases of overlapping buffer zones, the crime will be assigned to the buffer zone that is nearest. This does force the reduction of the data set to only include those crimes that occurred within a buffer zone of a green light. However, this will be discussed in more depth in the alternative specifications section of this paper. Lastly, calls for service will address the important question of the mechanism that may be influencing the results found in the paper. That is, is there an increase in the likelihood that the community seeks the help of the police department, or is it through an 
increase in policing a particular area that there is a change in the crime rate? Results suggest that these green lights may decrease crime within the particular business block, and that there may be a diffusion of benefits for the blocks that neighbor an area that received a green light. However, the mechanism does not consistently suggest a change in the calls for service, as measured by the combination of police initiated interactions and 9-1-1 phone calls. However, findings here suggest that there may be an increase in proactive policing where police expend more resources in this area, which may occur either as a result of responses to events captured on the CCTV security systems, or through more proactive policing of these areas. The evaluation of this program adds to a larger literature in both economics and criminology regarding policy that aims to deter crime.

Two strands of the literature are particularly relevant for this paper: The effect of increase police presence on crime, and the effect of surveillance systems on crime. With respect to the impact of police presence on crime, Klick and Tabarrok (2005) exploit the Homeland Security Advisory System, which increased police presence within the Washington D.C. during periods of high alert. Using the variation in this plausibly exogenous alerting ranking and utilizing daily data, the authors find that the increased police presence decreased total crimes within the city and that this effect was concentrated in non-violent crimes, particularly auto thefts. The analysis is similar to that in Di Tella and Schargrodsky (2004), where the authors investigated a terrorist attack in Buenos Aires, Argentina in 1994 that led to an increase in police presence around Jewish institutions. This study also finds a decrease in motor vehicle thefts utilizing this plausibly exogenous increase in police presence. Each of these studies utilizes events that can be plausible said to be exogenous. The current paper does not benefit from the same identification, as businesses must buy the equipment necessary to participate in the program. However, the potential for increased police presence to deter crime could be one mechanism through which Project Green Light impacts crime rates.

However, effects may extend beyond motor vehicle thefts. Cheng and Long (2018) consider the question of police presence using the French Quarter Task Force in New Orleans, Louisiana. This program sought to increase the visibility of police within the French Quarter. After the implementation of this program, robberies, aggravated assaults, and thefts decreased by at least $13 \%$. A unique wrinkle in this program is that management changed hands during their sample. Utilizing this change, the authors also found that incentive programs for police officers within the overall program led to an additional decrease across these crimes. This suggests that the estimates mentioned earlier may not capture the full effect of an increase in police presence as compliance of the officers is critical to the success of these visibility programs. Compliance is an important issue when it comes to studying Project Green Light. With the initiative set on increasing police responsiveness and visibility within areas, if the officers are not adhering to the goals of the program, it will likely be ineffective. However, police behavior can be addressed in an indirect way, as described in the Alternative Specification section of the paper.

Chicago implemented a similar program to reduce crime in specific areas, however it was not through an increase in police presence, rather civilian presence. Chicago's Safe Passage program was designed to create corridors of safety for students to travel to and from school. This program launched during the 2009-2010 school year and saw massive expansion within five years. These programs are not patrolled by formal police officers, however, and instead are patrolled by regular citizens. Interestingly, it is found that the presence of regular citizens can also have a deterrent effect on crime, with violent crime decreasing by $14 \%$ on average (McMillen, Sarmiento-Barbieri, \& Singh, 
2019). Taken together, these papers suggest that the Green Light Project should be successful at reducing crime within the areas of the green lights, under the assumption that the visibility of police either through patrols, or response times, improves. ${ }^{1}$ None of the aforementioned papers are able to find any results related to the potential displacement of this crime to areas unaffected by the program. These displacement effects in crime studies can be difficult to measure. Not only can displacement be defined as crime moving to another location, but it could also manifest itself in different types of crimes occurring within the treated area (Yang, 2008; Ratcliffe \& Breen, 2011; Rosenfeld et al., 2014). While an interesting program to study, the granular treatment areas for the current paper make transitions to other criminal activities difficult to measure.

While the studies mentioned previously inform the potential mechanisms through which there may be a result, the broader literature this paper contributes to addresses the effect of CCTV cameras on crime prevention. This is an active literature that continues to grow as these programs become more popular around the world. Many good discussions of this literature exist, for a comprehensive review, see Piza, Welsh, Farrington, and Thomas (2019). However, these programs do appear to create a modest decrease in crime in the aggregate, particularly in public (Welsh \& Farrington, 2009) and residential areas (Piza et al., 2019). These programs are particularly effective when directly targeting specific areas and specific crimes. Consideration needs to be made about the evaluation of the effectiveness of these programs. It may be the case that deterrence is the ultimate goal. In fact, that is what is stated for Project Green Light. However, it may be a facade for increasing the conviction rate, as these camera systems may lead to an increased probability of apprehending the suspect. Unfortunately, this paper is unable to address the latter goal with the data that are currently available.

Project Green Light has piqued the interest of other researchers as well. Namely, Circo and McGarrell (2020) evaluate the same program, but only consider the first 87 businesses to participate. These businesses are then matched to an additional 201 businesses to evaluate the effectiveness of the Green Light Project at reducing crimes within the green light zones. The authors find an unstable reduction in property crimes and no impact on violent crimes. These results are consistent with a large body of literature on the topic (see Welsh and Farrington (2009) for a review of the literature). This study is the most relevant to the current study, and therefore an explanation of the differences between the two papers is necessary. To begin, the difference in the number of businesses considered and the period of investigation allows my paper to evaluate potential impacts of the growth of the program, as well as provides us with a stronger pre-treatment period. The data set to be used considers all crime within the city from 2009-2019, whereas their pre-period starts at the beginning of the initiative in 2015 and only continues through the second year of implementation, the end of 2017. Additionally, they utilize a 200 foot buffer zone, while also considering shorter radii on buffers to investigate even more immediate effects of this program. My paper provides an additional approach using business blocks as well as buffer zones. While Circo and McGarrell (2020) provides an excellent investigation into the program, I believe my study complements their paper by contributing additional insights that were not covered in the initial analysis of the program.

The paper proceeds as follows. Section 2 discusses the Detroit Green Light Project, providing institutional details about the program. Section 3 discusses the data used for this project, while

\footnotetext{
${ }^{1}$ Some other studies on the topic include: Rosenfeld, Deckard, and Blackburn (2014); Koper (1995); Lin (2009); Weisburd (2016); and Draca, Machin, and Witt (2011), among others.
} 
Section 4 introduces the methodology to be used in the analysis. Section 5 presents the results broken up into various sub-sections for different approaches to the analysis. Section 6 adds to the results by decomposing the coefficients in the difference-in-difference analysis using the Bacon Decomposition. Second 7 considers alternative specifications and the calls for service data set. Finally, Section 8 concludes with a discussion of the findings.

\subsection{Detroit's Green Light Project}

Detroit's Project Green Light is a public-private partnership between the police department and local businesses in an effort to reduce crime within the city. With upwards of $25 \%$ of violent crime occurring within 500 feet of gas stations, the police department concluded that targeting these late night businesses was a feasible approach to reduce violent crime within the city (Project, 2019). This program places cameras outside of participating businesses, covering all areas generally accessible by the general public. The goal is to reduce crime at the business and in the immediate surrounding area. The program began on January 1, 2016 with the initial involvement of eight gas stations. Since its implementation, the program has grown to over 500 businesses and has faced both praise and critique from residents and local businesses. Joining this program can be done in a few different ways. For example, individual businesses can join, or groups of five-or-more businesses within a two to three block radius can join together (known as a corridor). The program is aptly named, with the most visible component of this program being physical, flashing, green lights located on store fronts. The intent of this is to serve as a deterrent effect on potential criminals, as seeing this green light notifies these individuals that this location is closely monitored by the police department and will see a rapid response. In addition to the green lights, these programs also install closed-circuit television systems (CCTV) for visual monitoring of the areas. These cameras feed directly into a real-time crime center (RTCC) associated with the police department and are monitored 24/7. These real-time video feeds from businesses across the city were implemented with the intention of quick notification to police of the criminal activity that is occurring. These faster response times may have a deterrant effect on crime themselves (Weisburd, 2016). As a last line of notification to criminals that this business may not be the one to commit criminal activity in or near, there is also posted signage that this business is a partner with the Green Light Project. ${ }^{2}$

The cameras installed in this businesses are high-definition (HD) and allow the police department to work with clear pictures to then notify the community of the suspects. The implementation of a technological approach to fighting crime has been praised by the police department in the city, and the growth of the program to over 550 businesses within three years may suggest that the program is effective at deterring crime around the business. However, participating businesses must incur out of pocket costs to join the program. Individual businesses must purchase the CCTV surveillance cameras from a verified dealer, a physical green light to place on their business, and signage for the exterior of the building in order to participate in the program. These costs typically range in total between $\$ 4,000$ and $\$ 6,000$ for an individual businesses. ${ }^{3}$ These costs are for if a business would like to purchase the cameras, though there are options for leasing. These leasing options are

\footnotetext{
${ }^{2}$ For a full description of the program, visit https://detroitmi.gov/departments/police-department/project-greenlight-detroit.

${ }^{3}$ Costs can be found here https://detroitmi.gov/departments/police-department/project-green-lightdetroit\#collapse-vbp-accordion-21131-1
} 
far more affordable in the short term, with installation costs that may be as high as $\$ 1,000$ but monthly fees of $\$ 130$ - $\$ 180$ per month to participate in the program. The costs associated with the program may be an issue with any analysis that follows, as there is likely to be selection into which businesses participate in this program and those that don't. Finally, while businesses must purchase the cameras from verified vendors and have them installed, the police department decides where these cameras are placed. Generally, cameras are placed inside of businesses and also on the exterior in view of any public entrances to the business.

Even with a direct feed to the RTCC, the program explicitly states that it should not replace the traditional suggestion of calling 9-1-1 in the event of an emergency. However, dispatch is aware of all businesses that are active participants in the program, and will relay that information to the dispatched officers. Along with the 24/7 surveillance, all calls from a Green Light participating business are designated for priority 1 response, the highest priority within the police department. This should serve to decrease response times to any emergencies that occur at these locations. However, this increased responsiveness, and overall attention given to these businesses has led some to view the program as unfair, as some businesses that could benefit are excluded because of the prohibitive cost to join the program.

\subsection{Data}

The sample of green lights includes 554 green light locations across the city of Detroit and can be seen in Figure 1.1. In this figure are all the locations that had a green light turn on since the beginning of the program in 2016 and the collection of the data in 2019. The lines within the boundary of Detroit represent the 207 neighborhoods within the city. As can be seen in the figures, there are a few green light locations that fall outside of the boundary of Detroit. These observations will be removed as will be explained later through the merging of crime data and green light locations.

Figure 1.1: Green Light Locations in Detroit

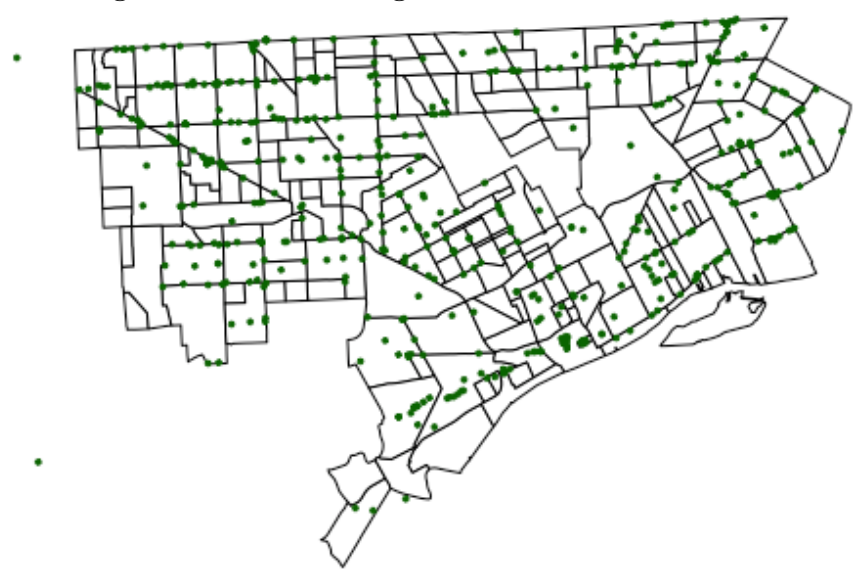

All green light locations within Detroit are shown in green dots. These are presented irrespective of the year in which they became live. The boundaries within the city of Detroit represent the 208 neighborhoods within the city.

In effect, since there are no crimes present in these green lights they will be discarded from the 
data set. ${ }^{4}$ Therefore, the information presented within the results section of this paper is under the assumption that the information provided by the Detroit Open Data Portal is fully correct and that these crimes, and these green lights, were coded intentionally as where they actually occurred or are located.

\subsubsection{Parcel Data}

Rather than using buffer zones around the green lights and varying the diameter of the buffer, property information through parcel files will be used. The primary reason for this is that these green lights are intended to reduce crime around businesses that might be most susceptible to criminal activity. Using these parcel files will allow us to evaluate the effectiveness of the program at a very granular level. As with the crime and green light data, the parcel files can be accessed through Detroit's Online Data Portal. ${ }^{5}$ Traditionally, spatial crime papers utilize buffer zones around the area of interest to measure either the impact on crime or potential displacement effects (Bowers \& Johnson, 2003; Linden \& Rockoff, 2008; Waples, Gill, \& Fisher, 2009; Bell, Jaitman, \& Machin, 2014; Cui \& Walsh, 2015). ${ }^{6}$ My deviation from the traditional measurement of crime is important. Namely, this is conducted because these green lights are targeted to reduce crime around businesses. By using the traditional buffering method, it may be capturing areas in which the green light would not be expected to effect (for example, a business that was next to a park may have no effect on the park, but that may be the majority of the buffer). Therefore, each parcel file that is zoned for some type of business (business, mixed-use, or industrial) will be included and then aggregated to the block-street level. Even with this benefit, there are important limitations to this strategy. Primarily, these business blocks are not uniform in size and shape. Therefore, a business block could contain only one business, while another contains a dozen. Additionally, these areas will generally be smaller than what would be covered under, for example, a $250 \mathrm{ft}$. buffer zone. Given these limitations, the analysis will be buttressed with results using the traditional buffer zones, with the specific methodology largely following Circo and McGarrell (2020).

This parcel file contains all parcel information for the city, including the full address, squarefootage, assessed value, number of buildings, and the zoning code. For the purposes of this study, only those parcels that are zoned for business or multi-use purposes will be retained. That is, any residential or government properties will be removed from the data set. ${ }^{7}$ Figure 1.2 displays the coverage of these parcels.

In order to correctly specify the green light geometry within a particular parcel, the potential for multiple businesses within a block joining the green light project must be discussed. Because of this, some concessions need to be made. Namely, if there are multiple green lights in a particular block, only consider the first active green light within a parcel will be used for the location and active date of the light. For example, if there are two green lights in a district, with the first one active on January 1, 2016, and the second one active on January 1, 2017, the live date for that parcel's green

\footnotetext{
${ }^{4}$ It is assumed that the geo-located data provided by Detroit is correct. However, these locations will be verified later on. An issue arises where the data may be incorrect when checked and incorrectly changed. Therefore, all green light coordinates provided by the Detroit Open Data Portal will be assumed correct and utilized for the analysis.

${ }^{5}$ The file for parcels can be found here: https://data.detroitmi.gov/datasets/parcels-2?geometry=$83.668 \% 2 \mathrm{C} 42.264 \% 2 \mathrm{C}-82.533 \% 2 \mathrm{C} 42.442$

${ }^{6}$ For a review of some studies using buffer zones to evaluate crime placement, see Bernasco and van Dijke (2020).

${ }^{7}$ The codes retained are B-codes (business districts), M-codes (industrial districts), SD-codes (special development districts), and transitional industrial and waterfront districts (TM and W1, respectively). Zoning codes can be found here: https://detroitmi.gov/sites/detroitmi.localhost/files/2018-05/Zoning\%20Classifications1.pdf
} 
light will be January 1, 2016. Refining in this way reduces the total green light count from 554 to 440 .

Figure 1.2: Detroit Business Parcels

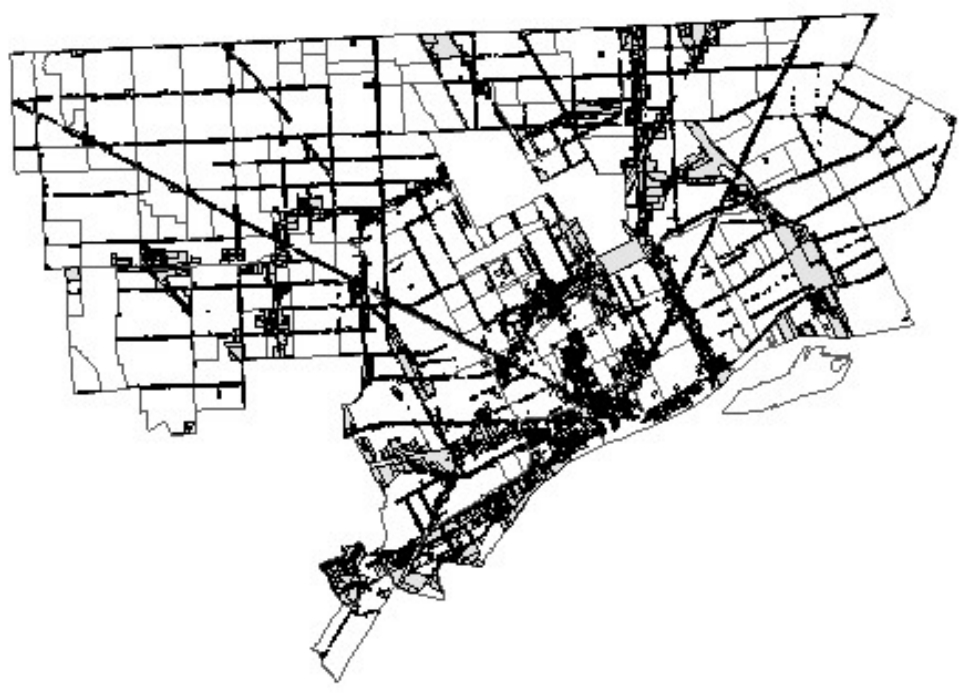

However, as can be seen in Figure 1.2, there are spaces of Detroit that are not designated as business, industrial, or mixed-use parcels. In an ideal world, these green lights would only be active in these parcels, however, there are a significant number of them that are outside of the parcel boundaries. Of these 440 remaining light-groups, 148 lie outside of the business parcels (292 remain). Figure 1.3 provides a visual of the green light differentiation.

Figure 1.3: Greenlights in Business Parcels

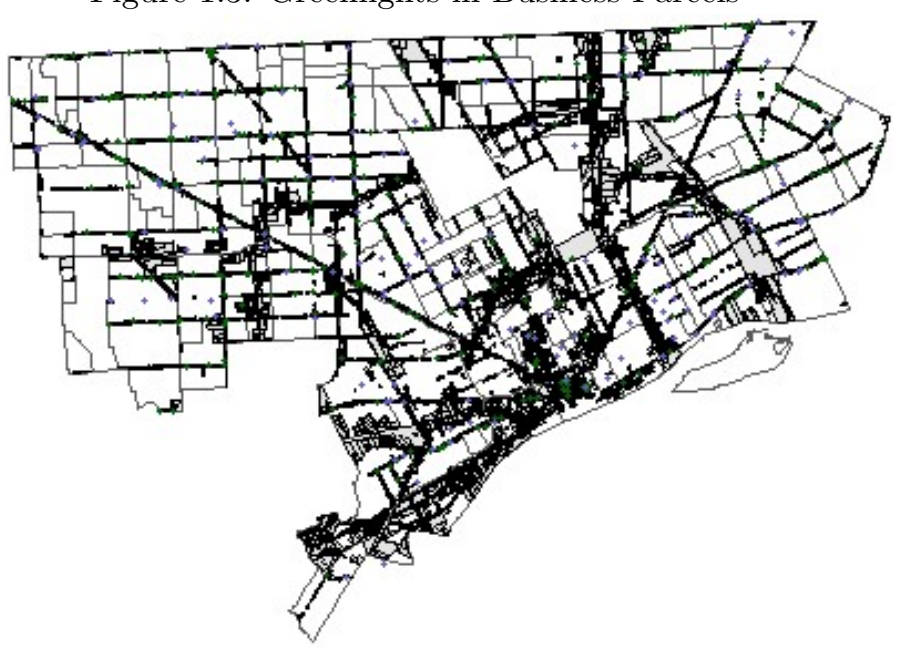

Now that green lights are assigned to individual parcels, parcels can be aggregated to the blockstreet level. This is done using the full address of the parcel as provided in the raw data. To do this, each is changed to only represent the hundredth block it corresponds to. That is, each number for the parcel is divided by 100 to create blocks that would represent, for example, the 1600 block of a particular street would group all parcels on that street that had 16xx for their address. These 
blocks are then aggregated by their streets to create an aggregated parcel file of each 100-block of a street. This may include multiple parcels, or it may only include one. These blocks will vary in size and coverage. Using the aggregation method, there are 7,319 business blocks. These business blocks are then filtered to include those that have at least one crime or call for service, depending on the data used. This is due to the minimization algorithm for the assignment of crimes that will be discussed later. This leaves us with 3,174 business blocks. These remaining business blocks will then be assigned their two nearest neighboring business blocks. Importantly, only those that are within the 3,174 blocks that saw at least one crime occur during the sample period are considered for the pool of potential neighbors. This presents the possibility of neighbors being far away from one another. However, the neighbors will be the two closest, which will attempt to reduce the distance as much as possible.

As discussed previously, if a parcel has multiple green lights, only the first live green light is used for the assignment of an active green light within the parcel. From this, the earliest green light within the newly aggregated business block is also utilized. Importantly, information for the neighboring business blocks green lights are also included. Therefore, the data set includes an ID for each business block, and the ID's for both of the neighboring business blocks. ${ }^{8}$ Retaining the ID information allows for the control of the impact of a green light becoming live within a neighboring block, to address any displacement effects or diffusion of benefits. With the inclusion of two neighbors, it would be unwise to assign importance to one neighbor over the other. Therefore, the earliest green light information across both neighbors will be used to check for these effects.

With the creation of the parcel files in mind, the discussion of the two data sets that may represent crime and police activity within these areas follows in the subsections below.

\subsubsection{Crime Data}

The data used for this project was gathered from Detroit's Open Data Portal. ${ }^{9}$ This data portal includes geo-located information for each crime that has occurred within the city from the beginning of 2009 through the $15^{\text {th }}$ week of 2019 . The criminal data includes a crime ID that can be utilized to group individual events of crime that had multiple arrest charges into one. It also includes a description of the crime that will be utilized in order to separate violent crimes from property crimes. The refinement of these crimes was a decision of the author, though there was an attempt to remain as consistent as possible with the Uniform Crime Report (UCR) designation for each. Violent crimes capture activities that were perpetrated against individuals with force, such as assault, robbery, and homicide. Meanwhile, property crimes are crimes that violated the rights of ownership over something physical. These include property damage, larceny, burglary, and arson. These lists are not exhaustive, however, they give a general sense of what categories crimes fall into. ${ }^{10}$ Lastly, it may be the case that there are multiple entries for the same crime ID. To ensure there is not a double counting of crimes, each crime is grouped by its crime ID. ${ }^{11}$

\footnotetext{
${ }^{8}$ Blocks cannot be neighbors with themselves.

${ }^{9}$ https://data.detroitmi.gov/

${ }^{10}$ Additionally, there is some overlap between the two separate data sets in 2016. In these cases, the crime listing from the 2009-2016 data are used and the overlapping observations from the 2016-2019 observations are discarded.

${ }^{11}$ In the 2009-2016 data there are some issues with the coordinates for crimes. In some cases, the coordinates are expanded beyond the usual number of decimal places, thus placing it in a slightly different location. To fix this, each coordinate is rounded to the nearest thousandth place. Just under $2 \%$ of the data remain without an ability to match the coordinates between multiple occurrences of a crime ID. Because it is unclear which area to assign the crime to,
} 
The aggregation of crimes into total crimes, which will primarily be used for the analysis, does not just count violent and property crimes. There is inclusion of crimes that do not fall directly into that category (such as fraud). These crimes will then be merged by their location with their nearest business block street. Due to the smaller size of these business blocks, there do exist many zeros in the dependent variable. This creates an issue for the most accurate assignment of if a crime occurred before or after a green light. Namely, since there is the specific date for each crime and the active date of each green light, it would be ideal to conduct the analysis at a daily level. Obviously, daily is not possible given the nature of most crime. However, with an aggregation to the weekly level, there would not be a great loss in precision. Unfortunately, weekly data presents an over-dispersion of zeros, with which a zero-inflated Poisson (ZIP) (Lambert, 1992) or a zeroinflated binomial regression (ZIB) (D. B. Hall, 2000) would more correctly specify the data. Due to issues raised by Goodman-Bacon (2018), difference-in-difference estimators may not be accurately capturing the effect of time-varying treatment effects if those treatments "turn on" and stay on. With this in mind, there is not yet a way to efficiently calculate ZIP or ZIB models with the Bacon Decomposition, and thus traditional OLS is used. Of course, there are trade-offs to using each. However, with the size of the data, all choices are very computationally expensive, and to be current with the developments in the economics literature, potential mis-specification due to over-dispersion of zeros is ignored for a more accurate specification of the difference-in-difference estimates. Therefore, crime is aggregated at the monthly, business-block level. This creates an issue with the assignment of a particular month in a business block as having a green light or not. With no convention to follow, the $15^{\text {th }}$ of the month of used as a cutoff date. That is, if the green light becomes active prior to or on the $15^{\text {th }}$, that month will be counted as having an active green light, whereas if it is after the $15^{\text {th }}$, it will not.

Table 1.1: Summary Statistics - Monthly Blocks

\begin{tabular}{lccccc}
\hline \hline $\mathrm{N}=393,576$ & Mean & St. Dev. & Min & Max & \% Zero \\
\hline Total Crimes & 0.405 & 1.190 & 0 & 88 & $79.36 \%$ \\
Violent Crimes & 0.110 & 0.447 & 0 & 40 & $91.77 \%$ \\
Property Crimes & 0.145 & 0.515 & 0 & 20 & $89.58 \%$ \\
\hline Acres & 3.738 & 12.523 & 0.000 & 356.851 & - \\
\# Buildings & 5.074 & 5.128 & 0 & 55 & - \\
Live & 0.007 & 0.085 & 0 & 1 & - \\
Neighbor Live & 0.015 & 0.122 & 0 & 1 & - \\
\hline \hline
\end{tabular}

Summary statistics for monthly crime counts for each business block-street group is presented in Table 1.1. Included in this table along with traditional descriptive statistics is also the percentage of observations for the dependent variables with a count of zero. This count of zero percentage is omitted from the other variables in the table, as presented by a line within the table. Here, there are 393,576 observational month of year by block street observations. ${ }^{12}$ For these data, there is an average of just under one crime per month. As stated previously, these crimes are not simply the summation of violent and property crimes, but include all crimes include those outside of the categorization of violent and property crimes. Looking at the violent and property crimes, there

they are removed from the data.

${ }^{12}$ This can be checked by dividing the number of observations by the number of weeks in the data, 124 , to see the 3,174 business blocks utilized. 
is a little over one-tenth of a crime per month. Therefore, it is easy to suggest that crime is not exceptionally prevalent within the majority of areas, though there are certainly times where these crimes are more prevalent than others, represented by the maximum value. The percentage of observations with zero for the dependent variables is exceptionally concerning. This over-dispersion of zeros will almost guarantee that this model is incorrectly specified. However, compensation for the variation in treatment is of importance, and the inability to conduct the correct tests within a Bacon Decomposition force this author to make that concession for interpretation that is consistent with current economic research recommendations.

Below the separating line within the table, there is some information about these business parcels. These will not be directly used in the regressions, as they are time-invariant and unique to individual parcels (for the majority) and thus are perfectly co-linear with the spatial variable. However, considerations will be made for groupings in later specifications of the model to add some control for the size and density of businesses within these blocks. However, there is an average of three acres for each business block, with a wide standard deviation. Similarly, the number of buildings present five on average with a standard deviation just about equal to the mean. Lastly, the primary variable of interest, "Live" is a very small percentage of the data, at less than $1 \%$. This is due to the large number of observations that occur prior to any treatment. ${ }^{13}$ Additionally, only about $1 \%$ of the data has a neighbor with an active green light. This number is higher because there are two potential neighbors that could contribute to this variable, while the Live variable only has one.

\subsubsection{Calls for Service}

In addition to using reported crimes, calls for service in Detroit that led to the response of the Detroit Police Department are used as a secondary data set. Calls for service are provided by Detroit's Open Data Portal, and are available for 2016-2020. These data provide a different view into the question of this analysis, by using police interactions (both from citizen phone calls and officer initiated interactions) to measure the prevalence of crime within an area. Previously, the crime reported were crimes that were charged to individuals. These crimes do not necessarily need to result in an arrest, though they may. Therefore, these data can potentially capture a few different aspects of the question crime data would not be able to address. First, is there a change in the likelihood of policing a given area? This may have an effect on the crime data discussed previously. Second, is there a change in the proclivity of residents within these areas to contact the police if crimes or suspicious activities are occurring. If so, there may be a bias in the coefficients reported using the crime data as an unobservable variable (willingness to call 9-1-1) could be influencing the dependent variable. Lastly, part of the Project Green Light is to increase response times to these green light businesses. This will be directly testable using the duration at each step from dispatch to resolution of the incident. Additionally, the total time spent for each incident can be investigated.

There are just over 2.3 million calls for service during this period. However, in order to address the mechanism through which this works, the entire data set will also be split into 9-1-1 calls and officer initiated incidents. True calls for service (non-officer initiated incidents) make up 967,176 observations, or $41.7 \%$ of the data. The remaining $58.3 \%$ of the data are officer initiated contacts. These data are split in order to address the change in the likelihood citizens report crimes, as well as

\footnotetext{
${ }^{13}$ Recall, the data begin in 2009 , but the first green light is not active until 2016. Therefore, 84 of the 124 months are not even eligible for treatment.
} 
proactive policing within the area. Due to the shorter time period in which these data are available, this analysis will only occur across 33 months. Additionally, these data were attempted to be used with the business blocks. However, this is not possible given the small percentage $(<1 \%)$ of these calls that occur within those small areas. Therefore, the calls for service will serve as an alternative specification for the secondary analysis of buffer zones.

\subsection{Methodology}

The analysis used is a two-way fixed effects model utilizing variation in the month and year, and the particular location. For each business block, there is a set number of ID's. These green lights may or may not include a green light. Additionally, neighbors have the potential to have an active green light even if the particular business block of interest does not. Therefore, these ID's act as the spatial variation, while each month from 2009-2019 acts as the time variation. The formal methodology is best represented by Equation 1.1 where Live $_{i t}$ is the interaction between the time and space variables. This incarnation of the results do not consider the possibility of a neighboring green light. However, this would be represented by a $\beta_{4}$ coefficient on a time and space varying neighbor's live variable. The following equation is specified particularly to measure the total crime within a business block for a given month, however, the dependent variable will change as seen in the following results section, but the analysis will remain the same.

$$
C_{i t}=\alpha+\beta_{1} I D_{i}+\beta_{2} M_{t}+\beta_{3} \text { Live }_{i t}+\varepsilon
$$

Here $C_{i t}$ represents the total amount of crime within a given ID for a particular month of the sample. $I D_{i}$ is the spatial variation and is a variable with a separate ID for each of the 3,174 business blocks. As can be seen, there is not an inclusion of other variables at the business block level. This is due to the inability to accurately measure traditional variables that are correlated with the prevalence of crime (income, housing prices, age of the area). Additionally, since these are primarily business areas, it would be hard to control for that demographic information. It may be the case that the ID for each business block is capturing these effects anyway, assuming that they are time invariant throughout the data. $M_{t}$ represents the variation in time for the data. This represents every month within the data set, of which there are 124. Therefore, the Live $_{i t}$ variable is the interaction term of these two components. That is, for business block ID's there will be a point at which they become active with the Detroit Green Light Project. This particular month for

a given ID is chosen as the earliest date of entrance into the program by all potential green lights within a business block. As described before, the $15^{\text {th }}$ of the month is used as a cutoff date for assigning that month as active. That is, a green light must be active on or before the $15^{\text {th }}$ of that month to be considered active that month. This is a necessary concession that must be made when grouping multiple green light locations under one business block ID. However, when that particular ID reaches the month in which it becomes active, the Live $_{i t}$ variable switches from zero to one and remains on for the rest of the sample. Therefore, it is the interaction of the spatial $\left(I D_{i}\right)$ and time $\left(W_{t}\right)$ variables.

However, an issue has recently been raised with analyses such as this. Goodman-Bacon (2018) 
discusses the issue present in analyses where treatment turns on at various times and remains on throughout the rest of the sample. Put simply, the first green lights to become active occur relative to no activity, while the last green lights to be activated occur relative to no activity and previously active green lights. The coefficient within the difference-in-difference estimator does not distinguish between these two effects and may paint an unclear and incorrect picture of the results. He proposes a decomposition of the results into three groups: Earlier vs. Later Treated, Later vs. Earlier Treated, and Treated vs. Untreated. This decomposition allows for correction in the bias of the effect that is created by some units receiving treatment earlier than others and thus potentially effecting the results seen between the various combinations. This will be taken into consideration for the results, though the traditional difference-in-difference estimations will also be presented.

\subsection{Bacon Decomposition}

Prior to moving to the results, it is necessary to discuss the motivation behind the strategy taken in this paper. The Bacon Decomposition as proposed in Goodman-Bacon (2018) does not group the effect of all treated units into one difference-in-difference coefficient. Rather, this effect is disaggregated into three groups: Early v. Late Treated, Late v. Early Treated, and Treated v. Untreated. Each group will then have a coefficient that represents the effect from its respective group and a weight for its contribution to the traditional difference-in-difference estimate. Combining the coefficient for each group with its weight and summing across all three estimates will provide that same estimate as the difference-in-difference coefficient of interest. This is especially important in studies that face time-varying treatments that do not "turn off." The current study is one that must pay careful attention, as these green lights become active and do not shut off. Therefore, by using traditional difference-in-difference estimates, precision is lost in what is contributing to the effect.

To discuss more specifically, consider the groups mentioned above. That is, there are some observations that are treated towards the beginning of the data, some towards the middle and end, and others that aren't treated at any point. The first treated observations will have a comparison group that is only treated observations. In other words, the effect seen for those observations would be the effect of the green light becoming active relative to no other treated units. However, as time progresses, the later green lights that turn on experience a different control group. When these later green lights become active, the effect is not only relative to the untreated units, but also the units that have already experienced the treatment. Aggregating the effect of the treatment between these two may create an interpretation of the results that paints the effect in one specific way or another. Disaggregating into components that can take into account the effect of observations receiving treatments at different times allows us to see if there was a different effect for the first green lights to join the program relative to the green lights that joined it later. These programs can be very computationally complex, however, and therefore are unable to be conducted for the regressions in business blocks. Bacon decomposition's will be utilized for all results using the buffer zones. Importantly, these Bacon Decomposition will only consider direct effects, and will not provide any additional insight into time-varying effects for displacement. 


\subsection{Results}

This section of the paper will present the results in a number of subsections. First, the main analysis using monthly crime data with business parcels will be presented. This primary analysis will be followed up by the presentation of monthly calls for service data using the same methodology for business blocks and their neighbors. Following the discussion of the primary results, multiple alternative specifications will be utilized including weekly rather than monthly data, and the use of buffer zones.

\subsubsection{Monthly Crime in Business Blocks}

Primarily, this study is concerned with the potential for these green lights to have an effect on crime. Since this program specifically targets businesses, the use of business blocks will command the primary attention of this paper. Table 1.2 presents the results using monthly crime within these business blocks. Three separate crime values are utilized: Total crimes, violent crimes, and property crimes. Recall, total crimes may include more than the crimes used to create the index of violent and property crimes, and so it would not be expected that the coefficients of the green light on violent and property crimes sum to the coefficient for total crime.

Table 1.2: Crime in Business Blocks - Monthly

\begin{tabular}{|c|c|c|c|c|c|c|}
\hline \multirow[t]{2}{*}{ Dep. Var: } & \multicolumn{2}{|c|}{ Total Crime } & \multicolumn{2}{|c|}{ Violent Crime } & \multicolumn{2}{|c|}{ Property Crime } \\
\hline & Live Only & W/ Neighbor & Live Only & W/ Neighbor & Live Only & W/ Neighbor \\
\hline Live & $\begin{array}{c}-0.484^{* * *} \\
(0.099)\end{array}$ & $\begin{array}{c}-0.463^{* * *} \\
(0.098)\end{array}$ & $\begin{array}{c}-0.146^{* * *} \\
(0.030)\end{array}$ & $\begin{array}{c}-0.139^{* * *} \\
(0.030)\end{array}$ & $\begin{array}{c}-0.151^{* * *} \\
(0.040)\end{array}$ & $\begin{array}{c}-0.146^{* * *} \\
(0.021)\end{array}$ \\
\hline Neighbor Live & & $\begin{array}{c}-0.201^{* * *} \\
(0.056)\end{array}$ & & $\begin{array}{c}-0.072^{* * *} \\
(0.019)\end{array}$ & & $\begin{array}{c}-0.049^{* *} \\
(0.021)\end{array}$ \\
\hline ID & $\checkmark$ & $\checkmark$ & $\checkmark$ & $\checkmark$ & $\checkmark$ & $\checkmark$ \\
\hline Month of Year & $\checkmark$ & $\checkmark$ & $\checkmark$ & $\checkmark$ & $\checkmark$ & $\checkmark$ \\
\hline Adj. $R^{2}$ & 0.380 & 0.381 & 0.219 & 0.219 & 0.255 & 0.256 \\
\hline $\mathrm{N}$ & 393,576 & 393,576 & 393,576 & 393,576 & 393,576 & 393,576 \\
\hline
\end{tabular}

$* * *, * *, *$ represents $\mathrm{p}<0.01, \mathrm{p}<0.05, \mathrm{p}<0.1$, respectively

Standard errors are clustered at the block-street level. These data include 124 months for all 3,174 block-street groups.

Within each grouping of the crime, two specifications are run. Firstly, the leftward column under each sub-heading presents the results that only consider the effect of an active green light within that business block. That is, it does not consider any impact from the neighboring areas. Also, this effect is only presented for the business block that saw the light become active during this period. ${ }^{14}$ Across all crimes, there is a statistically and economically significant reduction in crime following the implementation of a green light within a business block. This effect is also present for violent and property crimes. The rightward column within each sub-heading provides an idea of any displacement or spillover effects of this green light. It could be reasoned that the presence of crime deterrence in a specific area would simply move the crime from that area to another. If this

\footnotetext{
${ }^{14}$ Recall, the date of the first green light was used in the case where there were multiple green lights in a business block. Additionally, if the green light was active prior to or on the $15^{\text {th }}$ of the month then the month was counted as "live."
} 
theory were to be correct for the current study, one would expect to see a positive coefficient on if a neighbor had an active green light. However, findings suggest there may be some spillover benefits to an area joining the green light program. These effects are smaller in magnitude than the direct effect on the business block that received the light, which is to be expected. Importantly, however, for all crimes, violent crimes, and property crimes, there is a reduction in the reported crime within the neighboring business blocks as well.

While limitations of this analysis have already been discussed in the sections above, it is important to note the potential for these spillover effects to expand beyond just the two closest neighbors to others. If it were the case that these neighbors were very close to the business block that received a green light, they may fall within the traditional buffer zone generally utilized in these types of studies. If the analysis were to expand to the three nearest, or four nearest, there may be additional insight of some adverse effect that occurs even further out. However, as mentioned previously, it may already be a concern that these neighbors may not be close enough to the green light business block. Expanding the number of neighbors only makes this concern greater, and is therefore not considered.

\subsubsection{Weekly Crime in Business Blocks}

The main analysis utilizes business blocks at the monthly level to compensate for the high percentage of observations with zero for the dependent variable. However, the analysis at the weekly level is still conducted, even though the model may become even more mis-specified. First, the crime data set is used. However, if the analysis were to remain the same as above (using months), the regression would be too computationally large ( 535 weeks by 3,174 groups). To overcome this computational limitation, the data set is filtered. First, only the business blocks that had an active green light at some point were sectioned off from the remaining 3,011 business blocks. From the remaining 3,011 business blocks, 500 were randomly sampled 50 unique times to run 50 separate regressions in which there were 663 business blocks for the 535 weeks. While there would ideally be more samples for the regressions to see an average effect, it is not possible given computational constraints.

Table 1.3: Business Blocks Regressions - Live Only

\begin{tabular}{lccc}
\hline \hline & Min. & Mean & Max \\
\hline Live & $-0.117^{* * *}$ & $-0.103^{* * *}$ & $-0.086^{* * *}$ \\
& $(0.022)$ & $(0.022)$ & $(0.023)$ \\
\hline ID & $\boldsymbol{V}$ & $\boldsymbol{\checkmark}$ & $\checkmark$ \\
Week of Year & $\boldsymbol{V}$ & $\boldsymbol{\checkmark}$ & $\checkmark$ \\
\hline Adj.R $R^{2}$ & 0.173 & 0.195 & 0.212 \\
$\mathrm{~N}$ & 354,705 & 354,705 & 354,705 \\
\hline \hline
\end{tabular}

The data were created in such a way that all areas that had a green light active at some point were retained (163 business blocks), and then of the remaining, 500 ID's were sampled 50 times to create 50 unique regressions. This table reports the results for the lowest coefficient and the maximum coefficient. Additionally, the mean column averages the coefficient, standard error, and $R^{2}$. For all regressions, active lights represent $2.7 \%$ of the data.

Table 1.3 presents the results for the regressions with the minimum and maximum coefficients on the variable of interest. The results reported in each of these columns are the actual regression results from a particular sample. The middle column, however, represents the average of the coefficient, and 
the average of the standard error to create a pseudo-coefficient and pseudo-p value. Additionally, the $R^{2}$ value is averaged across all regressions for that column. ${ }^{15}$ Here, the results are similar to the results for monthly crime at the business block level. Namely, the result is negative and statistically significant.

\subsection{Buffer Zone Results}

The previous section presented results for monthly crime within business blocks. To support the analysis, buffer zones are used rather than business blocks. These buffer zones are more traditionally used in these studies. The analysis utilizing buffer zones around the green light will be conducted in a specific way. First, all crime that does not occur within a green light zone will be removed. Theoretically, this does not need to occur if sampling random areas that remain within the city (by remain I mean non-green light buffer zones) was conducted. However, that creates the potential to be counting areas that would be unlikely to see crime, such as green spaces. Once the crime is refined, it will then be be assigned to the nearest green light. This resolves the issue of overlapping boundaries either needing to be dissolved (and thus losing accuracy on the date the green light went live), or potentially double-counting crime. To do this, a similar minimization function to the one used to assign crime to the nearest business block is utilized, however, this time it is assigned to the buffer zones. This analysis will focus on the monthly effects for comparability with the previous findings and the lower density of observations with zero in the dependent variable.

\subsubsection{Monthly Crime in Buffer Zones}

The earlier analysis presented the obvious issue of many zeros due to the small area of analysis. Traditionally, buffer zones around a location of interest are used to analyze the effect. In this section, a 500 foot buffer around each green light is used. From this 500 foot buffer, three separate interior buffers of 150 feet, 250 feet, and 350 feet are created. This interior buffer may also be referred to as the direct effect of the green light. Meanwhile, with the creation of each interior buffer, there will be a remaining exterior buffer from the initial 500 foot buffer. This exterior buffer will capture potential spillover or displacement effects of the live green light. Importantly, each crime will again be assigned to its nearest green light. Doing this does present an issue, however. Many green lights are close together and thus have overlapping 500 foot buffers. Many still overlap at even 150 feet. Because of this, the exterior area as is considered the untreated area, and the interior as the intent to treat group. This will give us areas where green lights are not possible, and thus will serve as an imperfect control group for the green lights. For example, considering the 150 foot interior buffer with a 350 foot exterior buffer, all crimes within the 350 foot buffer are considered to occur in the same area. The assignment to the nearest buffer zone is not utilized, since the overlap is essentially treated as one unit itself. However, for the crimes that occur within the 150 foot interior buffer, any overlap that occurs will be dealt with by assigning the crime to the nearest green light zone in straight line distance. This will ensure that there is no double counting of crimes, while also retaining as many green lights as possible, and thus have the most accurate date in which that area becomes treated. With this, there are 287 exterior groups that are created. This number will remain

\footnotetext{
${ }^{15}$ All regressions to create this table are available upon request.
} 
constant through all of the interior buffers, since they are not separated and assigned to individual green lights. This informs us that the 554 green lights overlap in such a way to create 284 grouped areas at a 500 foot buffer. ${ }^{16}$ Additionally, there will be a consistent baseline number of crimes that is 206,640. This number is the crime ID's that fall within the 500 foot buffer. Recall, these are still grouped by their crime ID, and thus represent criminal instances, rather than a count of criminal charges.

\section{0 ft. Interior Buffer - 350 ft. Exterior Buffer}

The analysis will begin with the 150 foot interior buffer and a 350 foot exterior buffer. With this, there are 41,300 crimes, or just about $20 \%$ of the total crime within the 500 foot buffer. These crimes are then grouped across the 554 green lights and summed across each month. For months in which there were no crimes, zeros are filled in to each of the crime categories. However, if no crime occurred within these areas at any point throughout the period, they are removed from the data set. This leaves us with a balanced panel of crime in 491 green light areas across 124 months, or 60,884 month of year by interior green light zone observations. In the remaining 350 foot buffer, there are 284 groups formed from the green lights that extend beyond the 150 foot buffer but not further than 500 feet. As with the interior buffer, there are 124 months. Therefore, the crime in the exterior buffer is a balanced panel of 284 groups across 124 months, or 35,216 observations. Combining these two data sets creates a data set of 775 locations across 124 months, with a final balanced panel of 96,100 observations.

Table 1.4: Summary Stats - $150 \mathrm{ft}$. Interior Buffer - $350 \mathrm{ft}$. Exterior

\begin{tabular}{lcccc}
\hline \hline $\mathrm{N}=96,100$ & Mean & St. Dev. & Min & Max \\
\hline Total Crimes & 2.283 & 4.469 & 0 & 103 \\
Violent Crimes & 0.681 & 1.488 & 0 & 52 \\
Property Crimes & 0.824 & 1.926 & 0 & 52 \\
Live & 0.081 & 0.273 & 0 & 1 \\
Live W/in Buffer & 0.057 & 0.231 & 0 & 1 \\
\hline \hline
\end{tabular}

There are 124 months spread across 775 groups. 491 groups are individual green lights within a $150 \mathrm{ft}$. buffer around each location. For those, crimes are assigned to the green light they are nearest to in straight line distance. The additional 284 groups are from the remaining $350 \mathrm{ft}$. of buffer. Crimes within these areas are merely merged by the buffer ID and not assigned to the buffer of the nearest green light. These green light buffers are treated as one unit if there is overlap.

Summary statistics for these data are presented in Table 1.4. Here, there are many more occurrences of crimes per month, from about one-half of a crime to over two with the expansion to a buffer zone. Additionally, there is an increase in the percentage of the observations that have an active green light. There is now over $8 \%$ of the observations that are live, as opposed to under $1 \%$ from the business block analysis. Importantly, an area is only eligible for an active green light if it is within the $150 \mathrm{ft}$. buffer. That is, the observational months of crime within the buffer zones cannot be live at any point. Rather, there is a separate variable that is created to account for a potential differential effect from the buffer surrounding an area that now has an active green light. While these buffer zones are serving as the untreated observations, it may be the case that they could also contribute to the findings earlier about spillover or displacement effects. For this line of questioning,

\footnotetext{
${ }^{16}$ Initially, they are grouped into 287 areas. However, there are three that do not experience any crime as they fall outside of the city. Therefore, these are removed from the data leaving us with 284 groups.
} 
consideration will be given to the activity of green lights within a buffer. However, only the first active green light from the area the buffer zone surrounds will be used to consider that buffer to be surrounding a live area. This is similar to the approach used with business blocks in the previous analysis.

Table 1.5: Crime in Buffers - $150 \mathrm{ft}$. Interior - $350 \mathrm{ft}$. Exterior

\begin{tabular}{|c|c|c|c|c|c|c|}
\hline \multirow[t]{2}{*}{ Dep. Var: } & \multicolumn{2}{|c|}{ Total Crime } & \multicolumn{2}{|c|}{ Violent Crime } & \multicolumn{2}{|c|}{ Property Crime } \\
\hline & Live Only & W/ Buffer & Live Only & W/ Buffer & Live Only & W/ Buffer \\
\hline Live & $\begin{array}{c}1.342^{* * *} \\
(0.138)\end{array}$ & $\begin{array}{c}0.469^{* * *} \\
(0.089)\end{array}$ & $\begin{array}{c}0.372^{* * *} \\
(0.038)\end{array}$ & $\begin{array}{c}0.115^{* * *} \\
(0.028)\end{array}$ & $\begin{array}{c}0.390^{* * *} \\
(0.050)\end{array}$ & $\begin{array}{c}0.159^{* * *} \\
(0.033)\end{array}$ \\
\hline Live W/in Buffer & & $\begin{array}{c}-2.227^{* * *} \\
(0.224)\end{array}$ & & $\begin{array}{c}-0.656^{* * *} \\
(0.062)\end{array}$ & & $\begin{array}{c}-0.589^{* * *} \\
(0.077)\end{array}$ \\
\hline ID & $\checkmark$ & $\checkmark$ & $\checkmark$ & $\checkmark$ & $\checkmark$ & $\checkmark$ \\
\hline Month of Year & $\checkmark$ & $\checkmark$ & $\checkmark$ & $\checkmark$ & $\checkmark$ & $\checkmark$ \\
\hline Adj. $R^{2}$ & 0.724 & 0.731 & 0.529 & 0.534 & 0.632 & 0.635 \\
\hline $\mathrm{N}$ & 96,100 & 96,100 & 96,100 & 96,100 & 96,100 & 96,100 \\
\hline
\end{tabular}

$* * *, * *, *$ represents $\mathrm{p}<0.01, \mathrm{p}<0.05, \mathrm{p}<0.1$, respectively

Standard errors are clustered at the ID level. An ID represents each green light and each dissolved buffer zone around green lights. These data include 124 months for all 491 interior groups and 284 exterior groups. Two regressions were run for each category of crime. Live only considers only the activity of the green lights within the $150 \mathrm{ft}$. buffer. The second column under each sub-heading also looks at the effect in the $350 \mathrm{ft}$. buffer around the green light when one of the green lights within the buffer becomes active. The date of the first live green light within the buffer is used to create this designation.

Results for the $150 \mathrm{ft}$ interior buffer are presented in Table 1.5. Here, three dependent variables are investigated: Total crime, violent crime, and property crime. As with the previous results using the crime data, total crime does consider more crime than just those used to create the violent and property crime designations. Therefore, effects across those two will not sum to the cumulative effect. Across all results there is a different story than the results found in the business blocks file would suggest. With the small interior buffer, there is an increase in the number of crimes reported after the green light becomes active. This stands in contrast to the previous results that found a decrease in the incidence of crime within business blocks after the green light turned on. This increase is quite substantial as well, with about a $50 \%$ increase in the average number of crimes per month. Interestingly, when the exterior buffer is considered, the story seems consistent with the one found earlier. Recall, the Live within buffer variable is equal to one if there is an active green light in one of the green lights that the buffer surrounds. When a green light becomes active, there is an increase in crime in the immediate area, while the 350 foot area surrounding the green light experiences a reduction in crime. Taken alone, it may appear that green lights are attracting, rather than deterring crime. However, as mentioned previously the mechanism through which the results may appear will be explored in a later section of this paper.

The Bacon Decomposition for the total monthly crimes is provided in Table 1.6. Here, the coefficient from Table 1.5 is provided for reference, as the three values and weights are "decomposing" this result into its time-varying treatment effects. In the discussion of treated against untreated, untreated observations produce the most weight for the coefficient, and also the largest estimate in magnitude. However, if considering the results of joining the green light program, more information appears that we previously could not discover from traditional difference-in-difference methods. That 
is, those observations that joined early in the program did in fact see a decrease in crime, relative to those that joined later in the program. This coefficient is quite small, and likely economically insignificant. However, considering the later treated against the earlier, those that joined later do have an increase in crime relative to those that joined earlier, though the interpretation of this estimate is considerably more difficult.

Table 1.6: Total Crime Bacon Decomposition - 150ft Interior \& $350 \mathrm{ft}$. Exterior

\begin{tabular}{lcc}
\hline \hline OLS: & Coef & SE \\
\hline Live & $1.342^{* * *}$ & $(0.138)$ \\
\hline Bacon Decomposition: & & \\
Type & Weight & Avg. Estimate \\
\hline Earlier vs. Later Treated & 0.343 & -0.038 \\
Later vs. Earlier Treated & 0.030 & 0.078 \\
Treated vs. Untreated & 0.627 & 2.158 \\
\hline \hline
\end{tabular}

The coefficient under the OLS portion of the table is the first column of Table 1.5. Taking the weighted sum of each estimate will provide the OLS estimate presented.

Table 1.7: Violent Crime Bacon Decomposition - 150ft Interior \& 350 ft. Exterior

\begin{tabular}{lcc}
\hline \hline OLS: & Coef & SE \\
\hline Live & $0.372^{* * *}$ & $(0.038)$ \\
\hline Bacon Decomposition: & & \\
Type & Weight & Avg. Estimate \\
\hline Earlier vs. Later Treated & 0.343 & -0.011 \\
Later vs. Earlier Treated & 0.030 & 0.024 \\
Treated vs. Untreated & 0.627 & 0.598 \\
\hline \hline
\end{tabular}

The coefficient under the OLS portion of the table is the third column of Table 1.5. Taking the weighted sum of each estimate will provide the OLS estimate presented.

Table 1.8: Property Crime Bacon Decomposition - 150ft Interior \& 350 ft. Exterior

\begin{tabular}{lcc}
\hline \hline OLS: & Coef & SE \\
\hline Live & $0.390^{* * *}$ & $(0.050)$ \\
\hline Bacon Decomposition: & & \\
Type & Weight & Avg. Estimate \\
\hline Earlier vs. Later Treated & 0.343 & 0.006 \\
Later vs. Earlier Treated & 0.030 & 0.029 \\
Treated vs. Untreated & 0.627 & 0.618 \\
\hline \hline
\end{tabular}

The coefficient under the OLS portion of the table is the fifth column of Table 1.5. Taking the weighted sum of each estimate will provide the OLS estimate presented.

The Bacon Decomposition was also conducted for violent (Table 1.7) and property (Table 1.8) crimes. As with all Bacon Decompositions within this paper, only the direct effect will be evaluated. That is, displacement effects are not considered. These results are consistent with the results shown 
in Table 1.6, so a discussion will be avoided for brevity. The consistency of the estimates is present in the total crimes and violent crimes. Though the effect is once again likely not economically significant, it is worth mentioning that there was an increase in property even for those earlier treated observations. This supposes that these green lights may not have the deterrent effect one might expect on property crimes.

\section{$250 \mathrm{ft}$. Interior Buffer - $250 \mathrm{ft}$. Exterior Buffer}

The process discussed in the previous subsection was followed for this section, as well as the one that follows it. The only change that was made was an increase in the size of the interior buffer. Now, $250 \mathrm{ft}$. interior buffer, with a $250 \mathrm{ft}$. remaining exterior buffer is evaluated. As before, those crimes that fall within the interior buffer are assigned to their nearest green light using a straight line distance minimization algorithm. Here, 284 exterior buffers remain. However, there are 511 individual green lights that experienced a crime at some point through the period of this study.

Table 1.9: Summary Stats - $250 \mathrm{ft}$. Interior Buffer - $250 \mathrm{ft}$. Exterior

\begin{tabular}{lcccc}
\hline \hline $\mathrm{N}=98,580$ & Mean & St. Dev. & Min & Max \\
\hline Total Crimes & 2.225 & 3.375 & 0 & 93 \\
Violent Crimes & 0.664 & 1.229 & 0 & 45 \\
Property Crimes & 0.803 & 1.471 & 0 & 37 \\
Live & 0.082 & 0.274 & 0 & 1 \\
Live W/in Buffer & 0.055 & 0.228 & 0 & 1 \\
\hline \hline
\end{tabular}

There are 124 months spread across 795 groups. 511 groups are individual green lights within a $250 \mathrm{ft}$. buffer around each location. For those, crimes are assigned to the green light they are nearest to in straight line distance. The additional 284 groups are from the remaining $250 \mathrm{ft}$. of buffer. Crimes within these areas are merely merged by the buffer ID and not assigned to the buffer of the nearest green light. These green light buffers are treated as one unit if there is overlap.

This is up from the 491 green lights in the smaller $150 \mathrm{ft}$. buffer. Here, observations from the interior green light zones of 250 feet account for $64 \%$ of the 98,580 month of year by area observations. Again, this is a balanced panel with 124 months by 795 areas. Table 1.9 is nearly identical to Table 1.4 , and therefore no discussion will occur. As before, the treated observations account for about $8 \%$ of the observations, while there are just over 2 crimes per month per area on average.

Results for total crimes, violent crimes, and property crimes are provided in Table 1.10. These results are quite similar to the results found with the previous buffer zones. However, the coefficients are smaller in magnitude for most estimates. Interestingly, however, while a positive effect persists for a live area when both including and not including the live status of the surrounding buffer zone for total and property crime, it loses all of its significance for violent crimes.

An explanation of this phenomenon is not obvious. However, if it is to be assumed that the increase in crime is occurring due to the presence of a green light, and those are not seen within the $250 \mathrm{ft}$. interior buffer, then it stands to reason that it may be because violent crimes may often occur without as much forethought. Therefore, if re-targeting by criminals of these areas is causing the increase in crime, then violent crime would not be expected to commensurately increase. However, that explanation seems quite unlikely. Alternatively, if there is an increase in the reporting of crimes leading to the increase found within the results, then for similar reasoning as above, violent crimes would not be expected to change with the presence of a green light. 
Table 1.10: Crime in Buffers - $250 \mathrm{ft}$. Interior - $250 \mathrm{ft}$. Exterior

\begin{tabular}{|c|c|c|c|c|c|c|}
\hline \multirow[t]{2}{*}{ Dep. Var: } & \multicolumn{2}{|c|}{ Total Crime } & \multicolumn{2}{|c|}{ Violent Crime } & \multicolumn{2}{|c|}{ Property Crime } \\
\hline & Live Only & W/ Buffer & Live Only & W/ Buffer & Live Only & W/ Buffer \\
\hline Live & $\begin{array}{c}0.831^{* * *} \\
(0.117)\end{array}$ & $\begin{array}{c}0.194^{* *} \\
(0.086)\end{array}$ & $\begin{array}{c}0.236^{* * *} \\
(0.035)\end{array}$ & $\begin{array}{c}0.041 \\
(0.027)\end{array}$ & $\begin{array}{c}0.269^{* * *} \\
(0.039)\end{array}$ & $\begin{array}{c}0.089^{* * *} \\
(0.030)\end{array}$ \\
\hline Live W/in Buffer & & $\begin{array}{c}-1.661^{* * *} \\
(0.200)\end{array}$ & & $\begin{array}{c}-0.508^{* * *} \\
(0.060)\end{array}$ & & $\begin{array}{c}-0.470^{* * *} \\
(0.065)\end{array}$ \\
\hline ID & $\checkmark$ & $\checkmark$ & $\checkmark$ & $\checkmark$ & $\checkmark$ & $\checkmark$ \\
\hline Month of Year & $\checkmark$ & $\checkmark$ & $\checkmark$ & $\checkmark$ & $\checkmark$ & $\checkmark$ \\
\hline Adj. $R^{2}$ & 0.587 & 0.594 & 0.376 & 0.380 & 0.471 & 0.474 \\
\hline $\mathrm{N}$ & 98,580 & 98,580 & 98,580 & 98,580 & 98,580 & 98,580 \\
\hline
\end{tabular}

***, $* *, *$ represents $\mathrm{p}<0.01, \mathrm{p}<0.05, \mathrm{p}<0.1$, respectively

Standard errors are clustered at the ID level. An ID represents each green light and each dissolved buffer zone around green lights. These data include 124 months for all 511 interior groups and 284 exterior groups. Two regressions were run for each category of crime. Live only considers only the activity of the green lights within the $250 \mathrm{ft}$. buffer. The second column under each sub-heading also looks at the effect in the $250 \mathrm{ft}$. buffer around the green light when one of the green lights within the buffer becomes active. The date of the first live green light within the buffer is used to create this designation.

Investigating further with the Bacon Decomposition in Table 1.12, while there have been some benefit for the early adopters, there is not much of an effect across another of the categories. The smallest, in magnitude, of the estimate is for the treated vs. untreated in this table as well. The investigation into this mechanism will be explored later on when using the calls for service. The Bacon Decomposition for both total crimes in Table 1.11 and property crimes, Table 1.13, tell a similar story to the decomposition conducted for the $150 \mathrm{ft}$. interior buffer above. That is, there may be some benefit for early adopters of the green light in the reduction of crime overall, but this reduction is not seen when exclusively considering property crimes.

Table 1.11: Total Crime Bacon Decomposition - 250ft Interior \& 250 ft. Exterior

\begin{tabular}{lcc}
\hline \hline OLS: & Coef & $\mathrm{SE}$ \\
\hline Live & $0.831^{* * *}$ & $(0.117)$ \\
\hline Bacon Decomposition: & & \\
Type & Weight & Avg. Estimate \\
\hline Earlier vs. Later Treated & 0.349 & -0.052 \\
Later vs. Earlier Treated & 0.031 & 0.076 \\
Treated vs. Untreated & 0.621 & 1.365 \\
\hline \hline
\end{tabular}

The coefficient under the OLS portion of the table is the first column of Table 1.10. Taking the weighted sum of each estimate will provide the OLS estimate presented.

\section{$350 \mathrm{ft}$. Interior Buffer - $150 \mathrm{ft}$. Exterior Buffer}

Moving to the final split of the 500 foot buffer, a $350 \mathrm{ft}$. interior buffer zone, with the remaining 150 ft. considered the exterior buffer is evaluated. Here, two of the exterior buffers (284 to 282) are lost due to zero crimes throughout the sample period. This occurs because in the now smaller catchment area for crime, two of the exterior buffers do not experience crime at any point during the period. 
Table 1.12: Violent Crime Bacon Decomposition - 250ft Interior \& $250 \mathrm{ft}$. Exterior

\begin{tabular}{lcc}
\hline \hline OLS: & Coef & SE \\
\hline Live & $0.236^{* * *}$ & $(0.035)$ \\
\hline Bacon Decomposition: & & \\
Type & Weight & Avg. Estimate \\
\hline Earlier vs. Later Treated & 0.349 & -0.016 \\
Later vs. Earlier Treated & 0.031 & 0.020 \\
Treated vs. Untreated & 0.621 & 0.388 \\
\hline \hline
\end{tabular}

The coefficient under the OLS portion of the table is the third column of Table 1.10. Taking the weighted sum of each estimate will provide the OLS estimate presented.

Table 1.13: Property Crime Bacon Decomposition - 250ft Interior \& $250 \mathrm{ft}$. Exterior

\begin{tabular}{lcc}
\hline \hline OLS: & Coef & SE \\
\hline Live & $0.269^{* * *}$ & $(0.039)$ \\
\hline Bacon Decomposition: & & \\
Type & Weight & Avg. Estimate \\
\hline Earlier vs. Later Treated & 0.349 & 0.004 \\
Later vs. Earlier Treated & 0.031 & 0.006 \\
Treated vs. Untreated & 0.621 & 0.432 \\
\hline \hline
\end{tabular}

The coefficient under the OLS portion of the table is the fifth column of Table 1.10. Taking the weighted sum of each estimate will provide the OLS estimate presented.

Of the 98,828 observations, $63,860(64.7 \%)$ come from the combination of the 515 individual green lights, with the remaining observations coming from the 124 month observations of the remaining 282 exterior zones. Summary statistics for this sample, in Table 1.14, are similar to the summary statistics presented for the other two splits of the $500 \mathrm{ft}$. buffer zone.

Table 1.14: Summary Stats - 350 ft. Interior Buffer - 150 ft. Exterior

\begin{tabular}{lcccc}
\hline \hline $\mathrm{N}=98,828$ & Mean & St. Dev. & Min & Max \\
\hline Total Crimes & 2.220 & 2.937 & 0 & 94 \\
Violent Crimes & 0.663 & 1.135 & 0 & 40 \\
Property Crimes & 0.801 & 1.288 & 0 & 23 \\
Live & 0.082 & 0.275 & 0 & 1 \\
Live W/in Buffer & 0.055 & 0.227 & 0 & 1 \\
\hline \hline
\end{tabular}

There are 124 months spread across 797 groups. 515 groups are individual green lights within a $250 \mathrm{ft}$. buffer around each location. For those, crimes are assigned to the green light they are nearest to in straight line distance. The additional 282 groups are from the remaining $250 \mathrm{ft}$. of buffer. Crimes within these areas are merely merged by the buffer ID and not assigned to the buffer of the nearest green light. These green light buffers are treated as one unit if there is overlap.

The results for this iteration do paint a much different picture than the previous results utilizing the buffer zone method. Table 1.15 once again present the difference-in-difference coefficient for a green light becoming active within a particular area on total crimes, violent crimes, and property crimes. As can be seen in the odd-numbered columns of the table, these results from the activity of a green light does not appear to have any effect on crime across all three categorizations of crime. 
Table 1.15: Crime in Buffers - $350 \mathrm{ft}$. Interior - $150 \mathrm{ft}$. Exterior

\begin{tabular}{|c|c|c|c|c|c|c|}
\hline \multirow[t]{2}{*}{ Dep. Var: } & \multicolumn{2}{|c|}{ Total Crime } & \multicolumn{2}{|c|}{ Violent Crime } & \multicolumn{2}{|c|}{ Property Crime } \\
\hline & Live Only & W/ Buffer & Live Only & W/ Buffer & Live Only & W/ Buffer \\
\hline Live & -0.096 & $-0.301^{* *}$ & -0.035 & $-0.103^{* * *}$ & 0.034 & -0.035 \\
\hline & $(0.117)$ & $(0.098)$ & $(0.032)$ & $(0.029)$ & $(0.034)$ & $(0.031)$ \\
\hline \multirow{2}{*}{ Live W/in Buffer } & & $-0.538^{* * *}$ & & $-0.178^{* * *}$ & & $-0.181^{* * *}$ \\
\hline & & $(0.127)$ & & $(0.044)$ & & $(0.048)$ \\
\hline ID & $\checkmark$ & $\checkmark$ & $\checkmark$ & $\sqrt{ }$ & $\checkmark$ & $\checkmark$ \\
\hline Month of Year & $\checkmark$ & $\checkmark$ & $\checkmark$ & $\checkmark$ & $\checkmark$ & $\checkmark$ \\
\hline Adj. $R^{2}$ & 0.492 & 0.493 & 0.302 & 0.302 & 0.357 & 0.357 \\
\hline $\mathrm{N}$ & 98,828 & 98,828 & 98,828 & 98,828 & 98,828 & 98,828 \\
\hline
\end{tabular}

$* * *, * *, *$ represents $\mathrm{p}<0.01, \mathrm{p}<0.05, \mathrm{p}<0.1$, respectively

Standard errors are clustered at the ID level. An ID represents each green light and each dissolved buffer zone around green lights. These data include 124 months for all 515 interior groups and 284 exterior groups. Two regressions were run for each category of crime. Live only considers only the activity of the green lights within the $250 \mathrm{ft}$. buffer. The second column under each sub-heading also looks at the effect in the $250 \mathrm{ft}$. buffer around the green light when one of the green lights within the buffer becomes active. The date of the first live green light within the buffer is used to create this designation.

This may be due to the area becoming too wide for the green light to have an effect. However, in the even-numbered columns that include an indicator variable for if there is an active green light within green lights that compose of the exterior buffer, different results are found again, but this time the results are consistent with previous findings using business blocks. For total crime and violent crime, the activity of a green light appears to be associated with a decrease of about $13 \%$ and $15 \%$ respectively. Combing this with the insignificance of an effect of a green light on property crime, it appears that these green lights may be directly impacting the amount of violent crime within a 350 foot area around the green light.

However, with both of these estimates, the coefficient for the spillover effect is larger in magnitude, and also negative. This suggests that the spillover effect may be stronger than the direct effect itself. This could occur for a number of reasons. One plausible explanation is that there is selection on what businesses join the Green Light Project. Namely, that businesses that face higher crime rates join the program. If the areas surrounding these businesses do not generally face as much crime as the businesses joining the program, it may be that criminals are shifting their activity to areas that are even further. Therefore, a spillover benefit occurs on the businesses that were previously experiencing a negative externality associated with the poor surveillance within the green light locations themselves. With these results finding no aggregate effect of green lights on crime, it is especially important to use the Bacon Decomposition.

Table 1.16 suggests that the negative effect seen on the coefficient, while insignificant, is coming through the early adopters of the policy. This suggested decrease has been consistent through all of the Bacon Decompositions, except for those with property crime. Additionally, for violent and property crimes in Tables 1.17 and 1.18, respectively, there is a negative estimate for the early adopters vs the late adopters. Putting this information together, there are likely decreasing returns to the scaling of this program, where those that joined early received benefits, but those that joined later did not. 
Table 1.16: Total Crime Bacon Decomposition - 350ft Interior \& 150 ft. Exterior

\begin{tabular}{lcc}
\hline \hline OLS: & Coef & SE \\
\hline Live & -0.096 & $(0.117)$ \\
\hline Bacon Decomposition: & & \\
Type & Weight & Avg. Estimate \\
\hline Earlier vs. Later Treated & 0.352 & -0.312 \\
Later vs. Earlier Treated & 0.031 & 0.165 \\
Treated vs. Untreated & 0.617 & 0.014 \\
\hline \hline
\end{tabular}

The coefficient under the OLS portion of the table is the first column of Table 1.15. Taking the weighted sum of each estimate will provide the OLS estimate presented.

Table 1.17: Violent Crime Bacon Decomposition - 350ft Interior \& $150 \mathrm{ft}$. Exterior

\begin{tabular}{lcc}
\hline \hline OLS: & Coef & SE \\
\hline Live & -0.035 & $(0.032)$ \\
\hline Bacon Decomposition: & & \\
Type & Weight & Avg. Estimate \\
\hline Earlier vs. Later Treated & 0.352 & -0.114 \\
Later vs. Earlier Treated & 0.031 & 0.035 \\
Treated vs. Untreated & 0.617 & 0.006 \\
\hline \hline
\end{tabular}

The coefficient under the OLS portion of the table is the third column of Table 1.15. Taking the weighted sum of each estimate will provide the OLS estimate presented.

Table 1.18: Property Crime Bacon Decomposition - 350ft Interior \& $150 \mathrm{ft}$. Exterior

\begin{tabular}{lcc}
\hline \hline OLS: & Coef & SE \\
\hline Live & 0.034 & $(0.034)$ \\
\hline Bacon Decomposition: & & \\
Type & Weight & Avg. Estimate \\
\hline Earlier vs. Later Treated & 0.352 & -0.035 \\
Later vs. Earlier Treated & 0.031 & 0.042 \\
Treated vs. Untreated & 0.617 & 0.074 \\
\hline \hline
\end{tabular}

The coefficient under the OLS portion of the table is the third column of Table 1.15. Taking the weighted sum of each estimate will provide the OLS estimate presented. 


\subsection{Results Using Calls for Service in Buffer Zones}

Previously, business blocks and buffer zones were used with monthly crime data to address the effect of these green lights on crime within the area. Results appear mixed, between a reduction when using the business blocks, and an increase when using the buffer zones. To support this analysis, and uncover the potential mechanism behind the results, the analysis will turn to the calls for service data set. These data exist for 2016-2020, and cover 33 individual months. This analysis will also be conducted at the monthly level, but business blocks are unable to be analyzed due to a dearth of observations within these areas. Therefore, only the buffer zone analysis will be utilized for these data. The results will follow a similar presentation as the results previously, using a 500 foot buffer and discarding any calls that occur outside of this area. Then, three separate combinations of an interior and exterior buffer will disaggregate the 500 foot buffer into an interior and exterior zone. The interior zones will be 150 feet, 250 feet, and 350 feet, with the exterior being the remaining distance to 500 feet. The number of groups the green lights dissolve into when dissolving the buffer zones (284) will remain the same as before. ${ }^{17}$ Each subsection that follows will cover three different types of data: All calls, 9-1-1 calls, and officer initiated interactions. Each will have their own summary statistics, but the results will be presented in one table.

For all calls, there is no disaggregation between whether the incident was in fact a call from a citizen, or an interaction that was started by the officer. This group will be used in an attempt to address three questions. First, do the number of incidents (calls and officer initiated responses) increase? This first question will allow us to analyze if the green lights have an effect on crime, but using this data set allows us to view crime through a potentially different lens. Second, are the police faster to respond to incidents after a green light becomes active? Part of this initiative was to increase the speed in which police arrive on scene for calls coming from these green light areas. However, there is an issue when using all crime for this. It may be that response times change as a function of a change in the composition of incidents. That is, if there are more calls and fewer police officer initiated incidents, then it may be the case that response times increase. The results themselves may create a bleaker picture than the reality. To address this, a third question is addressed: Does the composition of incidents change following a green light turning on? To do this, the percentage of all incidents that were not officer initiated are the focus. While this may provide us with some information, it still may mask the true effect for those response times to calls for service.

To address this more formally, the data set is broken down into calls for service and officer initiated incidents. Using the formal calls for service, the analysis will focus on the number of incidents and the response time. Using the number of incidents here provides information on any change in the likelihood of residents to call the police in a time of need. If this changes, it could be driving the results one way or another. Also, using the response time only with the non-officer initiated incidents, there will be a cleaner identification of the change in response times to crimes reported in green light areas after the light officially joins the program. Lastly, the data set will only consider officer initiated responses. These will allow us to check if there is any change in the proactive policing that may be going on in the green light areas. In other words, if the police are policing an area more/less frequently, it may be expected to see higher/lower crime rates in this

\footnotetext{
${ }^{17} \mathrm{Keep}$ in mind, if there are no observations in a given area throughout the entire period, they are dropped from the data set. Therefore, there may be fewer than 284 exterior groups present in any one analysis.
} 
area.

\subsubsection{Calls for Service - $150 \mathrm{ft}$. Interior - $350 \mathrm{ft}$. Exterior}

First, the smallest interior buffer, with the largest exterior buffer will be analyzed. This will help to capture the most direct effect on the green lights. Here, there are 518 groups spread across 33 months. There are 234 individual green lights, with all 284 buffering groups seeing at least one call for service over the period. Summary statistics for all calls (not breaking down by officer initiated or not) are presented in Table 1.19. Here, it can be seen that the number of calls in these areas far exceed the number of crimes seen in Table 1.4. This also reduces the number of observations where the dependent variable (total calls) are equal to zero (under 4\%). A mean of nearly 37 calls per month suggest that the average area would have just over one call per day. Additionally, the average response time throughout the sample is about 15 minutes. This response time is the minutes between the call coming in and the officer arriving on scene. The percentage of calls show that only $40 \%$ of all incidents within this data set come from citizen reports, while the remaining $60 \%$ are officer initiated interactions. ${ }^{18}$

Table 1.19: Summary Statistics - All Calls - $150 \mathrm{ft}$. Interior - $350 \mathrm{ft}$. Exterior

\begin{tabular}{lcccc}
\hline \hline $\mathrm{N}=17,094$ & Mean & St. Dev. & Min & Max \\
\hline Total Calls & 36.999 & 72.569 & 0 & 1,243 \\
Total Response Time & 14.845 & 29.064 & 0.000 & $1,314.800$ \\
\% Calls & 0.392 & 0.286 & 0 & 1 \\
Live & 0.330 & 0.470 & 0 & 1 \\
Live W/in Buffer & 0.422 & 0.494 & 0 & 1 \\
\hline \hline
\end{tabular}

The number of observations come from 234 interior green lights and 284 exterior buffers across 33 months. Total response time is the number of minutes between intake and the arrival of the officer on the scene. Percentage of calls is the percentage of all incidents that were not officer initiated. Live is an indicator variable for if the month of year is after the month of year the green light became active. Finally, Live W/in Buffer is an indicator variable for if one of the green lights that formed the exterior buffer was active during that month.

Lastly, there is a much higher percentage of the buffer-months that have an active green light. About $33 \%$ of the observations are with an active green light. This is due to the shorter period for which the calls for service data are available (2016-2020). This significantly reduces the pre-period for many of the observations. Meanwhile, over $40 \%$ of the observational months have an active green light within their buffer zone.

Results for calls for service can be found in Tables 1.22 and 1.23 for the presentation of results from the live only regressions, and the consideration for a spillover effect into a buffer area after the green light have turned on, respectively. Table 1.22 also includes the Bacon Decomposition for those results. To start, only the first three columns of each table are considered, namely the aggregate results of both phone calls and officer initiated incidents.

Considering the impact on the number of incidents, results suggest that the status of a green light has no effect. That is, the presence of an active green light is not associated with an increase or decrease in the number of incidents reported for both the 150 foot buffer, and the 350 foot exterior buffer after they have received their first green light. These results could suggest that there is not

\footnotetext{
${ }^{18}$ It is important to mention that there is not a designation for a separate green light response. Because of this, green light incidents are assumed to be coded as non-officer initiated, though because they could come through the central DPD system, that may not be the case.
} 
a change in the number of calls for service in each buffer zone each month. However, since this includes officer initiated responses as well, that result is unclear with the current results. Moving to the total response time from intake to the arrival of the officer on scene, there may be some spillover benefit in the area surrounding the green light, but no direct benefit for the 150 foot area around the green light.

Reducing the data set to only those calls for service that were not officer initiated, 182,146 observations remain, or about $19 \%$ of the total calls within the 500 foot buffer. This number of observations will remain the same throughout all three interior and exterior breakdowns. ${ }^{19}$ Of these remaining calls, 42,462 fall within the interior buffer of 150 feet. For this analysis, 233 green lights had a call originate within their 150 foot buffer, while there are 282 of the 284 exterior buffers that have a call. This leaves us with 515 groups across 33 months. Summary statistics for this sample are provided in Table 1.20 .

Table 1.20: Summary Statistics - 911 Calls - $150 \mathrm{ft}$. Interior - $350 \mathrm{ft}$. Exterior

\begin{tabular}{lcccc}
\hline \hline $\mathrm{N}=16,995$ & Mean & St. Dev. & Min & Max \\
\hline Total Calls & 10.718 & 15.070 & 0 & 219 \\
Total Response Time & 31.920 & 40.043 & 0.000 & $1,314.800$ \\
Live & 0.330 & 0.470 & 0 & 1 \\
Live W/in Buffer & 0.422 & 0.494 & 0 & 1 \\
\hline \hline
\end{tabular}

The number of observations come from 233 interior green lights and 282 exterior buffers, for a total of 515 across 33 months. Total response time is the number of minutes between intake and the arrival of the officer on the scene. Percentage of calls is the percentage of all incidents that were not officer initiated. Live is an indicator variable for if the month of year is after the month of year the green light became active. Finally, Live W/in Buffer is an indicator variable for if one of the green lights that formed the exterior buffer was active during that month.

As should be expected with using a reduced sample, the average number of calls decrease to just over 10 per area per month. Additionally, since the officer initiated contacts are excluded, response time increases to 31 minutes on average. There is no change in the percentage of the observations that are live, or the percentage of the observations that have an active green light within the green lights that are used to create the exterior buffer zones. Lastly, the variable representing the percentage of calls was omitted from the analysis. This is because only using non-officer initiated observations are used, and this variable will always be equal to 1 . Additionally, officer initiated calls will be analyzed separately. Summary statistics for this sample are reported in Table 1.21.

Table 1.21: Summary Statistics - Non-Calls - $150 \mathrm{ft}$. Interior - $350 \mathrm{ft}$. Exterior

\begin{tabular}{lcccc}
\hline \hline Statistic & Mean & St. Dev. & Min & Max \\
\hline Total Calls & 26.344 & 65.795 & 0 & 1,222 \\
Live & 0.330 & 0.470 & 0 & 1 \\
Live W/in Buffer & 0.422 & 0.494 & 0 & 1 \\
\hline \hline
\end{tabular}

The number of observations come from 234 interior green lights and 284 exterior buffers, for a total of 518 across 33 months. Live is an indicator variable for if the month of year is after the month of year the green light became active. Finally, Live W/in Buffer is an indicator variable for if one of the green lights that formed the exterior buffer was active during that month.

Using these two groups from the overall call data set will allow us to break down the results

\footnotetext{
${ }^{19}$ To clarify, this is because out of the 976,176 total calls within the 500 foot buffer, 182,146 of those are not officer initiated. The remaining 794,030 calls for service were initiated by the officer. These call totals will make up the total number of calls used for each analysis.
} 
found in the aggregate to a more granular level, hopefully to increase the understanding of previous results, or to answer the questions in a different way. These results are in the final three columns of Tables 1.22 and 1.23. Interestingly, when analyzing only the number of calls for service that were not officer initiated, there is a decrease in the monthly calls by nearly $10 \%$. Combined with this is the increase in the number of calls reported in the remaining buffer zone outside of the green light area.

Table 1.22: Calls for Service - $150 \mathrm{ft}$. Interior - $350 \mathrm{ft}$. Exterior

\begin{tabular}{|c|c|c|c|c|c|c|}
\hline \multirow[t]{2}{*}{ Data: } & \multicolumn{3}{|c|}{ All Calls } & \multicolumn{2}{|c|}{ Non-Officer Initiated } & \multirow{2}{*}{$\frac{\text { Officer Initiated }}{\text { Incidents }}$} \\
\hline & Calls & Response Time & $\%$ Call & Calls & Response Time & \\
\hline Live & $\begin{array}{l}-4.483 \\
(3.611)\end{array}$ & $\begin{array}{c}1.942 \\
(1.293)\end{array}$ & $\begin{array}{c}-0.098^{* * *} \\
(0.015)\end{array}$ & $\begin{array}{c}-1.675^{* * *} \\
(0.413)\end{array}$ & $\begin{array}{c}1.552 \\
(1.849)\end{array}$ & $\begin{array}{l}-2.819 \\
(3.518)\end{array}$ \\
\hline ID & $\checkmark$ & $\checkmark$ & $\checkmark$ & $\checkmark$ & $\checkmark$ & $\checkmark$ \\
\hline $\begin{array}{l}\text { Month of Year } \\
\% \text { Call }\end{array}$ & $\checkmark$ & $\begin{array}{l}\checkmark \\
\checkmark\end{array}$ & $\checkmark$ & $\checkmark$ & $\checkmark$ & $\checkmark$ \\
\hline $\begin{array}{l}\text { Adj. } R^{2} \\
\mathrm{~N}\end{array}$ & $\begin{array}{c}0.768 \\
17,094 \\
\end{array}$ & $\begin{array}{c}0.322 \\
17,094 \\
\end{array}$ & $\begin{array}{c}0.454 \\
17,094 \\
\end{array}$ & $\begin{array}{c}0.809 \\
16,995 \\
\end{array}$ & $\begin{array}{c}0.165 \\
16,995 \\
\end{array}$ & $\begin{array}{c}0.741 \\
17,094 \\
\end{array}$ \\
\hline Bacon Decomposition & & & & & & \\
\hline Earlier vs Later Treated & $\begin{array}{l}16.167 \\
{[0.045]}\end{array}$ & $\begin{array}{l}-4.316 \\
{[0.045]}\end{array}$ & $\begin{array}{l}-0.174 \\
{[0.045]}\end{array}$ & $\begin{array}{c}0.306 \\
{[0.045]}\end{array}$ & $\begin{array}{l}-0.363 \\
{[0.045]}\end{array}$ & $\begin{array}{l}15.871 \\
{[0.045]}\end{array}$ \\
\hline Later vs Always Treated & $\begin{array}{l}15.973 \\
{[0.036]}\end{array}$ & $\begin{array}{c}-13.690 \\
{[0.036]}\end{array}$ & $\begin{array}{l}-0.210 \\
{[0.036]}\end{array}$ & $\begin{array}{c}1.068 \\
{[0.036]}\end{array}$ & $\begin{array}{l}-6.925 \\
{[0.036]}\end{array}$ & $\begin{array}{l}14.911 \\
{[0.036]}\end{array}$ \\
\hline Later vs Earlier Treated & $\begin{array}{c}5.426 \\
{[0.135]}\end{array}$ & $\begin{array}{l}-9.865 \\
{[0.135]}\end{array}$ & $\begin{array}{l}-0.174 \\
{[0.135]}\end{array}$ & $\begin{array}{c}0.740 \\
{[0.135]}\end{array}$ & $\begin{array}{l}-5.383 \\
{[0.135]}\end{array}$ & $\begin{array}{c}4.686 \\
{[0.135]}\end{array}$ \\
\hline Treated vs Untreated & $\begin{array}{l}-8.308 \\
{[0.784]}\end{array}$ & $\begin{array}{l}-0.370 \\
{[0.784]}\end{array}$ & $\begin{array}{l}-0.076 \\
{[0.784]}\end{array}$ & $\begin{array}{l}-2.333 \\
{[0.783]}\end{array}$ & $\begin{array}{c}3.250 \\
{[0.783]}\end{array}$ & $\begin{array}{l}-5.994 \\
{[0.784]}\end{array}$ \\
\hline
\end{tabular}

$* * *, * *, *$ represents $\mathrm{p}<0.01, \mathrm{p}<0.05, \mathrm{p}<0.1$, respectively

Standard errors are clustered at the ID level. An ID represents each green light and each dissolved buffer zone around green lights. These data include 33 months for all 234 interior groups and 284 exterior groups. Due to the starting date of these data, some observations are always treated. In the Bacon Decomposition within the table, this category is included. For the Bacon Decomposition, estimates are presented along with their weights in brackets. A weighted sum of all estimates and their weights will yield the above difference-in-difference estimate. The $\%$ of calls are included in the OLS estimates for the All Crimes portion of the table, but are omitted from the Decomposition, so those estimates will only approximate the OLS coefficient.

This could be suggestive of displacement occurring. Where citizens immediately around the green light see a reduction in crime, and therefore contact police less frequently, whereas those in the outer areas are contacting police more frequently due to an increase in crime in those areas. If this were the case, and these results were to explain the earlier finding in the buffer zones of increased crime following a green light, this decrease in calls should be outweighed by an increase in officer initiated incidents. However, the final column of each table does not find this increase, though the decrease reported is not statistically significant. The attempt to reconcile with previous results is puzzling at this buffer level. Lastly, when analyzing response times exclusively for non-officer initiated contacts, there is no statistically significant effect of the green light on the immediate area surrounding the green light. However, as with out results with the aggregate data, there is a large decrease in the response time for police in the area outside of the green light buffer zone. 
Table 1.23: Calls for Service W/ Buffer Live - $150 \mathrm{ft}$. Interior - $350 \mathrm{ft}$. Exterior

\begin{tabular}{|c|c|c|c|c|c|c|}
\hline \multirow[t]{2}{*}{ Data: } & \multicolumn{3}{|c|}{ All Calls } & \multicolumn{2}{|c|}{ Non-Officer Initiated } & \multirow{2}{*}{$\frac{\text { Officer Initiated }}{\text { Incidents }}$} \\
\hline & Calls & Response Time & $\%$ Call & Calls & Response Time & \\
\hline \multirow[t]{2}{*}{ Live } & -2.200 & 0.173 & $-0.140^{* * *}$ & $-1.292^{* * *}$ & -0.652 & -0.910 \\
\hline & $(3.017)$ & $(1.352)$ & $(0.015)$ & $(0.444)$ & $(1.794)$ & $(2.895)$ \\
\hline \multirow[t]{2}{*}{ Live W/in Buffer } & 5.000 & $-3.796^{* * *}$ & $-0.091^{* * *}$ & $0.842^{*}$ & $-4.487^{* * *}$ & 4.180 \\
\hline & $(3.300)$ & $(1.181)$ & $(0.013)$ & $(0.444)$ & $(1.741)$ & $(3.155)$ \\
\hline ID & $\checkmark$ & $\checkmark$ & $\checkmark$ & $\sqrt{ }$ & $\checkmark$ & $\checkmark$ \\
\hline Month of Year & $\checkmark$ & $\checkmark$ & $\checkmark$ & $\checkmark$ & $\checkmark$ & $\checkmark$ \\
\hline$\%$ Call & & $\checkmark$ & & & & \\
\hline Adj. $R^{2}$ & 0.768 & 0.323 & 0.459 & 0.809 & 0.165 & 0.741 \\
\hline $\mathrm{N}$ & 17,094 & 17,094 & 17,094 & 16,995 & 16,995 & 17,094 \\
\hline
\end{tabular}

$* * *, * *, *$ represents $\mathrm{p}<0.01, \mathrm{p}<0.05, \mathrm{p}<0.1$, respectively

Standard errors are clustered at the ID level. An ID represents each green light and each dissolved buffer zone around green lights. These data include 33 months for all 234 interior groups and 284 exterior groups.

\subsubsection{Calls for Service - $250 \mathrm{ft}$. Interior - $250 \mathrm{ft}$. Exterior}

Next, the size of the interior buffer zone is increased, and the exterior buffer is decreased. This increase could potentially reveal information that gets lost in the previous split of 150 feet and 350 feet. For this set of data, summary statistics for all three samples of this data set are provided in Table 1.24. For all three data samples, there are fewer calls on average. This is intuitive, as the largest area decreased, potentially splitting some calls that were entirely within the exterior buffer at the larger size. Along with this, there is an increase in the percentage of observations with an active green light, and a decrease in the percentage of exterior buffers that have an active green light within them. This increase in the percentage of the observations that are treated is due to the increase in the number of green lights that saw at least one call throughout the period with the increased size of the buffer zone.

As before, results will be broken down into two separate tables. Table 1.25 presents the results with only including the variable of interest that corresponds with the immediate area surrounding the green light after it becomes active. Additionally, the results from a Bacon Decomposition are included within this table. Interestingly, we see an increase in calls when viewing the data in the aggregate. That is, without splitting the data into officer initiated and non-officer initiated incidents, there is a substantial increase of $38 \%$ in the number of incidents reported. This is more in line with the results found previously when using crime data, and is potentially suggestive of using too granular of an interior buffer zone in the previous analysis with calls for service. Once again, there is a significant decrease in the percentage of incidents that came from calls. Interestingly, this decrease in the percentage of calls almost matches the magnitude of the increase in calls. Response time, however, remains unaffected in this aggregate.

To check the mechanism through which this increase in calls is coming through, officer or nonofficer initiated incidents, attention is turned to the final three columns. Here, there is no change in the number of calls made from citizens for police help. This would be suggestive of an increase in policing within the area potentially accounting for the increase in the reported number of crimes, and the reported incidents. 
Table 1.24: Summary Statistics - $250 \mathrm{ft}$. Interior - $250 \mathrm{ft}$. Exterior

\begin{tabular}{lcccc}
\hline \hline & Mean & St. Dev. & Min & Max \\
\hline All Calls: $\mathbf{N}=\mathbf{2 2 , 7 0 4}$ & & & & \\
\cline { 1 - 3 } Total Calls & 27.857 & 57.372 & 0 & 1,243 \\
Total Response Time & 15.403 & 30.400 & 0.000 & $1,314.800$ \\
\% Calls & 0.406 & 0.296 & 0 & 1 \\
Live & 0.441 & 0.497 & 0 & 1 \\
Live W/in Buffer & 0.312 & 0.464 & 0 & 1 \\
& & & & \\
911 Calls: $\mathbf{N}=\mathbf{2 2 , 5 3 9}$ & & & & \\
\hline & & & & \\
Total Calls & 8.081 & 9.986 & 0 & 132 \\
Total Response Time & 32.022 & 41.039 & 0.000 & $1,314.800$ \\
Live & 0.441 & 0.497 & 0 & 1 \\
Live W/in Buffer & 0.313 & 0.464 & 0 & 1 \\
Officer Initiated: $\mathbf{N}=\mathbf{2 2 , 7 0 4}$ & & & & \\
\hline & & & & \\
Total Calls & 19.834 & 53.881 & 0 & 1,222 \\
Live & 0.441 & 0.497 & 0 & 1 \\
Live W/in Buffer & 0.312 & 0.464 & 0 & 1 \\
\hline \hline
\end{tabular}

The number of observations come from the number of groups across 33 months. For All Calls and Officer Initiated, there are 409 individual green lights and 279 exterior groups. For 911 Calls, individual green lights represent 406 areas, with an additional 277 in the exterior buffer zone. Total response time is the number of minutes between intake and the arrival of the officer on the scene. Percentage of calls is the percentage of all incidents that were not officer initiated. Live is an indicator variable for if the month of year is after the month of year the green light became active. Finally, Live W/in Buffer is an indicator variable for if one of the green lights that formed the exterior buffer was active during that month. 
Table 1.25: Calls for Service - $250 \mathrm{ft}$. Interior - $250 \mathrm{ft}$. Exterior

\begin{tabular}{|c|c|c|c|c|c|c|}
\hline \multirow[t]{2}{*}{ Data: } & \multicolumn{3}{|c|}{ All Calls } & \multicolumn{2}{|c|}{ Non-Officer Initiated } & \multirow{2}{*}{$\frac{\text { Officer Initiated }}{\text { Incidents }}$} \\
\hline & Calls & Response Time & $\%$ Call & Calls & Response Time & \\
\hline Live & $\begin{array}{c}10.066^{* * *} \\
(2.642)\end{array}$ & $\begin{array}{c}0.355 \\
(1.105)\end{array}$ & $\begin{array}{c}-0.156^{* * *} \\
(0.011)\end{array}$ & $\begin{array}{c}0.027 \\
(0.284)\end{array}$ & $\begin{array}{c}-4.291^{* * *} \\
(1.506)\end{array}$ & $\begin{array}{c}9.864^{* * *} \\
(2.580)\end{array}$ \\
\hline ID & $\checkmark$ & $\checkmark$ & $\checkmark$ & $\checkmark$ & $\checkmark$ & $\checkmark$ \\
\hline $\begin{array}{l}\text { Month of Year } \\
\% \text { Call }\end{array}$ & $\checkmark$ & $\begin{array}{l}\checkmark \\
\checkmark\end{array}$ & $\checkmark$ & $\checkmark$ & $\checkmark$ & $\checkmark$ \\
\hline $\begin{array}{l}\text { Adj. } R^{2} \\
\mathrm{~N}\end{array}$ & $\begin{array}{c}0.734 \\
22,704\end{array}$ & $\begin{array}{c}0.303 \\
22,704\end{array}$ & $\begin{array}{c}0.428 \\
22,704\end{array}$ & $\begin{array}{c}0.720 \\
22,539\end{array}$ & $\begin{array}{c}0.155 \\
22,539\end{array}$ & $\begin{array}{c}0.719 \\
22,704\end{array}$ \\
\hline \multicolumn{7}{|l|}{ Bacon Decomposition: } \\
\hline Earlier vs Later Treated & $\begin{array}{l}17.156 \\
{[0.065]}\end{array}$ & $\begin{array}{l}-6.058 \\
{[0.065]}\end{array}$ & $\begin{array}{l}-0.175 \\
{[0.065]}\end{array}$ & $\begin{array}{c}0.165 \\
{[0.065]}\end{array}$ & $\begin{array}{l}-3.975 \\
{[0.065]}\end{array}$ & $\begin{array}{l}16.999 \\
{[0.065]}\end{array}$ \\
\hline Later vs Always Treated & $\begin{array}{c}4.231 \\
{[0.077]}\end{array}$ & $\begin{array}{l}-4.976 \\
{[0.077]}\end{array}$ & $\begin{array}{l}-0.154 \\
{[0.077]}\end{array}$ & $\begin{array}{l}-0.070 \\
{[0.078]}\end{array}$ & $\begin{array}{c}1.611 \\
{[0.078]}\end{array}$ & $\begin{array}{c}4.320 \\
{[0.077]}\end{array}$ \\
\hline Later vs Earlier Treated & $\begin{array}{c}5.962 \\
{[0.206]}\end{array}$ & $\begin{array}{l}-8.825 \\
{[0.206]}\end{array}$ & $\begin{array}{l}-0.155 \\
{[0.206]}\end{array}$ & $\begin{array}{c}0.420 \\
{[0.206]}\end{array}$ & $\begin{array}{l}-5.418 \\
{[0.206]}\end{array}$ & $\begin{array}{c}5.546 \\
{[0.206]}\end{array}$ \\
\hline Treated vs Untreated & $\begin{array}{l}11.346 \\
{[0.652]}\end{array}$ & $\begin{array}{l}-5.726 \\
{[0.652]}\end{array}$ & $\begin{array}{l}-0.155 \\
{[0.652]}\end{array}$ & $\begin{array}{c}0.176 \\
{[0.651]}\end{array}$ & $\begin{array}{l}-4.670 \\
{[0.651]}\end{array}$ & $\begin{array}{l}11.174 \\
{[0.652]}\end{array}$ \\
\hline
\end{tabular}

***, **, * represents $\mathrm{p}<0.01, \mathrm{p}<0.05, \mathrm{p}<0.1$, respectively

Standard errors are clustered at the ID level. An ID represents each green light and each dissolved buffer zone around green lights. These data include 33 months for all 234 interior groups and 284 exterior groups. Due to the starting date of these data, some observations are always treated. In the Bacon Decomposition within the table, this category is included. For the Bacon Decomposition, estimates are presented along with their weights in brackets. A weighted sum of all estimates and their weights will yield the above difference-in-difference estimate. The $\%$ of calls are included in the OLS estimates for the All Crimes portion of the table, but are omitted from the Decomposition, so those estimates will only approximate the OLS coefficient. 
The final column in Table 1.25 suggests just that. The increase in the number of officer initiated incidents is statistically indistinguishable from the increase seen in total calls. Previously, a theory was discussed that an increase in police presence could be contributing to the increase in reported crime. While the evidence is not suggestive of a decrease in crime (from the insignificance found when analyzing 9-1-1 calls for service at this buffer zone level), there may be an increase in the proactive measures taken by the police department. If this were true, it could be overstating the number of crimes within these green light areas. That is, if there is an increase in police presence to prevent crime that is leading to an increase in the number of individuals arrested by, or encountering police, then there may be an increase in the reported number of crimes even though there may not be a commensurate increase in the number of crimes committed within the area. Finally, there is a significant decrease in the response time for non-officer initiated contacts, of over $10 \%$. The significance here, and not in the 150 foot buffer analysis, suggest once again that the previous analysis may have been considering too narrow of an area. Results with the inclusion of an active green light within the exterior buffer zone in Table 1.26 are similar to those in Table 1.25. Namely, there does not appear to be any effect outside of the interior 250 foot buffer zone, but those results do persist through this change in the empirical approach.

Table 1.26: Calls for Service W/ Buffer Live - $250 \mathrm{ft}$. Interior - $250 \mathrm{ft}$. Exterior

\begin{tabular}{|c|c|c|c|c|c|c|}
\hline \multirow[t]{2}{*}{ Data: } & \multicolumn{3}{|c|}{ All Calls } & \multicolumn{2}{|c|}{ Non-Officer Initiated } & \multirow{2}{*}{$\frac{\text { Officer Initiated }}{\text { Incidents }}$} \\
\hline & Calls & Response Time & $\%$ Call & Calls & Response Time & \\
\hline Live & $\begin{array}{c}9.352^{* * * *} \\
(2.138)\end{array}$ & $\begin{array}{l}-0.431 \\
(1.175)\end{array}$ & $\begin{array}{c}-0.165^{* * *} \\
(0.012)\end{array}$ & $\begin{array}{c}0.250 \\
(0.291)\end{array}$ & $\begin{array}{c}-4.774^{* * *} \\
(1.599)\end{array}$ & $\begin{array}{c}9.105^{* * *} \\
(2.060)\end{array}$ \\
\hline Live W/in Buffer & $\begin{array}{l}-1.883 \\
(2.534)\end{array}$ & $\begin{array}{l}-2.057 \\
(1.340)\end{array}$ & $\begin{array}{c}-0.025^{* *} \\
(0.012)\end{array}$ & $\begin{array}{c}0.115 \\
(0.316)\end{array}$ & $\begin{array}{l}-1.272 \\
(1.889)\end{array}$ & $\begin{array}{l}-2.004 \\
(2.446)\end{array}$ \\
\hline ID & $\checkmark$ & $\checkmark$ & $\checkmark$ & $\checkmark$ & $\checkmark$ & $\checkmark$ \\
\hline $\begin{array}{l}\text { Month of Year } \\
\% \text { Call }\end{array}$ & $\checkmark$ & $\begin{array}{l}\checkmark \\
\checkmark\end{array}$ & $\checkmark$ & $\checkmark$ & $\checkmark$ & $\checkmark$ \\
\hline $\begin{array}{l}\text { Adj. } R^{2} \\
\mathrm{~N}\end{array}$ & $\begin{array}{c}0.734 \\
22,704\end{array}$ & $\begin{array}{c}0.303 \\
22,704\end{array}$ & $\begin{array}{c}0.428 \\
22,704\end{array}$ & $\begin{array}{c}0.720 \\
22,539\end{array}$ & $\begin{array}{c}0.155 \\
22,539\end{array}$ & $\begin{array}{c}0.719 \\
22,704\end{array}$ \\
\hline
\end{tabular}

***, **, * represents $\mathrm{p}<0.01, \mathrm{p}<0.05, \mathrm{p}<0.1$, respectively

Standard errors are clustered at the ID level. An ID represents each green light and each dissolved buffer zone around green lights. These data include 33 months for all 234 interior groups and 284 exterior groups.

Lastly, the results for the Bacon Decomposition warrant brief discussion. Primarily of interest is the increase in the officer initiated contacts, as they seem to explain the increase in the number of calls for service. Within each of these Bacon Decompositions, it appears that those that were treated early have seen the largest decrease in the number of officer initiated incidents. This may be due to the increased presence to show the strength of the program, to persuade others to join or to show the commitment of the program so criminals would be less likely to test it in the future. That underlying mechanism is unable to be evaluated here. However, the reduced increase in other areas could also be due to an increase in usage to areas that generally saw less crime than those that joined the program early on. 


\subsubsection{Calls for Service - $350 \mathrm{ft}$. Interior - $150 \mathrm{ft}$. Exterior}

Finally, the analysis shifts to the disaggregation of the 500 foot buffer zone that has the largest interior of 350 feet, and the smallest exterior of 150 feet. Summary statistics for all three separate data sets used for this analysis can be found in Table 1.27. Here, there is less variation in the number of individual green lights that have at least one call throughout the period. Additionally, summary statistics for these buffer zones look very similar to the summary statistics for the 250 foot interior buffer in Table 1.24. Therefore, the results for these buffer zones will be presented immediately.

Table 1.27: Summary Statistics - $350 \mathrm{ft}$. Interior - $150 \mathrm{ft}$. Exterior

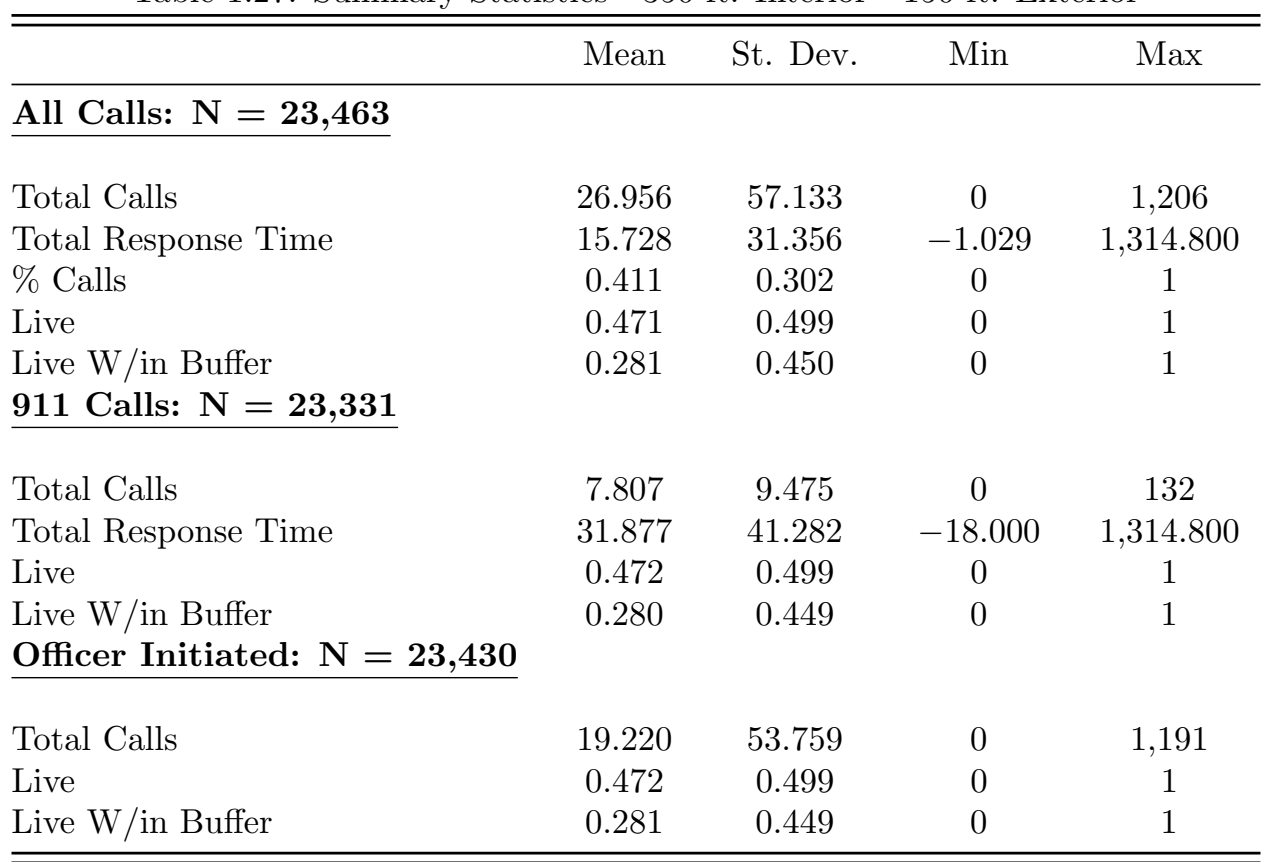

The number of observations come from the number of groups across 33 months. For All Calls there are 452 individual green lights and 259 exterior groups. For 911 Calls, individual green lights represent 450 areas, with an additional 258 in the exterior buffer zone. For Officer Initiated incidents, there are 452 individual green lights and 258 exterior groups. Total response time is the number of minutes between intake and the arrival of the officer on the scene. Percentage of calls is the percentage of all incidents that were not officer initiated. Live is an indicator variable for if the month of year is after the month of year the green light became active. Finally, Live $\mathrm{W} /$ in Buffer is an indicator variable for if one of the green lights that formed the exterior buffer was active during that month.

Table 1.28 present the results with only the difference-in-difference estimate of interest (not including any spillover or displacement effects) along with the Bacon Decompositions. Here, there is an increase in the number of calls, consistent with findings for previous buffer zones. This time, the increase in the number of incidents increases by nearly $60 \%$. This is of course economically significant. Breaking this result down into the effect of an active green light on 9-1-1 calls and officer initiated incidents, there is an increase in both. However, there is a significant portion of the increase in total incidents that originate with an officer initiated contact. This does shed some light on a potential story when combining the results for the number of calls across all buffer zones, and all subsets of the data. Namely, it appears from Table 1.22 that in the immediate area around a green light, there may be a decrease in crime. However, as the size of the buffer zone increases there is either a change in the likelihood citizens report suspected crime to the police, or an increase in the number of crimes these citizens could be witnessing. Across the two larger buffers (Tables 1.25 and 
1.28), there is a significant increase in the police presence within these areas, as measured by a large increase in the number of contacts that were officer initiated.

Table 1.28: Calls for Service - $350 \mathrm{ft}$. Interior - $150 \mathrm{ft}$. Exterior

\begin{tabular}{|c|c|c|c|c|c|c|}
\hline \multirow[t]{2}{*}{ Data: } & \multicolumn{3}{|c|}{ All Calls } & \multicolumn{2}{|c|}{ Non-Officer Initiated } & \multirow{2}{*}{$\frac{\text { Officer Initiated }}{\text { Incidents }}$} \\
\hline & Calls & Response Time & $\%$ Call & Calls & Response Time & \\
\hline Live & $\begin{array}{c}16.163^{* * *} \\
(1.848)\end{array}$ & $\begin{array}{l}-0.906 \\
(1.085)\end{array}$ & $\begin{array}{c}-0.179^{* * *} \\
(0.011)\end{array}$ & $\begin{array}{c}0.821^{* * *} \\
(0.257)\end{array}$ & $\begin{array}{c}-5.858^{* * *} \\
(1.429)\end{array}$ & $\begin{array}{c}15.323^{* * *} \\
(1.797)\end{array}$ \\
\hline ID & $\checkmark$ & $\checkmark$ & $\checkmark$ & $\checkmark$ & $\checkmark$ & $\checkmark$ \\
\hline $\begin{array}{l}\text { Month of Year } \\
\% \text { Call }\end{array}$ & $\checkmark$ & $\begin{array}{l}\checkmark \\
\checkmark\end{array}$ & $\checkmark$ & $\checkmark$ & $\checkmark$ & $\checkmark$ \\
\hline $\begin{array}{l}\text { Adj. } R^{2} \\
\mathrm{~N} \\
\end{array}$ & $\begin{array}{c}0.742 \\
23,463 \\
\end{array}$ & $\begin{array}{c}0.297 \\
23,463 \\
\end{array}$ & $\begin{array}{c}0.401 \\
23,463 \\
\end{array}$ & $\begin{array}{c}0.709 \\
23,331 \\
\end{array}$ & $\begin{array}{c}0.157 \\
23,331 \\
\end{array}$ & $\begin{array}{c}0.727 \\
23,430 \\
\end{array}$ \\
\hline \multicolumn{7}{|l|}{ Bacon Decomposition: } \\
\hline Earlier vs Later Treated & $\begin{array}{l}20.628 \\
{[0.073]}\end{array}$ & $\begin{array}{l}-5.097 \\
{[0.073]}\end{array}$ & $\begin{array}{l}-0.167 \\
{[0.073]}\end{array}$ & $\begin{array}{c}0.277 \\
{[0.073]}\end{array}$ & $\begin{array}{l}-3.975 \\
{[0.073]}\end{array}$ & $\begin{array}{l}20.353 \\
{[0.073]}\end{array}$ \\
\hline Later vs Always Treated & $\begin{array}{c}4.685 \\
{[0.090]}\end{array}$ & $\begin{array}{l}-5.726 \\
{[0.090]}\end{array}$ & $\begin{array}{c}-0.152 \\
{[0.090]}\end{array}$ & $\begin{array}{l}-0.237 \\
{[0.090]}\end{array}$ & $\begin{array}{c}0.811 \\
{[0.090]}\end{array}$ & $\begin{array}{c}4.935 \\
{[0.090]}\end{array}$ \\
\hline Later vs Earlier Treated & $\begin{array}{c}3.630 \\
{[0.226]}\end{array}$ & $\begin{array}{l}-8.505 \\
{[0.226]}\end{array}$ & $\begin{array}{l}-0.139 \\
{[0.226]}\end{array}$ & $\begin{array}{c}0.412 \\
{[0.227]}\end{array}$ & $\begin{array}{l}-4.194 \\
{[0.227]}\end{array}$ & $\begin{array}{c}3.220 \\
{[0.227]}\end{array}$ \\
\hline Treated vs Untreated & $\begin{array}{l}21.952 \\
{[0.611]}\end{array}$ & $\begin{array}{l}-9.256 \\
{[0.611]}\end{array}$ & $\begin{array}{l}-0.199 \\
{[0.611]}\end{array}$ & $\begin{array}{c}1.195 \\
{[0.610]}\end{array}$ & $\begin{array}{l}-8.038 \\
{[0.610]}\end{array}$ & $\begin{array}{l}20.745 \\
{[0.610]}\end{array}$ \\
\hline
\end{tabular}

$* * *, * *, *$ represents $\mathrm{p}<0.01, \mathrm{p}<0.05, \mathrm{p}<0.1$, respectively

Standard errors are clustered at the ID level. An ID represents each green light and each dissolved buffer zone around green lights. These data include 33 months for all 234 interior groups and 284 exterior groups. Due to the starting date of these data, some observations are always treated. In the Bacon Decomposition within the table, this category is included. For the Bacon Decomposition, estimates are presented along with their weights in brackets. A weighted sum of all estimates and their weights will yield the above difference-in-difference estimate. The $\%$ of calls are included in the OLS estimates for the All Crimes portion of the table, but are omitted from the Decomposition, so those estimates will only approximate the OLS coefficient.

Additionally, the program appears to have significantly reduced the response time to these green light areas. Namely, in this buffer zone the time from intake to the arrival of an officer on scene decrease by over $15 \%$. This could be attributed to an increase in the amount of time officers are spending in these areas, or it could be due to the increased usage of priority 1 designation (lights and sirens) to calls from these green light businesses.

Finally, the Bacon Decomposition of these results are similar to results of previous buffer zones with the calls for service data. Namely, early adopters appear to see the largest increase in the number of officer initiated incidents, while the later treated observations appear to have a slightly larger decrease in the response time. This could be due to an increase in efficiency of responding to calls from these areas as the program grows and officers and dispatchers become better equipped to promptly service these calls, though the difference is economically negligible.

Lastly, Table 1.29 present the results that can potentially point to any spillover or displacement effects of these green lights and the police response to them. Here, there is an increase in the number of calls across the immediate 350 foot buffer, but a decrease in the exterior zone. This could be suggestive of a spillover benefit of these green lights, displacing criminals outside of the 500 foot buffer zone. Alternatively, it could suggest that there is a decrease in police presence in these areas, causing the number of officer initiated incidents to decrease. The fourth and sixth columns of the 
Table 1.29: Calls for Service W/ Buffer Live - $350 \mathrm{ft}$. Interior - $150 \mathrm{ft}$. Exterior

\begin{tabular}{|c|c|c|c|c|c|c|}
\hline \multirow[t]{2}{*}{ Data: } & \multicolumn{3}{|c|}{ All Calls } & \multicolumn{2}{|c|}{ Non-Officer Initiated } & \multirow{2}{*}{$\frac{\text { Officer Initiated }}{\text { Incidents }}$} \\
\hline & Calls & Response Time & $\%$ Call & Calls & Response Time & \\
\hline Live & $\begin{array}{c}13.042^{* * *} \\
(1.666)\end{array}$ & $\begin{array}{l}-1.238 \\
(1.126)\end{array}$ & $\begin{array}{c}-0.169^{* * *} \\
(0.011)\end{array}$ & $\begin{array}{l}0.626^{* *} \\
(0.267)\end{array}$ & $\begin{array}{c}-4.901^{* * *} \\
(1.496)\end{array}$ & $\begin{array}{c}12.401^{* * *} \\
(1.594)\end{array}$ \\
\hline Live W/in Buffer & $\begin{array}{c}-8.878^{* * *} \\
(2.004)\end{array}$ & $\begin{array}{l}-0.954 \\
(1.236)\end{array}$ & $\begin{array}{l}0.027^{* *} \\
(0.013)\end{array}$ & $\begin{array}{c}-0.556^{*} \\
(0.298)\end{array}$ & $\begin{array}{c}2.716 \\
(2.005)\end{array}$ & $\begin{array}{c}-8.334^{* * *} \\
(1.919)\end{array}$ \\
\hline ID & $\checkmark$ & $\checkmark$ & $\checkmark$ & $\checkmark$ & $\checkmark$ & $\checkmark$ \\
\hline $\begin{array}{l}\text { Month of Year } \\
\% \text { Call }\end{array}$ & $\checkmark$ & $\begin{array}{l}\checkmark \\
\checkmark\end{array}$ & $\checkmark$ & $\checkmark$ & $\checkmark$ & $\checkmark$ \\
\hline Adj. $R^{2}$ & 0.743 & 0.297 & 0.401 & 0.709 & 0.157 & 0.728 \\
\hline $\mathrm{N}$ & 23,463 & 23,463 & 23,463 & 23,331 & 23,331 & 23,430 \\
\hline
\end{tabular}

$* * *, * *, *$ represents $\mathrm{p}<0.01, \mathrm{p}<0.05, \mathrm{p}<0.1$, respectively

Standard errors are clustered at the ID level. An ID represents each green light and each dissolved buffer zone around green lights. These data include 33 months for all 234 interior groups and 284 exterior groups.

table suggest that both theories may be plausible. There is also a decrease in the number of incidents reported by citizens, though the statistical significance is weak. However, there is a large decrease in the number of incidents that were initiated by police officers. For the first time in the results, there may be a shifting of police resources into green light areas and away from those areas that do not participate in the program. Finally, there does not appear to be any effect on response time for those areas outside of the 350 foot interior buffer zone.

\subsection{Discussion}

The goal of this paper was to evaluate the effectiveness of Detroit's Project Green Light on reducing crime within the immediate areas surrounding participating businesses. Utilizing a data set of geolocated crime within the city from 2009-2019, this paper considers the temporal variation in the presence of crime in business blocks as well as buffers of 150 feet, 250 feet, and 350 feet. The results between the buffers and business blocks are not consistent, however. When evaluating the crime in business blocks relative to the two nearest business blocks in straight line distance, there is a consistent decrease in total crime, violent crime, and property crime. This reduction is quite large and is both statistically and economically significant. The strategy using these business blocks does not account for all 554 green lights that were active at some point during the sample period. This is due to these green lights occurring outside of blocks that were zoned for business or mixed-use purposes. However, these results may best evaluate the program as it was targeted to reduce crime in and around businesses. These results stand in contrast to two of the three results found in the buffer zone analysis. While a reduction in crime with business blocks is found, there is an increase in crime with interior buffer zones of 150 and 250 feet. This positive effect is seen throughout both the inclusion and exclusion of the exterior buffer having an active green light within the area it is buffering. These positive effects are more consistently seen throughout total crimes and violent crimes, whereas property crimes appears to be less responsive to this surveillance system. However, the negative result once again appears when considering a 350 foot buffer for the direct effect of a green light on crime. For this buffer, there is a reduction of $13 \%$ in crime for all crimes, and $15 \%$ 
for violent crimes, with no effect on property crime.

Both spatial measurements of the change in crime allow us to evaluate potential spillover or displacement effects of this program. Additionally, each analysis is consistent in the findings that there appears to be a spillover benefit to either the neighboring blocks, or the area surrounding the main buffer zone. This may suggest that crime is overall displaced from these green light areas, and thus moves it even further out than this paper considers.

Importantly, all results using the crime data suffer from a high percentage of zeros in the dependent variable. This forced a decision in whether to utilize a model that is more correctly specified to deal with both the count nature, and number of zeros for the dependent variable. Due to computational complexity of models such a zero-inflated models and Bacon Decompositions, only Bacon Decompositions were utilized to disaggregate the aggregate coefficient into its components (early vs. late treated, late vs. early treated, and treated vs. untreated). In all specifications of the Bacon Decomposition's, findings suggest that those businesses that joined early in the program saw a reduction in crime relative to those that joined later.

Lastly, utilizing a separate data set of calls for service for the buffer zones, allows for the exploration of the mechanism to the results. Namely, it may be the case that the increase in crime found in the immediate area around each green light is due to an increase in either citizen willingness to contact police, or police activity. These results suggest that there may be a decrease in the number of 9-1-1 calls from the immediate area surrounding the green light. Additionally, response times do appear to significantly decrease by between $13-15 \%$ as interior buffer zones expand.

Combining this information with the previous results using crime in buffer zones, the results may be suggestive of an increase in police presence, and not a formal increase in crime that is leading to the increase in reported crimes. Therefore, it may not actually be an increase in the number of crimes committed in the area, only those that are investigated and tried. However, there is a possibility that these green lights have caused a displacement of police resources away from other areas and into those areas that participate in Project Green Light.

This innovative program in the United States could be considered for expansion into other metropolitan areas. The results in this paper do find positive results, through a reduction in the number of crimes perpetrated on the business blocks that house these green lights. There are even spillover effects found to other blocks. Future research should further address the question of how these programs effect the allocation of police resources. 


\section{Chapter 2}

\section{Bargaining in the Shadow of the Trial? Deaths of Law Enforcement Officials and the Plea Bargaining Process}

\section{$2.1 \quad$ Introduction}

In the United States, plea bargaining is ubiquitous. It was not an overstatement when Justice Anthony Kennedy referred to U.S. criminal justice as a "system of pleas".${ }^{1}$ For a typical state in the U.S., more than $95 \%$ of felony convictions arise from guilty pleas, which are often negotiated via a plea bargaining process. To appreciate the social concerns of crime's costs and consequences, prison overcrowding, and the financial burden on the public of the legal system, one must appreciate the functioning of our plea bargaining system.

The standard framework in applied theory is to consider the bargaining game between the prosecutor and the defense (treating the defendant and his/her attorney as a single player). In a negotiation, the defendant can agree to a sanction and enter a guilty plea. Presumably, this sanction is less than what could be levied if the defendant is convicted in a jury trial and sentenced by a judge. In practice, plea bargaining can take numerous forms such as sentence bargaining, where the prosecutor agrees to recommend a mitigated sentence to the judge, or charge bargaining where the prosecutor accepts a guilty plea for a less-serious crime in return for dropping more-serious charges. Regardless of the form the plea bargaining takes, economists typically argue that it is efficient. If the two parties form similar expectations of what will happen if the case proceeds to a jury trial, and the trial itself is costly, then agreeing to a penalty close to the expected sanction received at trial will save both sides the costs and hence be mutually agreeable. In fact, the defendant may even receive a plea discount due to the monetary and time savings he provides the prosecutor's office by pleading guilty. $^{2}$

\footnotetext{
${ }^{1}$ Lafler v Cooper (2012)

${ }^{2}$ There is not a standardized definition of the plea discount in the literature. If $b$ is the plea bargain agreed to
} 
Thus, standard theoretical models of plea bargaining treat the expected outcomes of a jury trial as the default outcome of the bargaining process. Consequently, changes in the expected trial outcomes would then be expected to be reflected in the negotiated guilty plea. This framework is so well established and frequently used that it has been called "bargaining in the shadow of the trial" (Mnookin \& Kornhauser, 1979; Cooter, Marks, \& Mnookin, 1982).

The modeling decision theoretical economists have focused on, then, is which market imperfection can explain the existence of trials. Building on the seminal contribution of Reinganum (1988), asymmetric information models dominate the literature. ${ }^{3}$ One party may have private information on guilt, the quality of the evidence, or even risk preferences. Introducing asymmetric information allows for plea bargaining to imperfectly sort (Bjerk, 2007) and can explain the use of jury trials in equilibrium. In other theoretical frameworks, noisy information (Priest \& Klein, 1984; D. S. Abrams, 2011) or optimism bias (Gould, 1973; Posner, 1973; Shavell, 1982; Farmer \& Pecorino, 2002) is employed to explain bargaining's failure.

Research evaluating the efficacy of legal institutions relies on this theoretical framework. Reinganum (2000) provides an early contribution by exploring sentencing guideline's impact on the plea bargaining process. Bar-Gill and Gazal Ayal (2006) evaluate theoretically an informationally-constrained, budget-constrained prosecutor's choice of which cases to pursue, showing that restrictions placed on plea discounts could reduce the "innocence problem" of innocent defendants pleading guilty. Bandyopadhyay and McCannon $(2014,2015)$ evaluate how a prosecutor's re-election concerns distort the plea bargaining rate. Klick and Mungan (2015) use the framework to show how exoneree compensation should improve the sorting function of plea bargaining. Empirical evaluations of prosecutor salary and turnover (Boylan and Long, 2005), for example, implicitly utilize this framework by using the trial rate as an outcome variable. Structural models have been used to forecast the consequences of sentencing policy change, such as eliminating mandatory minimums and using alternatives to incarceration, which are built under the presumption of bargaining failure leading to trials (Silveira, 2017).

Outside of economics, criminologists and legal researchers have criticized the bargaining in the shadow of the trial framework as an inaccurate description of the plea bargaining process. An influential critique of plea bargaining by Bibas (2004) focuses on two primary shortcomings. First, he argues that structural impediments distort bargaining. Poor lawyering and attorney self-interest create a disconnect between the outcome that would arise at trial and the negotiated plea. Pre-trial detention, as another example, may matter more for the decision to enter a guilty plea than the expected outcome at trial (Dobbie, Goldin, \& Yang, 2018; Stevenson, 2018). Second, Bibas (2004) challenges the presumption that actors are fundamentally rational. Psychological biases and the defendants' lack of sophistication are pervasive. If a defendant is unable to anticipate the likely outcomes of a jury trial, and his attorney is not incentivized to provide fully effective counsel, then guilty pleas need not reflect expected trial outcomes.

Bushway, Redlich, and Norris (2014) conduct a novel experiment with actual judges, prosecu-

and $s$ is the sanction that would arise with a trial conviction, one could define a plea discount occurring when $b<s$. Alternatively, it can be defined as occurring only when $b<p s$ where $p$ is the probability of conviction at trial. Here, we will measure the size of the plea discount as $\frac{s-b}{s}$. Also, we do not distinguish or use the (potential) synonym of a trial penalty.

${ }^{3}$ The initial theoretical models using asymmetric information by Bebchuk (1984) and Reinganum and Wilde (1986) focused on the closely related issue of pre-litigation bargaining. Grossman and Katz (1983) discuss at length the potential sorting function of plea bargaining in their early contribution and Landes (1971) for an early contribution discussing its resource conservation value. 
tors, and defense attorneys. Each is given a hypothetical criminal case and is asked to assign the probability that the accused will be convicted at trial $(p)$ and the sanction expected if convicted $(s)$. Also, they ask the professionals what sentence they would recommend the defendant to accept $(b)$. They provide mixed results. In the aggregate, the framework does well $(\overline{p s}=6.75 \& \bar{b}=6.11)$. Also, at the individual level, for those who assess a greater conviction probability or a more severe trial sanction, their proposed plea bargain is greater. On the other hand, for the sample of judges, their assessed probability of conviction does not correlate with the plea bargain. Instead, their behavior can best be explained by a constant plea discount unrelated to the jury's probability of conviction. For prosecutors and defense attorneys, a nonlinear relationship exists, where the plea bargain does not increase at the same rate as the expected trial sanction.

Furthermore, suggestive evidence questioning the framework arises in Lacosse and Payne (1999). Their objective is to estimate differences in outcomes between judges and how Federal sentencing guidelines and mandatory minimums affect these disparities. While they show that judges sentence differently, both before and after the policy change, they provide evidence that sentences following plea bargaining exhibit substantially less judge-specific variation than sentences following trial convictions. They suggest that prosecutor influences matter more.

Bushway and Redlich (2012) engage in a useful exercise. They use a rich data set that includes information on the evidence available. They use this information to estimate the probability of incarceration for those who go to trial and use this model to create the counterfactual incarceration probability at trial for those who plead guilty. With this approach they test the accuracy of the shadow of the trial framework. They compare the outcomes of those who went to trial to the expected trial outcome for those who entered a guilty plea. In the aggregate the two values match up, suggesting that plea bargaining occurs in the shadow of the trial. At the individual level there is wide variation, suggesting that important individual level variables are driving behavior other than the expected outcome at trial, supporting Bibas (2004). Again, it is unclear whether negotiated deals capture the outcomes that would arise at trial.

Knowing whether the theoretical framework commonly used describes the bargaining process is crucial for criminal justice reform. For one, numerous policy debates surround the selection of judges. Commentators have criticized and evaluated the impact of their selection and retention mechanism (i.e., appointment versus election) (Berdejo and Yuchtman, 2013; lim2013) and the role that partisan affiliation has on outcomes (Lim \& Snyder Jr, 2015). Policy changes intending to hold judges more accountable will have only muted impacts if plea bargaining ignores these changes. Also, efforts to handcuff judicial sentencing discretion, such as mandatory minimums and sentencing guidelines, are more powerful when plea bargaining responds to the expected sanction at trial. Importantly, the plea bargaining process has been for the most part unregulated. Only recent Supreme Court decisions have even chosen to weigh in on the institution. Most recently in a pair of cases, Lafler $v$ Cooper (2012) and Missouri v Frye (2012), the Supreme Court addressed the issue of whether ineffective assistance by counsel even applied to plea bargaining. ${ }^{4}$ At trial, rules of evidence regulate dubious confessions and policing practices (i.e., search and seizure standards). The scrutiny applied by judges, jurors, and the public is lost when a plea deal is reached. As summarized nicely by Bibas

\footnotetext{
${ }^{4}$ In Padilla $v$ Kentucky (2010) the court applied ineffective counsel to allow a defendant to withdraw a guilty plea. In the two 2012 decisions, ineffective counsel is applied to a rejected plea offer. In these split decisions, the dissenting opinion argued there is no constitutional right to plea bargaining, while the majority argued that it is so pervasive that Supreme Court oversight is now necessary.
} 
(2004), "if highly proceduralized and regulated trials serve as a backstop to largely unregulated plea bargaining, we do not need new procedural safeguards for pleas because plea outcomes already incorporate the value of trial safeguards" (p. 2466). If the conceptual framework fails to explain outcomes adequately, then "plea bargaining practices need many reforms" (p. 2408).

Therefore, our objective is to investigate whether the bargaining in the shadow of the trial framework is the appropriate one to use to study plea bargaining. To do this, we take advantage of a large data set from the state of Florida. It provides case processing information for every individual arrested for a felony offense since 2004. The data set tracks the case as prosecutors file, drop, refile, and pursue a conviction. Whether or not the individual saw his charges dropped, whether he pled guilty, and whether the case went to trial is known. Furthermore, sentencing information is available. The data set includes more than 21 million processed criminal counts.

The empirical dilemma is how to make a causal identification. The prosecutor and defendant's expectations of the jury's likelihood of conviction is not measurable; nor is whether this probability was factored into the bargaining process at all. Changes in jury procedures, such as variation in the number of jurors who hear a case or whether unanimity is required for conviction ${ }^{5}$, are expected to be made by policymakers who have identified a problem with the criminal justice system. Hence, institutional changes are endogenous, and it would not be clear whether it was in fact the jury's proclivity to convict that was driving plea bargaining. Changes in sentencing harshness also fail to provide causal inferences since sentencing guidelines are, again, intentional policy tools used in response to crime and to promote deterrence, thus potentially influencing the mix of individuals and acts that arise in the criminal justice system (Bushway \& Redlich, 2012). The primary shortcoming is that a counterfactual outcome of what would have happened at trial is unknown. One should reasonably expect selection effects to be pronounced, so that outcomes experienced by those who choose to go to trial are poor predictors of what would have occurred to those who enter a guilty plea.

To make a causal identification of bargaining in the shadow of the trial we use data on every incident in the state of Florida where a law enforcement official died in the line of duty. We argue that the death of a police officer is a salient tragedy in the community. Just as in Philippe and Ouss (2018), who show that French jurors respond to media coverage of crime in the days prior to the beginning of a trial, we argue that the resulting media coverage of the incident primes those in the local community to the problems of violence and the risks law enforcement officials expose themselves to. ${ }^{6}$ We argue that this acts as an exogenous shock to the pool of potential jurors. We consider those felony cases where the arrest had already been made and the initial charges had already been filed, but the case had not yet been disposed of when the police officer's death occurred. For these accused defendants, the law enforcement official's death acts as a quasi-natural experiment. These cases become the treated sample. With this novel, quasi-natural experiment, we use a differencein-difference estimation to identify whether these cases resulted in different outcomes than those processed without the shock of an officer's death.

If plea bargaining occurs in the shadow of the trial, then we expect the severity of the sentences

\footnotetext{
${ }^{5}$ For example, in 2018 Louisiana voters passed a referendum to change the requirement for conviction at criminal trials from $\frac{10}{12}^{\text {ths }}$ to unanimity. In some states, criminal trials only utilize six jurors, rather than the standard twelve.

${ }^{6}$ Relatedly, Lim, Snyder Jr, and Strömberg (2015) provide evidence that judges respond to newspaper coverage of their decisions. Thus, there is a close link between local community news and the actions taken by those engaged in the legal system.
} 
agreed to in the plea bargaining process, relative to those obtained from a jury trial conviction, to become more severe. Theoretically, the difference between the sanction received at trial and the one agreed to at the bargaining table should be driven primarily by the conviction probability. ${ }^{7}$ Simply put, plea discounts should become less generous. If, on the other hand, the plea bargaining process is unrelated to the jury's willingness to convict, then the sentences arising from plea bargaining will not change.

We find strong evidence that plea bargaining adjusts for cases in process when the exogenous shock occurs. Outside of this period, the sentence received from plea bargaining, relative to the sentence received from a trial, is approximately 52 cents on the dollar (i.e., 8.5 fewer months). When a law enforcement official dies in the line of duty, guilty pleas serve approximately 61 cents on the dollar (i.e., 7.0 fewer months). ${ }^{8}$ Thus, the plea discount reduces.

Consistent with our hypothesis, we further show that the reduction in the plea discount is larger in magnitude for serious crimes. While for all felonies the plea discount reduces by $18 \%$ when a law enforcement official dies in the line of duty, for serious crimes the plea discount drops by almost $24 \%$. Additionally, we show that the effect is concentrated in deaths that are expected to be more salient in the local community. Specifically, we show that the effect is concentrated in gun-related deaths of law enforcement officials. Also, using Google searches for information on law enforcement officials, we show that the effects are larger when there is a higher volume and greater uptick in Google searches in that area of the state. Also, for those treated cases where the time since arrest is longest, the magnitude of the effect is greater. Presumably, these cases are closer to the trial date where violence's salience in the jury pool is strongest. Finally, we show that the reduction in the plea discount is stronger if the fallen officer has a public infrastructure, such as a road, dedicated in his/her name. Again, we argue the dedication coincides with heightened salience in the local community.

The bargaining in the shadow of the trial framework does not, though, give a clear prediction of what will happen to the trial rate when a law enforcement official dies in the line of duty. When prosecutors make less-generous offers, one would expect that the probability of a defendant accepting those terms would reduce. On the other hand, an increase in the conviction probability can reasonably expand the bargaining zone, leading to fewer trials. Using the quasi-natural experiment, we show an important increase in the rate at which cases are taken to trial. The trial rate increases by $80 \%$. Thus, not only are accused criminals, whose crimes are unrelated to the circumstances that caused the law enforcement official's death, accepting harsher sanctions when they do agree to a plea (i.e., the intensive margin), but they are experiencing harsher sentences because more are going to trial, which generates stiffer expected sentences (i.e., the extensive margin).

Finally, we provide suggestive evidence that it is, in fact, changes in the anticipated jurors' behavior that drives the results. This is important since our argument relies on changes in the probability the jury will convict that trickles down to the negotiation. We disentangle the trials, separating those that go before a jury from bench trials, where the judge determines both guilt and the sentence. Considering sentencing, the reduction in the (relative) plea discount only occurs for jury trials. The difference-in-difference effect is statistically indistinguishable from zero for bench

\footnotetext{
${ }^{7}$ In addition, factors such as the trial costs and decision making under uncertainty preferences are important factors as well.

${ }^{8}$ The calculation of the number of months uses the estimated percentage change from the primary regression and the mean value for the sentence variable used in the analysis (see Tables 2 and 3 in the upcoming sections).
} 
trials. Similarly, the increase in the trial rate only occurs for jury trials. Thus, it is not changes in beliefs about the judge's sentencing, but rather alterations in the expectations of jurors' behavior that can explain our observations. Furthermore, estimating the conviction probability, the deaths are associated with a noticeable decrease in the likelihood of an acquittal (12.3\%), with a greater effect for jury trials and a statistically zero effect for bench trials.

We are the first to explore exogenous variation in the probability a jury will convict ${ }^{9}$ to test the bargaining in the shadow of the trial framework. Our work complements Bushway and Redlich (2012) effort in that rather than trying to estimate the counterfactual, as they did, we take advantage of an exogenous shock to the conviction probability to estimate directly the relative change in negotiated plea deals. We obtain strong evidence that negotiated discounts adjust to the expected trial outcome.

A sizeable literature attempts to estimate the plea discount without being able to account for selection effects. Earlier, important contributions documented different sentences received by those who plead guilty and those who have their case taken to trial (Albonetti, 1997). For example, Ulmer and Bradley (2006) estimate that those whose cases go to a jury trial are 2.65 times more likely to be incarcerated, and receive sentences that are 1.57 times as long. As stated, though, selection effects can be expected to be important influencing the size of these estimates. By taking advantage of a quasi-natural experiment, we can identify the causal relationship between the expected sanction arising from a jury trial and the negotiated sanction from a guilty plea.

In our extension to the analysis of the trial rate, our work closely relates to the findings of Boylan (2012). He asks whether prosecutors respond to the harshness of the judge. If prosecutors are not responding to the judge (and, consequently, not responding to the expected sanction from trial), they will offer the same plea deal invariant to the judge assigned to the case. Exploiting random assignment of cases to Federal judges, Boylan (2012) estimates the relationship between the likelihood of going to trial and the harshness of the judge. Our work complements his in that we show that the expected outcome at trial filters back to the plea bargaining process. While Boylan (2012) documents that the trial rate responds to judges' sentencing practices (which we also find in our state level data), we show that it also responds to the jury's conviction probability. Importantly, unlike Boylan (2012), we are also able to document changes in the plea discount. Thus, plea outcomes are not simply a fixed discount on the judge's sentence, as suggested by Bushway et al. (2014), but actively responding to anticipated jury decision-making. Rather, $b$ responds to $p$, along with $s .{ }^{10}$

Section 2 provides a simplified version of the bargaining in the shadow of the trial conceptual framework. It presents the hypothesized changes in the plea discount from an exogenous shock to the conviction probability. Section 3 presents the data. Section 4 evaluates sentencing and the plea discount. It first evaluates the identification strategy, and then provides the main results, including an analysis of average and heterogeneous treatment effects. Section 5 explores the rate at which cases are taken to trial. In Section 6, we explore suggestive evidence that the mechanism through which the guilty plea sanctions adjust is changes in the jury's behavior, as hypothesized. Section 7 concludes.

\footnotetext{
${ }^{9}$ There is recent work evaluating whether the probability a jury convicts responds to the harshness of the sanction. Bindler and Hjalmarsson (2018) use changes in the use of capital punishment in a prominent 1700s \& 1800s English court, along with the shock of the American Revolution. Breen (2011) investigates juries in military courts who both convict and sentence individuals.

${ }^{10}$ Thus, we complement the research on bargaining in the shadow of the judge literature (LaCasse \& Payne, 1999; Boylan, 2012; Marselli, McCannon, \& Vannini, 2015). Similarly, our work complements the findings of Dobbie et al. (2018) and Stevenson (2018) who document the relationship between pre-trial detention and willingness to plea bargain.
} 


\subsection{Theory}

Consider a simple theoretical model of a prosecutor and a defendant engaged in plea bargaining. The model we present is a simplification of those common in the literature. The defendant has a binary choice: whether to accept a plea offer or to reject it and go to trial. Let $b \geq 0$ be the plea bargain offer. Let $s>0$ be the sanction received if convicted at trial, and let the sanction be 0 if acquitted. The probability of conviction at trial, as assessed by the defendant, is $p_{d}$. Furthermore, going to trial incurs an additional cost of $c_{d} \geq 0$ for the defendant. For simplicity, assume the defendant is risk-neutral, minimizing the loss from incarceration. Hence, he will accept the plea bargain when

$$
b \leq p_{d} s+c_{d} .
$$

The prosecutor, on the other hand, is assumed to prefer the highest sentence possible. One can presume that the sanction $s$ set by, for example, the legislative body via sentencing guidelines is representative of society's desired sanction. The prosecutor, then, wants the sanction to be as close to this as possible, but is given discretion to accept a less severe sanction. Let the probability of conviction at trial, as assessed by the prosecutor, be denoted $p_{p}$. Also, let the prosecutor's cost of pursuing the case at trial be $c_{p} \geq 0$. Again, assume the prosecutor is risk neutral. Hence, she is willing to accept the plea bargain when

$$
b \geq p_{p} s-c_{p} .
$$

Therefore, a mutually agreeable plea bargain exists if $p_{d} s+c_{d} \geq p_{p} s-c_{p}$. The interval,

$$
\left[p_{p} s-c_{p}, p_{d} s+c_{d}\right]
$$

is referred to as the bargaining zone. Plea bargaining fails, on the other hand, when this interval is empty, or rather,

$$
\left(p_{p}-p_{d}\right) s>c_{d}+c_{p}
$$

This condition is commonly referred to as the trial condition. ${ }^{11}$ Jury trials arise, in this simple framework, when the divergence in beliefs is sufficiently great and the costs to trial are sufficiently small.

The conundrum of the bargaining in the shadow of the trial literature is that with rational expectations $p_{p}=p_{d}=\widehat{p}$. That is, if both the prosecutor and the defense attorney are experienced and knowledgeable about the local criminal justice system, if exculpatory evidence is shared (which is mandatory given the Brady v. Maryland Supreme Court ruling ${ }^{12}$ ), and if the rules of evidence and court procedures are commonly known, then the two parties should share common beliefs. With this observation, the trial condition always fails and no cases go to trial.

Theoretical models, then, look to "market" imperfections to explain jury trials. If one side holds private information, then the two beliefs can diverge. If there is noise in the assessments or optimism bias, then the two probabilities again do not necessarily have to equal. Hence, trials might arise in

\footnotetext{
${ }^{11}$ See McCannon (2019) for an extended presentation of this framework.

${ }^{12}$ See Daughety and Reinganum (2018) for a recent theoretical analysis of prosecutors' incentives to share exculpatory evidence.
} 
equilibrium. ${ }^{13}$

Staying within this simple framework, suppose a shock occurs to $p_{i}$, increasing it to $\alpha_{i} p_{i} \in(0,1)$. If one assumes $\alpha_{d}=\alpha_{p}=\alpha>1$, so that the increase in the conviction probability affects all parties' assessments uniformly, then the trial condition becomes

$$
\left(p_{p}-p_{d}\right) \alpha s>c_{d}+c_{p}
$$

and the left-hand-side is greater than that in (4), resulting in more jury trials. Similarly, the bargaining zone becomes

$$
\left[\alpha p_{p} s-c_{p}, \alpha p_{d} s+c_{d}\right]
$$

The interval stays the same 'length' but shifts rightward. Thus, one would expect the negotiated plea, when plea bargaining arises, to carry a higher sanction.

If, on the other hand, the shock does not affect expectations uniformly, as might be the case in an asymmetric information environment, then the bargaining zone might expand or contract as it shifts rightward. Thus, while the set of mutually agreeable plea bargains becomes more severe, a contraction of the bargaining zone may lead to more trials (as bargaining fails at a higher rate), and an expansion of the bargaining zone may lead to fewer trials. Deck and Farmer (2007) provides experimental evidence that the size of the bargaining zone corresponds to the disagreement rate. Thus, the exogenous shock to the conviction probability increases the agreed sanction, if the participants are bargaining in the shadow of the trial, but has an ambiguous effect on the trial rate.

Alternatively, if plea bargained outcomes are unrelated to the expected trial outcome, these predictions no longer hold. As suggested by Bushway et al. (2014), for example, plea offers may simply be fixed discounts off the trial sanction, $b^{\prime}=\delta s$. The discount, $\delta \in(0,1)$, may be driven by the defendant's socio-economic status (e.g., gender, race, income, etc.) or the prosecutor's caseload pressures. In this alternative scenario, a shock to the jury's conviction probability will not affect the plea discount or the trial rate.

\subsection{Data}

To test the hypothesis that bargaining occurs in the shadow of the trial, we evaluate data from Florida. First, we describe the data on law enforcement deaths, which acts as a quasi-natural experiment and is essential for our identification strategy. Second, we elaborate on the available data on case prosecution decisions.

\subsubsection{Police Deaths}

Information on law enforcement official deaths in Florida was collected from the Officer Down Memorial Page, which collects information on every law enforcement official killed in the line of duty from 1791 to date. For the period under study, 132 members of Florida law enforcement

\footnotetext{
${ }^{13} \mathrm{An}$ interested reader is encouraged to consult the sizeable plea bargaining theoretical examples which build more sophisticated models to derive divergent beliefs as an equilibrium phenomenon. For example, Reinganum (2000) evaluates the impact of sentencing guidelines. Baker and Mezzetti (2001) add resource constraints with endogenous information collection. Bjerk (2007) studies incomplete sorting due to Bayesian juries. Farmer and Pecorino (1994) incorporate asymmetric information in risk preferences, self-serving bias (Farmer \& Pecorino, 2002), and bilateral asymmetric information (Farmer \& Pecorino, 2010). This is just a sample of the literature.
} 
Table 2.1: Law Enforcement Official Deaths

\begin{tabular}{llllll}
\hline \hline Year & \# deaths & Year & \# deaths & Cause of Death & \# deaths \\
\hline 2004 & 12 & 2011 & 15 & Automobile related & 53 \\
2005 & 7 & 2012 & 5 & Gunfire & 47 \\
2006 & 9 & 2013 & 4 & Heart attack & 12 \\
2007 & 16 & 2014 & 6 & Assault & 3 \\
2008 & 10 & 2015 & 1 & Duty related illness & 1 \\
2009 & 8 & 2016 & 4 & Heat exhaustion & 1 \\
2010 & 10 & 2017 & 10 & Fall & 1 \\
\hline \hline
\end{tabular}

agencies were killed in the line of duty, including $14 \mathrm{~K} 9 \mathrm{~s}$. These K9 deaths were removed from our sample. In addition, eight incidents occurred in one of the five counties that do not have full reporting of their criminal justice system statistics. ${ }^{14}$ Thus, they must be removed. This leaves us with 108 officer deaths from 2004 to 2017. Table 2.1 provides the time series of the deaths.

As one can see, the deaths of law enforcement officials in the line of duty are spread out temporally. There is at least one death in every year of our study's time frame, reaching a peak of 16 deaths. This dispersion across time is valuable for estimating the impact, as it will allow us to separate the unfortunate events from other time-varying changes (e.g., macroeconomic fluctuations) using time fixed effects.

Table 2.1 also presents the cause of death in the broad classifications provided. Gunfire deaths comprise $40 \%$ of our data, with automobile-related deaths being the most prevalent at $45 \%$. Variation in the cause of death will allow us to evaluate heterogeneous treatment effects (which we do in Section 2.4.3).

These data come at the department level, which we connect to the county within which it operates. There is also a spatial dispersion of deaths. A total of 31 counties were fortunate enough not to have a death occur between 2004 and 2017, while 31 saw such fatalities. Obviously, heavily populated, urban areas (Miami, Tampa, Orlando) see more deaths $(>5)$, but the incidents occur across the entire state. This is valuable for our estimation strategy as it allows us to disentangle the incidents from other time-invariant characteristics of each county using county fixed effects.

Thus, each law enforcement official's death is recorded by the county in which the incident occurred and the date. We will use these two identifiers to connect the death to the criminal cases being handled at that time in that location.

\subsubsection{Charging and Prosecution in Florida}

We obtained the universe of charges within the state of Florida from the Office of the State Courts Administrator. This rich data set includes approximately 21 million charges filed during the period 2004-17. Each charge is referenced with a court docket number, which represents a single case for a particular defendant. ${ }^{15}$ Associated with each charge is a sequence number. This sequence number is unique, and allows us to track changes to each charge within an individual docket. Each charge is

\footnotetext{
${ }^{14}$ In two of eight incidents, two officers died together. Thus, there are ten omitted deaths. Table 2.1, though, include all 118 officer deaths. Approximately $22 \%$ of the deaths (26 deaths, 13 incidents) were part of the same incident (same department, date, and cause of death).

${ }^{15}$ Dockets are not split between co-defendants. If there are multiple people charged in the commission of the same crime, each person will be available under a different court docket number.
} 
divided into four distinct phases: initial phase, prosecutor phase, court phase, and sentencing phase. Each level details the specific criminal violation for each charge with Florida's criminal code chapter, section, and subsection of the violation included. These charges may vary across the phases.

The initial phase includes all information from the arrest and provides us with demographic information for the defendant including race, gender, and date of birth. Additional dates in this section include the offense date and the arrest date. Birth date and arrest date are used to construct a defendant's age at arrest. ${ }^{16}$

The prosecutor phase begins when the suspect has officially been arrested and booked. When the prosecutor receives the case details, the formal charges that will be filed moving forward are determined. The prosecutor has discretion to dismiss, re-file, or add add charges to a docket. Since it is the prosecutor's decision whether to pursue a conviction, the specific date on which the prosecutor made his/her final decision on whether to pursue the case is included. Also, included within this phase is information on the defendant's counsel type.

The court phase provides us with the last period of potential variation in the number or type of charges for a particular docket. This phase includes the final charges that were brought to court (or plea bargained on) at the same granular level as the other two sections, and the date of court appearance. It is important to note that in the case of plea bargaining, a defendant will still have a court date on which they formally submit their guilty plea to the judge and the agreement is stated for the court record. Following this phase, a sentencing date will be provided for each individual who is found (or pleads) guilty on at least one charge. This particular phase details the method of incarceration (prison, jail) or alternatives (restitution, probation, etc.), and the sentence length for each charge.

We aggregate the individual charges to the docket level. We choose to limit the data by removing cases where all charges were dismissed. ${ }^{17}$ The total number of counts in each phase is then calculated, allowing us to see potential changes in the filing decisions across the life of the criminal procedure. From these dockets, we select only those where at least one felony was charged at some point in the case's handling. Any case that did not experience a felony charge is removed. Also, individuals convicted of life sentences or receiving capital punishment are eliminated from the data set. This process leaves us with a final data set of 1,471,774 felony dockets that were disposed of between 2004 and 2017.

The outcome variable for the primary analysis is the length of the sentence. Any charge that did not receive formal incarceration (defined as not prison or jail) is set as having a zero sentence. Our sentencing variable represents the number of months for which an individual is to be incarcerated for. ${ }^{18}$

To create this sentence variable, being consistent with the current literature, we consider the longest sentence length received by a defendant. For each count on which the individual is convicted of, an upper bound and lower bound to the sentence is provided. We use the upper bound as our measurement of sentencing severity. If the defendant is convicted of only one crime, then its

\footnotetext{
${ }^{16}$ Since birth date is only provided at the month of year level, the day of birth is imputed to be the $15^{\text {th }}$ of every month.

${ }^{17}$ In this case, dismissed can refer to all charges formally dismissed by the prosecutor, re-filed under a different court docket number, transferred to a different court, or extradited. Successful appellate cases are also removed because the initial filing information was overwritten.

${ }^{18}$ We transform sentences provided in either days (e.g., 120 days) or years (e.g., 10 years) to their equivalent in months (3 and 120, respectively). An upper bound of 1200 months is used as well.
} 
upper bound measurement captures the potential severity of the sentence, which is the focus of our analysis. For a defendant convicted of more than one count, we take the longest sentence of the upper bounds as our measurement of the sentence. ${ }^{19}$

The primary focus of our analysis is the exogenous shock of a law enforcement official's death. As mentioned, we record the date and county of the incident. Using the arrest date and court date, we create an indicator variable equal to one if an observation is in process at the time of a law enforcement official's death within the county. Cases that have already been resolved (with a dismissal, acquittal, or conviction) prior to the incident, cases where the arrest has not yet occurred, and cases outside the county become the control group for our "treated" cases. These treated cases are unrelated to the incident that resulted in the law enforcement official's death. Thus, the death is an exogenous shock.

For each docket, we create an indicator variable for whether any count was taken to trial. Within the administrative data set provided, a variable denoting the trial type is provided. This allows us to distinguish which counts proceeded to trial (either a jury trial or bench trial) and which resulted in a guilty plea. From this, we create an indicator variable for whether the case was plea bargained. We will use this as our primary explanatory variable to estimate the plea discount.

Some information regarding the defendant's criminal history is provided. Unfortunately, we do not have access to each offender's full background. We do, though, have information on whether s/he falls within one of Florida's three habitual offender statutes. These will be included as controls.

Finally, it is necessary to include controls for the crime committed. For each docket, we identify the top charge. We do this for each count within each phase by extracting the charge level (e.g., felony) and charge degree (e.g., first degree) to create a charge severity ranking. We then take the highest charge level/charge degree within each phase and identify the highest one across the phases. The chapter in Florida's criminal code that is associated with this top charge becomes the crime indicator. ${ }^{20}$ Table 2.2 presents the summary statistics for this final data set.

With our final data set only including those felony cases that were disposed of through plea bargaining or trial, our plea bargaining variable is defined for any docket that remains in our data set but did not go to trial. Plea bargaining occurs over $97 \%$ of the time, consistent with previous literature on the topic. ${ }^{21}$ The average sentence is approximately 18 months but, as is to be expected, shows a wide variation. The death of a law enforcement official in the county occurs in approximately one in seven of our observations.

Our defendants are typically male with whites having a slight majority. ${ }^{22}$ Florida provides a state funded public defender office in every judicial circuit in the state. Thus, the majority of our sample are represented by a public defender. ${ }^{23}$

\footnotetext{
${ }^{19}$ Florida has sentencing guidelines. A formula converts the "sentencing points" to a lowest permissible sentence in months. The sentencing points are determined by the felony degree, offense level, seriousness of the victim's injury, and prior record. The maximum sentence is determined by statute. A "legitimate, uncensored plea bargain" is an allowable mitigating circumstance, so that sentences below the minimum can be granted. Thus, Florida's sentencing guidelines should not restrict the sentences much.

${ }^{20}$ If more than one count shares the same charge level and charge degree, then we use the criminal chapter of the one arising in the earliest phase.

${ }^{21}$ Bandyopadhyay and McCannon (2014) show that plea bargaining occurs for just less than $97 \%$ of convictions in North Carolina. Federal data tends to see plea bargaining occur for $95 \%$ of convictions.

${ }^{22}$ There is not a separate classification for Hispanics in the data file provided by the state.

${ }^{23}$ With the "other" category, self defense, and missing observations, the proportion of reported cases with a public defender is substantially higher. In our data it is possible (but not frequent) that multiple representation modes arises. Hence, the categories are not mutually exclusive.
} 
Table 2.2: Descriptive Statistics

\begin{tabular}{|c|c|c|c|c|c|}
\hline & $\mu$ & $\sigma$ & $\min$. & med. & $\max$. \\
\hline \multicolumn{6}{|l|}{ All Pursued Felony Cases } \\
\hline Plea Bargain & 0.9756 & 0.1544 & 0 & 1 & 1 \\
\hline Sentence & 17.903 & 39.802 & 0 & 6 & 1200 \\
\hline Death & 0.1428 & 0.3498 & 0 & 0 & 1 \\
\hline \multicolumn{6}{|l|}{ Demographic Controls } \\
\hline Female & 0.176 & 0.381 & 0 & 1 & 1 \\
\hline Age & 33.12 & 11.26 & 14 & 31 & 95 \\
\hline White & 0.590 & 0.492 & 0 & 0 & 1 \\
\hline Black & 0.403 & 0.491 & 0 & 0 & 1 \\
\hline Native American & 0.001 & 0.027 & 0 & 0 & 1 \\
\hline Asian & 0.002 & 0.042 & 0 & 0 & 1 \\
\hline \multicolumn{6}{|c|}{ Case Characteristic Controls } \\
\hline Total Counts & 2.65 & 6.02 & 1 & 2 & 899 \\
\hline Private Attorney & 0.208 & 0.406 & 0 & 0 & 1 \\
\hline Public Defender & 0.559 & 0.497 & 0 & 1 & 1 \\
\hline Court Appointed Attorney & 0.053 & 0.223 & 0 & 0 & 1 \\
\hline \multicolumn{6}{|c|}{ Habitual Offender Controls } \\
\hline Habitual Offender & 0.0059 & 0.0767 & 0 & 0 & 1 \\
\hline Habitual Violent Offender & 0.0009 & 0.0307 & 0 & 0 & 1 \\
\hline Career Violent Offender & $4.4 \times 10^{-5}$ & 0.0066 & 0 & 0 & 1 \\
\hline
\end{tabular}

Docket-level data set considered excluding any that does not involve at least one felony and excluding those where all charges are dismissed. Thus, it includes guilty pleas and both trial convictions and trial acquittals; $N=1,471,774$.

The sentence variable is measured in the number of months. It is the upper bound to the top charge the defendant is convicted of. Non-incarceration sentences and acquittals take values of zero.

Other forms of representation not presented are self-defense, an "other" category, and an indicator variable for missing observations. Each of these are also used as controls in the upcoming specifications. Also, the defendant can be a business.

Cases that are not plea bargained are taken to trial. Trials include both jury trials and bench trials. 
Figure 2.1: Does Sentencing Severity Correspond to Law Enforcement Officials' Deaths?

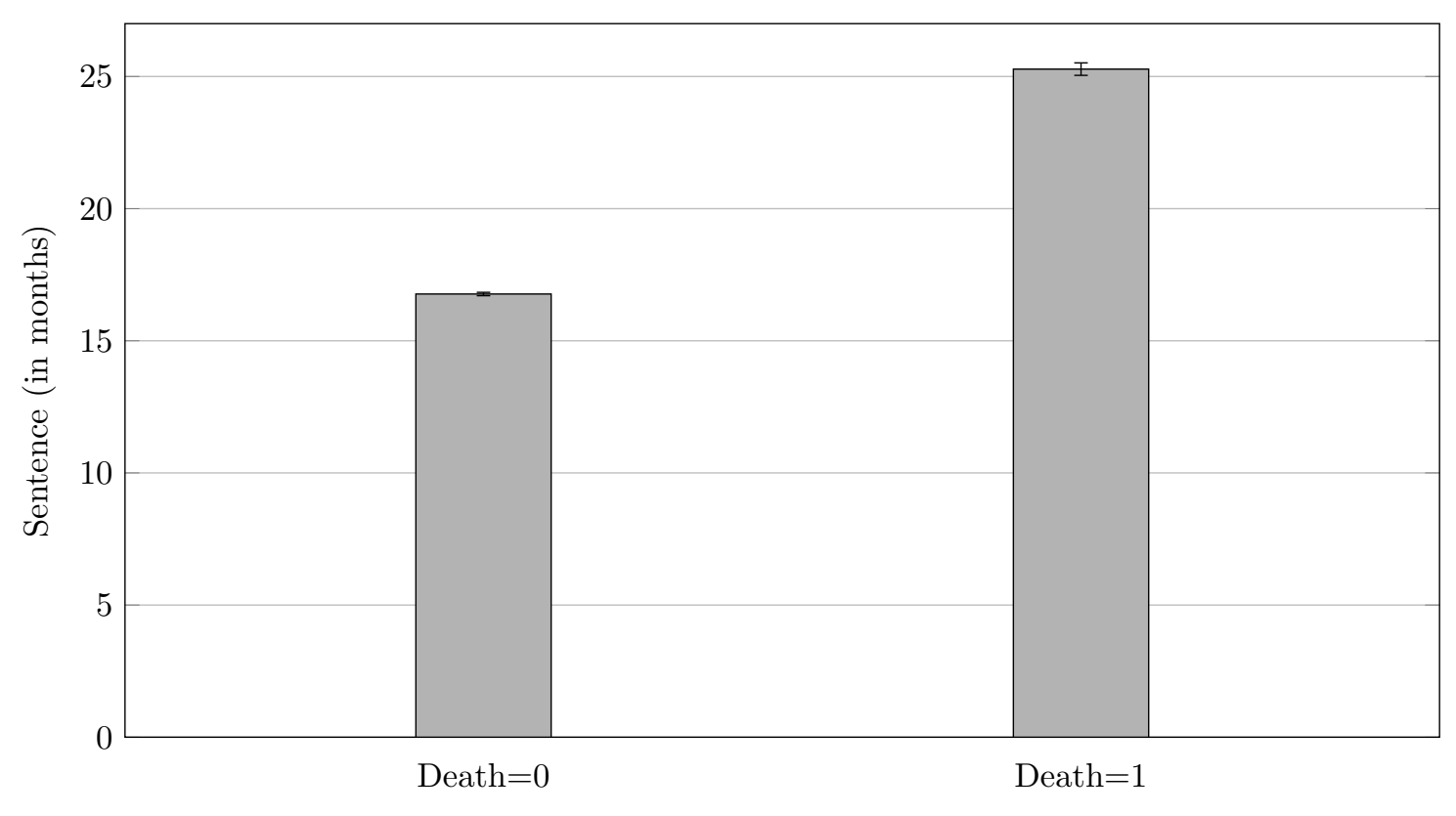

Confidence intervals depicted by the black lines.

A two-sided, difference-in-means t-test (allowing for unequal variances) has $|t|=68.2$. A Wilcoxon Ranksum test for differences in the distributions has $|z|=50.3$. A Kolmogorov-Smirnov stochastic dominance test has $D=0.0808$. For all three, $p<0.001$.

The average number of counts on a docket is 2.65 . Thus, at some time during the case's processing, a typical defendant will have multiple charges filed on their case (64.6\% have more than one count). As examples, this can be either the stacking of multiple charges or re-filing with one count being removed and another one added.

\subsection{Sentencing and the Plea Discount}

Our primary question is whether sentences received respond to the death of a law enforcement official. We begin by simply partitioning our sample into those observations where there is a death and those observations where there is not. Acquittals are removed from the data set in this section so that only convictions are considered.

A noticeable change arises. When a law enforcement official dies in the line of duty, those cases already in process are treated differently. They see an increase in the sentence length. The mean number of months of incarceration jumps from 16.8 to 25.3 months, which is a $51 \%$ increase. In the upcoming subsections, we unpack this observation to study the plea bargaining process specifically.

Our hypothesized mechanism relies on the probability the jury convicts increases when there is a death. In our data, trial convictions are more frequent and acquittals relatively rare for those cases which are treated with a law enforcement official's death. Partitioning the set of cases that go to trial into those with trial convictions (on at least one count) to acquittals, the mean acquittal rate decreases by $5.9 \%$, which is significant at the $5 \%$ level. While there are obviously important omitted variables to be concerned about which can, in part, explain these observations, it is at least 
suggestive that deaths lead to increased conviction probabilities and harsher sentences.

\subsubsection{Estimation Strategy}

Do these harsher sentences from the plea bargaining process respond to a heightened probability of conviction at trial?

As is common in the sentencing literature, we regress the indicator variable for whether the case ended with a plea bargain on the sentence received. The estimated coefficient is the measure of the difference between sanctions received by those convicted at trial and those entering a guilty plea. Importantly, this measurement includes the negotiated plea discount.

We include numerous fixed effects to separate out other factors that could be influencing sentencing. We include demographic controls, recognizing that there are important gender disparities (Starr, 2015) and racial disparities (Rehavi \& Starr, 2014) in sentencing, for example. We include case characteristics acknowledging that there are important differences in who is able to afford private attorneys (Agan, Freedman, \& Owens, 2017), and that public defenders may generate more favorable outcomes than court-appointed attorneys for the indigent (Roach, 2014). Furthermore, county fixed effects are included to extract differences across the state. We consider the more saturated model where the county effects are allowed to vary over time. Thus, we account for both systematic differences in the population across the state, but allow these to vary over time to account for macroeconomic events and policy changes. Month of the year fixed effects allow us to account for seasonal variation that may affect outcomes. We present standard errors that are clustered at the county by year level to account for differences in both cross-sectional and temporal variation. There are 865 clusters.

Regarding the dependent variable, as discussed previously, we consider the length of the sentence handed down for the top charge on which the defendant is convicted. Specifically, for the charge that has the longest potential sentence, we identify the maximum number of months that the conviction of that crime results in. Figure 2.2 provides a histogram of the sentences observed in the data. ${ }^{24}$

Two issues arise with this variable. First, it is right-skewed: that is, while the bulk of the observations are centered around the median of 6 , the right-tail extends out including sentences with extremely long lengths of incarceration. For data such as these, it is common to use a transformation that pulls in the tail. The most common is the log transformation, which we will use in our primary specification, denoted here as $\ln$ (sentence). As is well known, this is not defined for sentences of zero length. In criminal sentencing data, zero-length incarcerations are common. An alternative transformation is the inverse hyperbolic sine transformation (Burbidge, Magee, \& Robb, 1988), denoted here as IHS(sentence). In it, $\widetilde{z}=\log \left(z+\sqrt{z^{2}+1}\right)$. This transformation is defined for zero and, while not needed here, is defined for negative values of $z$ as well. Also, importantly, it approximates the $\log$ transformation for all but the lowest values of $z$ (Bellemare \& Wichman, 2020) so that the estimated coefficients can be interpreted just as a log transformation. With the $\log$ transformation, we follow the standard in the literature by setting $\ln (0)=0$, in effect treating non-incarcerations as if they received one month in jail. ${ }^{25}$

\footnotetext{
${ }^{24}$ The histogram only includes non-zero sentences. Additionally, to improve the visual depiction, the final bin clumps all sentences greater than or equal to 25 years.

${ }^{25}$ This also requires setting incarcerations of less than one month equal to one month as well. Also, it is not uncommon to recode zero sentences to small levels. We consider both 0.1 and 0.001. In addition, one can redefine the sentence as Sentence $=$ Sentence +1 . In all of these alternatives, our main result (i.e., the sign and significance
} 
Figure 2.2: Sentences

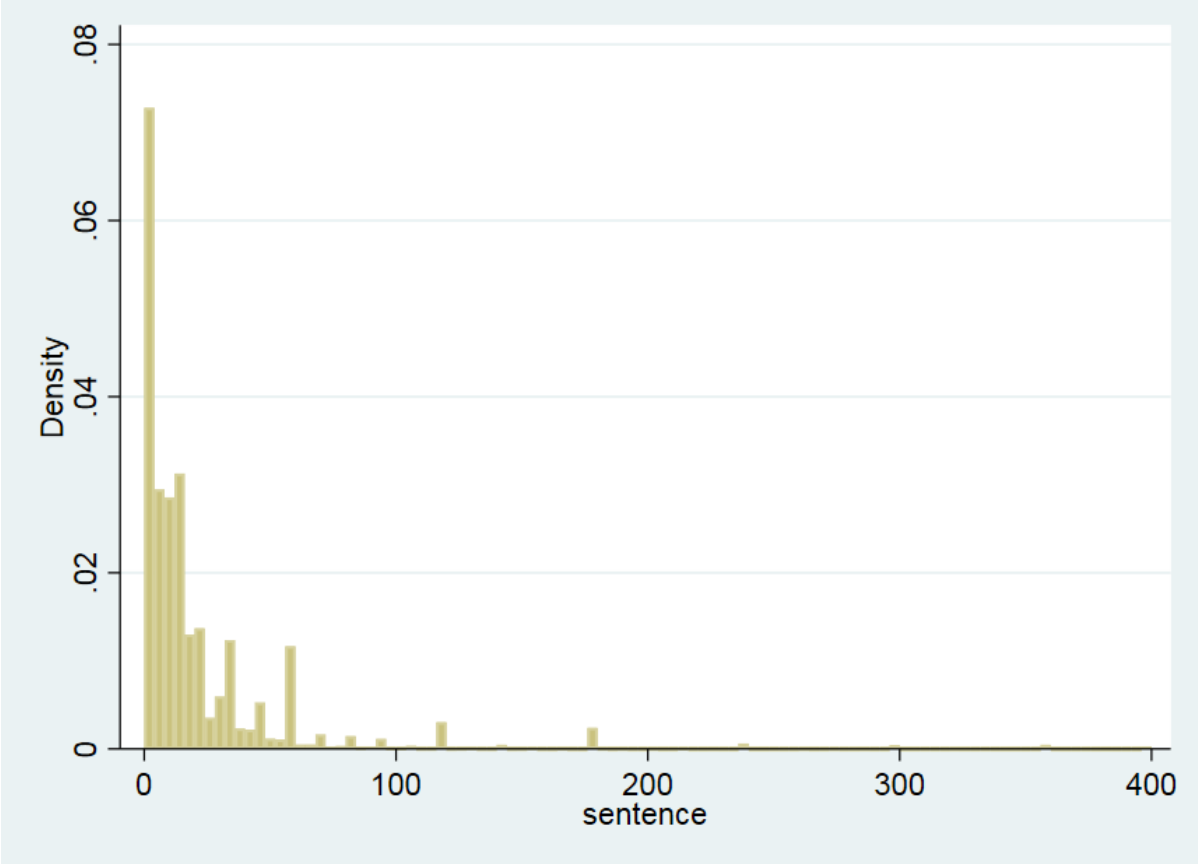

Second, the data have a large number of zeros. In fact, approximately $23 \%$ of the convictions resulted in alternatives to active incarceration. Along with presenting results from the fixed effect linear regression, we also present results from a Tobit specification left-censored at zero. Tobit estimations of sentencing are a commonly employed technique in empirical criminology research (e.g., Albonetti (1997)). In upcoming robustness checks, we will also consider alternative estimations - namely hurdle models and quantile regressions.

As discussed, the primary concern with simply regressing plea bargains on sentence length is the endogeneity of case selection. Those cases that go to trial need not be representative of the plea bargained ones. As discussed, we use the death of a law enforcement official as a quasi-natural experiment to the plea bargaining process. The indicator variable Death $h_{i c m y}$ is equal to one if case $i$ is active in the county $c$ of the law enforcement official's death at the time of that death. To be active, the case must already have had the initial charging decision made, but not yet have it disposed (either with all charges dropped, a trial decision, or a plea sentence determined). Hence, the death acts as an exogenous shock to these unrelated cases.

With this, we employ a difference-in-difference estimation. How the gap between sanctions following trial convictions and guilty pleas changes with the occurrence of these death is our primary question. Hence, we estimate the following:

$$
\begin{aligned}
\text { Sentence }_{i c m y}= & \beta_{1} \text { Plea Bargain }_{i c m y}+\beta_{2} \text { Death }_{i c m y}+\beta_{3} \text { Plea Bargain }_{i c m y} \times \text { Death }_{i c m y} \\
& +\delta_{c y}+\mu_{m}+X_{i c m y} \beta+\epsilon_{i c m y} .
\end{aligned}
$$

County x Year fixed effects, $\delta_{c y}$, and Month of Year fixed effects, $\mu_{m}$, are included in each specification. The sentence received by individual $i$ in county $c$ in month $m$ of year $y$, transformed as described previously, is the dependent variable, and a number of individual level variables (demoof the difference-in-difference coefficient) remains. 
Table 2.3: Randomness Check

\begin{tabular}{lll}
\hline \hline & coefficient & (st. error) \\
\hline Female & $-0.0089^{* * *}$ & $(0.0015)$ \\
Age & $-0.0007^{* * *}$ & $(0.0001)$ \\
Business & $0.0954^{* *}$ & $(0.0887)$ \\
Black & $0.0043^{* *}$ & $(0.0013)$ \\
Asian & 0.0060 & $(0.0072)$ \\
Native American & 0.0065 & $(0.0072)$ \\
Race: Other & 0.0022 & $(0.0120)$ \\
Public Defender & $-0.0448^{* * *}$ & $(0.0048)$ \\
Appointed Counsel & $0.0264^{* * *}$ & $(0.0066)$ \\
Self-Defense & $-0.0028^{* *}$ & $(0.0044)$ \\
Counsel: Other & $0.0339^{* * *}$ & $(0.0190)$ \\
Counsel: Missing & -0.0079 & $(0.0069)$ \\
Number of Counts & $0.0009^{* * *}$ & $(0.0001)$ \\
Habitual Offender & $0.0664^{* * *}$ & $(0.0105)$ \\
Habitual Violent Offender & 0.0411 & $(0.0423)$ \\
Career Violent Offender & $0.0764 * *$ & $(0.0375)$ \\
\hline \hline
\end{tabular}

All cases (dropping those with all counts dismissed) included; $N=1,416,540$.

Dependent variable equals one if the observation is treated by the law enforcement official's death.

Specification includes the crime controls, County x Year fixed effects, and Month of Year fixed effects.

Standard errors clustered by County x Year presented in parentheses (865 clusters); ${ }^{* * *} 1 \%,{ }^{* *} 5 \%,{ }^{*} 10 \%$ level of significance.

graphics, crimes committed, repeat offender status, and type of defensive counsel), $X$, are included as controls. The difference-in-difference coefficient, $\beta_{3}$, is the primary estimate of interest, as the bargaining in the shadow of the trial framework predicts $\beta_{3}>0$, while arguments against the framework suggest that $\beta_{3}=0$.

\subsubsection{Identification Concerns}

A number of concerns arise when one wants to make a causal claim of the deaths' effects on plea bargaining and whether the difference-in-difference coefficient accurately estimates the change in the plea discount.

First, we engage in a randomness check. While the event is obviously unrelated to the cases already in process in that county at that time, there is no reason to believe that those areas of the state that experience violence against law enforcement are representative of the rest of the state. For example, deaths of law enforcement officials may occur disproportionately in high violent-crime areas. If this is the case, then treated dockets can be expected to involve more serious crimes. Also, judges, prosecutors, and (importantly) jurors may respond by being tougher on crime in these jurisdictions. As a result, one can be concerned that the harsher sentencing observed is due to the way more serious crimes that occur in the areas that happen to have these deaths are handled, so that there is not a direct effect of the death on plea bargaining at all.

To address this question, we take our primary specification but instead estimate it with Death as the dependent variable removing it and the plea bargaining indicator from the right-hand-side. This allows us to assess whether observable characteristics of the cases correlate with the prevalence of law enforcement deaths. Table 2.3 presents the results. 
A number of observations correlate with deaths. For example, women make up $18.2 \%$ of the sample unaffected by the deaths, but $14.2 \%$ of those treated. Law enforcement official killings occur in those areas that are more black and less white, as well, with $38.9 \%$ of defendants black in the baseline, and $48.7 \%$ with the sample of those affected by the deaths. Also, contrary to expectations, deaths occur in counties with lower sentences. The mean sentence length is 17.7 months for cases arising in counties that do not experience a death over our sample period, while observations coming from counties that do have a mean of 19.2 months $(t=17.2, p<0.001)$. Thus, absent the use of fixed effects to account for regional differences, the effect of the death on sentence length would be biased downward towards zero. Plea bargaining practices are similar, though. For observations coming from the counties without recorded deaths over our sample period, $98.3 \%$ of pursued cases result in a guilty plea, while for those treated at some point in our sample period $97.9 \%$ are plea bargained.

To address this observation, the use of county fixed effects along with demographic and case controls is important. All specifications will use a highly saturated model with time varying county fixed effects. In addition, in a sensitivity check following the presentation of the main result, we will consider changes to the control, untreated sample.

Our threat to identification, though, is whether the observations within a county prior to being treated look similar to observations in the non-treated counties in the time periods just prior to the treatment. If they do not follow "parallel trends" prior to the treatment, then the divergence observed after the treatment, rather than reflecting the causal impact of the death, may instead be capturing the naturally occurring distinction between the areas that happen to experience the death and those that do not. Thus, to address our second identification concern, we engage in a parallel trends analysis.

To do so, we conduct the following method. First, we collapse the data into a monthly, countylevel panel data set. In it, the mean sentence, the median sentence, and the proportion of dockets with outcomes resulting in non-incarceration are recorded. The first two mirror the primary dependent variable studied previously; the third is included in recognition of importance of the leftcensored, zero incarcerations as prevalent outcomes of the criminal justice system. In addition, the demographic and case characteristic controls become proportions. ${ }^{26}$ Importantly, for each county in each month the proportion of resolved cases where a law enforcement official's death occurred during the period in which the case was being prosecuted is recorded. Since there is substantial variation in the length of time it takes for a case to be resolved, the collapsed "death" variable for the panel data set, which we denote here as $D_{c m y}$ to distinguish this aggregation from the caseload Death indicator, takes on values between zero and one. A given event records $D_{c m y}>0$ over numerous months.

With this county by month panel data set, we focus on a subset of law enforcement official's deaths. In the panel data set, we record a death observation occurring if a county experiences an uptick in treated observations $(D>0.05)$ preceded by a string of months (two or more) with zero/negligible resolved cases having been treated $(D<0.01) .^{27}$

\footnotetext{
${ }^{26}$ For the total number of counts and the defendant's age, the mean values are used.

${ }^{27}$ This procedure does not record every law enforcement death as a unique event. Some counties experience multiple deaths clumped closely together. Since we require that prior to the incident there were multiple months without a noticeable number of treated observations, we are unable to differentiate the treatment effect of some deaths. Also, 13 of the incidents involved two law enforcement officials being killed in the same incident ( 26 deaths). Thus, we consider the 64 distinct deaths that occurred in counties without any incidents in the recent past.
} 
Table 2.4: Test of Parallel Trends

\begin{tabular}{llll}
\hline \hline & $\begin{array}{l}\text { Without Any } \\
\text { Controls } \\
(1)\end{array}$ & $\begin{array}{l}\text { With County } \\
\text { FEs } \\
(2)\end{array}$ & $\begin{array}{l}\text { With County } \\
\text { FEs and controls } \\
(3)\end{array}$ \\
\hline Mean Sentence & 0.0938 & 0.0908 & 0.1142 \\
& $(0.0789)$ & $(0.0654)$ & $(0.0630)$ \\
& $\{0.239\}$ & $\{0.171\}$ & $\{0.075\}$ \\
Median Sentence & 0.0404 & 0.0374 & 0.0527 \\
& $(0.0811)$ & $(0.0765)$ & $(0.0753)$ \\
Proportion Not Incarcerated & $\{0.620\}$ & $\{0.627\}$ & $\{0.486\}$ \\
& -0.0003 & -0.0002 & -0.0005 \\
& $(0.0013)$ & $(0.0012)$ & $(0.0011)$ \\
& $\{0.829\}$ & $\{0.855\}$ & $\{0.661\}$ \\
\hline \hline
\end{tabular}

Each row is the result from a specification with a different dependent variable. Each column varies the use of control variables in the parallel trends test.

Estimated value of $\gamma_{3}$ presented.

Standard errors clustered by County are presented in parentheses.

The p-values are reported in curly brackets.

$N=77,847$

For these treated counties, we record the variables' values for the 12 months preceding the death and the 12 months following the death. We also record the values for the other counties in Florida that were not treated. ${ }^{28}$ Again, we record these control counties in the 12 months before and the 12 months after the incident. We then pool each identified death event into a new data set.

From this, we estimate the time trends for the outcome variables and ask if prior to the event the treated and controls are following the same path. Specifically, we estimate:

$$
\begin{gathered}
Y_{c m y}=\gamma_{0}+\gamma_{1} \text { Treat }_{c}+\gamma_{2} \text { Time }_{c m y}+\gamma_{3} \text { Time }_{c m y} \times \text { Treat }_{c}+\gamma_{4} \text { Post }_{m y}+\gamma_{5} \text { Post }_{m y} \times \text { Treat }_{c}+ \\
\gamma_{6} \text { Time }_{c m y} \times \text { Post }_{m y}+\gamma_{5} \text { Time }_{c m y} \times \text { Post }_{m y} \times \text { Treat }_{c}+\epsilon_{c m y} .
\end{gathered}
$$

The outcome variable $Y_{c m y}$ is county c's value in month $m$ of year $y$. All three outcome variables are considered. The time trend variable, Time cmy $_{\text {, }}$ is equal to the distance from the incident with Time $_{c m y}=0$ as the month of the event. The indicator variable Post ${ }_{m y}$ is equal to one if the observation occurs after the incident. Finally, Treat $_{c}=1$ if it is a treated county.

From this estimation, we can test statistically whether there are parallel trends prior to the treatment in the treated and control counties. They are parallel in the pre-treatment period if $\gamma_{3}=0$. We estimate (8) with and without County fixed effects. Standard errors are clustered at the county level. ${ }^{29}$ Table 2.4 presents the estimation results.

\footnotetext{
${ }^{28}$ That is, we delete a control county's observation for any month where the proportion of disposed cases treated by a law enforcement death is great (proportion treated $>5 \%$ ).

${ }^{29}$ Since a county can be treated for one death event but be a control for other events, the treatment variable is not co-linear with the County fixed effects. The clustering is done to match as closely as possible the specifications presented in the main results (since they calculate standard errors clustered at the County x Year level). The lack of significance reported in Table 2.4 and Figure 2.3 remains if unadjusted standard errors are used.
} 
As one can see, consistent across the specifications, the treated and control counties exhibit parallel trends. This is true for all three outcome variable measurements. Thus, there is not anything noticeably different about how criminal cases are being handled in the treated and control areas of the state prior to the law enforcement official's death that would call our causal identification into question.

While this test evaluates a potential discrepancy in the time trend prior to the event, it presumes the trend is linear. An alternative estimation, allowing for nonlinearities, is to create separate indicator variables for each of the twelve months prior to the event and use them rather than only the one variable, Time $_{c m y}$, in (8). In addition, each of the twelve indicator variables is interacted with the treatment variable, Treat $_{c}$. Each of the resulting twelve coefficients on these interaction terms can be tested to evaluate whether there is a discrepancy in the outcomes of cases prior to the incidents in those areas that were treated and those that were not. We depict these coefficients, along with their confidence intervals, in Figure 2.3. The three panels differ according to which outcome variable is considered.

Across the three, the coefficients on the twelve interaction terms have confidence intervals that overlap zero. ${ }^{30}$ Thus, we can be confident that in the periods leading up to the death of a law enforcement official, the outcomes observed in those counties regarding their criminal justice systems resemble outcomes observed in the untreated counties. ${ }^{31}$

\subsubsection{Main Result}

Consequently, our difference-in-difference estimation should provide reliable estimates of changes in the plea discount. Table 2.5 presents the initial, primary results.

Importantly, across all specifications, the difference-in-difference coefficient is positive and statistically significant. Given the quasi-natural experiment affecting these defendants, the results are consistent with the hypothesis that an increase in the probability a jury will vote to convict a defendant causes the negotiated plea deals to be less favorable, relative to the sentence arising from a trial conviction. This finding strongly supports the bargaining in the shadow of the trial framework as an accurate depiction of the plea bargaining process.

Plea bargains, as expected, are associated with shorter sentences. Using the first column, an individual who is sentenced after entering a guilty plea receives an incarceration that is only $47.7 \%$ as long as an individual who is convicted at trial. Rather, he receives a $52.3 \%$ plea discount. When a law enforcement official dies in the line of duty, using the first column, the plea discount is only

\footnotetext{
${ }^{30}$ The only exception is the three months in the mean sentence length specification and the two months in the proportion not incarcerated specification.

${ }^{31} \mathrm{We}$ do not test the divergence in the time trend after the incidents because our identification strategy does not predict a persistent trend shift. Only those cases directly treated are expected to be affected by the shift. We do not expect that the death causes a permanent effect on case disposition, but rather it will be a transitory shock to those cases already being processed. In fact, given the substantial time it takes some cases to be disposed, the treatment can be spread over a number of months. Also, one would expect those cases disposed of quickly to be different from those treated cases that take a long time to process. We can, though, compare the values of the outcome variables prior to the shock to those after it for the treated counties. The mean and median sentences grow in the twelve months after the death and the proportion incarcerated increases for those counties treated with the death $(+0.90 \%$ and $+4.64 \%$, respectively), while in the control counties, slight reductions are measured $(-0.96 \%$ and $-1.88 \%$, respectively). The proportion of those convicted who avoid incarceration shrinks substantially after a death (-4.61\%). Again, this effect is not present for the control counties $(+0.40 \%)$. Thus, not only do the treated and control counties follow parallel trends prior to the death of a law enforcement official, but a jump in sentencing harshness arises in the treated counties in the months following the incident.
} 
Figure 2.3: Test of Parallel Trends
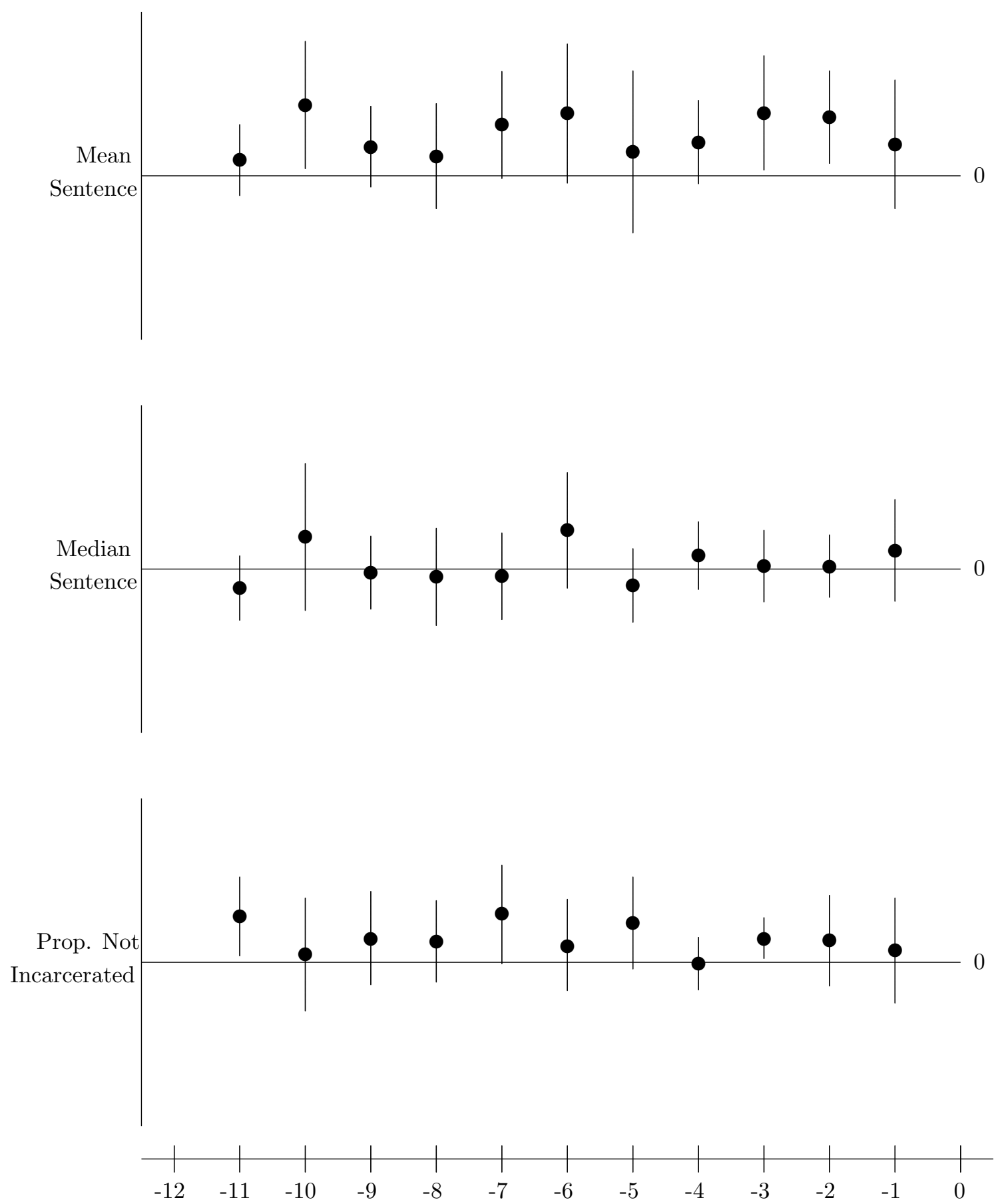
Table 2.5: Bargaining in the Shadow of the Trial?

\begin{tabular}{llll}
\hline \hline Dependent variable: & $\begin{array}{l}\ln (\text { sentence) } \\
\text { OLS } \\
\text { Model: }\end{array}$ & $\begin{array}{l}\text { IHS(sentence) } \\
\text { OLS } \\
(1)\end{array}$ & $\begin{array}{l}\text { ln(sentence) } \\
\text { Tobit } \\
(2)\end{array}$ \\
\hline Plea Bargain & $\begin{array}{l}-0.647^{* * *} \\
(0.043)\end{array}$ & $\begin{array}{l}-0.647^{* * *} \\
(0.048)\end{array}$ & $\begin{array}{l}-0.735^{* * *} \\
(0.054)\end{array}$ \\
& $\begin{array}{l}0.201^{* * *} \\
\text { Death }\end{array}$ & $\begin{array}{l}0.192^{* *} \\
(0.076)\end{array}$ & $0.249^{* *}$ \\
& & & $(0.082)$ \\
& & & \\
Death x Plea Bargain & $0.153^{* *}$ & $0.167^{* *}$ & $0.205^{* *}$ \\
& $(0.065)$ & $(0.071)$ & $(0.080)$ \\
& & & \\
Demographic Controls? & Yes & Yes & Yes \\
Crime Controls? & Yes & Yes & Yes \\
Habitual Offender Controls? & Yes & Yes & Yes \\
Type of Counsel Controls? & Yes & Yes & Yes \\
County x Year FEs? & Yes & Yes & Yes \\
Month of Year FEs? & Yes & Yes & Yes \\
$R^{2}$ & & & \\
AIC & 0.154 & 0.145 & 0.044 \\
\hline \hline
\end{tabular}

All cases with at least one conviction included (dropping those with all counts dismissed or with a trial acquittal); $N=1,410,751$.

Demographic controls include indicator variables for being female, black, Asian, Native American, and a business (both in the gender and race variables). Hence, being male and white are the omitted categories. In addition, the defendant's age and number of counts filed are included.

Crime controls are indicator variables for the criminal chapter of the top charge filed.

Habitual offender controls include indicator variables for the defendant being classified as a habitual offender, habitual violent offender, or career violent offender. Not being a habitual offender is the omitted category.

Type of counsel controls include indicator variables for having a public defender, court-appointed attorney, selfrepresentation, "other", and an indicator variable for missing information. Note that some defendants will change legal representation so that these need not be perfectly multicollinear. Having a private attorney is the omitted category.

Standard errors clustered by County x Year presented in parentheses (865 clusters); *** 1\%, ** $5 \%,{ }^{*} 10 \%$ level of significance.

Tobit model is left-censored at zero (468,573 censored observations and 942,178 uncensored). 
39.1\%. Thus, the difference between trial and plea bargaining sentencing shrinks. This corresponds to an economically-significant $18.1 \%$ reduction in the plea discount.

The significance of the difference-in-difference coefficient remains if a Tobit is estimated, (3), and if the alternative transformation is considered, (2). In addition, time-varying county fixed effects are included. If a less saturated model is used, with county or circuit fixed effects and month by year fixed effects, the main results are unaffected. Also, if the standard errors are clustered only at the county level, circuit level, or if two-way clustering is estimated, the difference-in-difference coefficient's statistical significance remains in all specifications. Thus, the results are not sensitive to the estimation techniques presented.

Also, it is worth pointing out that the coefficient on Death is positive and statistically significant as well. This suggests that judge's sentencing after trial convictions is also affected. This finding is in line with Bushway, Owens, and Piehl (2012) providing evidence that judge's personal preferences influence sentences, rather than sentencing guidelines solely driving sanctions observed. While sentencing by judges seems to be affected by the event, importantly sentences following plea negotiations are affected more. From the theoretical model, the death events are affecting both $p$ and $s$.

The results in Table 2.5 pool together all crimes. Indicator variables for the crime associated with the top charge are included as controls. One would not reasonably expect the death of a law enforcement official to affect all crimes the same. Serious, and especially violent, crimes are expected to be impacted more strongly.

Table 2.6 separates the serious from the less-serious felonies. Specifically, we consider the criminal chapters that have at least 3000 observations. From those, we select the seven crimes commonly viewed as serious: homicide, sexual battery, robbery, burglary, assault, arson, and weapons-related crimes.

Considering only serious crimes, the difference-in-difference coefficients are greater in magnitude than those presented in Table 2.5. Using the first column, guilty pleas receive a $56.0 \%$ plea discount relative to those convicted at a trial, and this shrinks to $33.5 \%$ when a law enforcement official dies. Thus, this $23.8 \%$ decrease in the plea discount is substantially more than the $18.1 \%$ reduction for all felonies. This is further evidence consistent with our hypothesis that it is the jury's salience in the problems of violent crime that drives the plea bargaining process.

\section{Disentangling the Effect by Crime Type}

To further appreciate how plea bargaining over serious crimes reacts to the exogenous shock, Table 2.7 separates each of the seven serious crime categories. Each row presents the estimation with a different sub-sample of observations.

The alteration in the guilty plea's sanction is not confined to one particular type of crime, but arises across numerous serious crimes. The difference-in-difference coefficient is positive and relatively large for most serious crimes, reaching statistical significance for assaults and burglaries. Only robbery and arson show near zero effects, and sexual assaults, while insignificant, record an increase in the plea discount. Homicides record the largest reduction in the plea discount, which is consistent with our hypothesized mechanism that jurors are responding to violent crime. The insignificance of this effect can be attributed to the large number of fixed effects used and the relative small number of observations. Also, while not presented here, if all serious crimes are left 
Table 2.6: Serious Crimes

\begin{tabular}{|c|c|c|c|}
\hline $\begin{array}{l}\text { Dependant variable: } \\
\text { Model: }\end{array}$ & $\begin{array}{l}\ln (\text { sentence }) \\
\text { OLS } \\
(1)\end{array}$ & $\begin{array}{l}\text { IHS(sentence) } \\
\text { OLS } \\
(2)\end{array}$ & $\begin{array}{l}\ln (\text { sentence }) \\
\text { Tobit } \\
\text { (3) }\end{array}$ \\
\hline Plea Bargain & $\begin{array}{l}-0.580 \text { *** } \\
(0.049)\end{array}$ & $\begin{array}{l}-0.5655^{* * *} \\
(0.055)\end{array}$ & $\begin{array}{l}-0.621 \text { *** } \\
(0.061)\end{array}$ \\
\hline Death & $\begin{array}{l}0.210^{* * *} \\
(0.082)\end{array}$ & $\begin{array}{l}0.203 * * \\
(0.090)\end{array}$ & $\begin{array}{l}0.221 * * \\
(0.100)\end{array}$ \\
\hline Death x Plea Bargain & $\begin{array}{l}0.172 * * \\
(0.081)\end{array}$ & $\begin{array}{l}0.184 * * \\
(0.090)\end{array}$ & $\begin{array}{l}0.219 * * \\
(0.100)\end{array}$ \\
\hline Demographic Controls? & Yes & Yes & Yes \\
\hline Crime Controls? & Yes & Yes & Yes \\
\hline Habitual Offender Controls? & Yes & Yes & Yes \\
\hline Type of Counsel Controls? & Yes & Yes & Yes \\
\hline County x Year FEs? & Yes & Yes & Yes \\
\hline Month of Year FEs? & Yes & Yes & Yes \\
\hline$R^{2}$ & 0.144 & 0.139 & 0.040 \\
\hline $\mathrm{AIC}$ & $1.8 \times 10^{6}$ & $2.0 \times 10^{6}$ & $1.8 \times 10^{6}$ \\
\hline
\end{tabular}

All cases with at least one conviction included (dropping those with all counts dismissed or with a trial acquittal) and only serious crimes; $N=505,963$.

The dependent variable's mean is 24.549 .

The control variables are the same as was used in Table 2.5.

Standard errors clustered by County x Year presented in parentheses (862 clusters); *** $1 \%,{ }^{* *} 5 \%,{ }^{*} 10 \%$ level of significance.

Tobit model is left-censored at zero (142,423 censored observations and 363,540 uncensored).

Table 2.7: Breakdown by Crime

\begin{tabular}{llllll}
\hline \hline & DiD & (s.e.) & {$[\mathrm{p}$-value] } & $N$ & \% $\Delta$ plea discount \\
\hline Robbery (812) & 0.080 & $(0.101)$ & {$[0.424]$} & 309,761 & $-11.7 \%$ \\
Assault (784) & $0.210^{* *}$ & $(0.107)$ & {$[0.049]$} & 83,673 & $-25.8 \%$ \\
Burglary (810) & $0.244^{*}$ & $(0.125)$ & {$[0.052]$} & 64,443 & $-40.0 \%$ \\
Weapons (790) & 0.269 & $(0.168)$ & {$[0.109]$} & 25,108 & $-34.3 \%$ \\
Arson (806) & 0.098 & $(0.246)$ & {$[0.690]$} & 13,232 & $-19.1 \%$ \\
Sexual Battery (794) & -0.329 & $(0.276)$ & {$[0.235]$} & 6046 & $+59.9 \%$ \\
Homicide (782) & 0.339 & $(0.256)$ & {$[0.186]$} & 3700 & $-52.5 \%$ \\
\hline \hline
\end{tabular}

All cases with at least one conviction included (dropping those with all counts dismissed or with a trial acquittal) and only serious crimes. Each row presents the estimation results from the sub-sample of each of the seven serious crimes.

Dependent variable is the log of the sentence (upper bound of the top charge).

The specification reported in each row is the reproduction of the one presented in the first column of Table 5. Only the difference-in-difference coefficient is presented.

Standard errors clustered by County x Year presented in the parentheses; ${ }^{* * *} 1 \%,{ }^{*} 5 \%, * 10 \%$ level of significance. 
pooled together and the seven crime chapters are each interacted with the plea bargain indicator, the same findings arise. Taken together, the shock of the law enforcement official's death is felt across numerous serious crimes. Similarly, while not presented here, if only less serious crimes are considered, the difference-in-difference coefficient is positive and statistically significant, but smaller.

\section{Accounting for Non-Incarceration Sanctions}

As mentioned previously, estimating the plea discount in sentencing data is challenging due to the high prevalence of zeros. As is common, we presented results from a Tobit regression, which accounts for the left censoring of the data. While the statistical significance of the results persists with this alternative estimation, there are two shortcomings of this approach. First, the coefficients are notoriously difficult to interpret. Second, the Tobit model does not account for the two-stage decision process in the sentencing of less serious crimes. It may be more reasonable to think of a judge first deciding whether to incarcerate. Conditional on making the decision to incarcerate, the sentence length is determined. A hurdle model more appropriately estimates this two-stage process. Doing so allows us to identify separately the impact of the law enforcement official's death on the likelihood of receiving a sanction with active incarceration (akin to its extensive margin) and the length of that sentence when incarceration arises (the intensive margin).

Thus, we estimate a Cragg hurdle model (Cragg, 1971). This requires the use of unique variables to estimate the selection model first, and then the use of unique variables in the intensive margin estimation. For the former, we choose to use the age of the defendant and whether the defendant is a business. Our belief is that a judge is more likely to choose a non-incarceration sentence for younger defendants. Also, for the small number of cases where a business is the criminal defendant, incarceration is not an option. For the latter model, we use the total number of counts as the explanatory variable unique to the estimation of the sentence length under the presumption that the number of counts most dramatically affects the length of the incarceration. In addition, sentence length will be affected by the criminal record. Thus, we also use the three habitual offender status measurements as unique identifiers for the intensive margin estimations. Each estimation includes the gender, race, and type of counsel controls, because we feel that the disparities existing in these three dimensions are likely to affect both whether a defendant is incarcerated and how long the incarceration lasts. County x Year and Month of Year fixed effects are also included in both. Table 2.8 presents the results.

The plea discount adjusts at both margins for both the full data set and the subset of serious crimes. While those who plead guilty are less likely to be incarcerated, (1), this effect is essentially negated when a law enforcement official's death occurs. Conditional on receiving a sentence involving incarceration, those who enter a guilty plea typically receive a shorter sentence, but this reduction dwindles with the death, (2). Hence, both margins are affected. Similar changes occur when only serious crimes are considered, (3) and (4).

An alternative way to deal with the 'zero problem' in sentencing data was proposed by Rehavi and Starr (2014) in their study on racial disparities in sentencing. They argue that estimating quantile regressions is best. By focusing on the $40^{t h}$ through the $90^{\text {th }}$ deciles of sentencing, they argue that the effects of race on the sentence length can be evaluated across the different sentence lengths without being distorted by the bulk of cases with zero sentence sanctions. Also, one can consider the sensitivity of the results due to the use of the log transformation, since changes in the 
Table 2.8: Hurdle Model

\begin{tabular}{lllll}
\hline \hline Dataset: & $\begin{array}{l}\text { full } \\
\text { Model: } \\
\text { Selection } \\
\text { Margin } \\
(1)\end{array}$ & $\begin{array}{l}\text { full } \\
\text { Intensive } \\
\text { Model } \\
(2)\end{array}$ & $\begin{array}{l}\text { serious } \\
\text { Selection } \\
\text { Margin } \\
(3)\end{array}$ & $\begin{array}{l}\text { serious } \\
\text { Intensive } \\
\text { Model } \\
(4)\end{array}$ \\
\hline Plea Bargain & $-0.086^{* * *}$ & $-0.842^{* * *}$ & 0.006 & $-0.861^{* * *}$ \\
& $(0.010)$ & $(0.010)$ & $(0.015)$ & $(0.015)$ \\
& & & & \\
Death & 0.028 & $0.334^{* * *}$ & -0.009 & $0.341^{* * *}$ \\
& $(0.020)$ & $(0.019)$ & $(0.040)$ & $(0.034)$ \\
& & & & \\
Death x Plea Bargain & $0.090^{* * *}$ & $0.103 * * *$ & $0.093^{* * *}$ & $0.131^{* * *}$ \\
& $(0.020)$ & $(0.019)$ & $(0.029)$ & $(0.029)$ \\
& & & & \\
Crime Controls? & Yes & Yes & Yes & Yes \\
Type of Counsel Controls? & Yes & Yes & Yes & Yes \\
County x Year FEs? & Yes & Yes & Yes & Yes \\
Month of Year FEs? & Yes & Yes & Yes & Yes \\
\hline \hline
\end{tabular}

All cases with at least one conviction included (dropping those with all counts dismissed or with a trial acquittal); $N=1,410,751$ for (1) and (2) and $N=505,963$ for (3) and (4).

Dependent variable is the log of the sentence (upper bound of the top charge). Selection model uses an indicator equal to one if a non-zero sentence arises.

Cragg Hurdle model estimated where defendant's age and being a business are used in the unique identifiers in the selection model and total number of counts and the three habitual offender controls are used as the unique variables in the intensive margin estimation. The race, gender, crime, and type of counsel controls are included in both specifications (along with County x Year and Month of Year fixed effects).

Standard errors clustered by County x Year presented in the parentheses (865/862 clusters); *** $1 \%$, ** 5\%, * $10 \%$ level of significance. 
length of shorter sentences have a larger impact than changes in the length of longer sentences. A quantile regression can provide information on whether the shock affects sentences of differing lengths asymmetrically. Our data are similar to theirs, in that just under $30 \%$ of their observations have a non-incarceration sanction. Thus, we too begin the estimation at the $40^{\text {th }}$ decile and follow their lead in estimating a quantile regression.

We choose to depict the results graphically in Figure 2.4. Specifically, we present the estimated coefficients for Plea Bargain at each decile. The line with the closed, black circles represents the coefficients arising under normal circumstances; i.e., without the death of a law enforcement official. The line with the open circles includes the additional values from the difference-in-difference coefficient. It represents the sentence reduction arising from pleading guilty when a law enforcement official dies in the line of duty. The gap between the two lines is the change in the plea discount.

Across all deciles, the plea discount exists and shrinks when a law enforcement official dies in the line of duty. The coefficients for Plea Bargain and Death x Plea Bargain are statistically significant at the $1 \%$ level at each decile. The plea discount grows somewhat for the highest deciles. The effect of the death on the plea discount (i.e., the gap between the two lines) is quite stable. ${ }^{32}$ Similar results arise if the data set is not restricted to convictions of serious crimes.

\section{Permutation Test}

It is clear that the death of a law enforcement official is unrelated to the crime of the individual who has already been arrested and had charges filed against him. Thus, the death acts as a random shock to that person's case. One can be concerned, though, that the death itself is not random. Factors that give rise to violence against law enforcement might also drive the results presented.

One such concern is the problem of false positives - that is, the unrelated deaths of law enforcement officials do not necessarily spill over onto those cases in process but, by random chance, the deaths tend to occur at times in areas of heightened sentences. Thus, a concern is that the results incorrectly attribute an effect to sentences that does not exist.

To address this, we conduct a permutation test. We create "false" deaths of law enforcement officials applied to the data at random by permuting the Death variable. We then re-estimate the main results with the truly random false death. The process is repeated 1000 times. If the observed effect presented previously is a false positive, then it should also arise frequently in the false deaths. If, on the other hand, the estimated effect on the case outcomes looks significantly different than what arises in the distribution of the results from the 1000 permutations, then we can be confident that we are not picking up a false positive result, but rather that the deaths do in fact influence case outcomes.

Table 2.9 presents the results from the permutation test re-estimating the first columns of Tables 2.5 and 2.6. Statistics from the distribution of estimated difference-in-difference coefficients are given. ${ }^{33}$

\footnotetext{
${ }^{32}$ The percentage change in the plea discount ranges from $41 \%$ to $58 \%$ across the deciles. This is in line with the results from the Hurdle model in that for serious crimes the change in the plea discount is larger and is primarily affecting those who receive active incarceration. The coefficients presented are the result of a two-step estimation. First, the main specification, as in the first column of Table 2.5, without Death, Plea Bargain, and Death x Plea Bargain is estimated. The residuals are saved and used as the dependent variable in the quantile regression with only these three as explanatory variables.

${ }^{33}$ The table provides three points in the distributions. For (1) the mean and standard deviation for the distribution of coefficients is -0.00060 and 0.03552 , while for the p-values they are 0.40979 and 0.30906 . For (2) the coefficients have $\mu=0.00243$ and $\sigma=0.05252$, while for the p-values they are $\mu=0.40796$ and $\sigma=0.31025$.
} 
Figure 2.4: Quantile Regression: Sentence Reduction for Pleading Guilty

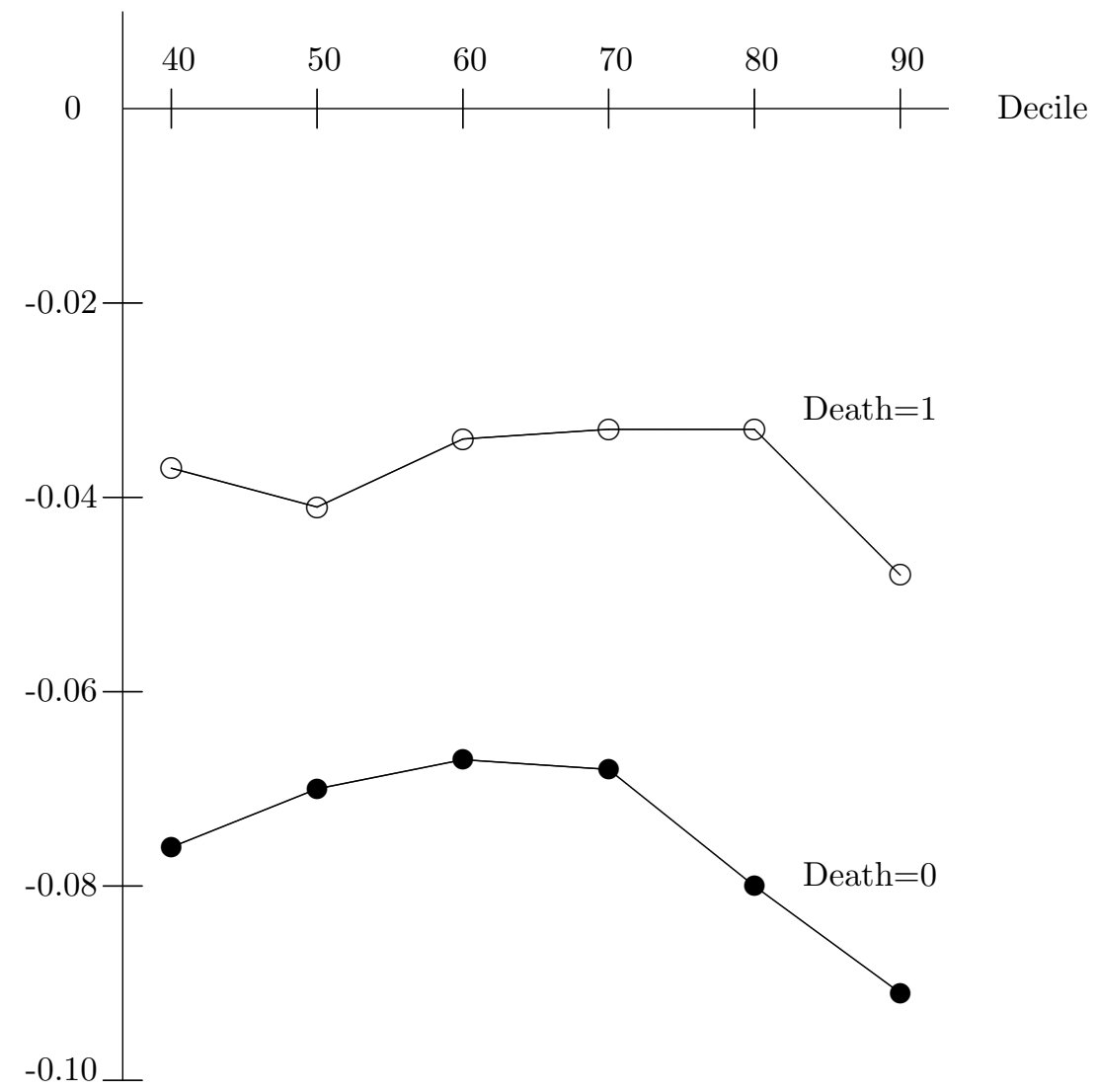

Closed circles denote the coefficient for Plea Bargain for each decile (i.e., without a Law Enforcement Official death). Open circles present the coefficient for Plea Bargain with a death (i.e., adding the interaction term's coefficient) for each decile.

The coefficients for Plea Bargain and Death x Plea Bargain are statistically significant at the 1\% level at each decile.

All cases with at least one conviction included (dropping cases with all counts dismissed or with a trial acquittal) and only serious crimes; $N=505,963$.

Table 2.9: Permutation Test: Plea Discount

\begin{tabular}{lllll}
\hline \hline Data set: & full & & $\begin{array}{l}\text { serious } \\
(2)\end{array}$ & \\
& $(1)$ & & $(2)$ & p-value \\
\hline $\begin{array}{l}\text { Estimated DiD: } \\
\text { from Table 5/6) }\end{array}$ & $\begin{array}{l}\text { coefficient } \\
\text { 0.15262 }\end{array}$ & 0.00018 & 0.17168 & 0.03378 \\
& & & & \\
Permutation Results & & & & \\
$1^{\text {st }}$ percentile & -0.08058 & 0.00081 & -0.11579 & 0.00069 \\
median & -0.00214 & 0.37800 & 0.00265 & 0.36125 \\
$99^{\text {th }}$ percentile & 0.08310 & 0.98300 & 0.13087 & 0.98365 \\
\hline \hline
\end{tabular}

Results from 1000 permutation tests replicating (1) of Table 3 for the first column and (1) of Table 4 in the second column. 
Figure 2.5: DiD Coefficient from 1000 Permutations

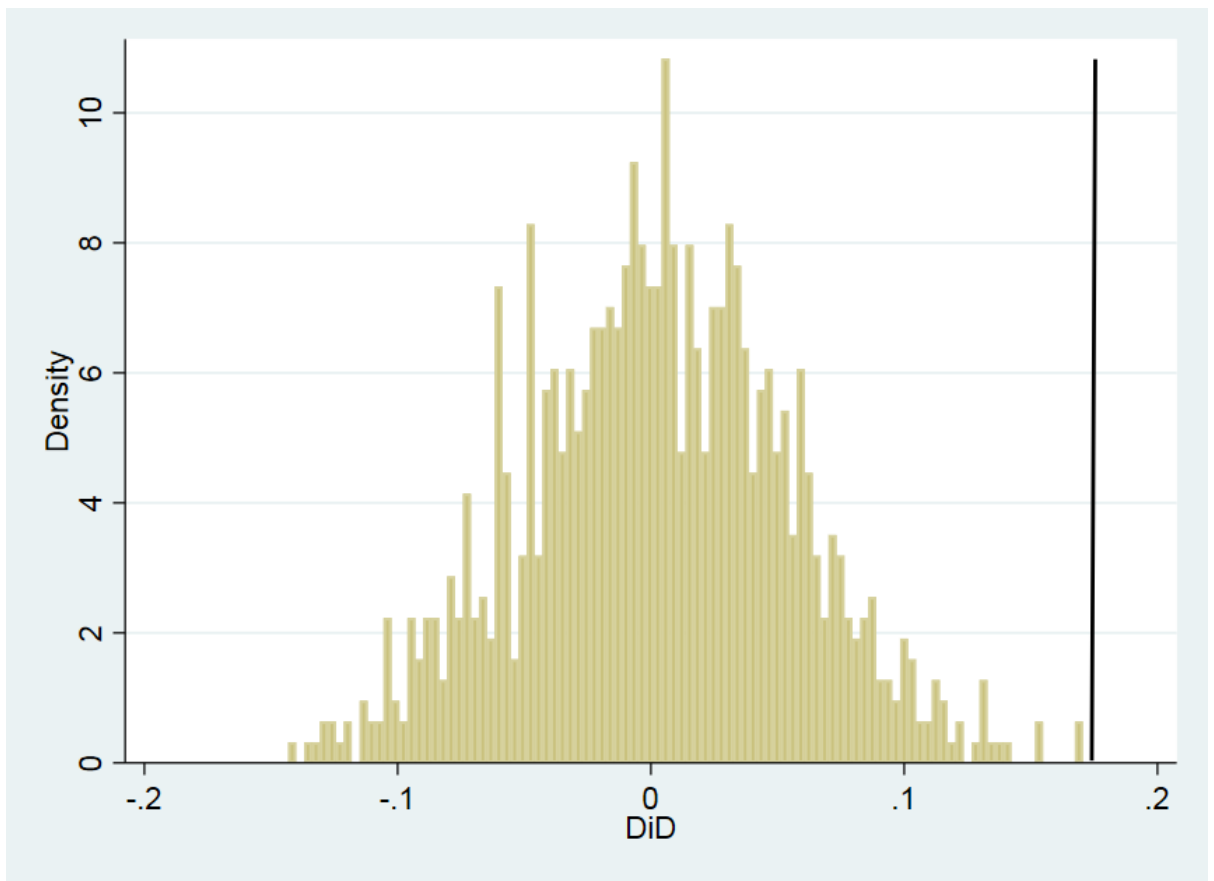

Results from the data set of convictions of serious crimes only is presented.

The black line depicts the estimated coefficient from the actual deaths.

As can be seen, the estimated coefficient is substantially greater than those that arise with these false, permuted deaths. The estimate presented in the top row is substantially greater than even the estimate at the $99^{t h}$ percentile. Thus, the effect of the death of the law enforcement official on the plea discount differs from what would arise by random chance. This observation occurs for both the full data set and when restricted to only the serious felonies.

To illustrate, Figure 2.5 provides a histogram of the permuted difference-in-difference coefficients. The solid black line is the value estimated using the actual death occurrence.

Consistent with the results presented in Table 2.9, the actual effect sits far outside the support of the distribution of estimates from the permutations.

In addition, one can think of permutation tests as being designed to be a non-parametric identification of a p-value. Thus, the p-value for each permutation is also calculated. For the full data set, the p-value calculated from the actual deaths of law enforcement officials in Florida is substantially smaller than any p-value that arises when using the false deaths in the 1000 permutations. For serious crimes only, a small handful of permutations were able to generate a p-value matching the value from Table 6 . Overall, Table 2.9 provides little evidence that our main finding is a false positive result.

\section{DiD Timing}

Another important concern arises when the timing of the treatment varies across the counties. As pointed out by Goodman-Bacon (2018), the difference-in-difference coefficient is the weighted average of four different effects. Those observations treated earlier in time differ from both those 
not yet treated and from those never treated. In addition, the later-treated experience differences from both the never-treated and previously-treated.

For our observations, the cases receive the treatment and are disposed of, so that the last effect should be minimal. The only potential issue is that arrests made immediately after the death may be distinct from other untreated cases. It is reasonable to presume that law enforcement responds to the death of a law enforcement official. This is important in our analysis if arrest and charging immediately after the death adjusts substantially. The results in Table 5 consider those cases already in process at the time of the death, but those cases arising immediately after the death are pooled with those not close (either temporally or spatially) to the death.

To address this issue, if arrests made within a week of the death, or arrests made within a month of the death, are excluded from the analysis, the results are unchanged. For example, using the specification in the first column of Table 5 , the plea discount drops by $18.1 \%$ with the death of a law enforcement official. This effect is a decrease of $18.7 \%$ and $19.9 \%$ respectively if the arrests occurring within a week and a month of the death are omitted. Thus, the distortion of previously treated observations affecting the difference-in-difference estimate of later-treated observations is minimal.

Another timing check is to omit all observations coming from counties that never experience a death over our sample period. This allows us to assess the distinction between the treated and the not-yet treated and the difference between the treated and never-treated units.

While not presented here, if the first column of Table 6 is re-estimated, for example, with observations coming from counties that never experience a death are excluded, the results are unaffected. The difference-in-difference coefficient remains positive and statistically significant. Importantly, the estimated change in the plea discount is $24.1 \%$, which is quite close to the $23.8 \%$ estimated with all counties included. Thus, the distinction between not-yet treated and never-treated units is minimal.

\section{Plea Discount or Case Mix?}

A final concern is that the exogenous treatment variable affects the independent variable of interest. As we will explore in Section 5, deaths can be expected to affect whether cases go to trial. If this occurs, then the change in the sentences received previously estimated may not solely be the difference between the realized sentence and the counterfactual outcome of what the agreed to sanction would have been had there not been a death. Instead, it could be driven in part by a change in the composition of cases that are plea bargained.

One way to investigate this concern is to consider crimes that infrequently go to trial. For those crimes, there can be expected to be little change in the composition, compared to those that frequently see cases go to trial. Changes in the average plea discount for crimes that rarely go to trial should then be a product of adjustments in the plea bargaining process and not changes in the mix of cases that are plea bargained. We consider the impact of the treatment on the difference between sentences arising from guilty pleas and sentences arising from trial convictions for crimes rarely going to trial, as compared to crimes that frequently do. If we find that the estimated effects are driven

primarily by those crime types that frequently go to trial, one can reasonably be concerned that we are not estimating the actual change in the plea discount.

To do this analysis, we first consider those crimes with at least 2500 untreated observations. There are 28 such crimes. They make up 1,376,935 observations in total (97.2\% of the sample). There is quite a bit of variation in the trial rate. Some crimes rarely go to court. A few have 
relatively high trial rates. Forgery cases, for example, only go to trial $0.5 \%$ of the time. Sexual assaults, on the other hand, result in trials $11.7 \%$ of the time.

We can gain confidence in the interpretation of our main result if we see the change in the plea discount being rather large for those cases with low trial rates. If, on the other hand, our estimated average treatment effect is driven primarily by those with high trial rates, we can be concerned that our results are being driven by changes in the composition of cases that go to trial when the death occurs.

Figure 6 depicts the relationship between the average trial rate and the estimated change in the plea discount when a law enforcement official is killed in the line of duty. The estimated coefficients on Plea Bargain and Death x Plea Bargain are used to calculate the plea discounts with and without the law enforcement official's death, so that the decrease in the plea discount can be estimated. This decrease is placed on the y-axis. The crime's baseline trial rate is put on the x-axis. Figure 2.6 presents the scatterplot. The best fitting line is also depicted.

A strong, negative relationship exists between the trial rate experienced within a particular crime category in the untreated observations, and the estimated change in the plea discount when a law enforcement official dies. For those crimes where the trial rate is low, the plea discount reduces substantially. For those cases with relatively high trial rate, the plea bargaining process does not lead to much of a change in the sentence. ${ }^{34}$

Again, this finding is important in that a positive relationship between the two would call into question the conclusions reached in the paper. The average treatment effect is not arising from those crimes that often go to trial. Therefore, it is unlikely that our estimated effect is coming from a change in the mix of cases.

\subsubsection{Heterogeneous Treatment Effects}

Our hypothesis is that the death of a law enforcement official is working through the community's salience with the problems of crime. One would not expect all deaths to have equivalent impacts. Incidents that resonate louder with a community should have a greater impact on the plea bargaining process if the bargaining in the shadow of the trial framework is correct.

To identify heterogeneous effects, we first distinguish gun-related deaths from non-gun-related deaths. Presumably, a shooting primes potential jurors on the problem of violence, more so than deaths not involving gunfire. We disaggregate the variable Death into those caused by gunfire, Gun Death, and those not related to gunfire, Non-Gun Death. For the results we present here, only serious crimes are considered, but the message is unchanged if the full data set is used. Table 2.10 presents the results.

Disaggregating the cause of the law enforcement official's death, (1), gun-related deaths see an increase in the sentences received when a guilty plea is entered relative to the trial sanction. Non-gun-related deaths have an essentially zero effect on the negotiated pleas. ${ }^{35}$

\footnotetext{
${ }^{34} \mathrm{~A}$ similar scatterplot and relationship arises if instead of the baseline trial rate, the estimated effect of the death on the trial rate is considered (as will be estimated in Section 5). Thus, the finding is not sensitive to whether the trial rate or change in the trial rate is used.

${ }^{35}$ Anecdotally, quite a few of the non-gun related deaths were important, newsworthy events. Oftentimes, the vehicle-related deaths are impactful. Law enforcement officials have died in high speed pursuits, for example. Also, the stabbing of a deputy sheriff transporting a prisoner to a court hearing, which resulted in a widespread manhunt, and a corrections officer being stabbed by a inmate on a new, controversial work release program, are examples of non-gun related deaths. These events can be expected to be impactful in the community as well.
} 
Figure 2.6: Relationship between Trial Rate and Plea Discount

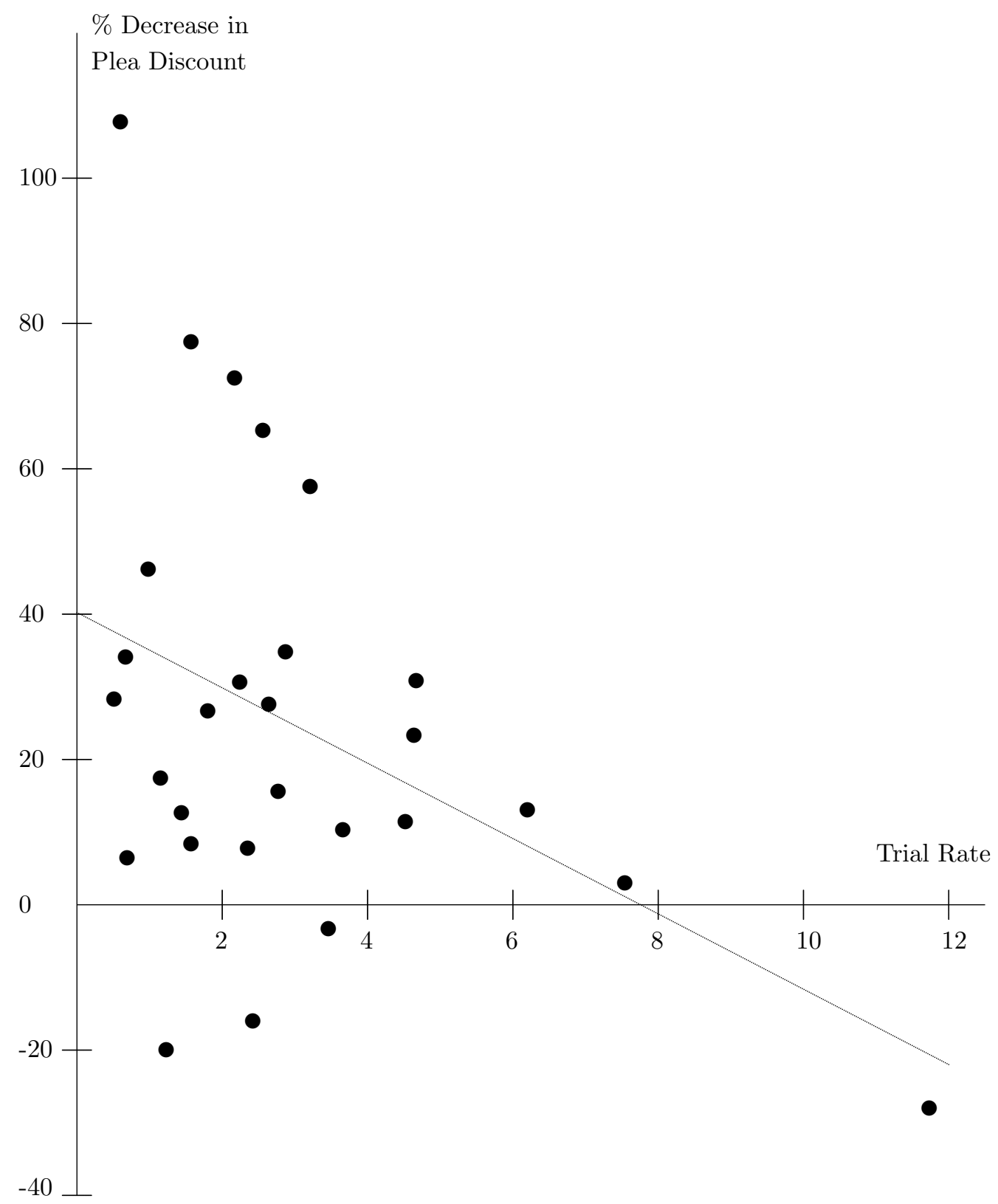


Table 2.10: Heterogeneous Treatment Effects

\begin{tabular}{|c|c|c|c|c|c|}
\hline Salient death: & $\begin{array}{l}\text { Gun } \\
\text { death } \\
(1)\end{array}$ & $\begin{array}{l}\text { High volume } \\
\text { of searches } \\
(2)\end{array}$ & $\begin{array}{l}\text { Spike in } \\
\text { searches } \\
(3)\end{array}$ & $\begin{array}{l}\text { Long time } \\
\text { since arrest } \\
\text { (4) }\end{array}$ & $\begin{array}{l}\text { Dedications } \\
(5)\end{array}$ \\
\hline Plea Bargain & $\begin{array}{l}-0.580 \text { *** } \\
(0.049)\end{array}$ & $\begin{array}{l}-0.650^{* * *} \\
(0.053)\end{array}$ & $\begin{array}{l}-0.665 \text { *** } \\
(0.054)\end{array}$ & $\begin{array}{l}-0.582 * * * \\
(0.048)\end{array}$ & $\begin{array}{l}-0.579^{* * *} \\
(0.049)\end{array}$ \\
\hline Death & $\begin{array}{l}0.211 * * * \\
(0.082)\end{array}$ & $\begin{array}{l}0.299 * * * \\
(0.086)\end{array}$ & $\begin{array}{l}0.207 * * \\
(0.089)\end{array}$ & $\begin{array}{l}0.200 * * * \\
(0.081)\end{array}$ & $\begin{array}{l}0.210 \text { *** } \\
(0.081)\end{array}$ \\
\hline Salient Death x Plea Bargain & $\begin{array}{l}0.224 * * \\
(0.090)\end{array}$ & $\begin{array}{l}0.247 * * \\
(0.111)\end{array}$ & $\begin{array}{l}0.272 * * * \\
(0.109)\end{array}$ & $\begin{array}{l}0.472 * * * \\
(0.0082)\end{array}$ & $\begin{array}{l}0.273 * * \\
(0.132)\end{array}$ \\
\hline Less-Salient Death x Plea Bargain & $\begin{array}{l}0.131 \\
(0.085)\end{array}$ & $\begin{array}{l}0.081 \\
(0.087)\end{array}$ & $\begin{array}{l}0.070 \\
(0.087)\end{array}$ & $\begin{array}{l}0.086 \\
(0.083)\end{array}$ & $\begin{array}{l}0.151 * \\
(0.079)\end{array}$ \\
\hline Demographic Controls? & Yes & Yes & Yes & Yes & Yes \\
\hline Crime Controls? & Yes & Yes & Yes & Yes & Yes \\
\hline Habitual Offender Controls? & Yes & Yes & Yes & Yes & Yes \\
\hline Type of Counsel Controls? & Yes & Yes & Yes & Yes & Yes \\
\hline County x Year FEs? & Yes & Yes & Yes & Yes & Yes \\
\hline Month of Year FEs? & Yes & Yes & Yes & Yes & Yes \\
\hline$R^{2}$ & 0.144 & 0.101 & 0.082 & 0.145 & 0.144 \\
\hline AIC & $1.8 \times 10^{6}$ & $1.9 \times 10^{6}$ & $1.9 \times 10^{6}$ & $1.8 \times 10^{6}$ & $1.9 \times 10^{6}$ \\
\hline
\end{tabular}

All cases with at least one conviction included (dropping those with all counts dismissed or with a trial acquittal) and only serious crimes; $N=505,963$.

Dependent variable is the log of the sentence (upper bound of the top charge). OLS model estimated as in the first column of Table 2.5.

The control variables are the same as was used in Table 2.5.

In the first column a death is salient if it was gun related. In (2) the (relative) number of Google searches for "Law Enforcement Official" must be greater than one of that region's standard deviation above its mean to be a salient death. In (3), the number of searches must increase by five points or more from the previous month to be salient. In (4), the number of days between arrest and the death must exceed 233. Finally, in (5) a road must be dedicated in the name of the law enforcement official to be salient.

Standard errors clustered by County x Year presented in parentheses (865 clusters); *** $1 \%, * * 5 \%, * 10 \%$ level of significance. 
Another way we identify heterogeneous effects is through Google search data. We use Google Trends data employing the search phrase "Law Enforcement Official", collecting data from 2004 to 2017. Specifically, Google Trends provides the number of searches for the phrase by month. The data are normalized by the peak observation over that time period.

We drill down just to searches in the state of Florida. Within Florida, the state is separated into regions. We collect the normalized Google Trends search data for each region for each month our data covers. Then, for each law enforcement official death, we use the county in which s/he was employed and link it to the region defined by Google. This process gives us information about the changes in Google searches related to law enforcement in the region at the time of the death.

One way we choose to code a high level of internet searches in a region is to consider the mean and standard deviation in the region's monthly searches. We then identify those months where the searches exceed one standard deviation above the region's mean. Where law enforcement deaths coincide with the Google Trends data having a high level of searches, we denote the death as being salient. The less salient deaths are those that do not coincide with a high volume of searches.

A second way we take advantage of the Google Trends data is to consider those deaths where there is an uptick in the month of the death compared to the previous month. Since the Google Trends data are normalized by the region's peak observation over the time period (set equal to 100), we also define a salient death as one that provokes an increase in searches by five or more points. An event that does not see a spike in the Google Trends data in that month is treated as a less salient event. The results are presented in (2) and (3) of Table 10.

Once again, both difference-in-difference coefficients are positive and statistically significant for the salient deaths. The less salient deaths see positive but statistically insignificant effects. Thus, heightened community interest is correlated with a large reductions in the plea discount.

Next, we calculate the number of days between the defendant's arrest and the law enforcement official's death. Reasonably, if the death makes more salient the problems of violence and crime in a community, then it will affect the negotiations of those cases closer to the court date. A case which will not have a trial for months can expect only a muted effect on the jurors by the time the trial occurs. Since the court date is endogenous, we use the days since arrest. To identify those close to the court date, we create an indicator variable equal to one if the number of days since the arrest is in the top $20 \%$ in length. For our data set, this corresponds to cases with more than 233 days since the arrest. The less salient deaths, then, are those that are closer to their arrest date.

Yet again, both difference-in-difference coefficients are positive, but only the treated observations far from their arrest date have statistically significant impacts.

As a final heterogeneous treatment effect, we obtain a list of every road dedication in the state. Anecdotally, a common way for a community to honor those who have made a sacrifice is to name a roadway after the individual. We find that $12 \%$ of the law enforcement officials have received such a dedication. Our presumption is that these deaths were especially impactful to their communities. Consequently, if citizens are expected to respond when assigned to a jury, and if plea bargaining occurs in the shadow of the trial, then the difference-in-difference coefficient will be larger in magnitude.

This is precisely what we see. In (5), the coefficient is $80.8 \%$ larger for deaths associated with dedications. We do see some significance in the less-salient deaths here. This could be explained by some more recent deaths which were impactful, but there has not yet been enough time to get a 
roadway dedicated to the fallen officer. Taken together, we feel the weight of the evidence provided by these heterogeneous treatment effects strongly suggest the mechanism we hypothesize is accurate. Anticipated increases in the jury's likelihood of conviction filters back to the plea bargaining process.

While not presented here, similar findings arise if sentences receive the inverse hyperbolic sine transformation, or a Tobit model is estimated. In addition, similar findings arise if the treatment variable, Death, is also disaggregated by incident type. Also, while Table 10 presents the results considering only the subsample of serious crimes, the results with the full data set of felonies provides nearly identical results.

Finally, we considered spatial spillover effects. Florida's legal system organizes its 67 counties into 20 judicial circuits. Conceivably, the death event in a county could affect those in neighboring counties within the same circuit. We find that the deaths do not have a statistically significant impact on cases in process in other counties within the same judicial circuit. Also, we are unable to document a spillover across the rest of the state. The impact of the tragic event is only felt in the local community. Given the insignificant results, we do not present them here.

\subsection{Going to Court}

Up to this point, the analysis has focused on sentences received. We now turn to an analysis of whether the case, when pursued by the prosecutor's office, ends up at trial. As stated, harsher sanctions offered by the prosecutor in pretrial negotiations can be expected to be rejected at a higher rate, leading to more trials. On the other hand, the more-severe expected trial sanction should increase the defendant's willingness to accept a plea, leading to fewer trials. These opposing effects make the direction of the net effect unclear.

Therefore, as before, we consider the data set of all cases where at least one count is not dismissed. Unlike the previous section, though, we also include cases that receive an acquittal at trial. The existence of a trial now becomes the dependent variable of interest.

First, we separate the sample into those observations that coincide with a law enforcement official's death in the county and those that do not. Figure 2.7 presents each sub-sample's average proportion of cases that went to trial.

There is a noticeable difference. Trials are more prevalent when the shock of a death occurs. This is consistent with the argument that the plea offers made by prosecutors become substantially less generous, pushing the accused to take their chances at trial instead.

Table 2.11 provides results from a linear probability model with the dependent variable equal to one if the case resulted in a trial. ${ }^{36}$ We explore whether there is a systematic relationship between the exogenous shock of an official's death and the probability of a trial arising. All fixed effects previously used are included, and standard errors are again clustered at the County by Year level.

The death of a law enforcement official results in an increase in the probability the case goes to trial, consistent with Figure 2.7. Using the estimated coefficient in the first column, the trial rate increases by $81.1 \%$.

Consequently, accused criminals are treated more harshly in two margins. Facing an escalated chance of conviction at trial, they agree to longer sentences in the plea negotiation. This is, then, an

\footnotetext{
${ }^{36}$ Here, we do not differentiate between jury trials and non-jury, bench trials. The former is rather rare in Florida. In the full data set $1.85 \%$ of cases result in a jury trial, while only $0.54 \%$ result in a bench trial. Disentangling the two will be done in the next section.
} 
Figure 2.7: Does LEO Death Correspond to Trials?

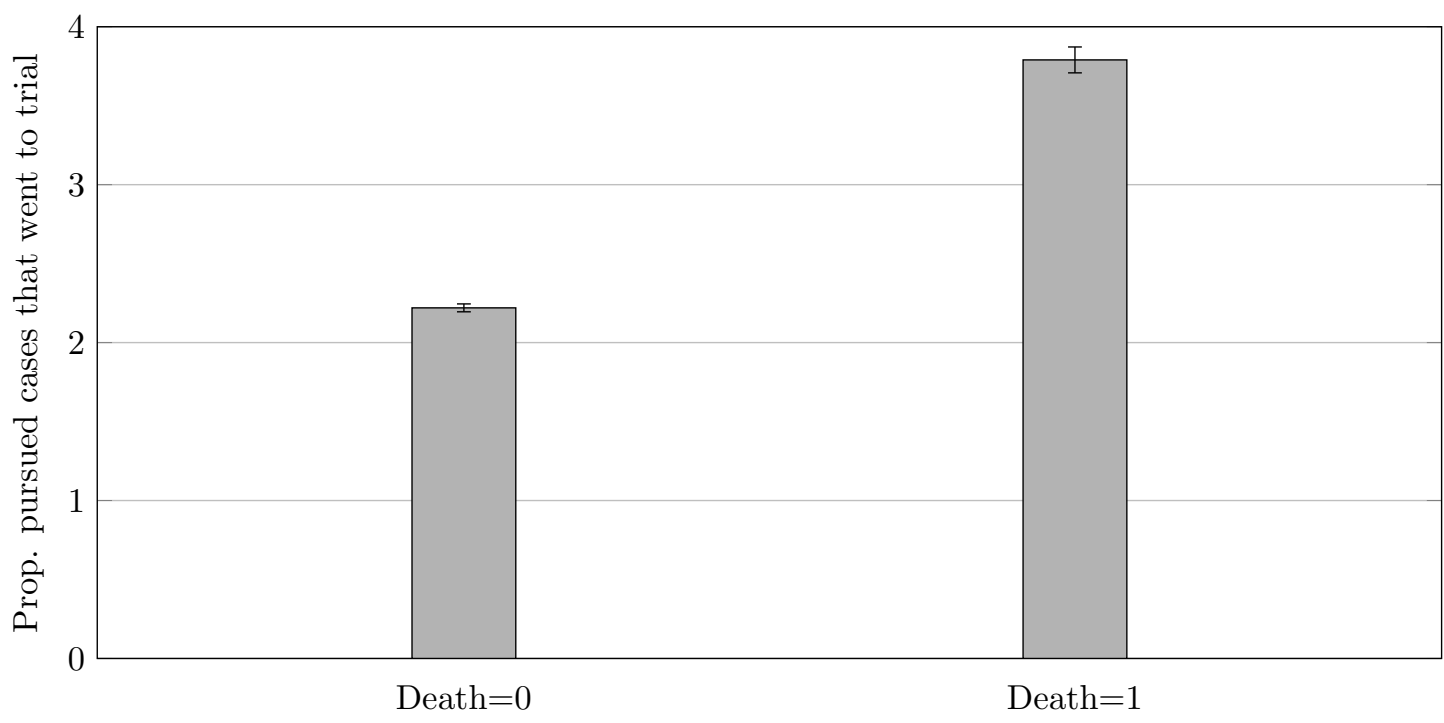

A two-tailed, difference-in-means t-test (allowing for unequal variances) has $t=36.0(p<0.001)$.

Table 2.11: Trial Rate

\begin{tabular}{lll}
\hline \hline Data set: & $\begin{array}{l}\text { full } \\
(1)\end{array}$ & $\begin{array}{l}\text { serious } \\
(2)\end{array}$ \\
\hline Death & $0.0198^{* * *}$ & $0.0249^{* * *}$ \\
& $(0.0015)$ & $(0.0019)$ \\
& & \\
Demographic Controls? & Yes & Yes \\
Crime Controls? & Yes & Yes \\
Habitual Offender Controls? & Yes & Yes \\
Type of Counsel Controls? & Yes & Yes \\
County x Year FEs? & Yes & Yes \\
Month of Year FEs? & Yes & Yes \\
& & \\
$R^{2}$ & 0.037 & 0.040 \\
AIC & $-1.5 \times 10^{6}$ & $-3.7 \times 10^{5}$ \\
$N$ & $1,416,540$ & 509,738 \\
DV $\mu$ & 0.0244 & 0.0303 \\
\hline \hline
\end{tabular}

All cases (dropping those with all counts dismissed or with a trial acquittal), both trial convictions and acquittals along with guilty pleas, included.

Dependent variable equal to one if any count charged is disposed at trial (jury or nonjury \& convicted or acquitted). Linear probability models are estimated.

The control variables are the same as was used in Table 2.5.

Standard errors clustered by County x Year presented in parentheses (865/862 clusters); *** $1 \%, * * 5 \%, * 10 \%$ level of significance. 
Table 2.12: Trial Rate: Heterogeneous Treatment Effects

\begin{tabular}{|c|c|c|c|c|c|}
\hline$\overline{\text { Salient death: }}$ & $\begin{array}{l}\text { Gun } \\
\text { deaths } \\
\text { (1) }\end{array}$ & $\begin{array}{l}\text { High volume } \\
\text { of searches } \\
(2)\end{array}$ & $\begin{array}{l}\text { Spike in } \\
\text { searches } \\
(3)\end{array}$ & $\begin{array}{l}\text { Long time } \\
\text { since arrest } \\
(4)\end{array}$ & $\begin{array}{l}\text { Dedications } \\
(5)\end{array}$ \\
\hline Salient Death & $\begin{array}{l}0.0114^{* * *} \\
(0.0027)\end{array}$ & $\begin{array}{l}0.0148^{\text {*** }} \\
(0.0039)\end{array}$ & $\begin{array}{l}0.0170 \text { *** } \\
(0.0045)\end{array}$ & $\begin{array}{l}0.0395 \text { *** } \\
(0.0029)\end{array}$ & $\begin{array}{l}0.0260 \text { *** } \\
(0.0037)\end{array}$ \\
\hline Less-Salient Death & $\begin{array}{l}0.0137 \text { *** } \\
(0.0017)\end{array}$ & $\begin{array}{l}0.0149 \text { *** } \\
(0.0015)\end{array}$ & $\begin{array}{l}0.0157 \text { *** } \\
(0.0015)\end{array}$ & $\begin{array}{l}0.0139 \text { *** } \\
(0.0012)\end{array}$ & $\begin{array}{l}0.0185 \text { *** } \\
(0.0015)\end{array}$ \\
\hline Demographic Controls? & Yes & Yes & Yes & Yes & Yes \\
\hline Crime Controls? & Yes & Yes & Yes & Yes & Yes \\
\hline Habitual Offender Controls? & Yes & Yes & Yes & Yes & Yes \\
\hline Type of Counsel Controls? & Yes & Yes & Yes & Yes & Yes \\
\hline County x Year FEs? & Yes & Yes & Yes & Yes & Yes \\
\hline Month of Year FEs? & Yes & Yes & Yes & Yes & Yes \\
\hline$R^{2}$ & 0.036 & 0.036 & 0.036 & 0.037 & 0.037 \\
\hline $\mathrm{AIC}$ & $-1.5 \times 10^{6}$ & $-1.5 \times 10^{6}$ & $-1.5 \times 10^{6}$ & $-1.5 \times 10^{6}$ & $-1.5 \times 10^{6}$ \\
\hline
\end{tabular}

All cases (dropping those with all counts dismissed), both trial convictions and acquittals along with guilty pleas, included; $N=1,416,540$.

Dependent variable equal to one if any count charged is disposed at trial (jury or nonjury \& convicted or acquitted). Linear probability models are estimated.

The control variables are the same as was used in Table 2.5.

Standard errors clustered by County x Year presented in parentheses (865 clusters); *** $1 \%,{ }^{* *} 5 \%, * 10 \%$ level of significance.

increase in the intensive margin of plea bargaining. More do not accept those terms and go to trial, where they face the prospect of the full sanction without the plea discount. Thus, the extensive margin moves, as well.

As articulated thoroughly by Boylan (2012), selection effects can lead to erroneous estimates of the factors that lead to more trials. Our quasi-natural experiment allows us to assess the causal impact of trial harshness on the trial rate. We find effects in line with Boylan (2012), providing further support that the plea bargaining process responds to judges and jurors.

Also, while not presented here, we disaggregate the serious crimes. The coefficient on Death is positive and statistically significant for all seven crimes. Only homicides show a less strong impact (but still significant at the $10 \%$ level).

Second, the same heterogeneous treatment effects, as explored previously are considered again. Table 2.12 presents the results.

Here, we find that both the salient and less salient deaths correspond to more trials. This suggests that the more salient deaths correspond to more uncertainty in the criminal justice system, which leads to more bargaining failure. While Table 12 considers all felonies where convictions are sought, similar results arise if only heterogeneous treatment effects on serious crimes are considered.

In addition, the permutation test, as was done in Section 2.4.3.3, can be carried out here to evaluate the potential for false positive results in Table 2.11. For the full data set, every permutation resulted in a coefficient smaller than what was estimated in column (1) of Table 2.11. For the sample of serious crimes, only $0.2 \%$ generated a greater estimated effect. Similarly, the p-value of the true 
Death variable is smaller than each of the permuted deaths estimates.

Similarly, we conduct a parallel trends analysis, as was performed in Section 4.2. As was the case in Figure 2.3, all but one of the pre-treatment trend variables has zero included within the confidence interval. Thus, we conclude that the treated counties do not follow a different time trend in the months preceding the death event, relative to the control counties. These additional results are available in our separate, supplemental appendix.

\subsection{Is it Really the Jurors?}

Our identification strategy rests on the argument that it is the exogenous shock of the death event which affects the community and, hence, influences the jury pool. The salience of violence and crime in society, we argue, makes the jury more likely to convict a defendant at trial, ceteris paribus. Recognizing this, the other actors in the criminal justice system, namely the prosecutor and defense attorney \& defendant, respond in their negotiations and the resulting 'price' of the crime increases.

Our presumption has thus far been untested. While direct measurement of the actors' beliefs about jurors is not measurable, the data available can be used to explore the existence of suggestive evidence.

\subsubsection{Separating Jury Trials from Bench Trials}

One interesting feature of the criminal justice system is that a small proportion of cases go to bench trials. In bench trials there is no jury, but instead the judge decides both makes the conviction/acquittal and the sentence (conditional on conviction). While the decision not to exercise one's right to a jury trial is endogenous, we nevertheless separate jury trials from bench trials and evaluate the relationship between the death of a law enforcement official and the sentencing that arises from these two separate institutions. Since we cannot ensure that the trial mode decision was made prior to the shock, the results should be treated as suggestive only.

Distinguishing judge behavior from jury behavior is important. If it is simply the case that judges, after both a negotiated plea and a trial conviction, sentence more harshly, then it is not necessarily obvious that the plea negotiations existed in the shadow of the trial. Bushway et al. (2014) experiment suggests, at least for the sample of judges, that plea discounts could be fixed reductions on the trial sanction invariant to the jury's conviction probability. If, on the other hand, the jury changes its anticipated behavior, then since the plea discount is theoretically driven primarily by the conviction probability, changes in the plea discounts verify that the bargaining in the shadow of the trial framework is correct. If bench trials also see harsher sentencing, then our hypothesis can be questioned.

Therefore, Table 2.13 re-estimates the main results presented previously. The important change is that while the results in Section 4 use Plea Bargain as the explanatory variable (with trials as the omitted variable), here we leave plea bargains as the omitted variable and include the trial as the explanatory variable. We separate these trials into those that occurred with a jury, Jury Trial, and those that did not, Bench Trial. Hence, Plea Bargain + Jury Trial + Bench Trial $=1$, since only convictions are considered. The difference-in-difference coefficient can be disaggregated as well. Table 2.13 includes all controls and fixed effects as previously used, and clusters the standard errors as before. 
Table 2.13: Is it Really Affecting Jurors? Plea Discount

\begin{tabular}{llll}
\hline \hline Dependent variable: & $\begin{array}{l}\text { ln(sentence) } \\
\text { OLS } \\
\text { Model: }\end{array}$ & $\begin{array}{l}\text { IHS(sentence) } \\
\text { OLS } \\
(1)\end{array}$ & $\begin{array}{l}\text { ln(sentence) } \\
\text { Tobit } \\
(2)\end{array}$ \\
\hline Death & $0.382^{* * *}$ & $0.387^{* *}$ & $0.440^{* * *}$ \\
& $(0.032)$ & $(0.035)$ & $(0.040)$ \\
& & & \\
Jury Trial & $0.674^{* * *}$ & $0.668^{* * *}$ & $0.737^{* * *}$ \\
& $(0.050)$ & $(0.057)$ & $(0.063)$ \\
& & & \\
Bench Trial & -0.079 & -0.149 & -0.205 \\
& $(0.097)$ & $(0.112)$ & $(0.135)$ \\
& & & \\
Death x Jury Trial & $-0.222 * * *$ & $-0.238 * * *$ & $-0.281^{* * *}$ \\
& $(0.083)$ & $(0.093)$ & $(0.102)$ \\
& & & \\
Death x Bench Trial & -0.265 & -0.290 & -0.324 \\
& $(0.167)$ & $(0.192)$ & $(0.236)$ \\
Demographic Controls? & & & \\
Crime Controls? & Yes & Yes & Yes \\
Habitual Offender Controls? & Yes & Yes & Yes \\
Type of Counsel Controls? & Yes & Yes & Yes \\
County x Year FEs? & Yes & Yes & Yes \\
Month of Year FEs? & Yes & Yes & Yes \\
$R^{2}$ & & & Yes \\
AIC & 0.144 & 0.139 & 0.040 \\
\hline \hline & $1.8 \times 10^{6}$ & $2.0 x 10^{6}$ & $1.8 \times 10^{6}$ \\
\hline
\end{tabular}

All cases with at least one conviction included (dropping those with all counts dismissed or with a trial conviction) and only serious crimes; $N=505,963$.

The control variables are the same as in Table 2.5.

Standard errors clustered by County x Year presented in parentheses (862 clusters); *** 1\%, ** 5\%, * $10 \%$ level of significance. 
Table 2.14: Is it Really Affecting Jurors? Trial Rate

\begin{tabular}{lllll}
\hline \hline $\begin{array}{l}\text { Dependent variable: } \\
\text { Data set: }\end{array}$ & $\begin{array}{l}\text { Bench Trial } \\
\text { full } \\
(1)\end{array}$ & $\begin{array}{l}\text { Jury Trial } \\
\text { full } \\
(2)\end{array}$ & $\begin{array}{l}\text { Bench Trial } \\
\text { serious } \\
(3)\end{array}$ & $\begin{array}{l}\text { Jury Trial } \\
\text { serious } \\
(4)\end{array}$ \\
\hline Death & 0.0007 & $0.0188^{* * *}$ & 0.0009 & $0.0232^{* * *}$ \\
& $(0.0005)$ & $(0.0015)$ & $(0.0005)$ & $(0.0019)$ \\
& & & & \\
Demographic Controls? & Yes & Yes & Yes & Yes \\
Crime Controls? & Yes & Yes & Yes & Yes \\
Habitual Offender Controls? & Yes & Yes & Yes & Yes \\
Type of Counsel Controls? & Yes & Yes & Yes & Yes \\
County x Year FEs? & Yes & Yes & Yes & Yes \\
Month of Year FEs? & Yes & Yes & Yes & Yes \\
& & & & \\
$R^{2}$ & 0.072 & 0.028 & 0.054 & 0.035 \\
AIC & $-1.3 \times 10^{6}$ & $-1.7 \times 10^{7}$ & $-1.5 \times 10^{6}$ & $-4.5 \times 10^{5}$ \\
\hline \hline
\end{tabular}

All cases (dropping those with all counts dismissed), both trial convictions and acquittals along with guilty pleas, included; $N=1,416,540$ in (1) and (2) and $N=509,738$.

Dependent variable equal to one if the case went to that type of trial (either jury or bench).

The control variables are the same as was used in Table 2.10.

Standard errors clustered by County x Year presented in parentheses (865/862 clusters); ${ }^{* * *} 1 \%,{ }^{* *} 5 \%,{ }^{*} 10 \%$ level of significance.

Considering serious crimes, as before, jury trials see a heightened sentence relative to guilty pleas, the omitted category. This difference shrinks with the death of a law enforcement official. This effect does not occur for bench trials. The death does not change the difference between sentences received from negotiated guilty pleas and trial conviction. The distinction between jury trials and bench trials arises with the alternative transformation of the dependent variable, (2), and with the estimation of a Tobit model, (3). This strongly suggests that changes in the plea bargaining process correspond to the presence of a jury.

Turning to the trial rate, Table 2.14 extends Table 2.11. Again, rather than consider the existence of a trial as the dependent variable, as in Table 2.11, Table 2.14 uses Bench Trial and Jury Trial as dependent variables.

The death of a law enforcement official coincides with an increase in jury trials, but there is no change in the prevalence of bench trials. This pattern arises for both the full data set of all crimes and the subsample of serious crimes. Plea bargaining's success does not change when a bench trial is the default outcome. Thus, the rate at which these negotiations fail and go to trial is unaffected. Again, this is suggestive that the deaths are working through the behavior of the jurors in their willingness to convict.

\subsubsection{Convictions versus Acquittals}

Potentially, a more direct way to evaluate whether it is in fact jurors increasing their likelihood of convicting is to explore the distinction between convictions and acquittals. Conditional on a case going to trial, the conviction probability should be higher for those cases that experienced the shock of the death. Additionally, this effect should not be there in bench trials if our hypothesis is correct.

As shown, there is a change in the volume of cases that go to trial and there is no reason to 
Table 2.15: Acquittal Rate

\begin{tabular}{|c|c|c|c|c|}
\hline Data set: & $\begin{array}{l}\text { All trials } \\
\text { (1) }\end{array}$ & $\begin{array}{l}\text { Trials with } \\
\text { serious crimes } \\
(2)\end{array}$ & $\begin{array}{l}\text { Jury trials } \\
\text { only } \\
(3)\end{array}$ & $\begin{array}{l}\text { Bench trials } \\
\text { only } \\
\text { (4) }\end{array}$ \\
\hline Death & $\begin{array}{l}-0.0212 \text { *** } \\
(0.0077)\end{array}$ & $\begin{array}{l}-0.0188^{* * *} \\
(0.0116)\end{array}$ & $\begin{array}{l}-0.0254 \text { *** } \\
(0.0072)\end{array}$ & $\begin{array}{l}-0.0087 \\
(0.0210)\end{array}$ \\
\hline Demographic Controls? & Yes & Yes & Yes & Yes \\
\hline Crime Controls? & Yes & Yes & Yes & Yes \\
\hline Habitual Offender Controls? & Yes & Yes & Yes & Yes \\
\hline Type of Counsel Controls? & Yes & Yes & Yes & Yes \\
\hline County x Year FEs? & Yes & Yes & Yes & Yes \\
\hline Month of Year FEs? & Yes & Yes & Yes & Yes \\
\hline$R^{2}$ & 0.187 & 0.214 & 0.165 & 0.512 \\
\hline $\mathrm{AIC}$ & $2.3 \times 10^{4}$ & $1.4 \times 10^{4}$ & $1.8 \times 10^{4}$ & -210 \\
\hline$N$ & 30,952 & 15,443 & 25,924 & 4286 \\
\hline DV $\mu$ & 0.1726 & 0.2444 & 0.1742 & 0.0713 \\
\hline
\end{tabular}

Each column presents the result from a different data set. The first uses all cases where at least one count went to trial. The second column refines this to only include serious crimes where at least one count went to trial. The third column considers only those cases that went to a jury trial. The fourth column considers only those cases that went to a bench trial.

Dependent variable is equal to one if the accused is acquitted of all charges and zero otherwise.

The control variables are the same as was used in Table 2.5.

Standard errors clustered by County x Year presented in parentheses (799, 721, 779, 481 clusters, respectively); $* * * 1 \%, * * 5 \%, * 10 \%$ level of significance.

believe that those new cases that go to trial when there has been a death are representative of the cases that would have gone to trial otherwise. Thus, one should hesitate to interpret the analysis as a causal identification of a change in the jury behavior. Nevertheless, if the probability of conviction at a trial does not increase, or if the conviction probability at a bench trial also increases, then doubt can be cast on the underlying argument we are using in our causal identification.

Thus, Table 2.15 considers only the data set of cases that go to trial. As before, we consider both the full data set, (1), and the subsample of serious felony crimes, (2). Also, the full data set is partitioned into those cases that were heard by a jury, (3), and those having a nonjury, bench trial, (4). As always, a saturated model is estimated with demographic, crime, habitual offender, and type of counsel controls, along with County x Year and Month of Year fixed effects. In addition, standard errors are clustered at the County x Year level.

The death of a law enforcement official is associated with a decrease in the likelihood of an acquittal arising at trial. For all trials, the conviction rate at the mean increases by $2.6 \%$. Concentrating on jury trials only, the rate increases by $3.1 \%$. This strongly suggests, for those cases that go to trial, that jurors are responding to the recent event. Most importantly, separating jury trials from bench trials, the effect is fully contained within the sample of jury trials. 


\subsection{Conclusion}

This paper seeks to contribute to the scholarly understanding of the mechanism behind the plea bargaining process. As academics have begun to study this institution, divergent beliefs have developed. Economists largely argue that plea bargaining occurs in the shadow of the trial, where the trial sentence is treated as the default outcome, and defendants are rewarded with a plea discount for sparing the prosecutor the costs of trial. Criminologists and legal scholars, on the other hand, question the validity of this conceptual framework, arguing that structural and psychological factors drive a wedge between expected trial outcomes and the plea bargaining process, leaving the two essentially unrelated. Using a quasi-natural experiment, we empirically test the accuracy of the bedrock model using case level data.

Disentangling the plea bargaining process is difficult. Selection effects and unobservable variables are prevalent. We believe our empirical investigation contributes significantly to the conversation by utilizing a novel identification strategy that relies on a plausibly exogenous event affecting the jury pool - law enforcement officer deaths. The results offer strong support for the bargaining in the shadow of trial framework. Namely, those cases that were in process at the time a law enforcement official was killed in the line of duty, within the same county, face a reduced plea discount of about $18 \%$ across all cases, with a larger reduction for serious crimes. To determine if our ex ante assumption that this acts by altering the beliefs of the probability of conviction at trial, we use additional measures of our death variable to capture what we argue supports the salience of the death to members of the community. For this, we use Google Trends search information to differentiate between those deaths that were more salient comparatively, along with separating gunrelated deaths from non-gun-related deaths, identifying cases closer to their trial date from further away, and differentiating deaths with road dedications for the fallen officers from those without the dedications. Also, suggestive results illustrate that the effects are not present for bench trials, where jurors are not used. These results are consistent with the hypothesis that the law enforcement deaths influence the jury pool, affecting trial conviction probabilities that filter down to the plea bargaining process through reduced plea discounts.

What is important is that not only do the deaths of law enforcement officials lead to harsh sanctioning, but the gap between sanctions arising from trial convictions and guilty pleas shrinks. This is the finding that supports the bargaining in the shadow of the trial framework, as this plea discount should be determined primarily by the probability the jury convicts, which we argue is affected by the death event.

In addition to contributing to the sentencing literature, we provide empirical support for the applied theoretical research on plea bargaining. It is appropriate to consider the default outcome in the bargaining to be the expected outcome at trial. For example, Bjerk (2007) incorporates how the sorting mechanism changes the jury's beliefs about guilty or innocence and explores how this feeds back to the plea bargaining process. That participants respond to the change in the jury's beliefs receives justification in our findings. Our results do not, though, weigh in on whether the asymmetric information framework, pioneered by Reinganum (1988), or the noisy beliefs model of Priest and Klein (1984), is a more accurate depiction of plea bargaining. Furthermore, our results do not imply that principal-agent problems, pretrial detention, risk and loss aversion, or other cognitive limitations

and behavioral biases do not matter. What our results suggest is that these other considerations are not so strong as to negate the relationship between the expected trial outcomes and the plea 
discount.

We provide an important test of the validity of the bargaining in the shadow of the trial environment. We are unable, however, to test the accuracy of the findings of others who have asked about the plea discount. For example, as previously discussed, Bushway and Redlich (2012) show a substantial variation in outcomes across individuals. Our identification strategy only allows us to estimate an average treatment effect. Bushway et al. (2014) report a nonlinear relationship between the agreed to plea bargain, $b$, and the expected sanction, ps. Without the ability to separately estimate $p$ we cannot test their findings.

Also left unexplored is the relationship between the evidence the prosecutor has against the accused and the plea offers made. Being able to measure the evidence available would allow direct estimation of the conviction probability. This would be valuable to assess which types of cases move, at the margin, to the courtroom and which see important changes in the plea offers. There is no reason to expect a systematic relationship between evidence availability and the quasi-natural experiment explored here, though. Hence, its non-availability should not threaten our identification strategy's validity. Future work should ideally incorporate the role of evidence.

It is worth pointing out that the bargaining in the shadow of the trial framework does not require the conviction probability to change. The framework also suggests that changes in the sentence handed down by the judge should be incorporated into a defendant's willingness to accept a plea. It is our identification strategy that exploits a change in $p$.

Our work points to an additional extralegal factor influencing sentences. The occurrence of a law enforcement official's death has nothing to do with the harm caused by the crime perpetuated by the defendant or his/her culpability. Thus, our work relates to extralegal factors influencing judicial behavior such as rulings correlated with lunch breaks (Danziger, Levav, \& Avnaim-Pesso, 2011), autocorrelation in asylum decisions (Chen, Moskowitz, \& Shue, 2016), or whether the state's college football team was victorious (Eren \& Mocan, 2018). Specifically, we related to the small literature on extralegal factors influencing jury outcomes such as television coverage of violence (Philippe \& Ouss, 2018) or racial and economic composition of the jury pool (Helland \& Tabarrok, 2003).

Finally, we believe a worthwhile policy discussion in the future is whether regulation and external monitoring are needed. Given the enormous prison population in the U.S. and well documented disparities in outcomes (Mustard, 2001), it is responsible to ask whether the relatively unregulated

plea bargaining mechanism is contributing to excessive incarceration. This broader question of potential welfare-improving interventions is beyond the scope of our present study, but we hope that our ability to document the validity of the conceptual framework will prove useful in these discussions.

\subsection{Appendix}

\subsubsection{Data}

In this section, we provide additional information on the data and data cleaning process.

\section{Police Deaths}

Figure 2.8 depicts a time-series of the deaths. 
Figure 2.8: LEO Deaths in Florida

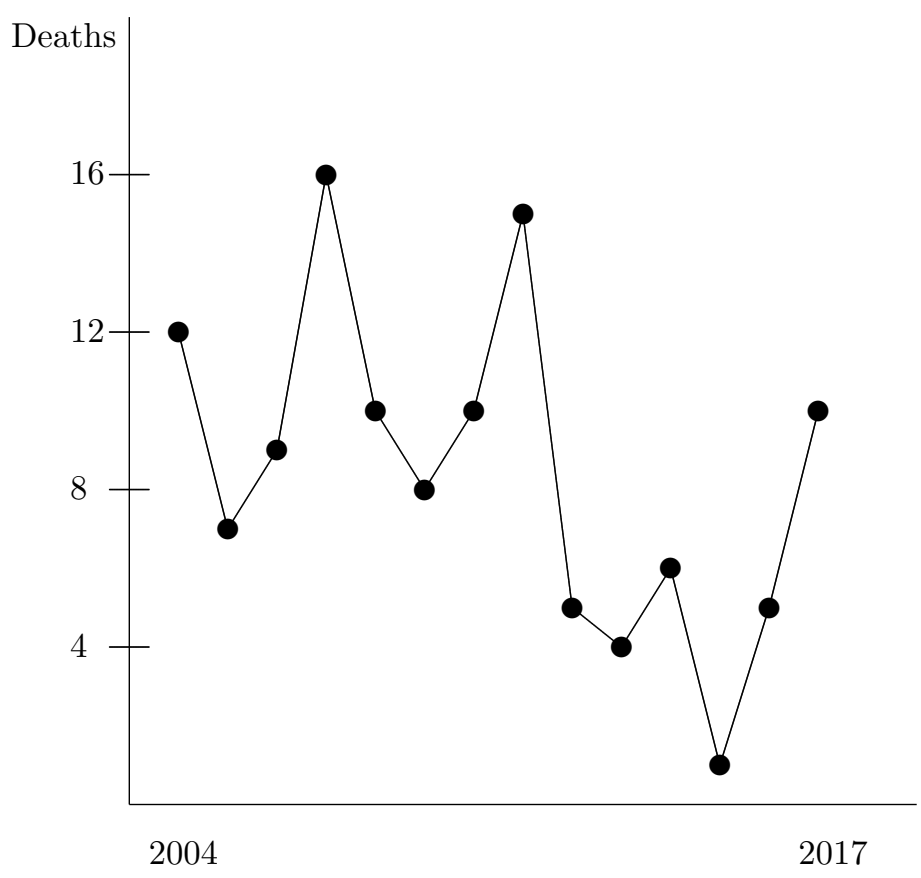

Each data point represents the number of law enforcement officials who died in the line of duty in the state in that year.

As one can see, the deaths of law enforcement officials in the line of duty is spread out temporally. There is at least one death in every year of our study's time frame, reaching a peak of 16 deaths in 2007. This dispersion across time is valuable for estimating the impact as it will allow us to separate the unfortunate events from other time-varying changes (e.g., macroeconomic fluctuations) using time fixed effects.

Figure 2.9 depicts graphically the spatial dispersion of deaths. Counties in black are those with five or more deaths within the sample period. There are six counties with more than five deaths in the sample time period; Broward (\# = 13), Dade (12), Orange (12), Hillsborough (8), Polk (8), and Volusia (6). On the other hand, there are seven counties with only one death. The counties in white $(\#=31)$ have been fortunate enough not to have a death occur between 2004 and 2017. Thus, there is variation in frequency across counties as well.

Deaths are spatially distributed, occurring in all areas of the state. Obviously, the heavily populated, urban areas (Miami, Tampa, Orlando) see more deaths, but the incidents occur across the entire state. This is valuable for our identification strategy as it allows us to disentangle the incidents from other time-invariant characteristics of each county using county fixed effects. Specifically, all specifications in the main text use County x Year fixed effects along with Month of Year fixed effects.

The concern of when and where the deaths occur can be illustrated. Figure 2.8 showed the number of deaths each year. As it illustrates, there is a non-zero number of deaths each year with non-trivial variation in the number by year. Table 2.16 is more direct as it focuses on the proportion of cases disposed that are treated each year. 
Figure 2.9: LEO Deaths Across the State

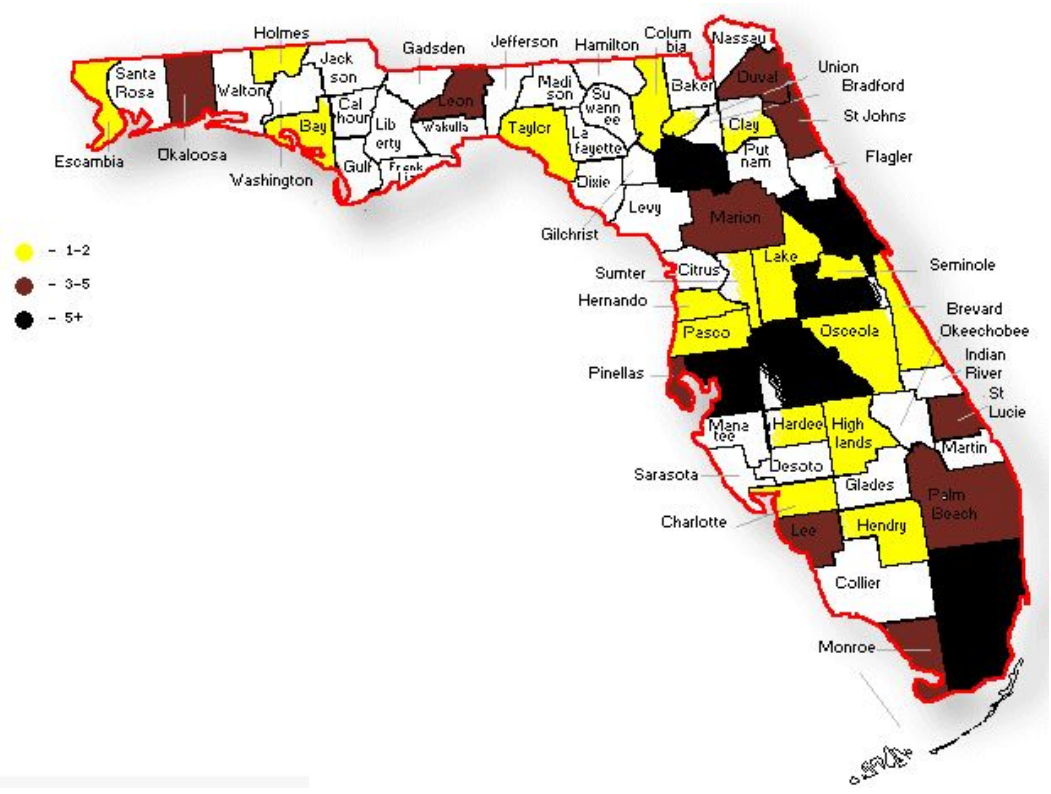

The black counties are those with five or more deaths over the time period. The blue counties are those with two, three, or four deaths. The green counties are those with one death. The counties in white did not have any death during the time period.

Table 2.16: Treatment Time Series

\begin{tabular}{llll}
\hline \hline Year & $\begin{array}{l}\text { Prop. of } \\
\text { obs. treated }\end{array}$ & Year & $\begin{array}{l}\text { Prop. of } \\
\text { obs. treated }\end{array}$ \\
\hline 2004 & $18.05 \%$ & 2011 & $15.43 \%$ \\
2005 & $15.93 \%$ & 2012 & $10.82 \%$ \\
2006 & $18.36 \%$ & 2013 & $8.44 \%$ \\
2007 & $22.36 \%$ & 2014 & $6.68 \%$ \\
2008 & $14.55 \%$ & 2015 & $4.37 \%$ \\
2009 & $15.69 \%$ & 2016 & $6.78 \%$ \\
2010 & $23.00 \%$ & 2017 & $7.57 \%$ \\
\hline \hline
\end{tabular}

All cases with at least one conviction included (dropping those with all counts dismissed or with a trial acquittal). 


\section{Data from Florida Criminal Justice}

Within this supplemental appendix, we describe the data cleaning process. To keep clarity in the steps, we will explain the data cleaning process as it appeared within the data set. That is, we will start with the basic phase, then move to the initial phase, prosecutor phase, court phase, and then finally the sentencing phase. After discussing each phase independently, we will then discuss the further steps taken to reach the final data set used in the paper.

Raw Data

The raw data set we receive from the Florida Office of the State Court Administrator includes 21,218,893 charges. These constitute all counts against all individuals with an arrest. We then group each of these charges into one observation for each case. That is, we group our raw data set of charges on the court docket number, which is unique for each court docket. This grouping gives us $12,651,219$ cases.

Basic Phase

To begin, we separate out the observations that have a special message as defined in the data. These special messages include appellate action, expunged, sealed, and "not applicable". We remove the observations that have any charges that included a special message other than not applicable. For appellate action, our reason from removing them is that if the defendant was successful in their appeal, the information for the original case is overwritten and replaced with the new details for the appellate case. Therefore, the dates provided do not accurately reflect the initial trial. If the data has a special message of expunged, then the information is not applicable for the case. We do not have any information on when this charge was expunged, so thus we must delete the observations. Lastly, we remove charges that were sealed because, again, we do not have full information on the case.

Within this phase, we have information on demographics including the defendant's birth month and birth year. We use these two variables to create the birthday. Since we do not have information on the day of the month, we define each person as having a birthday on the $15^{\text {th }}$ of the month they were born. Charging information also exists within this phase. For charging information, we use the sequence number. This sequence number is uniquely assigned to each charge within the docket. This allows us to count the number of charges that were filed against the defendant throughout the life of the case.

Initial Phase

The initial phase includes all of the information from the formal booking of the defendant. This is the information that is filed by the arresting officer. From this, we have the arrest date, charge level, and charge degree. The arrest date is used with the birth date (as defined in the previous section) to create a variable that reflects the age of the defendant when they were arrested. We transform this variable to only represent the year of their age (i.e. 42 years old).

We begin cleaning this data set by defining what level of charge was present for each charge filed. For our purposes, we only use felonies in our analysis. So we create an indicator for if the charge was a felony. Additionally, we use information on the charge degree to separate out the severity of the felony charges. Felonies have five separate charge degrees in the state of Florida. We will describe them in descending order of severity.

The points mentioned in this paragraph are used for creating the charge we designate as being the maximum charge for that particular docket. First, the most severe felony is a capital offense. We 
assigned it a value of 100. The second most severe is a felony with a sentence of life imprisonment. This is assigned a value of 50. Third, the state of Florida designates two tiers of first-degree offenses. One of these is a first-degree felony punishable by life imprisonment, which we assign a value of 40 points. The other is a first-degree felony with no special qualifiers, this is assigned a value of 30. Finally, we can have a second- or third-degree felony, which are assigned 20 and 10 points, respectively.

At this point, we now have a charge severity measurement for each charge within a docket. We then use this point variable to create an indicator variable for the charge from which this most severe ranking originates. This variable is going to be used later in assigning chapter controls for the most severe charge that was present throughout the life of the case.

\section{Prosecutor Phase}

After the initial phase, we move forward to the prosecutor phase. Within this phase, we have the charges that were present at the beginning of this phase. These charges may be the same as the charges in the initial phase, though they may be different. We follow a similar process to the one described in the previous section to create a charge severity variable for the prosecutor phase.

Also, within this section is the representation for the defendant. We have several indicators for the type of defense attorney the defendant had. They could have private counsel, public counsel, court-appointed counsel, self-counsel, or a final category defined as "other" in the raw data. We assign each of these to separate variables to include as controls within our analysis. Last, we also have the date for the prosecutor phase. The date we use is the date the prosecutor filed his/her final action. This can also be the date of a grand jury hearing. From here, we have the first glimpse into whether or not any charges were dropped. There is an indicator for if each charge was dropped or administratively dismissed.

\section{Court Phase}

Similar to the previous two sections, we use the charge level and degree present at this phase to create a charge severity variable. The process used for this is the same as the previous two sections. Also within this phase is the action taken in the court phase. This provides a designator for each charge about if it was acquitted, dismissed, or guilty. We then also have trial type. Trial type is broken down into three possible categories. A defendant can have no trial, a jury trial, or a bench trial. If any charge within a docket had a jury or bench trial, we code that as having a trial, and thus separate the guilty convictions into those with no trial (guilty pleas) or those with a trial.

Sentencing Phase

For each charge within a docket, we have the sentence separated into a lower bound and an upper bound. This gives us the bounds of the sentence. We transform both the lower and upper bound of each sentence for each charge into their duration in months. We also have information about where the person is to carry out their sentence: Prison, jail, or some other type of confinement. We then take the maximum of the upper bound sentences across all charges for a single docket and use that for our sentence length variable. We then use the incarceration information to separate out those cases that were sentenced to prison and those that were not. If a defendant was not sentence to prison, then we define them as having zero months of incarceration.

Lastly, within this section we have special sentence provisions. These provisions are what we use to control for potential criminal history, since we do not have the information directly. There are three separate types of prior offender designations we use. These are ajudged to be a habitual 
offender, sentenced as a habitual offender, ajudged to be a habitual violent offender, sentenced as a habitual violent offender, or ajudged to be or sentenced as a career violent offender.

Cleaning

First, we begin by dropping any dockets that do not have any felonies present at any point throughout the life of their case. This removes 8,176,644 dockets, leaving us with a data set of $4,474,575$ felony-including dockets. Then, since dates are crucial to our identification strategy, we must remove observations that do not have this information or have erroneously coded information. First, we remove any observation that has an arrest year that is prior to $2004 .{ }^{37}$ This removed 887,773 dockets, leaving us with a data set of $3,586,802$ observations. Then we remove dockets that have a prosecutor final decision year that was before 2004. This removes 15,045 observations (so that $3,571,757$ remain). Then, some cases have missing information for the prosecutor year. Again, this is necessary information. We thus delete these 76,898 observations to give us a data set of $3,494,859$ observations.

Then, we move into deleting observations related to dismissed cases. There are many ways a case can be dismissed within the raw data set. We describe the process we used to remove dismissed cases from our data set. First, the set of variables we use for dismissed are: Dismissed via speedy trial, dropped by prosecutor, no bill found by grand jury, waived to adult court, dismissed by prosecutor or court, diversion, no action taken by the prosecutor/grand jury, transferred to another court, nolle prosequi, consolidated into a different docket, dismissed upon payment of restitution, declared unable to stand trial, withheld adjudication, venue change to be heard in another court, extradited, dismissed upon estreature of a bond, and if the court declined to adjudicate. For each of these dismissal designations, we create an indicator variable for if the total number of charges with each of these designations is equal to the total number of counts within the docket. If so, we consider the case to be dismissed and drop them from our data set. Doing so removes 1,489,142 dockets, with $2,005,717$ remaining.

Next, we add all of these charges together, and test whether or not the total of these possibilities equals the total number of counts within the docket. If so, we remove them from our data set. This removes 282,465 observations, giving us a data set of 1,723,252 felony dockets.

We then begin adding these possibilities in three distinct combinations. To begin, we group together speedy trial, no bill, administratively dismissed by either court or prosecutor, no bill found by grand jury, transfer to another court, consolidated within another docket, and dismissed upon payment of restitution. Doing so removed 1,434 cases, with 1,721,818 dockets remaining after this step. The next two combinations look distinctly at the prosecutor and court phase, respectively. We add together all of the dismissal possibilities within the prosecutor phase and compare that to the total number of counts within the docket. If these two numbers equal, we remove them from our data set of felony dockets. This removes 9,654 additional dockets. We then follow a similar strategy for all dismissal possibilities within the court phase. This step removes 912 observations. Combining the total number of dockets removed from these two steps gives us 10,515 dockets that we drop. Our data set at this point has 1,711,303 felony dockets where a conviction is pursued.

Moving forward, we then adjust dockets based on the age of the defendant when they were arrested. We remove any cases where the age of the defendant was under 14 at the time of arrest.

\footnotetext{
${ }^{37}$ We do this since our data set is only supposed to include information from 2004-17, and were instructed that information prior to this year will be coded incorrectly.
} 
We choose this number because in Florida, anyone under the age of 14 is not allowed to be charged as an adult. This drops 585 cases, with 1,710,718 remaining. Next, there are some cases that did not have a birthday coded. Therefore, we drop those 1,137 observations. After cleaning for age at arrest, we are left with 1,709,581 criminal, felony dockets.

As mentioned previously in the Basic Phase section, we have an indicator for if there were any special messages about the docket. To deal with this, we only keep the dockets that do not have a special message attached to them. Doing so removes 28,312 observations. We now take 1,681,269 dockets into the next step.

We then remove cases that were either life sentences or death sentences. Doing so removes 3,267 and 107 observations, respectively. Lastly, we need to correct for the erroneous codings of sentences within our data set. Initially, the raw data set includes many observations with multiple 8's. This is the administrative code used for "not applicable" within the raw data. These are initially transformed to be equal to zero. However, erroneous codings still exist within our data set. We then need to make corrections so that we do not include non-sentence measurements as a sentence. It is common in the sentencing literature to choose a hard upper bound to the sentences. In the analysis in the main text we make our cutoff at 1200 months, which translates to over 100 years. We delete, as potential errors, those cases that have a conviction resulting in more than 1400 months. Removing these 79,463 observations gives us a data set of 1,598,432 felony dockets. As a final step, we drop all observations arising before 2004. In 2004, statewide reporting went into effect. Previously, only a subset of counties reported. Doing this reduces our sample to $1,416,540$ observations. This is the number of observations that are used in the main text. ${ }^{38}$

\subsubsection{Additional Results}

In this section of the supplemental appendix, numerous additional results are provided. This includes further results from the permutation tests and parallel trends test presented in the paper. Also, we conduct a sensitivity analysis to illustrate that the main message provided in the text is not sensitive to the empirical techniques used. This includes both explorations of the plea discount along with the trail rate.

The hypothesis we present argues the probability that the jury convicts increases when there is a death. Figure 2.10 considers only the sub-sample of cases that went to a trial. The proportion resulting in a conviction is presented.

Trial convictions are more frequent and acquittals relatively rare for those cases which are treated with a law enforcement official's death. The acquittal rate decreases by $5.9 \%$, which is significant at the $5 \%$ level. While there are obviously important omitted variables to be concerned about which can, in part, explain these observations, it is at least suggestive that deaths lead to increased conviction probabilities and harsher sentences.

Also, the text refers to the results when the sample is limited to only non-serious felony crimes. Those results are presented in Table 2.17.

The difference-in-difference coefficient is positive and statistically significant, but slightly smaller. Using the first column, the plea discount for less-serious felonies is $49 \%$ without the death, and $41 \%$

\footnotetext{
${ }^{38}$ Except that throughout we frequently consider the sub-sample of serious felonies. In addition, the results in Section 4 of the main text consider only those cases where a conviction arises since the focus is on sentencing. Thus, cases that go to trial and receive an acquittal (no conviction on any charge) are removed.
} 
Table 2.17: Less-Serious Crimes

\begin{tabular}{|c|c|c|c|}
\hline $\begin{array}{l}\text { Dependant variable: } \\
\text { Model: }\end{array}$ & $\begin{array}{l}\ln (\text { sentence }) \\
\text { OLS } \\
(1)\end{array}$ & $\begin{array}{l}\text { IHS(sentence) } \\
\text { OLS } \\
(2)\end{array}$ & $\begin{array}{l}\ln (\text { sentence }) \\
\text { Tobit } \\
(3)\end{array}$ \\
\hline Plea Bargain & $\begin{array}{l}-0.682^{* * *} \\
(0.046)\end{array}$ & $\begin{array}{l}-0.6911^{* * *} \\
(0.086)\end{array}$ & $\begin{array}{l}-0.800^{* * *} \\
(0.057)\end{array}$ \\
\hline Death & $\begin{array}{l}0.146 * \\
(0.081)\end{array}$ & $\begin{array}{l}0.133 \\
(0.086)\end{array}$ & $\begin{array}{l}0.204 * \\
(0.110)\end{array}$ \\
\hline Death x Plea Bargain & $\begin{array}{l}0.157 * * * \\
(0.068)\end{array}$ & $\begin{array}{l}0.173^{* * * *} \\
(0.074)\end{array}$ & $\begin{array}{l}0.206 * * \\
(0.085)\end{array}$ \\
\hline Demographic Controls? & Yes & Yes & Yes \\
\hline Crime Controls? & Yes & Yes & Yes \\
\hline Habitual Offender Controls? & Yes & Yes & Yes \\
\hline Type of Counsel Controls? & Yes & Yes & Yes \\
\hline County x Year FEs? & Yes & Yes & Yes \\
\hline Month of Year FEs? & Yes & Yes & Yes \\
\hline$R^{2}$ & 0.152 & 0.142 & 0.045 \\
\hline $\mathrm{AIC}$ & $3.1 \times 10^{6}$ & $3.4 \times 10^{6}$ & $3.0 \times 10^{6}$ \\
\hline
\end{tabular}

All cases with at least one conviction included (dropping those with all counts dismissed or with a trial acquittal) and only non-serious crimes; $N=904,788$.

The dependent variables mean is 14.513 .

The control variables are the same as was used in Table 2.5

Standard errors clustered by County x Year presented in parentheses (865 clusters); *** 1\%, ** 5\%, * $10 \%$ level of significance.

Tobit model is left-censored at zero (326,150 censored observations and 578,638 uncensored). 
Figure 2.10: Does Trial Convictions Correspond to LEO Deaths?

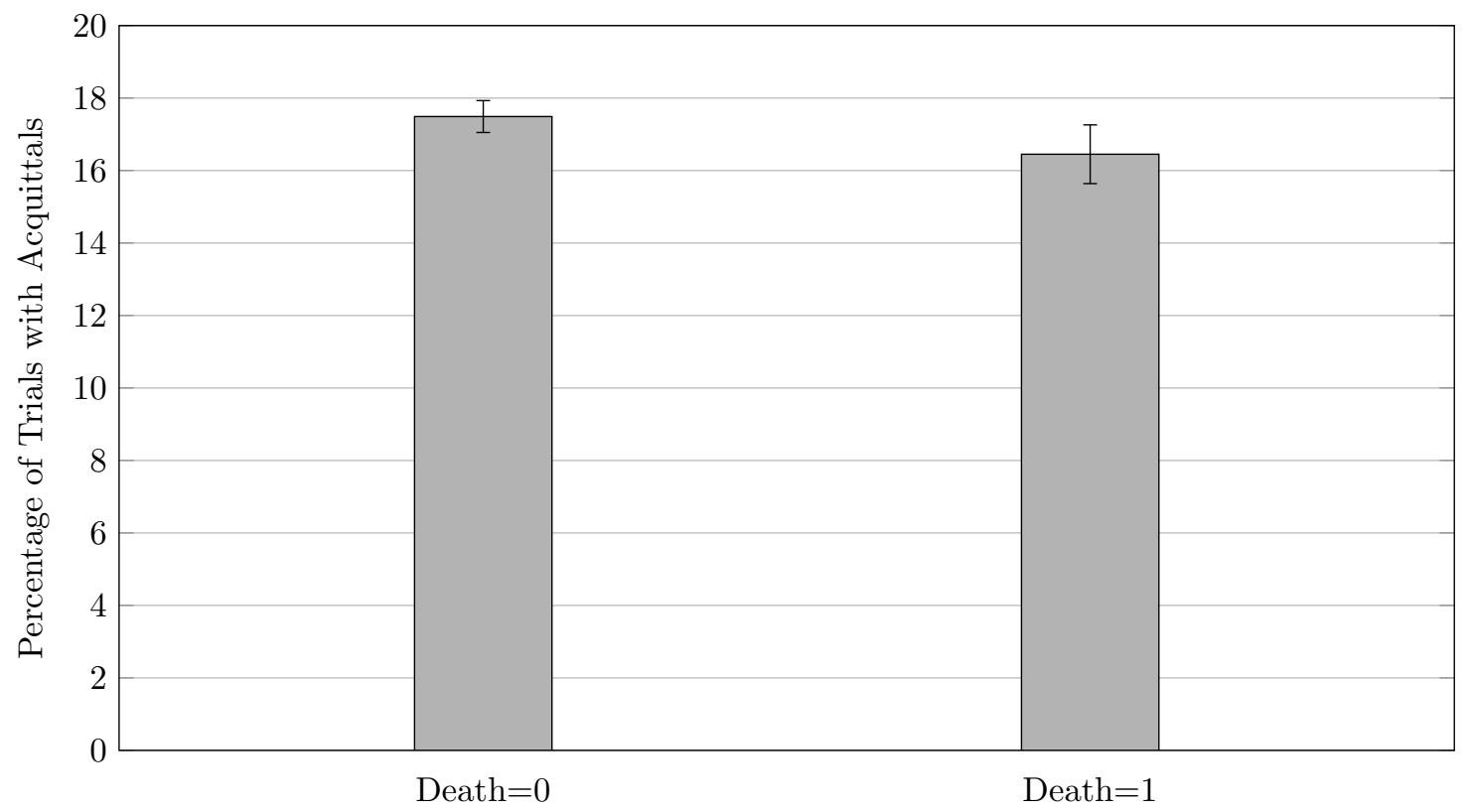

Confidence intervals depicted by the black lines.

A two-sided, difference-in-means t-test (allowing for unequal variances) has $|t|=2.20 ; p=0.028$.

with it. Thus, the plea discount drops by $17.4 \%$, which is less than the $23.8 \%$ reduction estimated previously for the serious crimes. Importantly, it is not a (statistically) zero effect. Thus, the deaths' effects are felt across all types of felony crimes.

Figure 4 in the main text presented the results from a quantile regression. Those estimates are presented in Table 2.18 here.

Figure 4 depicts the results from the serious crimes subsample, provided here in the bottom panel. As one can see, the difference-in-difference coefficient is significant at the $1 \%$ level for each decile. Results using the full data set are provided in the top panel. Similar effects exist.

Regarding the plea discount, as stated in the text, we do not test the divergence in the time trend after the incidents because our identification strategy does not predict a persistent trend shift. The values of the outcome variables prior to the shock to those after it for the treated counties is discussed in the text. Table 2.19 provides the comparison mentioned.

The mean and median sentences grow in the twelve months after the death and the proportion incarcerated increases for those counties treated with the death. In fact, in the control counties, slight reductions are measured. The proportion of convicted who avoid incarceration shrinks substantially after the death. Again, this effect is not present for the control counties. Thus, not only do the treated and control counties follow parallel trends prior to the death of a law enforcement official, but a jump in sentencing harshness arises in the treated counties in the months following the incident.

Also, in the main text an analysis of parallel trends was conducted (Section 2.4.2). There, we provide figures of the coefficient for each month in the pre-death period interacted with the indicator variable for whether the case was the result of a guilty plea (Figure 2.10). Here, Table 2.20 provides the formal results. Only the coefficients from the interaction terms (the dummies for months prior times the treatment indicator variable) are presented. 
Table 2.18: Quantile Regression

\begin{tabular}{|c|c|c|c|c|c|c|}
\hline Full data set & $\overline{40}$ & 50 & 60 & 70 & 80 & 90 \\
\hline Plea Bargain & $0.037^{* * *}$ & $0.015 * * *$ & -0.001 & $-0.016^{* * *}$ & $-0.036^{* * *}$ & $-0.071^{* * *}$ \\
\hline & $(0.005)$ & $(0.010)$ & $(0.003)$ & $(0.004)$ & $(0.003)$ & $(0.005)$ \\
\hline Death & $\begin{array}{l}0.038 \text { *** } \\
(0.007)\end{array}$ & $\begin{array}{l}0.003 \\
(0.006)\end{array}$ & $\begin{array}{l}-0.030 \text { *** } \\
(0.005)\end{array}$ & $\begin{array}{l}-0.063^{* * *} \\
(0.007)\end{array}$ & $\begin{array}{l}-0.1011^{* * *} \\
(0.007)\end{array}$ & $\begin{array}{l}-0.160 * * * \\
(0.009)\end{array}$ \\
\hline Death x Plea Bargain & $\begin{array}{l}-0.084 \text { *** } \\
(0.007)\end{array}$ & $\begin{array}{l}-0.056 \text { *** } \\
(0.006)\end{array}$ & $\begin{array}{l}-0.027^{* * *} \\
(0.005)\end{array}$ & $\begin{array}{l}-0.009 \\
(0.007)\end{array}$ & $\begin{array}{l}0.010 \\
(0.007)\end{array}$ & $\begin{array}{l}0.041 \text { *** } \\
(0.009)\end{array}$ \\
\hline$R^{2}$ & 0.007 & 0.009 & 0.0011 & 0.0019 & 0.0030 & 0.0055 \\
\hline \multicolumn{7}{|l|}{ Serious felonies only } \\
\hline Plea Bargain & $\begin{array}{l}-0.076 \text { *** } \\
(0.006)\end{array}$ & $\begin{array}{l}-0.070 \text { *** } \\
(0.006)\end{array}$ & $\begin{array}{l}-0.067 \text { *** } \\
(0.006)\end{array}$ & $\begin{array}{l}-0.068^{* * *} \\
(0.006)\end{array}$ & $\begin{array}{l}-0.080 \text { *** } \\
(0.005)\end{array}$ & $\begin{array}{l}-0.091 \text { ** } \\
(0.008)\end{array}$ \\
\hline Death & $\begin{array}{l}0.036 \text { ** } \\
(0.014)\end{array}$ & $\begin{array}{l}0.040 \text { *** } \\
(0.011)\end{array}$ & $\begin{array}{l}0.029 * * \\
(0.012)\end{array}$ & $\begin{array}{l}0.016 \\
(0.012)\end{array}$ & $\begin{array}{l}-0.003 \\
(0.012)\end{array}$ & $\begin{array}{l}-0.029 * * * \\
(0.010)\end{array}$ \\
\hline Death x Plea Bargain & $\begin{array}{l}0.039 * * * \\
(0.015)\end{array}$ & $\begin{array}{l}0.029 \text { *** } \\
(0.011)\end{array}$ & $\begin{array}{l}0.033 \text { *** } \\
(0.012)\end{array}$ & $\begin{array}{l}0.035 \text { *** } \\
(0.012)\end{array}$ & $\begin{array}{l}0.047 * * * \\
(0.012)\end{array}$ & $\begin{array}{l}0.043 \text { *** } \\
(0.009)\end{array}$ \\
\hline$R^{2}$ & 0.0019 & 0.0020 & 0.0017 & 0.0014 & 0.0012 & 0.0006 \\
\hline
\end{tabular}

Standard errors reported in parentheses; *** $1 \%, * * 5 \%, * 10 \%$ level of significance.

$N=1,566,892$ in the top panel and $N=608,622$ in the bottom panel.

A two-step estimation is done. First, the specification, as in the first column of Table 5, without Death, Plea Bargain, and Death x Plea Bargain is estimated. The residuals are saved and used as the dependent variable in the quantile regression with only these three as explanatory variables.

Table 2.19: Treatment Effect

\begin{tabular}{lllll}
\hline \hline Outcome variable & & Post $=0$ & Post $=1$ & \% change \\
\hline Mean Sentence & Treated & 18.306 & 18.471 & $+0.90 \%$ \\
& Control & 19.277 & 19.093 & $-0.96 \%$ \\
& & & & \\
Median Sentence & Treated & 8.236 & 8.619 & $+4.64 \%$ \\
& Control & 9.543 & 9.364 & $-1.88 \%$ \\
\multirow{2}{*}{ Proportion Not Incarcerated } & & & \\
& Treated & 0.2446 & 0.2333 & $-4.61 \%$ \\
& Control & 0.2537 & 0.2548 & $+0.40 \%$ \\
\hline \hline
\end{tabular}

The first column presents the average value for the outcome variable in the 12 months prior to the treatment effect for those treated counties. The second column presents the average value for the outcome variable in the month of and the 12 months after the treatment effect for those treated counties. 
Table 2.20: Parallel Trends Test

\begin{tabular}{|c|c|c|c|}
\hline & $\begin{array}{l}\text { Mean } \\
\text { Sentence }\end{array}$ & $\begin{array}{l}\text { Median } \\
\text { Sentence }\end{array}$ & $\begin{array}{l}\text { Prop. Not } \\
\text { Incarcerated }\end{array}$ \\
\hline-11 & $\begin{array}{l}0.603 \\
(0.672)\end{array}$ & $\begin{array}{l}-0.728 \\
(0.613)\end{array}$ & $\begin{array}{l}0.035 * * \\
(0.015)\end{array}$ \\
\hline-10 & $\begin{array}{l}2.700 * * * \\
(1.214)\end{array}$ & $\begin{array}{l}1.230 \\
(1.400)\end{array}$ & $\begin{array}{l}0.006 \\
(0.021)\end{array}$ \\
\hline-9 & $\begin{array}{l}1.111 \\
(0.765)\end{array}$ & $\begin{array}{l}-0.146 \\
(0.693)\end{array}$ & $\begin{array}{l}0.018 \\
(0.018)\end{array}$ \\
\hline-8 & $\begin{array}{l}0.716 \\
(0.979)\end{array}$ & $\begin{array}{l}-0.296 \\
(0.921)\end{array}$ & $\begin{array}{l}0.016 \\
(0.016)\end{array}$ \\
\hline-7 & $\begin{array}{l}1.940 * \\
(1.017)\end{array}$ & $\begin{array}{l}-0.273 \\
(0.820)\end{array}$ & $\begin{array}{l}0.037 * \\
(0.019)\end{array}$ \\
\hline-6 & $\begin{array}{l}2.364 * \\
(1.325)\end{array}$ & $\begin{array}{l}1.466 \\
(1.100)\end{array}$ & $\begin{array}{l}0.012 \\
(0.018)\end{array}$ \\
\hline-5 & $\begin{array}{l}0.917 \\
(1.544)\end{array}$ & $\begin{array}{l}-0.633 \\
(0.699)\end{array}$ & $\begin{array}{l}0.030 * \\
(0.018)\end{array}$ \\
\hline-4 & $\begin{array}{l}1.286 \\
(0.792)\end{array}$ & $\begin{array}{l}0.513 \\
(0.644)\end{array}$ & $\begin{array}{l}-0.001 \\
(0.010)\end{array}$ \\
\hline-3 & $\begin{array}{l}2.399^{* *} \\
(1.082)\end{array}$ & $\begin{array}{l}0.115 \\
(0.678)\end{array}$ & $\begin{array}{l}0.018^{* *} \\
(0.008)\end{array}$ \\
\hline-2 & $\begin{array}{l}2.236 * * \\
(0.877)\end{array}$ & $\begin{array}{l}0.112 \\
(0.592)\end{array}$ & $\begin{array}{l}0.017 \\
(0.017)\end{array}$ \\
\hline-1 & $\begin{array}{l}1.199 \\
(1.230)\end{array}$ & $\begin{array}{l}0.710 \\
(0.965)\end{array}$ & $\begin{array}{l}0.009 \\
(0.020)\end{array}$ \\
\hline
\end{tabular}


Table 2.21: Permutation Test: Trial Rate

\begin{tabular}{|c|c|c|c|c|}
\hline Data set: & $\begin{array}{l}\text { full } \\
(1)\end{array}$ & & $\begin{array}{l}\text { serious } \\
(2)\end{array}$ & \\
\hline $\begin{array}{l}\text { Estimated Death: } \\
\text { (from Table 15) }\end{array}$ & $\begin{array}{l}\text { coefficient } \\
0.0198\end{array}$ & $\begin{array}{l}\mathrm{p} \text {-value } \\
2.2 \times 10^{-39}\end{array}$ & $\begin{array}{l}\text { coefficient } \\
0.0249\end{array}$ & $\begin{array}{l}\text { p-value } \\
5.4 \times 10^{-40}\end{array}$ \\
\hline \multicolumn{5}{|l|}{ Permutation Results } \\
\hline $\begin{array}{l}1^{s t} \text { percentile } \\
\text { median }\end{array}$ & $\begin{array}{l}-0.00078 \\
5.6 \times 10^{-6}\end{array}$ & $\begin{array}{l}0.00036 \\
0.32943\end{array}$ & $\begin{array}{l}-0.00143 \\
5.5 \times 10^{-6}\end{array}$ & $\begin{array}{l}0.01049 \\
0.49585\end{array}$ \\
\hline $99^{t h}$ percentile & 0.00082 & 0.98699 & 0.00150 & 0.99105 \\
\hline
\end{tabular}

Results from 1000 permutation tests replicating (1) of Table 11 for the first column and (2) of Table 11 in the second column.

\section{Permutation Test: Trial Rate}

As with the plea discount, we conduct a permutation test on the trial rate estimation to evaluate the chance that the result presented in Table 2.11 in the main text is a false positive result. Again, 1000 permutations, assigning false deaths to the data set, are created. The 1000 permutations are done twice, once for the model estimated in (1) of Table 2.11 and a second time for (2) of Table 2.11 (using only the sub-sample of serious felonies).

Table 2.21 presents the results from the permutation test. It considers whether the case was taken to trial or resulted in a guilty plea as the dependent variable.

As one can see, and as was also shown in the main text for the plea discount, the estimated coefficient is greater than what arose with these false deaths. For the full data set, every permutation resulted in a coefficient smaller than what was estimated in column (1) of Table 11. For the sample of serious crimes, only $0.2 \%$ generated a greater estimated effect. Similarly, the p-value of the true Death variable is smaller than every one of the permuted deaths estimates. Only $5.9 \%$ and $4.7 \%$ of the time does the permuted death estimation lead to a statistically significant effect of the false death (using the 0.05 level of significance convention) in the full data set and subsample of serious felonies, respectively. Thus, the effect of the law enforcement official's death on the trial rate differs from what would arise by random chance.

To illustrate, the following figure provides a histogram of the permuted Death coefficients. The solid black line is the value estimated using the actual death occurrence. Figure 2.11 provides the histogram for the subset of serious crimes. In the former, the bolded, black line denotes the estimated coefficient from the actual deaths. In the latter figure, the actual coefficient estimate is so much larger than the range of values arising from the permuted deaths that the true estimate lies off the scale.

\section{Parallel Trends: Trial Rate}

Also, the trend analysis conducted in Section 2.4.2 of the main text for the plea discount can be redone for the trial rate. Here, we use as the outcome variable the proportion of dockets in a county in a month that result in a guilty plea. We estimate equation (8) from the main text with this new outcome variable. Again, parallel trends requires $\gamma_{3}>0$. As was done previously, rather than restrict attention to a linear time trend, we use twelve indicator variables for each of the twelve 
Figure 2.11: Death Coefficient from 1000 Permutations: Serious Crimes Only

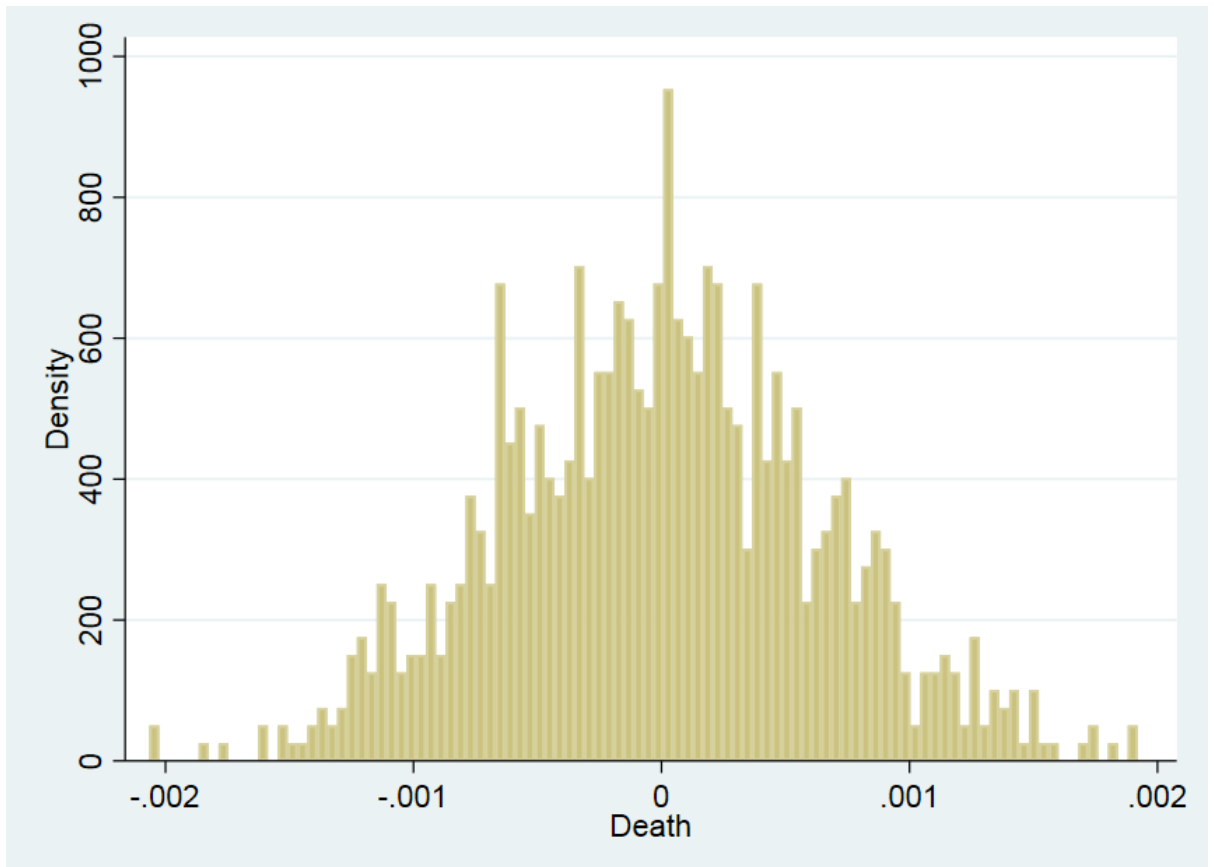

months prior to the event, and also interact them each with the treatment indicator. Figure 2.12 graphically depicts the coefficients of these interaction terms, along with their confidence intervals.

All but one of the pre-treatment trend variables has zero included within the confidence interval. Thus, we conclude that the treated counties are not following a different time trend in the months preceding the death event, relative to the control counties.

Table 2.22 presents the estimated coefficients used to construct the figure.

For the evaluation of the plea discount, the parallel trends analysis begins with the use of a linear time trend. Table 2.23 conducts a similar analysis for the trial rate. Specifically, in the county by month aggregated data, the proportion of cases that with a guilty plea is used as the dependent variable.

Clearly, restricting to a linear time trend, there is not a differential build-up in cases being taken to trial leading up to the death of the law enforcement official that can explain the results presented in the paper. Allowing for nonlinearities in Table 2.22 confirms this observation as well.

\section{Sensitivity Analysis}

The sensitivity analysis is divided into an evaluation of the results related to the size of the plea discount and the impact on the trial rate.

Sensitivity Analysis: Plea Discount

First, the main text mentions the lack of sensitivity of the results to the use of different augmentations of the dependent variable. This was discussed in a footnote of the text. A classic, common problem when log transforming a dependent variable is how to handle the presence of zeros. In the main body, we re-code all sanctions of less than one month as having one month of incarceration. Rather, $\ln (0)=0$ and $\ln (x)=0$ for $x \in(0,1)$. Three alternatives are considered here. First, zero- 
Figure 2.12: Test of Parallel Trends: Trial Rate

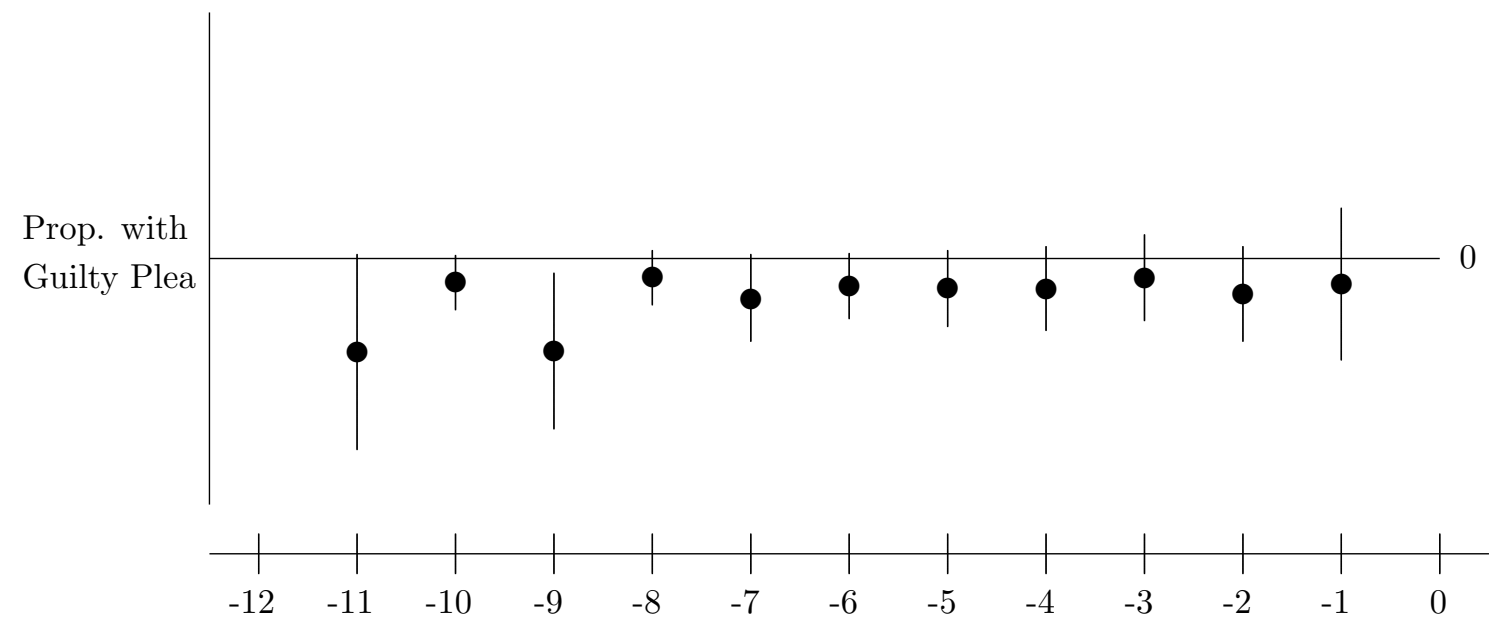

Table 2.22: Parallel Trends Test: Trial Rate

\begin{tabular}{llll}
\hline \hline Time & \multicolumn{3}{c}{ Time } \\
\hline-12 & - & -6 & $-0.0057^{*}$ \\
& & & $(0.0033)$ \\
& & & \\
-11 & $-0.0191^{*}$ & -5 & -0.0061 \\
& $(0.0099)$ & & $(0.0039)$ \\
& & & -0.0062 \\
-10 & $-0.0049^{* *}$ & -4 & $(0.0042)$ \\
& $(0.0027)$ & & \\
& & & -0.0040 \\
-9 & $-0.0189 * *$ & -3 & $(0.0043)$ \\
& $(0.0079)$ & & -0.0073 \\
& & & \\
-8 & -0.0039 & -2 & $0.0048)$ \\
& $(0.0028)$ & & -0.0052 \\
& & & $(0.0077)$ \\
\hline
\end{tabular}

Dependent variable is the proportion of cases plea bargained. $R^{2}=0.0008 ;$ AIC $=-2.1 \times 10^{5} ; N=77,847$

Table 2.23: Test of Parallel Trends: Trial Rate

\begin{tabular}{llll}
\hline \hline & $\begin{array}{l}\text { Without any } \\
\text { controls } \\
(1)\end{array}$ & $\begin{array}{l}\text { With County } \\
\text { FEs }\end{array}$ & $\begin{array}{l}\text { With County } \\
\text { FEs and controls } \\
(2)\end{array}$ \\
\hline Proportion with a Guilty Plea & 0.00043 & 0.00042 & 0.00044 \\
& $(0.00058)$ & $(0.00057)$ & $(0.00059)$ \\
& $\{0.461\}$ & $\{0.461\}$ & $\{0.458\}$ \\
\hline \hline
\end{tabular}

Dependent variable is the proportion of cases plea bargained. $N=77,847$ 
Table 2.24: Alternative Adjustments to the Dependent Variable

\begin{tabular}{|c|c|c|c|c|c|c|}
\hline $\begin{array}{l}\text { Transformation: } \\
\text { Data set: }\end{array}$ & $\begin{array}{l}\begin{array}{l}0.1 \\
\text { full } \\
(1)\end{array} \\
\text { (1) }\end{array}$ & $\begin{array}{l}0.1 \\
\text { serious } \\
(2)\end{array}$ & $\begin{array}{l}0.001 \\
\text { full } \\
(3)\end{array}$ & $\begin{array}{l}0.001 \\
\text { serious } \\
(4)\end{array}$ & $\begin{array}{l}+1 \\
\text { full } \\
(5)\end{array}$ & $\begin{array}{l}+1 \\
\text { serious } \\
(6)\end{array}$ \\
\hline Plea Bargain & $\begin{array}{l}-0.554^{* * *} \\
(0.070)\end{array}$ & $\begin{array}{l}-0.678^{* * *} \\
(0.061)\end{array}$ & $\begin{array}{l}-0.390 \text { *** } \\
(0.114)\end{array}$ & $\begin{array}{l}-0.582^{\text {*** }} \\
(0.095)\end{array}$ & $\begin{array}{l}-0.550^{* * *} \\
(0.048)\end{array}$ & $\begin{array}{l}-0.610^{\text {*** }} \\
(0.043)\end{array}$ \\
\hline Death & $\begin{array}{l}0.188 * \\
(0.113)\end{array}$ & $\begin{array}{l}0.194 * \\
(0.102)\end{array}$ & $\begin{array}{l}0.154 \\
(0.181)\end{array}$ & $\begin{array}{l}0.056 \\
(0.140)\end{array}$ & $\begin{array}{l}0.195^{* *} \\
(0.081)\end{array}$ & $\begin{array}{l}0.178^{* *} \\
(0.073)\end{array}$ \\
\hline Death x Plea Bargain & $\begin{array}{l}0.224 * * \\
(0.114)\end{array}$ & $\begin{array}{l}0.205^{* *} \\
(0.088)\end{array}$ & $\begin{array}{l}0.312 * \\
(0.185)\end{array}$ & $\begin{array}{l}0.332 * * \\
(0.139)\end{array}$ & $\begin{array}{l}0.159 * * \\
(0.080)\end{array}$ & $\begin{array}{l}0.143 * * \\
(0.063)\end{array}$ \\
\hline Demographic Controls? & Yes & Yes & Yes & Yes & Yes & Yes \\
\hline Crime Controls? & Yes & Yes & Yes & Yes & Yes & Yes \\
\hline Habitual Offender Controls? & Yes & Yes & Yes & Yes & Yes & Yes \\
\hline Type of Counsel Controls? & Yes & Yes & Yes & Yes & Yes & Yes \\
\hline County x Year FEs? & Yes & Yes & Yes & Yes & Yes & Yes \\
\hline Month of Year FEs? & Yes & Yes & Yes & Yes & Yes & Yes \\
\hline$R^{2}$ & 0.128 & 0.1305 & 0.118 & 0.115 & 0.143 & 0.149 \\
\hline AIC & $2.3 \times 10^{6}$ & $6.3 \times 10^{6}$ & $2.8 \times 10^{6}$ & $7.8 \times 10^{6}$ & $1.8 \times 10^{6}$ & $4.9 \times 10^{6}$ \\
\hline
\end{tabular}

All cases with at least one conviction included (dropping those with all counts dismissed or with a trial acquittal); $N=1,410,751$ for (1), (3), (5) and $N=505,963$ for (2), (4), (6).

The dependent variable is the log of the sentence (upper bound to the top charge) with the value being transformed to be equal to 0.1 (in the first two columns) and 0.001 (in the third and fourth columns) when the untransformed value is equal to zero. The transformed variable in the final two columns adds one (regardless of its value).

The control variables are the same as was used in Table 2.5.

Standard errors clustered by County x Year presented in parentheses (865/862 clusters); *** $1 \%, * * 5 \%, * 10 \%$ level of significance.

length incarcerations can be replaced with small, but positive values. We consider 0.1 and 0.001 . Both the main result, column (1) of Table 2.5 in the main text, on the full data set, and the analysis on the subset of serious crime, column (1) of Table 2.6, are re-produced with these augmentation in Table 2.24. A third alternative is to add one to each value of the sentence length. Rather, let the dependent variable be $\ln ($ sentence +1$)$. Thus, rather than only adjust observations in the left-tail, a monotonic transformation is applied to the entire data set. Again, the two results are re-estimated.

The main result is not sensitive to the augmentation of the dependent variable. The differencein-difference coefficient remains positive and statistically significant across all specifications. The magnitude in the estimated change in the plea discount varies from one specification to the next. For example, for serious felonies, the plea discount shrinks by $23.5 \%, 49.9 \%$, and $18.3 \%$, using the three alternative augmentations, respectively. Importantly, sentences arising from plea bargains, relative to those arising from trial convictions, become more severe, as is predicted by the bargaining in the shadow of the trial framework.

As with any data set that pools observations across space across time, the choice of fixed effects and clusters for standard error calculations have the potential to affect the coefficient estimates and hypothesis testing. In Table 2.25 we reproduce the first column of Table 2.5 from the main text, but instead consider a less-saturated model with County fixed effects and Month x Year fixed effects. 
Table 2.25: County Fixed Effects and Clusters

\begin{tabular}{llll}
\hline \hline Dependent variable: & $\begin{array}{l}\ln (\text { sentence) } \\
\text { OLS } \\
\text { Model: }\end{array}$ & $\begin{array}{l}\text { IHS(sentence) } \\
\text { OLS } \\
(1)\end{array}$ & $\begin{array}{l}\ln (\text { sentence) } \\
\text { Tobit } \\
(3)\end{array}$ \\
\hline Plea Bargain & -0.652 & -0.651 & -0.739 \\
& $(0.045)^{* * *}$ & $(0.050)^{* * *}$ & $(0.056)^{* * *}$ \\
& {$[0.111]^{* * *}$} & {$[0.142]^{* * *}$} & {$[0.139]^{* * *}$} \\
& & & \\
Death & 0.144 & 0.131 & 0.169 \\
& $(0.077)^{*}$ & $(0.083)$ & $(0.099)^{*}$ \\
& {$[0.137]$} & {$[0.145]$} & {$[0.180]$} \\
Death x Plea Bargain & & & \\
& 0.148 & 0.162 & 0.195 \\
& $(0.066)^{* *}$ & $(0.073)^{* *}$ & $(0.082)^{* *}$ \\
& {$[0.083]^{*}$} & {$[0.089]^{*}$} & {$[0.097]^{* *}$} \\
Demographic Controls? & Yes & Yes & Yes \\
Crime Controls? & Yes & Yes & Yes \\
Habitual Offender Controls? & Yes & Yes & Yes \\
Type of Counsel Controls? & Yes & Yes & Yes \\
County FEs? & Yes & Yes & Yes \\
Month x Year FEs? & Yes & Yes & Yes \\
$R^{2}$ & & & \\
AIC & 0.137 & 0.125 & 0.037 \\
\hline \hline
\end{tabular}

All cases with at least one conviction included (dropping those with all counts dismissed or with a trial acquittal); $N=1,410,751$.

The control variables are the same as was used in Table 2.5.

Standard errors clustered by County x Year presented in parentheses (865 clusters) and standard errors clustered by County presented in brackets (62 clusters); *** $1 \%, * * 5 \%, * 10 \%$ level of significance.

Tobit model is left-censored at zero (468,573 censored observations and 942,178 uncensored).

In addition, both standard errors clustered by County and standard errors clustered by County $\mathrm{x}$ Year, as is presented in the main body of the paper, are presented.

Once again, the sign, magnitude, and statistical significance persists. Using (1), the estimated change in the plea discount is $17.4 \%$, which mirrors the $18.1 \%$ reduction estimated in Table 2.5 with County x Year fixed effects. Thus, the estimates are not sensitive to the specification choice. The standard errors clustered only on the 62 counties is a bit larger, but still maintaining the statistical significance of the difference-in-difference coefficient.

Similarly, we consider a coarsening of the clusters. While we feel that the county is the appropriate level of clustering, one may be concerned that since the criminal justice system in Florida is organized into 20 circuits, then this should be the level of clustering. Prosecutor and public defender offices are circuit-level offices. Therefore, we consider both Circuit fixed effects (with Month x Year fixed effects as the relevant time dimension to control for) and Circuit x Year fixed effects (similar to the County $\mathrm{x}$ Year fixed effects presented in the main text), with Month of Year fixed effects included to capture seasonal changes. These two specifications are estimated on both the full data set and the subset of serious felony crimes. In addition, we calculate standard errors clustered at both the Circuit level and at the Circuit x Year level. In Table 2.26 we reproduce the (1) of Tables 
Table 2.26: Circuit Fixed Effects and Clusters

\begin{tabular}{lllll}
\hline \hline Data set: & full & full & serious & serious \\
& $(1)$ & $(2)$ & $(3)$ & $(4)$ \\
\hline Plea Bargain & -0.646 & -0.643 & -0.575 & -0.581 \\
& $(0.125)^{* * *}$ & $(0.046)^{* * *}$ & $(0.051)^{* * *}$ & $(0.146)^{* * *}$ \\
& {$[0.047]^{* * *}$} & {$[0.124]^{* * *}$} & {$[0.146]^{* * *}$} & {$[0.051]^{* * *}$} \\
& & & & \\
Death & 0.130 & 0.159 & 0.171 & 0.123 \\
& $(0.141)^{*}$ & $(0.079)^{* *}$ & $(0.085)^{* *}$ & $(0.106)$ \\
& {$[0.078]$} & {$[0.152]$} & {$[0.116]$} & {$[0.086]$} \\
Death x Plea Bargain & 0.147 & 0.152 & 0.171 & 0.165 \\
& $(0.082)^{*}$ & $(0.065)^{* * *}$ & $(0.051)^{* *}$ & $(0.063)^{* *}$ \\
& {$[0.066]^{* *}$} & {$[0.082]^{*}$} & {$[0.063] * *$} & {$[0.165]^{* *}$} \\
Demographic Controls? & Yes & Yes & Yes & Yes \\
Crime Controls? & Yes & Yes & Yes & Yes \\
Habitual Offender Controls? & Yes & Yes & Yes & Yes \\
Type of Counsel Controls? & Yes & Yes & Yes & Yes \\
Circuit FEs? & Yes & No & Yes & No \\
Circuit x Year FEs? & No & Yes & No & Yes \\
Month of Year FEs? & No & Yes & No & Yes \\
Month x Year FEs? & Yes & No & Yes & No \\
$R^{2}$ & & & & \\
AIC & 0.130 & 0.139 & 0.129 & 0.118 \\
\hline \hline
\end{tabular}

All cases with at least one conviction included (dropping those with all counts dismissed or with a trial acquittal). Dependent variable is the log of the sentence (upper bound of the top charge).

The control variables are the same as was used in Table 2.5.

Standard errors clustered by Circuit presented in parentheses (20 clusters) and standard errors clustered by Circuit $\mathrm{x}$ Year presented in brackets (280 clusters); *** $1 \%, * * 5 \%, * 10 \%$ level of significance.

2.5 and 2.6 from the main text, but instead consider these other models.

Once again, the main message of the paper is unaffected. The difference-in-difference coefficient is essentially unchanged and still statistically significant with the use of these coarser fixed effects and with the clustering on the more aggregated levels. Thus, our main result is robust to the model estimated.

On the other hand, we also consider a refining of the clusters and fixed effects. Again, while we feel that the county is the appropriate level of clustering, one may be concerned that we are only capturing variation across counties within the year. Once can be concerned that seasonal effects impact counties differently. Therefore, we consider the most-saturated model allowing for a unique intercept for each county for each month of each year. There are 10,380 of them. Therefore, in Table 2.27 we reproduce the first column from Tables 2.5 and 2.6 from the main text, but instead consider the highly less-saturated models. Standard errors are also clustered at the County x Month x Year level.

Even at this high level of saturation, the difference-in-difference coefficient is highly statistically significant.

As discussed in the text, a concern is that law enforcement and, importantly, prosecutors behave 
Table 2.27: A Further Refining of the Fixed Effects and Clusters

\begin{tabular}{lll}
\hline \hline Data set: & $\begin{array}{l}\text { full } \\
(1)\end{array}$ & $\begin{array}{l}\text { serious } \\
(2)\end{array}$ \\
\hline Plea Bargain & $-0.650^{* * *}$ & $-0.584^{* * *}$ \\
& $(0.024)$ & $(0.030)$ \\
& & \\
& $0.239^{* * *}$ & $0.252^{* * *}$ \\
Death & $(0.045)$ & $(0.056)$ \\
& & \\
& $0.179 * * *$ & $0.195 * * *$ \\
Death x Plea Bargain & $(0.040)$ & $(0.056)$ \\
& & \\
Demographic Controls? & Yes & Yes \\
Crime Controls? & Yes & Yes \\
Habitual Offender Controls? & Yes & Yes \\
Type of Counsel Controls? & Yes & Yes \\
County x Month x Year FEs? & Yes & Yes \\
& & \\
AIC & $5.0 \times 10^{6}$ & $1.8 \times 10^{6}$ \\
\hline \hline
\end{tabular}

All cases with at least one conviction included (dropping those with all counts dismissed or with a trial acquittal). Dependent variable is the log of the sentence (upper bound of the top charge).

The control variables are the same as was used in Table 2.5.

Standard errors clustered by County x Month x Year presented in parentheses (10,380 clusters); *** $1 \%,{ }^{* *} 5 \%$,

* $10 \%$ level of significance.

differently in the days and weeks immediately following a law enforcement official's death while in the line of duty. Police may more aggressively pursue violent offenders. Alternatively, manhunts may divert police resources. Similarly, prosecutors may adjust their charging decision. For example, an arrest that may otherwise be dismissed or may not have charges filed at all by the prosecutor may see a conviction pursued. These marginal cases can be expected to have relatively low expected sentences. Consequently, their inclusion as a "control" observation may distort the estimated treatment effect. To address this concern, Table 2.28 re-estimates Column (1) of Tables 2.5 and 2.6 from the main text dropping arrests made the week after the event in that county, and dropping the arrests the month after the incident, respectively.

Once again, the results persist as the difference-in-difference coefficient is essentially unchanged. The plea discount drops by $18.7 \%$ and $19.9 \%$ dropping the week and month after the event, using (1) and (3) above. They are slightly larger in magnitude (which resulted in an $18.1 \%$ reduction without these observations being excluded).

Another concern is that the law enforcement deaths are not spatially random. In certain areas of the state, violent crime may be more pervasive and, not coincidentally, law enforcement must put themselves in harm's way more frequently. Legal actors in the crime-plagued areas could reasonably respond with harsher sanctions so that the casual impact of the death is overstated. While county indicator variables, included in all specifications previously reported, capture the level differences across these counties, as a sensitivity check we identify which counties were fortunate enough to not have a death in our data set's time period. We then exclude every observation arising from these 31 counties and re-estimate the main findings, the first columns of Tables 2.5 and 2.6 in the main text. Table 2.29 here presents the results. 
Table 2.28: Dropping Arrests Immediately after the Death

\begin{tabular}{lllll}
\hline \hline Period dropped: & $\begin{array}{l}\text { Week After } \\
\text { full } \\
\text { Data set: }\end{array}$ & $\begin{array}{l}\text { Week After } \\
\text { serious } \\
(1)\end{array}$ & $\begin{array}{l}\text { Month After } \\
\text { full } \\
(2)\end{array}$ & $\begin{array}{l}\text { Month After } \\
\text { serious } \\
(4)\end{array}$ \\
\hline Plea Bargain & $-0.647^{* * *}$ & $-0.578^{* * *}$ & $-0.653^{* * *}$ & $-0.586^{* * *}$ \\
& $(0.043)$ & $(0.049)$ & $(0.044)$ & $(0.049)$ \\
& & & \\
Death & $0.197^{* * *}$ & $0.214^{* * *}$ & $0.194^{* *}$ & $0.205^{* *}$ \\
& $(0.077)$ & $(0.081)$ & $(0.078)$ & $(0.084)$ \\
& & & & \\
Death x Plea Bargain & $0.157^{* *}$ & $0.168^{* *}$ & $0.168^{* *}$ & $0.181^{* *}$ \\
& $(0.0651)$ & $(0.0801)$ & $(0.067)$ & $(0.082)$ \\
Demographic Controls? & Yes & Yes & Yes & Yes \\
Crime Controls? & Yes & Yes & Yes & Yes \\
Habitual Offender Controls? & Yes & Yes & Yes & Yes \\
Type of Counsel Controls? & Yes & Yes & Yes & Yes \\
County x Year FEs? & Yes & Yes & Yes & Yes \\
Month of Year FEs? & Yes & Yes & Yes & Yes \\
& & & & \\
$R^{2}$ & 0.154 & 0.144 & 0.154 & 0.144 \\
AIC & $5.0 x 10^{6}$ & $1.8 \times 10^{6}$ & $4.9 \times 10^{6}$ & $1.8 \times 10^{6}$ \\
$N$ & $1,401,813$ & 502,835 & $1,370,840$ & 492,388 \\
\hline
\end{tabular}

All cases with at least one conviction included (dropping those with all counts dismissed or with a trial acquittal). Dependent variable is the log of the sentence (upper bound of the top charge). OLS model estimated as in the first column of Table 2.5.

The control variables are the same as was used in Table 2.5.

Standard errors clustered by County x Year presented in parentheses (865/862 clusters); *** $1 \%,{ }^{* *} 5 \%,{ }^{*} 10 \%$ level of significance. 
Table 2.29: Dropping Counties without a Death

\begin{tabular}{lll}
\hline \hline Data set: & $\begin{array}{l}\text { full } \\
(1)\end{array}$ & $\begin{array}{l}\text { serious } \\
(2)\end{array}$ \\
\hline Death & $0.207^{* * *}$ & $0.205^{* *}$ \\
& $(0.078)$ & $(0.084)$ \\
& & \\
Plea Bargain & $-0.640^{* * *}$ & $-0.591^{* * *}$ \\
& $(0.078)$ & $(0.057)$ \\
& & \\
& & \\
Death x Plea Bargain & $0.446^{* *}$ & $0.178^{* *}$ \\
& $(0.068)$ & $(0.083)$ \\
& & \\
Demographic Controls? & Yes & Yes \\
Crime Controls? & Yes & Yes \\
Habitual Offender Controls? & Yes & Yes \\
Type of Counsel Controls? & Yes & Yes \\
County x Year FEs? & Yes & Yes \\
Month of Year FEs? & Yes & Yes \\
& & \\
$R^{2}$ & 0.153 & 0.142 \\
AIC & $4.2 \times 10^{6}$ & $1.6 \times 10^{6}$ \\
$N$ & $1,190,707$ & 428,831 \\
DV $\mu$ & 17.724 & 24.762 \\
\hline \hline
\end{tabular}

All cases with at least one conviction included (dropping those with all counts dismissed or with a trial acquittal), but excluding the 31 counties without a death incident.

Dependent variable is the log of the sentence (upper bound of the top charge). OLS model estimated as in the first column of Table 2.5.

The control variables are the same as was used in Table 2.5.

Standard errors clustered by County x Year presented in parentheses (865/862 clusters); *** $1 \%,{ }^{* *} 5 \%,{ }^{*} 10 \%$ level of significance. 
Table 2.30: Heterogeneous Treatment Effects: All Felonies

\begin{tabular}{llll}
\hline \hline Salient death: & $\begin{array}{l}\text { Gun-related } \\
\text { death }\end{array}$ & $\begin{array}{l}\text { High volume of } \\
\text { Google searches }\end{array}$ & $\begin{array}{l}\text { Spike in } \\
\text { Google searches }\end{array}$ \\
\hline Plea Bargain & $\begin{array}{l}-0.647^{* * *} \\
(0.077)\end{array}$ & $\begin{array}{l}-0.752^{* * *} \\
(0.087)\end{array}$ & $-0.622^{* * *}(0.172)$ \\
& $\begin{array}{l}0.201^{* * *} \\
(0.043)\end{array}$ & $\begin{array}{l}0.332^{* * *} \\
(0.112)\end{array}$ & $\begin{array}{l}0.399^{* *} \\
(0.189)\end{array}$ \\
Death & & & \\
& $0.205^{* *}$ & $0.225^{*}$ & 0.106 \\
Salient Death x Plea Bargain & $(0.072)$ & $(0.121)$ & $(0.194)$ \\
& & & -0.107 \\
Less-Salient Death x Plea Bargain & 0.111 & 0.032 & $(0.183)$ \\
& $(0.074)$ & $(0.108)$ & Yes \\
Demographic Controls? & Yes & Yes & Yes \\
Crime Controls? & Yes & Yes & Yes \\
Habitual Offender Controls? & Yes & Yes & Yes \\
Type of Counsel Controls? & Yes & Yes & Yes \\
County x Year FEs? & Yes & Yes & Yes \\
Month of Year FEs? & Yes & Yes & 0.079 \\
$R^{2}$ & & & $5.3 \times 10^{6}$ \\
AIC & 0.154 & 0.097 & $5.3 \times 10^{6}$ \\
\hline \hline
\end{tabular}

All cases with at least one conviction included (dropping those with all counts dismissed or with a trial acquittal); $N=1,410,751$.

Dependent variable is the log of the sentence (upper bound of the top charge). OLS model estimated as in the first column of Table 2.5.

The control variables are the same as was used in Table 2.5.

Standard errors clustered by County x Year presented in parentheses (865 clusters); *** $1 \%,{ }^{* *}$ $5 \%, * 10 \%$ level of significance.

The plea discount, again, shrinks and the trial rate increases. For the full data set, the marginal effect on the trial rate is nearly identical (here, the trial rate increases by $79.6 \%$ where before it was $80.1 \%$ ), but the plea discount sees a larger reduction (here, $62 \%$ as compared to $18 \%$ before). This provides support for the claims made in Section 2.4.3.4.

Section 2.4.4 in the main text considers heterogeneous treatment effects. The subsection presents results from the subsample of serious crimes. Table 2.30 reproduces Table 2.10 from the main text, but instead considers the full data set. Our focus here is on two of the important heterogeneous effects: gun-related deaths and high levels of Google searches.

Similar results arise. The only noticeable change is that when considering the spike in Google searching, the statistical significance of the plea discount reduction is lost. The search volume and gun related death effects persist.

Also, in the heterogeneous treatment effects results, the difference-in-difference coefficient was disentangled, separating the salient deaths from less-salient deaths. The treatment variable, Death, was not. Tables 2.31 and 2.32 here separate salient from less-salient events fully.

The results presented in the main text (and in Table 2.30 here) are not sensitive to the decision 
Table 2.31: Plea Discount: Heterogeneous Treatment Effects: All Felonies

\begin{tabular}{llll}
\hline \hline Salient death: & $\begin{array}{l}\text { Gun-related } \\
\text { death }\end{array}$ & $\begin{array}{l}\text { High volume of } \\
\text { Google searches }\end{array}$ & $\begin{array}{l}\text { Spike in } \\
\text { Google searches }\end{array}$ \\
\hline Plea Bargain & $\begin{array}{l}-0.738^{* * *} \\
(0.044)\end{array}$ & $\begin{array}{l}-0.841^{* * *} \\
(0.085)\end{array}$ & $\begin{array}{l}-0.713^{* * *} \\
(0.170)\end{array}$ \\
Salient Death & $\begin{array}{l}-0.349^{* * *} \\
(0.050)\end{array}$ & $\begin{array}{l}-0.491^{* * *} \\
(0.073)\end{array}$ & $-0.389^{* * *}$ \\
& & & $(0.084)$ \\
Less-Salient Death & $-0.211^{* *}$ & 0.020 & 0.041 \\
& $(0.86)$ & $(0.107)$ & $(0.185)$ \\
& & & \\
Salient Death x Plea Bargain & $0.507^{* * *}$ & $0.680^{* * *}$ & $0.605 * * *$ \\
& $(0.070)$ & $(0.109)$ & $(0.097)$ \\
& & & \\
Less-Salient Death x Plea Bargain & $0.522^{* * *}$ & $0.343^{* * *}$ & 0.249 \\
& $(0.083)$ & $(0.108)$ & $(0.180)$ \\
Demographic Controls? & Yes & Yes & Yes \\
Crime Controls? & Yes & Yes & Yes \\
Habitual Offender Controls? & Yes & Yes & Yes \\
Type of Counsel Controls? & Yes & Yes & Yes \\
County x Year FEs? & Yes & Yes & Yes \\
Month of Year FEs? & Yes & Yes & Yes \\
$R^{2}$ & & & 0.079 \\
AIC & 0.155 & 0.098 & $5.3 \times 10^{6}$ \\
\hline \hline
\end{tabular}

All cases with at least one conviction included (dropping those with all counts dismissed or with a trial acquittal); $N=1,410,751$.

Dependent variable is the log of the sentence (upper bound of the top charge). OLS model estimated as in the first column of Table 2.5.

The control variables are the same as was used in Table 2.5.

Standard errors clustered by County x Year presented in parentheses (865 clusters); *** $1 \%, * * 5 \%, * 10 \%$ level of significance. 
Table 2.32: Plea Discount: Heterogeneous Treatment Effects: Serious Crimes Only

\begin{tabular}{llll}
\hline \hline Salient death: & $\begin{array}{l}\text { Gun-related } \\
\text { death }\end{array}$ & $\begin{array}{l}\text { High volume of } \\
\text { Google searches }\end{array}$ & $\begin{array}{l}\text { Spike in } \\
\text { Google searches }\end{array}$ \\
\hline Plea Bargain & $\begin{array}{l}-0.683^{* * *} \\
(0.048)\end{array}$ & $\begin{array}{l}-0.745^{* * *} \\
(0.051)\end{array}$ & $\begin{array}{l}-0.754^{* * *} \\
(0.052)\end{array}$ \\
Salient Death & $\begin{array}{l}-0.349^{* * *} \\
(0.047)\end{array}$ & $\begin{array}{l}-0.391^{* * *} \\
(0.068)\end{array}$ & $-0.244^{* * *}$ \\
& & & $(0.075)$ \\
Less-Salient Death & $-0.267^{* * *}$ & -0.029 & $-0.168^{*}$ \\
& $(0.100)$ & $(0.098)$ & $(0.100)$ \\
& & & \\
Salient Death x Plea Bargain & $0.507^{* *}$ & $0.635^{* * *}$ & $0.535^{* * *}$ \\
& $(0.063)$ & $(0.091)$ & $(0.076)$ \\
& & & \\
Less-Salient Death x Plea Bargain & $0.604^{* * *}$ & $0.407^{* * *}$ & $0.4433^{* * *}$ \\
& $(0.102)$ & $(0.100)$ & $(0.097)$ \\
Demographic Controls? & & & Yes \\
Crime Controls? & Yes & Yes & Yes \\
Habitual Offender Controls? & Yes & Yes & Yes \\
Type of Counsel Controls? & Yes & Yes & Yes \\
County x Year FEs? & Yes & Yes & Yes \\
Month of Year FEs? & Yes & Yes & Yes \\
$R^{2}$ & & & 0.081 \\
AIC & 0.155 & 0.101 & $1.9 \times 10^{6}$ \\
\hline \hline
\end{tabular}

All cases with at least one conviction included (dropping those with all counts dismissed or with a trial acquittal) and only serious crimes; $N=505,963$.

Dependent variable is the log of the sentence (upper bound of the top charge). OLS model estimated as in the first column of Table 2.5.

The control variables are the same as was used in Table 2.5.

Standard errors clustered by County x Year presented in parentheses (862 clusters); *** 1\%, $* * 5 \%, * 10 \%$ level of significance. 
Table 2.33: Breakdown by Crime

\begin{tabular}{lllll}
\hline \hline $\begin{array}{l}\text { Serious Crime } \\
\text { Chapter }\end{array}$ & Uninteracted & $\begin{array}{l}\text { Interacted with } \\
\text { Plea Bargain }\end{array}$ & $\begin{array}{l}\text { Interacted } \\
\text { with Death }\end{array}$ & $\begin{array}{l}\text { Interacted with } \\
\text { Plea Bargain x Death }\end{array}$ \\
\hline 782 & $1.651^{* * *}$ & $-0.558^{* * *}$ & -0.028 & 0.291 \\
& $(0.162)$ & $(0.161)$ & $(0.241)$ & $(0.243)$ \\
784 & $-0.461^{* * *}$ & $-0.656^{* * *}$ & 0.117 & $0.202 *$ \\
& $(0.060)$ & $(0.056)$ & $(0.099)$ & $(0.105)$ \\
790 & -0.091 & $-0.644^{* * *}$ & 0.128 & 0.232 \\
& $(0.081)$ & $(0.092)$ & $(0.161)$ & $(0.167)$ \\
794 & $0.557^{* * *}$ & -0.273 & $0.479 *$ & -0.317 \\
& $(0.127)$ & $(0.133)$ & $(0.284)$ & $(0.300)$ \\
806 & $-0.731^{* * *}$ & $-0.455^{* * *}$ & 0.307 & 0.029 \\
& $(0.137)$ & $(0.137)$ & $(0.233)$ & $(0.234)$ \\
810 & -0.060 & $-0.537^{* * *}$ & 0.148 & $0.248 * *$ \\
& $(0.071)$ & $(0.074)$ & $(0.126)$ & $(0.125)$ \\
812 & - & $-0.564^{* * *}$ & $0.308 * * *$ & 0.097 \\
& & $(0.058)$ & $(0.105)$ & $(0.101)$ \\
\hline \hline
\end{tabular}

All cases with at least one conviction included (dropping those with all counts dismissed or with a trial acquittal) and only serious crimes; $N=505,963$.

Results from a single specification presented. The first column is the chapter fixed effects. The second column presents the interaction between each of the seven crime controls and the Plea Bargain indicator variable. The third column presents the interaction between each of the seven crime controls and the Death indicator variable. The fourth column presents the triple interaction between each of the seven crime controls, Death, and Plea Bargain.

Dependent variable is the log of the sentence (upper bound of the top charge).

The control variables are the same as was used in Table 2.5.

Standard errors clustered by County x Year presented in parentheses (862 clusters0; *** $1 \%,{ }^{* *} 5 \%,{ }^{*} 10 \%$ level of significance.

not to disentangle the treatment variable.

Table 2.7 in the main text further partitioned the data set separating the seven serious crimes from each other. The primary specification is re-estimated for each smaller sub-sample of convictions. An alternative approach is to maintain the full data set of serious crimes, but create seven separate indicator variables for the seven serious crimes. We then include them, interact each of them with Plea Bargain, interact each of them with Death, and importantly interact them with the Plea Bargain x Death. Table 2.33 presents the result.

Importantly, Chapter 784 (assault) and Chapter 810 (burglary) show, a statistically significant increase in the difference-in-difference coefficient. They are assaults and burglaries, respectively. This coincides with the results presented in Table 2.7 in the main text. There the difference-indifference coefficient is statistically significant for these two sub-samples there as well. Thus, the crime breakdown results are consistent.

The main text considers an indicator variable equal to one if the number of days exceeds 233, which puts the case into the top $20 \%$ of all treated observations (in terms of time since arrest). There, an important relationship was shown. The heterogeneous effects table in the main text considers the 
Table 2.34: A Long Time Since Arrest

\begin{tabular}{|c|c|c|c|c|}
\hline $\begin{array}{l}\text { Data set: } \\
\text { Dependent variable: } \\
\text { Model: }\end{array}$ & $\begin{array}{l}\text { full } \\
\ln (\text { sent.) } \\
\text { OLS } \\
(1) \\
\end{array}$ & $\begin{array}{l}\text { full } \\
\text { IHS(sent.) } \\
\text { OLS } \\
(2) \\
\end{array}$ & $\begin{array}{l}\text { serious } \\
\text { IHS(sent.) } \\
\text { OLS } \\
(3) \\
\end{array}$ & $\begin{array}{l}\text { serious } \\
\ln (\text { sent.) } \\
\text { Tobit } \\
(4) \\
\end{array}$ \\
\hline Plea Bargain & $\begin{array}{l}-0.650^{* * *} \\
(0.043)\end{array}$ & $\begin{array}{l}-0.649^{* * *} \\
(0.048)\end{array}$ & $\begin{array}{l}-0.568^{* * *} \\
(0.055)\end{array}$ & $\begin{array}{l}-0.624^{* * *} \\
(0.061)\end{array}$ \\
\hline Death & $\begin{array}{l}0.194 \text { *** } \\
(0.076)\end{array}$ & $\begin{array}{l}0.184 \text { *** } \\
(0.082)\end{array}$ & $\begin{array}{l}0.192 \text { ** } \\
(0.090)\end{array}$ & $\begin{array}{l}0.209 \text { ** } \\
(0.099)\end{array}$ \\
\hline Long Time Since Arrest x Plea Bargain & $\begin{array}{l}0.439 * * * \\
(0.069)\end{array}$ & $\begin{array}{l}0.470 * * * \\
(0.076)\end{array}$ & $\begin{array}{l}0.499 * * * \\
(0.091)\end{array}$ & $\begin{array}{l}0.557 \text { *** } \\
(0.101)\end{array}$ \\
\hline Not a Long Time Since Arrest x Plea Bargain & $\begin{array}{l}0.079 \\
(0.068)\end{array}$ & $\begin{array}{l}0.089 \\
(0.074)\end{array}$ & $\begin{array}{l}0.095 \\
(0.092)\end{array}$ & $\begin{array}{l}0.120 \\
(0.102)\end{array}$ \\
\hline $\begin{array}{l}\text { Demographic Controls? } \\
\text { Crime Controls? } \\
\text { Habitual Offender Controls? } \\
\text { Type of Counsel Controls? } \\
\text { County x Year FEs? } \\
\text { Month of Year FEs? }\end{array}$ & $\begin{array}{l}\text { Yes } \\
\text { Yes } \\
\text { Yes } \\
\text { Yes } \\
\text { Yes } \\
\text { Yes }\end{array}$ & $\begin{array}{l}\text { Yes } \\
\text { Yes } \\
\text { Yes } \\
\text { Yes } \\
\text { Yes } \\
\text { Yes }\end{array}$ & $\begin{array}{l}\text { Yes } \\
\text { Yes } \\
\text { Yes } \\
\text { Yes } \\
\text { Yes } \\
\text { Yes }\end{array}$ & $\begin{array}{l}\text { Yes } \\
\text { Yes } \\
\text { Yes } \\
\text { Yes } \\
\text { Yes } \\
\text { Yes }\end{array}$ \\
\hline $\begin{array}{l}R^{2} \\
\mathrm{AIC}\end{array}$ & $\begin{array}{l}0.155 \\
5.0 \times 10^{6}\end{array}$ & $\begin{array}{l}0.146 \\
5.4 \times 10^{6}\end{array}$ & $\begin{array}{l}0.140 \\
2.0 \times 10^{6}\end{array}$ & $\begin{array}{l}0.040 \\
1.8 \times 10^{6}\end{array}$ \\
\hline
\end{tabular}

All cases with at least one conviction included (dropping those with all counts dismissed or with a trial acquittal); $N=1,416,751$ for (1) and (2) and $N=505,963$ for (3) and (4).

Dependent variable is the upper bound on the top charge.

The control variables are the same as was used in Table 2.5.

Standard errors clustered by County x Year presented in the parentheses (865/862 clusters); *** 1\%, ** 5\%, * $10 \%$ level of significance.

Tobit model is left-censored at zero (142,423 censored observations and 363,540 uncensored).

subsample of serious crimes and presents the results with an OLS model estimated with the log of the sentence as the dependent variable. In Table 2.34 we provide further results to show that those presented in the text are not sensitive to the data set used or model estimated.

Similarly, the heterogeneous effects of death's associated with dedications can be disentangled from those deaths without dedications. Table 2.35 considers alternative samples, transformations of the dependent variable, and model estimated.

Finally, we consider the spatial dimension to the law enforcement official's death. It is reasonable to speculate that the unfortunate incident not only affects those within the community but, due to media coverage, potentially spills over and affects residents across the state. Thus, we create two new indicator variables, Death Circuit and Death State. The first equals one if a death of a law enforcement official occurs anywhere else in the circuit. Florida's 67 counties are organized into 20 judicial circuits. People who share the same circuit as those in other counties may be affected by their neighbor's misfortune. The second new variable is equal to one if the case is in process anywhere else in the state (outside the circuit). We include it in our primary specification (the first 
Table 2.35: Dedications

\begin{tabular}{|c|c|c|c|c|}
\hline $\begin{array}{l}\text { Data set: } \\
\text { Dependent variable: } \\
\text { Model: }\end{array}$ & $\begin{array}{l}\text { full } \\
\ln (\text { sent.) } \\
\text { OLS } \\
(1)\end{array}$ & $\begin{array}{l}\text { full } \\
\text { IHS(sent.) } \\
\text { OLS } \\
(2) \\
\end{array}$ & $\begin{array}{l}\text { serious } \\
\text { IHS(sent.) } \\
\text { OLS } \\
(3) \\
\end{array}$ & $\begin{array}{l}\text { serious } \\
\ln (\text { sent.) } \\
\text { Tobit } \\
(4)\end{array}$ \\
\hline Plea Bargain & $\begin{array}{l}-0.647^{* * *} \\
(0.043)\end{array}$ & $\begin{array}{l}-0.646^{* * *} \\
(0.048)\end{array}$ & $\begin{array}{l}-0.5655^{* * *} \\
(0.055)\end{array}$ & $\begin{array}{l}-0.621 \text { *** } \\
(0.061)\end{array}$ \\
\hline Death & $\begin{array}{l}0.200 \text { *** } \\
(0.077)\end{array}$ & $\begin{array}{l}0.191 * * \\
(0.082)\end{array}$ & $\begin{array}{l}0.202 \text { ** } \\
(0.090)\end{array}$ & $\begin{array}{l}0.221 * * \\
(0.100)\end{array}$ \\
\hline Dedication x Plea Bargain & $\begin{array}{l}0.266 \\
(0.119)\end{array}$ & $\begin{array}{l}0.283^{* *} \\
(0.129)\end{array}$ & $\begin{array}{l}0.285 * * \\
(0.144)\end{array}$ & $\begin{array}{l}0.316 \text { ** } \\
(0.129)\end{array}$ \\
\hline No Dedication x Plea Bargain & $\begin{array}{l}0.131 \text { ** } \\
(0.065)\end{array}$ & $\begin{array}{l}0.145 * * \\
(0.071)\end{array}$ & $\begin{array}{l}0.164 * \\
(0.088)\end{array}$ & $\begin{array}{l}0.199 \text { ** } \\
(0.098)\end{array}$ \\
\hline Demographic Controls? & Yes & Yes & Yes & Yes \\
\hline Crime Controls? & Yes & Yes & Yes & Yes \\
\hline Habitual Offender Controls? & Yes & Yes & Yes & Yes \\
\hline Type of Counsel Controls? & Yes & Yes & Yes & Yes \\
\hline County x Year FEs? & Yes & Yes & Yes & Yes \\
\hline Month of Year FEs? & Yes & Yes & Yes & Yes \\
\hline$R^{2}$ & 0.154 & 0.145 & 0.139 & 0.040 \\
\hline $\mathrm{AIC}$ & $5.0 \times 10^{6}$ & $5.4 \times 10^{6}$ & $2.0 \times 10^{6}$ & $1.8 \times 10^{6}$ \\
\hline
\end{tabular}

All cases with at least one conviction included (dropping those with all counts dismissed or with a trial acquittal); $N=1,416,751$ for (1) and (2) and $N=505,963$ for (3) and (4).

Dependent variable is the upper bound on the top charge.

The control variables are the same as was used in Table 2.5.

Standard errors clustered by County x Year presented in the parentheses (865/862 clusters); *** $1 \%$, ** 5\%, * $10 \%$ level of significance.

Tobit model is left-censored at zero (142,423 censored observations and 363,540 uncensored). 
column of Table 5 in the main text). This allows us to separate the local community effect from a statewide effect. Table 2.36 presents the spatial effects.

The effect of the death is concentrated in the county of that death. The difference-in-difference coefficients are all positive and statistically significant, but only so at the county level. Hence, the local effect is substantial. There is not much of a spillover onto the rest of the circuit. There is only weak evidence of an additional statewide effect in (3).

This can be viewed positively in that it is another piece of evidence that we do not have a spurious result. If, for example, we had found that plea bargained cases in Miami were affected as much (or more) as cases in Pensacola when a death occurs in Pensacola, our results could reasonably be questioned. We find here that a death in Pensacola, to continue with the example, only affects those other cases in Escambia County (the one that includes Pensacola).

Sensitivity Analysis: Trial Rate

The sensitivity of the results presented in Section 5 can also be assessed. First, the results presented in Table 2.11 in the main text use a linear probability model. One can, alternatively, estimate probit and logit models since the dependent variable is binary equal to one if the case went to trial. Table 2.37 presents them.

The results are not sensitive to the model used to estimate the death's impact on the trial rate. The estimated marginal effect for the full data set is a 1.73 percentage point increase in the trial rate, which is in line with that estimated with the linear probability model (1.98 percentage points).

Second, we previously checked the sensitivity of the results regarding changes in the plea discount by omitting observations from the non-treated group which can distort the point estimate. For one, Table 2.28 in this supplemental appendix re-estimated the first columns of Tables 2.5 and 2.6 from the main text dropping arrests the occurred the week after and the month after the death of the law enforcement official. Here, we do this again in Table 2.38, but estimate the new relationship between law enforcement official's deaths and the trial rate.

The results are essentially unchanged.

Similarly, Table 2.29 in this supplemental appendix considered the results dropping all observations from counties which did not experience any law enforcement official's death during the sample's time period. It considered changes in the plea discount. Here, in Table 2.39 we extend this to the trial rate.

Also, the paper illustrates the effect of the events on the trial rate for the full data set and for the sub-sample of serious felonies. What is not presented is the effect of the deaths on the trial rate for less-serious crimes. Table 2.40 provides those additional results.

The increase in the trial rate also occurs for less-serious crimes. This coincides with the findings in Table 2.17 of the supplemental appendix which illustrates that the plea discount also shrinks for less-serious crimes. Also, separating the salient deaths from the less-salient ones, consistently we find that even with less-serious crimes, the more impactful deaths correspond to disproportionately more trials.

As with the plea discount, alternative fixed effects and clusters can be considered. Table 2.41 considers the most-saturated model using County x Month x Year fixed effects. Standard errors are also clustered at that level.

Again, even at this high level of saturation, the coefficient on Death is highly statistically significant. 
Table 2.36: Spatial Effects

\begin{tabular}{|c|c|c|c|c|}
\hline Data set: & $\begin{array}{l}\text { full } \\
(1)\end{array}$ & $\begin{array}{l}\text { serious } \\
(2)\end{array}$ & $\begin{array}{l}\text { full } \\
(3)\end{array}$ & $\begin{array}{l}\text { serious } \\
(4)\end{array}$ \\
\hline Plea Bargain & $\begin{array}{l}-0.641^{\text {*** }} \\
(0.047)\end{array}$ & $\begin{array}{l}-0.574^{* * *} \\
(0.052)\end{array}$ & $\begin{array}{l}-0.649^{\text {*** }} \\
(0.044)\end{array}$ & $\begin{array}{l}-0.580 \text { *** } \\
(0.051)\end{array}$ \\
\hline Death & $\begin{array}{l}0.211 \text { *** } \\
(0.077)\end{array}$ & $\begin{array}{l}0.219 \text { *** } \\
(0.082)\end{array}$ & $\begin{array}{l}0.220 * * * \\
(0.080)\end{array}$ & $\begin{array}{l}0.225^{* * *} \\
(0.084)\end{array}$ \\
\hline Death Circuit & $\begin{array}{l}0.206 \text { ** } \\
(0.087)\end{array}$ & $\begin{array}{l}0.205 * \\
(0.105)\end{array}$ & $\begin{array}{l}0.200 * * \\
(0.080)\end{array}$ & $\begin{array}{l}0.201 * \\
(0.105)\end{array}$ \\
\hline Death State & & & $\begin{array}{l}-0.308 \\
(0.205)\end{array}$ & $\begin{array}{l}-0.217 \\
(0.248)\end{array}$ \\
\hline Death x Plea Bargain & $\begin{array}{l}0.146 \text { ** } \\
(0.066)\end{array}$ & $\begin{array}{l}0.166 \text { ** } \\
(0.082)\end{array}$ & $\begin{array}{l}0.136 \text { ** } \\
(0.068)\end{array}$ & $\begin{array}{l}0.158 * \\
(0.083)\end{array}$ \\
\hline Death Circuit x Plea Bargain & $\begin{array}{l}0.008 \\
(0.080)\end{array}$ & $\begin{array}{l}0.007 \\
(0.103)\end{array}$ & $\begin{array}{l}0.015 \\
(0.079)\end{array}$ & $\begin{array}{l}0.013 \\
(0.103)\end{array}$ \\
\hline Death State x Plea Bargain & & & $\begin{array}{l}0.350 * \\
(0.202)\end{array}$ & $\begin{array}{l}0.305 \\
(0.249)\end{array}$ \\
\hline Demographic Controls? & Yes & Yes & Yes & Yes \\
\hline Crime Controls? & Yes & Yes & Yes & Yes \\
\hline Habitual Offender Controls? & Yes & Yes & Yes & Yes \\
\hline Type of Counsel Controls? & Yes & Yes & Yes & Yes \\
\hline County x Year FEs? & Yes & Yes & Yes & Yes \\
\hline Month of Year FEs? & Yes & Yes & Yes & Yes \\
\hline$R^{2}$ & 0.155 & 0.144 & 0.155 & 0.144 \\
\hline $\mathrm{AIC}$ & $5.0 \times 10^{6}$ & $1.8 \times 10^{6}$ & $5.0 \times 10^{6}$ & $1.8 \times 10^{6}$ \\
\hline
\end{tabular}

All cases with at least one conviction included (dropping those with all counts dismissed or with a trial acquittal); $N=1,410,751$ for (1) and (3) and $N=505,963$ for (2) and (4).

Dependent variable is the log of the sentence (upper bound of the top charge). OLS model estimated as in the first column of Table 2.5.

The control variables are the same as was used in Table 2.5.

Standard errors clustered by County x Year presented in parentheses $(865 / 862$ clusters $) ; * * * 1 \%, * * 5 \%, * 10 \%$ level of significance. 
Table 2.37: Alternative Models

\begin{tabular}{llll}
\hline \hline Data set: & full & serious & serious \\
Model: & Probit & $\begin{array}{l}\text { Probit } \\
(1)\end{array}$ & $\begin{array}{l}\text { Logit } \\
(3)\end{array}$ \\
\hline $\begin{array}{l}\text { Death - Coefficient } \\
\text { Standard error }\end{array}$ & $0.3676^{* * *}$ & $0.3446^{* * *}$ & $0.7450^{* * *}$ \\
$\begin{array}{l}\text { Marginal effect } \\
\text { Marginal effect standard error }\end{array}$ & $0.0228)$ & $(0.0203)$ & $(0.0448)$ \\
& {$[0.0011]$} & $0.0206^{* * *}$ & $0.0211^{* * *}$ \\
& & $0.0013]$ & {$[0.0013]$} \\
Demographic Controls? & Yes & Yes & Yes \\
Crime Controls? & Yes & Yes & Yes \\
Habitual Offender Controls? & Yes & Yes & Yes \\
Type of Counsel Controls? & Yes & Yes & Yes \\
County x Year FEs? & Yes & Yes & Yes \\
Month of Year FEs? & Yes & Yes & Yes \\
& & & \\
Pseudo $R^{2}$ & 0.118 & 0.111 & 0.109 \\
AIC & $2.6 \times 10^{5}$ & $1.2 \times 10^{5}$ & $1.5 \times 10^{5}$ \\
$N$ & $1,407,672$ & 501,721 & 501,721 \\
\hline \hline
\end{tabular}

All cases (dropping those with all counts dismissed), both trial convictions and acquittals along with guilty pleas, included.

Dependent variable equal to one if any count charged is disposed at trial (jury or nonjury \& convicted or acquitted). The control variables are the same as was used in Table 2.5.

Standard errors clustered by County x Year presented in parentheses $\left(865 / 721\right.$ clusters); ${ }^{* * *} 1 \%,{ }^{* *} 5 \%,{ }^{*} 10 \%$ level of significance.

Table 2.38: Dropping Arrests Immediately After the Death: Trial Rate

\begin{tabular}{lllll}
\hline \hline Period dropped: & $\begin{array}{l}\text { Week After } \\
\text { full } \\
\text { Data set: }\end{array}$ & $\begin{array}{l}\text { Week After } \\
\text { serious } \\
(1)\end{array}$ & $\begin{array}{l}\text { Month After } \\
\text { full } \\
(2)\end{array}$ & $\begin{array}{l}\text { Month After } \\
\text { serious } \\
(4)\end{array}$ \\
\hline Death & $0.0199^{* * *}$ & $0.0250^{* * *}$ & $0.0205^{* * *}$ & $0.0256^{* * *}$ \\
& $(0.0015)$ & $(0.0019)$ & $(0.0015)$ & $(0.0019)$ \\
& & & & \\
Demographic Controls? & Yes & Yes & Yes & Yes \\
Crime Controls? & Yes & Yes & Yes & Yes \\
Habitual Offender Controls? & Yes & Yes & Yes & Yes \\
Type of Counsel Controls? & Yes & Yes & Yes & Yes \\
County x Year FEs? & Yes & Yes & Yes & Yes \\
Month of Year FEs? & Yes & Yes & Yes & Yes \\
& & & & \\
$R^{2}$ & 0.037 & 0.040 & 0.037 & 0.040 \\
AIC & $-1.5 \times 10^{6}$ & $-3.7 \times 10^{5}$ & $-1.4 \times 10^{6}$ & $-3.6 \times 10^{5}$ \\
$N$ & $1,407,569$ & 956,066 & $1,376,485$ & 996,062 \\
\hline \hline
\end{tabular}

All cases (dropping those with all counts dismissed), both trial convictions and acquittals along with guilty pleas included.

Dependent variable equal to one if any count charged is disposed at trial (jury or nonjury \& convicted or acquitted). Linear probability models are estimated.

The control variables are the same as was used in Table 2.5.

Standard errors clustered by County x Year presented in parentheses (866 clusters); ${ }^{* * *} 1 \%,{ }^{* *} 5 \%,{ }^{*} 10 \%$ level of significance. 
Table 2.39: Dropping Counties without a Death: Trial Rate

\begin{tabular}{lll}
\hline \hline Data set: & full & $\begin{array}{l}\text { serious } \\
(1)\end{array}$ \\
\hline Death & $0.0199^{* * *}$ & $0.0250^{* * *}$ \\
& $(0.0015)$ & $(0.0019)$ \\
& & \\
Demographic Controls? & Yes & Yes \\
Crime Controls? & Yes & Yes \\
Habitual Offender Controls? & Yes & Yes \\
Type of Counsel Controls? & Yes & Yes \\
County x Year FEs? & Yes & Yes \\
Month of Year FEs? & Yes & Yes \\
& & \\
$R^{2}$ & 0.036 & 0.039 \\
AIC & $-1.3 \times 10^{6}$ & $-3.1 \times 10^{6}$ \\
$N$ & $1,195,366$ & 431,933 \\
DV $\mu$ & 0.0250 & 0.0307 \\
\hline \hline
\end{tabular}

\footnotetext{
All cases (dropping those with all counts dismissed), both trial convictions and acquittals along with guilty pleas, included, but excluding the 31 counties without a death incident.

Dependent variable is the log of the sentence (upper bound of the top charge). OLS model estimated as in the first column of Table 2.5.

The control variables are the same as was used in Table 2.5.

Standard errors clustered by County x Year presented in parentheses (865/862 clusters); *** $1 \%,{ }^{* *} 5 \%, * 10 \%$ level of significance.
}

Next, for the assessment of heterogeneous effects, we chose to present the results from the full sample (in Table 2.12 of the main text). In Table 2.42 we restrict attention to only serious crimes.

Here, again, salient deaths continue to see escalated trial rates. In fact, the estimated effects here for serious crimes are larger than those using the full data set in Table 2.12 of the main text. Noticeably, also, the magnitude of the less-salient deaths grow. Thus, for serious crimes all law enforcement official deaths are impactful.

Additionally, the relationship between time since arrest and the trial rate can be further evaluated. The main body of the text presents results using an indicator variable equal to one if the length of time between arrest and being treated is in the top $20 \%$. Here, we consider the number of days as a running variable. Table 2.43 extends the results in the text by including the number of days, for those treated observations, since the arrest was made.

While the death is, as before, associated with an increase in the trial rate, this effect is magnified if there have been more days since the arrest date. Older cases, presumably closer to their court date, see an increase in the probability of going to trial.

As before, it is instructional to disaggregate the serious crimes. Table 2.44 analyzes the subsample of the seven serious crimes individually.

The trial rate increases consistently for the most serious crimes. Only homicides show a lessstrong impact. The trial rate increases, though, by a nontrivial amount. Its standard error is a bit larger. Regardless, across all the serious crimes, the trial rate increases with the death, suggesting that prosecutors make less-generous offers which are rejected at higher rates.

The seven separate crimes making up the serious crimes sub-sample can be decomposed using seven indicator variables for each crime, and then including an interaction term with Death (similar 
Table 2.40: Less-Serious Crimes: Trial Rate

\begin{tabular}{|c|c|c|c|c|c|}
\hline Salient death: & (1) & $\begin{array}{l}\text { Gun } \\
\text { deaths } \\
(2)\end{array}$ & $\begin{array}{l}\text { High volume } \\
\text { of searches } \\
(3)\end{array}$ & $\begin{array}{l}\text { Spike in } \\
\text { searches } \\
(4)\end{array}$ & $\begin{array}{l}\text { Dedications } \\
(5)\end{array}$ \\
\hline Death & $\begin{array}{l}0.0161 \text { *** } \\
(0.0014)\end{array}$ & & & & \\
\hline Salient Death & & $\begin{array}{l}0.0102 \text { *** } \\
(0.0024)\end{array}$ & $\begin{array}{l}0.0137 \text { *** } \\
(0.0034)\end{array}$ & $\begin{array}{l}0.0150 \text { *** } \\
(0.0038)\end{array}$ & $\begin{array}{l}0.0208 \text { *** } \\
(0.0033)\end{array}$ \\
\hline Less-Salient Death & & $\begin{array}{l}0.0104 \text { *** } \\
(0.0014)\end{array}$ & $\begin{array}{l}0.0115^{* * *} \\
(0.0013)\end{array}$ & $\begin{array}{l}0.0126^{* * *} \\
(0.0013)\end{array}$ & $\begin{array}{l}0.0151 \text { *** } \\
(0.0014)\end{array}$ \\
\hline Demographic Controls? & Yes & Yes & Yes & Yes & Yes \\
\hline Crime Controls? & Yes & Yes & Yes & Yes & Yes \\
\hline Hab. Offender Controls? & Yes & Yes & Yes & Yes & Yes \\
\hline Type of Counsel Controls? & Yes & Yes & Yes & Yes & Yes \\
\hline County x Year FEs? & Yes & Yes & Yes & Yes & Yes \\
\hline Month of Year FEs? & Yes & Yes & Yes & Yes & Yes \\
\hline$R^{2}$ & 0.034 & 0.034 & 0.034 & 0.034 & 0.034 \\
\hline $\mathrm{AIC}$ & $-1.2 \times 10^{6}$ & $-1.2 \times 10^{6}$ & $-1.2 \times 10^{6}$ & $-1.2 \times 10^{6}$ & $-1.2 \times 10^{6}$ \\
\hline
\end{tabular}

All cases (dropping those with all counts dismissed), both trial convictions and acquittals along with guilty pleas included and only less-serious crimes considered; $N=906,802$.

Dependent variable is the log of the sentence (upper bound of the top charge). OLS model estimated as in the first column of Table 2.5.

The control variables are the same as was used in Table 2.5

Standard errors clustered by County x Year presented in parentheses (866 clusters); ${ }^{* * *} 1 \%,{ }^{* *} 5 \%,{ }^{*} 10 \%$ level of significance.

Table 2.41: A Further Refining of the Fixed Effects and Clusters: Trial Rate

\begin{tabular}{lll}
\hline \hline Data set: & full & serious \\
& $(1)$ & $(2)$ \\
\hline Death & $0.0232^{* * *}$ & $0.0285^{* * *}$ \\
& $(0.0010)$ & $(0.0014)$ \\
& & \\
Demographic Controls? & Yes & Yes \\
Crime Controls? & Yes & Yes \\
Habitual Offender Controls? & Yes & Yes \\
Type of Counsel Controls? & Yes & Yes \\
County x Month x Year FEs? & Yes & Yes \\
& & \\
AIC & $-1.5 \times 10^{6}$ & $-3.8 \times 10^{5}$ \\
\hline \hline
\end{tabular}

All cases (dropping those with all counts dismissed), both trial convictions and acquittals along with guilty pleas, included.

Dependent variable is the log of the sentence (upper bound of the top charge)

The control variables are the same as was used in Table 2.5.

Standard errors clustered by County x Month x Year presented in parentheses (10,380 clusters); *** $1 \%$, ** $5 \%$,

* $10 \%$ level of significance. 
Table 2.42: Trial Rate: Heterogeneous Treatment Effects: Serious Crimes Only

\begin{tabular}{|c|c|c|c|c|c|}
\hline Salient death: & $\begin{array}{l}\text { Gun related } \\
\text { deaths }\end{array}$ & $\begin{array}{l}\text { High volume } \\
\text { of searches }\end{array}$ & $\begin{array}{l}\text { Spike in } \\
\text { searches }\end{array}$ & $\begin{array}{l}\text { Long time } \\
\text { since arrest }\end{array}$ & Dedications \\
\hline Salient Death & $\begin{array}{l}0.0128 \text { *** } \\
(0.0038)\end{array}$ & $\begin{array}{l}0.0158 \text { *** } \\
(0.0058)\end{array}$ & $\begin{array}{l}0.0194 \text { *** } \\
(0.0065)\end{array}$ & $\begin{array}{l}0.0454^{* * *} \\
(0.0035)\end{array}$ & $\begin{array}{l}0.0326^{* * *} \\
(0.0044)\end{array}$ \\
\hline Less-Salient Death & $\begin{array}{l}0.0183 \text { *** } \\
(0.0024)\end{array}$ & $\begin{array}{l}0.0200 \text { *** } \\
(0.0021)\end{array}$ & $\begin{array}{l}0.0201 \text { *** } \\
(0.0022)\end{array}$ & $\begin{array}{l}0.0178^{* * *} \\
(0.0016)\end{array}$ & $\begin{array}{l}0.0232 \text { *** } \\
(0.0019)\end{array}$ \\
\hline Demographic Controls? & Yes & Yes & Yes & Yes & Yes \\
\hline Crime Controls? & Yes & Yes & Yes & Yes & Yes \\
\hline Hab. Offender Controls? & Yes & Yes & Yes & Yes & Yes \\
\hline Type of Counsel Controls? & Yes & Yes & Yes & Yes & Yes \\
\hline County x Year FEs? & Yes & Yes & Yes & Yes & Yes \\
\hline Month of Year FEs? & Yes & Yes & Yes & Yes & Yes \\
\hline$R^{2}$ & 0.039 & 0.039 & 0.039 & 0.041 & 0.040 \\
\hline AIC & $-3.7 \times 10^{5}$ & $-3.7 \times 10^{5}$ & $-3.7 \times 10^{5}$ & $-3.7 \times 10^{5}$ & $-3.7 \times 10^{5}$ \\
\hline
\end{tabular}

All cases (dropping those with all counts dismissed), both trial convictions and acquittals along with guilty pleas included, included and only serious crimes; $N=509,738$.

Dependent variable equal to one if any count charged is disposed at trial (jury or nonjury \& convicted or acquitted). Linear probability models are estimated.

The control variables are the same as was used in Table 2.5.

Standard errors clustered by County x Year presented in parentheses (862 clusters); *** 1\%,** 5\%,*10\% level of significance.

Table 2.43: Time Since Arrest: Trial Rate

\begin{tabular}{lll}
\hline \hline Data set: & $\begin{array}{l}\text { full } \\
(1)\end{array}$ & $\begin{array}{l}\text { serious } \\
(2)\end{array}$ \\
\hline Death & $\begin{array}{l}0.0086^{* * *} \\
(0.0013)\end{array}$ & $\begin{array}{l}0.0117^{* * *} \\
(0.0018)\end{array}$ \\
& & \\
& $6.8 \times 10^{-5 * * *}$ & $7.3 \times 10^{-5} * * *$ \\
Days & $\left(6.3 \times 10^{-6}\right)$ & $\left(8.5 \times 10^{-6}\right)$ \\
& & \\
Demographic Controls? & Yes & Yes \\
Crime Controls? & Yes & Yes \\
Habitual Offender Controls? & Yes & Yes \\
Type of Counsel Controls? & Yes & Yes \\
County x Year FEs? & Yes & Yes \\
Month of Year FEs? & Yes & Yes \\
& & \\
$R^{2}$ & 0.038 & 0.041 \\
AIC & $-1.5 \times 10^{6}$ & $-3.7 \times 10^{5}$ \\
$N$ & $1,416,540$ & 509,738 \\
\hline \hline
\end{tabular}

All cases (dropping those with all counts dismissed), both trial convictions and acquittals along with guilty pleas, included.

Dependent variable is equal to one if any count charged is disposed at trial (jury or nonjury \& convicted or acquitted). Linear probability model is estimated.

The control variables are the same as was used in Table 2.5.

Standard errors clustered by County x Year presented in parentheses $\left(865 / 862\right.$ clusters; *** $1 \%,{ }^{* *} 5 \%,{ }^{*} 10 \%$ level of significance. 
Table 2.44: Trial Rate Broke Down by Crime

\begin{tabular}{llllll}
\hline \hline & Death & $($ s.e. $)$ & {$[\mathrm{p}$-value $]$} & $N$ & $\% \Delta$ trial rate \\
\hline Robbery (812) & $0.0193^{* * *}$ & $(0.0017)$ & {$[0.0001]$} & 310,863 & $105.0 \%$ \\
Assault (784) & $0.0355^{* * *}$ & $(0.0041)$ & {$[0.0001]$} & 85,223 & $69.8 \%$ \\
Burglary (810) & $0.0234^{* * *}$ & $(0.0030)$ & {$[0.0001]$} & 64,759 & $79.2 \%$ \\
Weapons (790) & $0.0378^{* * *}$ & $(0.0052)$ & {$[0.0001]$} & 25,315 & $71.5 \%$ \\
Arson (806) & $0.0399^{* * *}$ & $(0.0079)$ & {$[0.0001]$} & 13,409 & $96.4 \%$ \\
Sexual Battery (794) & $0.0378^{* *}$ & $(0.0173)$ & {$[0.032]$} & 6270 & $30.3 \%$ \\
Homicide (782) & $0.0358^{*}$ & $(0.0210)$ & {$[0.089]$} & 3899 & $17.3 \%$ \\
\hline \hline
\end{tabular}

All cases included (dropping those with all counts dismissed), both trial convictions and acquittals along with guilty pleas, included and only serious crimes. Each row presents the estimation results from the subsample of each of the seven serious crimes.

Dependent variable equal to one if any count charged is disposed at trial (jury or nonjury \& convicted or acquitted). The specification reported in each row is the reproduction of the one presented in the first column of Table 2.5. Only the difference-in-difference coefficient is presented.

Standard errors clustered by County x Year presented in the parentheses; ${ }^{* * *} 1 \%,{ }^{* *} 5 \%,{ }^{*} 10 \%$ level of significance.

as to what has been done in Table 2.33 in this supplemental appendix for the plea discount). Table 2.45 presents the results.

Across the serious crimes, the trial rate expands with the death. Hence, Tables 2.44 and 2.45 provide strikingly similar results.

The primary analysis uses a difference-in-difference estimation to identify whether the difference between sentences received when entering a guilty plea and sentences received when convicted at a trial changes with the death of the law enforcement official in the line of duty. Here, we separate the two to get an idea of which is changing. Specifically, we partition the data set of convictions into those arising from a guilty plea and those arising from a trial conviction. The dependent variable continues to be the sentence received by the defendant. The death of the law enforcement official is the primary explanatory variable, but all other controls and fixed effects are included, as before. Table 2.46 presents the results.

Both the sentence received after a guilty plea and the sentence received after a trial conviction increase. Thus, the shock of the death event is not solely expressed in the plea discount, but also affects the sanctions handed down by the judge after a trial conviction. Previous research has identified the role of judge's sentencing preferences (Bushway et al., 2012), so it is not surprising that deaths have an effect here.

\subsubsection{Breakdown By Crime Type}

A potential concern regarding the identification strategy is that the treatment variable Death affects the independent variable, Plea Bargain. As shown, the deaths cause more cases to go to trial. This affects the mix of cases that are plea bargained. Consequently, the change in the sentences received may not solely be the difference between the realized sentence and the counterfactual outcome of what the agreed to sanction would have been had there not been a death, but instead could be driven in part by a change in the composition of cases that are plea bargained.

One way to investigate this concern is to consider crimes that infrequently go to trial. For those crimes, there can be expected to be little change in the composition, compared to those that frequently see cases go to trials. Changes in the average plea discount for crimes that rarely go to trial should then be a product of adjustments in the plea bargaining process and not changes in the 
Table 2.45: Breakdown by Crime

\begin{tabular}{lll}
\hline \hline $\begin{array}{l}\text { Serious Crime } \\
\text { Chapter }\end{array}$ & Uninteracted & $\begin{array}{l}\text { Interacted } \\
\text { with Death }\end{array}$ \\
\hline 782 & $\begin{array}{l}0.174^{* * *} \\
(0.010)\end{array}$ & $\begin{array}{l}0.027^{*} \\
(0.015)\end{array}$ \\
784 & $\begin{array}{l}0.028^{* * *} \\
(0.001)\end{array}$ & $\begin{array}{l}0.034^{* * *}(0.004) \\
\end{array}$ \\
790 & $0.025^{* * *}$ & $0.036^{* * *}$ \\
& $(0.002)$ & $(0.005)$ \\
794 & $0.093^{* * *}$ & $0.036^{* * *}$ \\
& $(0.005)$ & $(0.014)$ \\
806 & $0.020^{* * *}$ & $0.039^{* * *}$ \\
& $(0.002)$ & $(0.007)$ \\
810 & $0.011^{* * *}$ & $0.024 * * *$ \\
& $(0.001)$ & $(0.003)$ \\
812 & - & $0.021^{* * *}$ \\
& & $(0.002)$ \\
\hline \hline
\end{tabular}

All cases with at least one conviction included (dropping those with all counts dismissed), both trial convictions and acquittals along with guilty pleas, included and only serious crimes; $N=505,963$.

Results from a single specification presented. The first column is the chapter fixed effects. The second column presents the interaction between each of the seven crime controls Death indicator variable.

Dependent variable is equal to one if any count charged is disposed at trial (jury or nonjury \& convicted or acquitted). Linear probability model is estimated.

The control variables are the same as was used in Table 2.5.

Standard errors clustered by County x Year presented in parentheses $(862$ clusters; $* * * 1 \%, * * 5 \%, * 10 \%$ level of significance. 
Table 2.46: Pleas or Trials?

\begin{tabular}{lllll}
\hline \hline Data set: & $\begin{array}{l}\text { full } \\
\text { Gubsample: } \\
(1)\end{array}$ & $\begin{array}{l}\text { serious } \\
\text { Guilty pleas } \\
(2)\end{array}$ & $\begin{array}{l}\text { full } \\
\text { Trials } \\
(3)\end{array}$ & $\begin{array}{l}\text { serious } \\
\text { Trials } \\
(4)\end{array}$ \\
\hline Death & $0.360^{* * *}$ & $0.386^{* * *}$ & $0.417^{* * *}$ & $0.482^{* * *}$ \\
& $(0.039)$ & $(0.032)$ & $(0.056)$ & $(0.073)$ \\
& & & & \\
Demographic Controls? & Yes & Yes & Yes & Yes \\
Crime Controls? & Yes & Yes & Yes & Yes \\
Habitual Offender Controls? & Yes & Yes & Yes & Yes \\
Type of Counsel Controls? & Yes & Yes & Yes & Yes \\
County x Year FEs? & Yes & Yes & Yes & Yes \\
Month of Year FEs? & Yes & Yes & Yes & Yes \\
& & & & \\
$R^{2}$ & 0.151 & 0.141 & 0.260 & 0.286 \\
AIC & $5.0 \times 10^{6}$ & $1.8 \times 10^{6}$ & $1.0 \times 10^{5}$ & $4.8 \times 10^{5}$ \\
$N$ & $1,385,588$ & 505,963 & 25,163 & 11,668 \\
\hline \hline
\end{tabular}

All cases with at least one conviction (dropping those with all counts dismissed or with a trial acquittal) included. Each column presents a partition of the data.

Dependent variable is the log of the sentence (upper bound of the top charge). OLS model estimated.

The control variables are the same as was used in Table 2.5.

Standard errors clustered by County x Year presented in the parentheses (865, 862, 768, x clusters, respectively);

$* * * 1 \%, * * 5 \%, * 10 \%$ level of significance.

mix of cases that are plea bargained. We consider the impact of the treatment on the difference between sentences arising from guilty pleas and sentences arising from trial convictions for crimes rarely going to trial, as compared to crimes that frequently do. If we find that the estimated effects are driven primarily by those crime types that frequently go to trial, one can reasonably be concerned that we are not estimating the actual change in the plea discount.

To do this analysis, we first consider those crimes with at least 2500 untreated observations. There are 28 such crimes. They make up 1,376,935 observations in total. Table 2.47 lists these crimes and provides the proportion of the (non-dismissed, felony) crimes pursued that go to trial. Specifically, the mean trial rate for the untreated observations is presented.

As one can see, there is quite a bit of variation in the trial rate. Some crimes rarely go to court. A few have relatively high rates. Forgery cases, for example, only go to trial $0.5 \%$ of the time. Sexual assaults, on the other hand, result in trials $11.7 \%$ of the time. It is this variation that we exploit.

We can gain confidence in the robustness of our main result if we see the change in the plea discount being rather large for those cases with low trial rates. If, on the other hand, our estimated average treatment effect is driven primarily by those with high trial rates, we can be concerned that our results are being driven by changes in the composition of cases that go to trial when the death occurs.

Table 2.48 replicates our primary specification (column (1) of Table 5 in the main text), but we restrict the sample to each of the 28 crime categories. We choose to present the coefficient and standard error for Death, Plea Bargain, and the interaction term Death x Plea Bargain. Each specification replicates the main result in its use of controls, fixed effects, and clustered standard errors.

Consistently across crime types, guilty pleas result in lower sanctions. Also, for the most part, 
Table 2.47: Crimes with at Least 2500 Observations

\begin{tabular}{llll}
\hline \hline Chapter number & Description & Number untreated & \% that went to trial \\
\hline 893 & drugs & 398,027 & 1.15 \\
812 & robbery & 263,236 & 1.57 \\
322 & drivers license & 96,980 & 0.69 \\
784 & assault & 73,029 & 4.64 \\
810 & burglary & 54,884 & 2.64 \\
843 & obstructing justice & 53,702 & 2.87 \\
831 & forgery & 30,292 & 0.51 \\
817 & fraud & 25,920 & 0.98 \\
948 & probation violation & 21,257 & 1.57 \\
790 & weapons & 20,689 & 4.67 \\
316 & traffic & 20,163 & 2.77 \\
918 & conduct at trial & 16,245 & 1.80 \\
901 & arrests & 14,496 & 1.44 \\
827 & child abuse & 11,982 & 3.46 \\
806 & arson & 11,545 & 3.66 \\
943 & Dept of law enforcement & 9995 & 2.17 \\
800 & lewdness & 9047 & 7.54 \\
951 & county prisoners & 7505 & 1.23 \\
914 & perjury & 6307 & 4.52 \\
832 & check fraud & 6096 & 0.67 \\
944 & state corrections & 5887 & 2.24 \\
794 & sexual battery & 4885 & 11.73 \\
900 & contempt & 4334 & 2.56 \\
787 & kidnapping & 3984 & 6.10 \\
856 & drunkenness & 3737 & 2.35 \\
796 & prostitution & 3310 & 0.60 \\
877 & miscellaneous crimes & 2957 & 3.21 \\
934 & surveillance & 2646 & 2.42 \\
\hline \hline
\end{tabular}


Table 2.48: Main Specification on Different Subsamples

\begin{tabular}{|c|c|c|c|c|c|c|c|}
\hline $\begin{array}{l}\text { Criminal } \\
\text { Chapter }\end{array}$ & $\begin{array}{l}\text { Death } \\
\text { coefficient }\end{array}$ & (st. error) & $\begin{array}{l}\text { Plea Bargain } \\
\text { coefficient }\end{array}$ & (st. error) & $\begin{array}{l}\text { DiD } \\
\text { coefficient }\end{array}$ & (st. error) & $\overline{N N}$ \\
\hline 893 & 0.1557 & $(0.1085)$ & -0.7700 & $(0.0660)^{* * *}$ & 0.1608 & $(0.0972)^{*}$ & 466,011 \\
\hline 812 & 0.3108 & $(0.1037) * * *$ & -0.5417 & $(0.0574) * * *$ & 0.0805 & $(0.1007)$ & 309,761 \\
\hline 322 & 0.0550 & $(0.1728)$ & -0.5670 & $(0.0766) * * *$ & 0.0629 & $(0.1661)$ & 109,385 \\
\hline 784 & 0.0465 & $(0.1044)$ & -0.6435 & $(0.0577) * * *$ & 0.2097 & $(0.1065) * *$ & 83,673 \\
\hline 810 & 0.1838 & $(0.1284)$ & -0.5251 & $(0.0764) * * *$ & 0.2439 & $(0.1254) *$ & 64,443 \\
\hline 843 & 0.0043 & $(0.1124)$ & -0.4844 & $(0.0600) * * *$ & 0.2991 & $(0.1112) * * *$ & 63,738 \\
\hline 831 & -0.1728 & $(0.2724)$ & -0.1082 & $(0.1712)$ & 0.2494 & $(0.2749)$ & 34,054 \\
\hline 817 & -0.2197 & $(0.2925)$ & -0.5110 & $(0.1344) * * *$ & 0.3795 & $(0.2903)$ & 30,040 \\
\hline 948 & -0.3302 & $(0.3933)$ & -0.6316 & $(0.0563) * * *$ & 0.5737 & $(0.3678)$ & 21,779 \\
\hline 790 & 0.1924 & $(0.1608)$ & -0.6412 & $(0.0923) * * *$ & 0.2690 & $(0.1675)$ & 25,108 \\
\hline 316 & 0.1201 & $(0.2066)$ & -0.7068 & $(0.1003) * * *$ & 0.1448 & $(0.2051)$ & 23,662 \\
\hline 918 & 0.0083 & $(0.2486)$ & -0.7446 & $(0.1123) * * *$ & 0.2368 & $(0.2440)$ & 19,300 \\
\hline 901 & 0.1289 & $(0.2486)$ & -0.8187 & $(0.1250) * * *$ & 0.1196 & $(0.2455)$ & 16,536 \\
\hline 827 & 0.6465 & $(0.2290) * * *$ & -0.8117 & $(0.127)^{* * *}$ & -0.0335 & $(0.2350)$ & 14,212 \\
\hline 806 & 0.2114 & $(0.2501)$ & -0.4325 & $(0.1527) * * *$ & 0.0981 & $(0.2463)$ & 13,232 \\
\hline 943 & -0.4537 & $(0.4759)$ & -0.6993 & $(0.1567) * * *$ & 0.5454 & $(0.4503)$ & 11,855 \\
\hline 800 & 0.3042 & $(0.2104)$ & -0.5564 & $(0.1181) * * *$ & 0.0297 & $(0.2199)$ & 11,084 \\
\hline 951 & 0.5599 & $(0.4872)$ & -0.5871 & $(0.1997) * * *$ & -0.2230 & $(0.4928)$ & 8,226 \\
\hline 914 & 0.1469 & $(0.3291)$ & -0.6916 & $(0.1383) * * *$ & 0.1080 & $(0.3222)$ & 7,366 \\
\hline 832 & 0.3421 & $(0.7136)$ & -0.0614 & $(0.4071)$ & 0.2931 & $(0.7720)$ & 6,924 \\
\hline 944 & 0.1062 & $(0.3899)$ & -0.4184 & $(0.1865) * * *$ & 0.2670 & $(0.3880)$ & 6,679 \\
\hline 794 & 0.6755 & $(0.2553) * * *$ & -0.3835 & $(0.1436) * * *$ & -0.3285 & $(0.2761)$ & 6,046 \\
\hline 900 & -0.3314 & $(0.3280)$ & -0.3538 & $(0.1697)^{* *}$ & 0.5024 & $(0.2829) *$ & 4,464 \\
\hline 787 & 0.2617 & $(0.3246)$ & -0.4259 & $(0.1743) * * *$ & 0.1225 & $(0.3401)$ & 4,835 \\
\hline 856 & 0.0805 & $(0.3821)$ & -0.2246 & $(0.2030)$ & 0.0752 & $(0.3753)$ & 4,271 \\
\hline 796 & -0.6720 & $(1.0284)$ & -0.7079 & $(0.7028)$ & 0.7310 & (1.0248) & 3,827 \\
\hline 877 & -0.0318 & $(0.3618)$ & -0.1787 & $(0.1958)$ & 0.4549 & $(0.3717)$ & 3,401 \\
\hline 934 & 0.2518 & $(0.9259)$ & -0.6893 & $(0.2696) * *$ & -0.1737 & $(0.9318)$ & 3,023 \\
\hline
\end{tabular}


the deaths correspond to decreases in the plea discount. Due to restricted sample sizes and large number of fixed effects used (eating up degrees of freedom), the statistical significance varies across crimes, but the magnitude of the estimated effects are typically substantial.

Our interest, though, is in the relationship between the average trial rate and the estimated change in the plea discount when a law enforcement official is killed in the line of duty. Figure 2.13 depicts it graphically (which is Figure 2.6 in the main text). The estimated coefficients on Plea Bargain and Death $\mathrm{x}$ Plea Bargain are used to calculate the plea discounts with and without the law enforcement official's death, so that the decrease in the plea discount can be estimated. This decrease is placed on the y-axis. The crime's trial rate, from Table 2.47 , is put on the x-axis. Figure 2.13 presents the scatterplot. The best fitting line also depicted.

A strong, negative relationship exists between the trial rate experienced within a particular crime category, in the untreated observations, and the estimated change in the plea discount when a law enforcement official dies. For those crimes where the trial rate is close to zero, the plea discount reduces substantially. For those cases with relatively high trial rate, the plea bargaining process does not lead to much of a change in the sentence.

Again, this finding is important in that a positive relationship between the two would call into question the conclusions reached in the paper. The average treatment effect is not arising from those crimes that go to trial. Therefore, it is unlikely that our estimated effect is coming from the mix of cases.

To further illustrate, if we bin the crimes by the trial rate, for those with plea bargaining occurring over $99 \%$ of the time, the plea discount reduces by $44.5 \%$ (calculating a simple unweighted mean of the estimated changes). For those crimes with a baseline level of plea bargaining between $98 \%$ and $99 \%$, the estimated change in the plea discount is $20.5 \%$. For trial rates in the $[2.0,3.0),[3.0,4.0)$, and $[4.0,5.0)$ bins, the change in the plea discount stabilizes at $29.8 \%, 21.5 \%$, and $21.9 \%$, respectively. Thus, those crimes with almost no trials are the ones that see the largest effect. The decrease in the plea discount is $-3.98 \%$ for those crimes with the trial rate exceeding $5 \% .{ }^{39}$

This analysis is done evaluating the baseline trial rate. One could, alternatively, categorize the crimes by the change in their trail rates. Again, one can be concerned about the interpretation of our results if the change in the plea discount we estimate occurs in those crime categories that also experience the largest estimated change in the trial rate.

Similar to Table 2.48, Table 2.49 re-estimates the primary specification for the effect of the law enforcement deaths on the trial rate (column (1), Table 11), but does so for each of the 28 subsamples previously used.

Once again, the deaths' effects are consistently positive across the crime categories. In fact, the deaths have a statistically significant increase in the trial rate for 22 of the 28 categories. The changes are insignificant for either relatively rare crimes (with few observations), such as drunkenness and prostitution prosecutions, or relatively minor crimes, such as probation violations.

As before, what is important is the relationship between the estimated change in the trial rate and the estimated change in the plea discount. Figure 2.14 depicts this graphically in a scatterplot of the 28 crime categories. The best fitting line is also depicted.

Figure 2.14 looks quite similar to Figure 2.13. A negative relationship exists between the size

\footnotetext{
${ }^{39}$ Each of these averages are calculated by simply identifying the unweighted mean of those crime categories with the baseline trial rate (proportion of cases pursued going to trial without the death treatment).
} 
Figure 2.13: Relationship between Trial Rate and Plea Discount

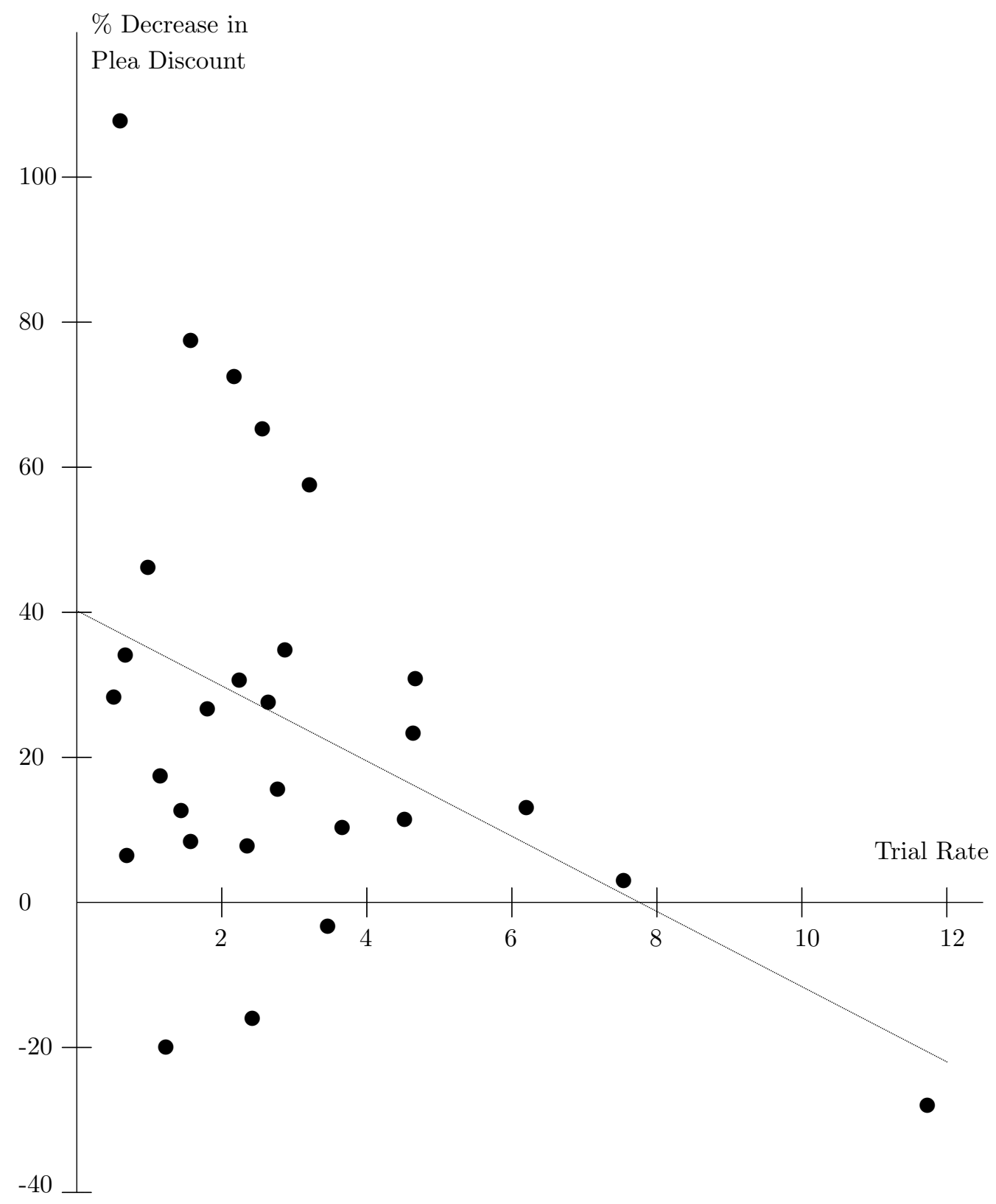


Table 2.49: Trial Rate Specification on Different Subsamples

\begin{tabular}{|c|c|c|}
\hline $\begin{array}{l}\text { Criminal } \\
\text { Chapter }\end{array}$ & $\begin{array}{l}\text { Death } \\
\text { coefficient }\end{array}$ & (st. error) \\
\hline 893 & 0.0132 & $(0.0012)^{* * *}$ \\
\hline 812 & 0.0193 & $(0.0017) * * *$ \\
\hline 322 & 0.0056 & $(0.0012) * * *$ \\
\hline 784 & 0.0355 & $(0.0041) * * *$ \\
\hline 810 & 0.0234 & $(0.0030) * * *$ \\
\hline 843 & 0.0335 & $(0.0033) * * *$ \\
\hline 831 & 0.0048 & $(0.0022) * *$ \\
\hline 817 & 0.0076 & $(0.0025) * * *$ \\
\hline 948 & 0.0073 & $(0.0080)$ \\
\hline 790 & 0.0378 & $(0.0052) * * *$ \\
\hline 316 & 0.0241 & $(0.0047) * * *$ \\
\hline 918 & 0.0260 & $(0.0043) * * *$ \\
\hline 901 & 0.0119 & $(0.0040) * * *$ \\
\hline 827 & 0.0403 & $(0.0079) * * *$ \\
\hline 806 & 0.0399 & $(0.0079) * * *$ \\
\hline 943 & 0.0021 & $(0.0048)$ \\
\hline 800 & 0.0440 & $(0.0106) * * *$ \\
\hline 951 & 0.0109 & $(0.0062) *$ \\
\hline 914 & 0.0309 & $(0.0102) * * *$ \\
\hline 832 & -0.0030 & $(0.0037)$ \\
\hline 944 & 0.0190 & $(0.0071) * * *$ \\
\hline 794 & 0.0373 & $(0.0173) * *$ \\
\hline 900 & 0.0606 & $(0.0361) *$ \\
\hline 787 & 0.0371 & $(0.0147) * *$ \\
\hline 856 & 0.0167 & $(0.0131)$ \\
\hline 796 & 0.0096 & $(0.0062)$ \\
\hline 877 & 0.0362 & $(0.0175) * *$ \\
\hline 934 & 0.0038 & $(0.0131)$ \\
\hline
\end{tabular}

Results from re-estimations of column (1) of Table 2.5 from the main text where all controls and fixed effects are included (except the crime controls). Standard errors are clustered at the county by year level.

Each row presents the result estimated on a sub-sample defined by the criminal chapter. 
Figure 2.14: Relationship between Change in the Trial Rate and Change in the Plea Discount

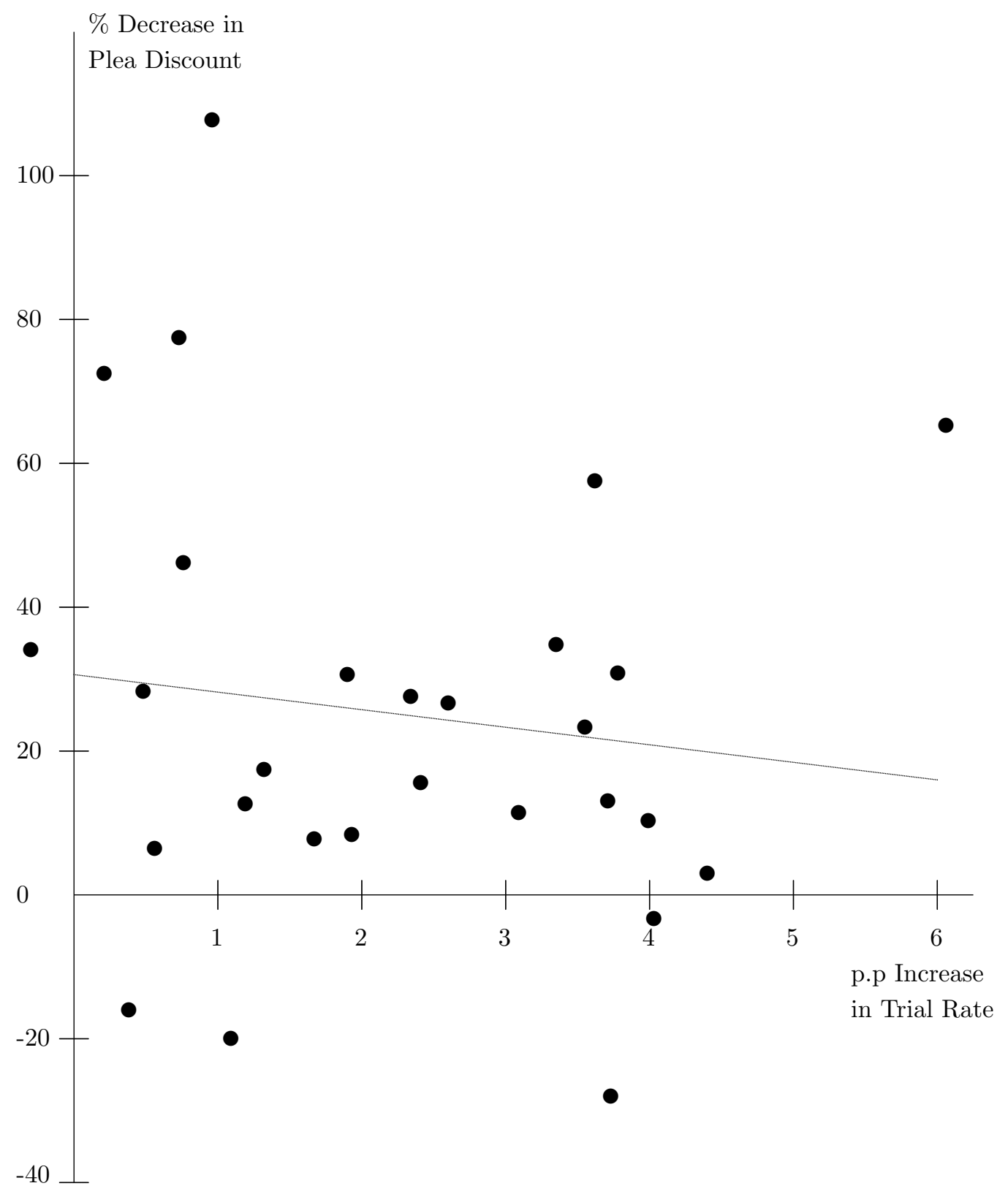


of the impact of the law enforcement officials' deaths on the trial rate and on the plea discount. For crimes that see the largest estimated increase in the trial rate, the estimated change in the plea discount is smallest.

Again, the threat to our identification was if a positive relationship existed. If it had been the case that those crimes with the largest change in the probability of going to trial were the ones that also experienced the largest reduction in the average plea discount, then it would be reasonable to argue that our results are not capturing changes in plea bargaining but instead capturing changes in the mix of cases that are plea bargained. Fortunately, this is not the case.

Therefore, we can be more confident that the hypothesized "bargaining in the shadow of the trial" is accurate. Those cases that are unlikely to go to trial, and therefore, unlikely to see large changes in the composition of cases that are plea bargained, are the ones that see the shadow framework generating differences in the plea discounts.

\subsubsection{Disparities}

Sentencing disparities have been well documented. Thus, it is prudent to explore their existence in our data. Prominent among them is gender and racial differences in outcomes. While these disparities are obviously a concern, exploring whether they are heightened in the plea bargaining process is a potentially interesting question.

To conduct the analysis, we simply disaggregate the difference-in-difference coefficient by, first, the gender of the accused and then, second, by whether s/he is white or black. ${ }^{40}$ With this disaggregation, we re-estimate our primary specification - the first column of Table 2.5 in the main text, which uses the $\log$ transformed sentence as the dependent variable in a fixed effects regression with clustered standard errors. Table 2.50 presents the results.

Women receive shorter sentences than men overall, which is in line with previous findings (Starr, 2015). Interestingly, the reduction in the plea discount when a law enforcement official dies in the line of duty is greater for men than women. Thus, male defendants are treated relatively harsher and this effect is escalated with the law enforcement official's death. For all felonies, men receive a $44.1 \%$ plea discount, while women receive a $49.2 \%$ discount. For serious crimes the plea discounts are $24.6 \%$ and $30.4 \%$, respectively.

The second column differentiates white from black defendants. As to be expected given past research on the topic, black defendants receive longer sentences than white defendants. Using these estimated coefficients, the reduction in the plea discount is approximately 5 percentage points greater for black defendants for all felonies and 10 percentage points greater for serious crimes.

Thus, not only do the results suggest that male and black defendants are receiving relatively harsher sentences when the law enforcement death occurs, but they indicate that some of these disparities are being driven by the plea bargaining process. The results are consistent with prosecutors anticipating different juror responses based on the gender and race of the defendant. Anticipating relatively greater changes in the jury's proclivity to convict, prosecutors are making less-generous offers.

Finally, the disparate impact can also be assessed on the trial rate. Table 2.51 uses whether the case when to a trial as the dependent variable. The variable Death is disaggregated by race and gender, respectively.

\footnotetext{
${ }^{40}$ For the sake of ease of the analysis, we do not include disaggregations for the other race variables.
} 
Table 2.50: Disparities: Plea Discount

\begin{tabular}{|c|c|c|c|c|}
\hline $\begin{array}{l}\text { Data set: } \\
\text { Demographic: }\end{array}$ & $\begin{array}{l}\text { full } \\
\mathbf{X}=\text { Female } \\
\mathbf{Y}=\text { Male } \\
(1)\end{array}$ & $\begin{array}{l}\text { full } \\
\mathbf{X}=\text { Black } \\
\mathbf{Y}=\text { White } \\
(2)\end{array}$ & $\begin{array}{l}\text { serious } \\
\mathbf{X}=\text { Female } \\
\mathbf{Y}=\text { Male } \\
(3)\end{array}$ & $\begin{array}{l}\text { serious } \\
\mathbf{X}=\text { Black } \\
\mathbf{Y}=\text { White } \\
(4)\end{array}$ \\
\hline Plea Bargain & $\begin{array}{l}-0.649^{* * *} \\
(0.043)\end{array}$ & $\begin{array}{l}-0.642^{* * *} \\
(0.043)\end{array}$ & $\begin{array}{l}-0.582^{* * *} \\
(0.048)\end{array}$ & $\begin{array}{l}-0.578^{* * *} \\
(0.048)\end{array}$ \\
\hline Death & $\begin{array}{l}0.202 \text { *** } \\
(0.076)\end{array}$ & $\begin{array}{l}0.224 * * * \\
(0.068)\end{array}$ & $\begin{array}{l}0.211 * * * \\
(0.082)\end{array}$ & $\begin{array}{l}0.223 * * * \\
(0.076)\end{array}$ \\
\hline $\mathrm{X}$ & $\begin{array}{l}-0.465 * * * \\
(0.007)\end{array}$ & $\begin{array}{l}0.189^{* * *} \\
(0.011)\end{array}$ & $\begin{array}{l}-0.662 * * * \\
(0.010)\end{array}$ & $\begin{array}{l}0.145^{* * *} \\
(0.010)\end{array}$ \\
\hline Death x Plea Bargain x Y & $\begin{array}{l}0.179^{* * *} \\
(0.064)\end{array}$ & $\begin{array}{l}0.115 \text { ** } \\
(0.058)\end{array}$ & $\begin{array}{l}0.198 * * \\
(0.081)\end{array}$ & $\begin{array}{l}0.121 \\
(0.075)\end{array}$ \\
\hline Death x Plea Bargain x X & $\begin{array}{l}-0.002 \\
(0.074)\end{array}$ & $\begin{array}{l}0.146 \text { *** } \\
(0.055)\end{array}$ & $\begin{array}{l}-0.011 \\
(0.085)\end{array}$ & $\begin{array}{l}0.205^{* * *} \\
(0.075)\end{array}$ \\
\hline Demographic Controls? & Yes & Yes & Yes & Yes \\
\hline Crime Controls? & Yes & Yes & Yes & Yes \\
\hline Habitual Offender Controls? & Yes & Yes & Yes & Yes \\
\hline Type of Counsel Controls? & Yes & Yes & Yes & Yes \\
\hline County x Year FEs? & Yes & Yes & Yes & \\
\hline Month of Year FEs? & Yes & Yes & Yes & Yes \\
\hline $\begin{array}{l}R^{2} \\
\text { AIC }\end{array}$ & $\begin{array}{l}0.089 \\
5.7 \times 10^{6}\end{array}$ & $\begin{array}{l}0.089 \\
5.7 \times 10^{6}\end{array}$ & $\begin{array}{l}0.116 \\
2.3 \times 10^{6}\end{array}$ & $\begin{array}{l}0.116 \\
2.37 \times 10^{6}\end{array}$ \\
\hline
\end{tabular}

All cases with at least one conviction included (dropping those with all counts dismissed or with a trial acquittal); $N=1,410,751$ in (1) and (2) and $N=505,963$ in (3) and (4).

Dependent variable is the log of the sentence (upper bound on the top charge). OLS model estimated as in the first column of Table 2.5 .

The control variables are the same as was used in Table 2.5.

Standard errors clustered by County x Year presented in the parentheses (865/862 clusters); *** $1 \%$, ** 5\%, * $10 \%$ level of significance. 
Table 2.51: Disparities: Trial Rate

\begin{tabular}{lllll}
\hline \hline Data set: & full & full & serious & serious \\
Demographic: & $\mathbf{X}=$ Female & $\mathbf{X}=$ Black & X = Female & X = Black \\
& Y= Male & Y= White & Y= Male & Y= White \\
& $(1)$ & $(2)$ & $(3)$ & $(4)$ \\
\hline Death x Y & $0.0206^{* * *}$ & $0.0168^{* * *}$ & $0.0254^{* * *}$ & $0.0212^{* * *}$ \\
& $(0.0016)$ & $(0.0013)$ & $(0.0020)$ & $(0.0017)$ \\
& & & & \\
Death x X & $0.0152^{* * *}$ & $0.0231^{* * *}$ & $0.0211^{* * *}$ & $0.0293^{* * *}$ \\
& $(0.0014)$ & $(0.0019)$ & $(0.0023)$ & $(0.0026)$ \\
X & & & & \\
& $-0.0046^{* * *}$ & $0.0099^{* * *}$ & $-0.0081^{* * *}$ & $0.0156^{* * *}$ \\
& $(0.0004)$ & $(0.0004)$ & $(0.0007)$ & $(0.0007)$ \\
Demographic Controls? & Yes & Yes & Yes & Yes \\
Crime Controls? & Yes & Yes & Yes & Yes \\
Habitual Offender Controls? & Yes & Yes & Yes & Yes \\
Type of Counsel Controls? & Yes & Yes & Yes & Yes \\
County x Year FEs? & Yes & Yes & Yes & \\
Month of Year FEs? & Yes & Yes & Yes & Yes \\
& & & & \\
$R^{2}$ & & & & 0.040 \\
AIC & 0.037 & 0.037 & 0.040 & $-3.7 \times 10^{5}$ \\
\hline \hline
\end{tabular}

All cases (dropping those with all counts dismissed), both trial convictions and acquittals along with guilty pleas, included; $N=1,416,540$ in (1) and (2) and $N=509,738$ in (3) and (4).

Dependent variable equal to one if any count charged is disposed at trial (jury or nonjury \& convicted or acquitted). Linear probability models are estimated.

The control variables are the same as was used in Table 2.5.

Standard errors clustered by County x Year presented in the parentheses (865/862 clusters); *** $1 \%$, ** $5 \%$, * $10 \%$ level of significance. 
With regards to gender, both male and female defendants see an increase in the likelihood of the case going to trail. Women go to trail less frequently. The increase in the trial rate is not as great for females either. Thus, the gender disparity grows.

With regards to race, Black defendants are more likely to go to trial as a baseline. The trial rate increases for both White and Black defendants, but the growth is larger for Blacks.

\subsubsection{Charge Stacking}

It is common to presume that juries provide noise in the system in that they open up the possibility of conviction with weak evidence and acquittal with strong evidence simply because they are nonprofessionals made up of a potentially random, small sample of the population. Gay, Grace, Kale, and Noe (1989) use this distinction, for an example, in their theoretical analysis of the use of bench versus jury trials. Prominent models of plea bargaining, such as Priest and Klein (1984) and D. S. Abrams (2011), which use a random noise component to negociants' expectations of the trial conviction probability, can be motivated by juries distorting accurate expectations in the bargaining process.

One claim is that prosecutors engage in a practice known as "charge stacking" where they add charges to the primary charge. These added charges act as threats in the bargaining process as they are included in the charges taken to a jury trial if a deal cannot be reached. The offered deal, then, proposes to drop these additional charges in return for a guilty plea for the primary offense. With a noisy jury, the charge stacking tactic can potentially be effective.

Therefore, we look for evidence of charge stacking in our data. Of course, we do not know the circumstances of each case such as when new evidence arises, when witnesses come forward, or when investigation leads to information on the occurrence of additional crimes. We can though consider the number of charges filed as the case proceeds through its process. We create an indicator variable equal to one if the number of charges filed increases from the initial charging phase coming out of the arrest to the number of charges pursued in the prosecution phase. In the full data set of felony convictions, $2.5 \%$ of cases see an increase in the number of counts. The following table estimates a linear probability model with the Increase in Counts variable as the dependent variable. As always, in Table 2.52 a full set of controls and fixed effects are included and clustered standard errors are calculated.

While plea bargained cases are overall less likely to see an increase in the number of counts, the difference diminishes with the death of a law enforcement official. Plea bargained cases see relatively more charges filed against when the shock occurs. This can explain, in part, the relative increase in the sanction received. 
Table 2.52: Charge Stacking

\begin{tabular}{llll}
\hline \hline Data set: & full & full & serious \\
& $(1)$ & $(2)$ & $(3)$ \\
\hline Death & 0.0008 & $-0.0103^{* * *}$ & $-0.0080^{* *}$ \\
& $(0.0010)$ & $(0.0033)$ & $(0.0041)$ \\
& & & \\
Plea Bargain & & $-0.0173^{* * *}$ & $-0.0181^{* * *}$ \\
& & $(0.0023)$ & $(0.0026)$ \\
& & & \\
Death x Plea Bargain & & $0.0112^{* * *}$ & $0.0100 * *$ \\
& & $(0.0030)$ & $(0.0040)$ \\
& & & \\
Demographic Controls? & Yes & Yes & Yes \\
Crime Controls? & Yes & Yes & Yes \\
Habitual Offender Controls? & Yes & Yes & Yes \\
Type of Counsel Controls? & Yes & Yes & Yes \\
County x Year FEs? & Yes & Yes & Yes \\
Month of Year FEs? & Yes & Yes & Yes \\
& & & \\
$R^{2}$ & 0.062 & 0.063 & 0.058 \\
AIC & $-2.0 x 10^{6}$ & $-2.0 x 10^{6}$ & $-6.0 x 10^{5}$ \\
Dep. Var. $\mu$ & 0.0252 & 0.0252 & 0.0260 \\
\hline \hline
\end{tabular}

All cases (dropping those with all counts dismissed), both trial convictions and acquittals along with guilty pleas, included; $N=1,416,540$ for (1) and (2) and $N=509,738$ for (3).

Dependent variable equals one if the total number of counts is higher after the prosecutor phase than the initial charging phase. Linear probability model estimated.

Standard errors clustered by County x Year presented in parentheses $(695 / 649$ clusters $) ; * * * 1 \%,{ }^{* *} 5 \%,{ }^{*} 10 \%$ level of significance.

The control variables are the same as was used in Table 2.5. 


\section{Chapter 3}

\section{If You Build It, We Will Make Them Come: The Impact of New Prison Construction on the Likelihood of Incarceration}

\subsection{Introduction}

The reformation of the criminal justice system has been a topic of discussion in recent years. As of 2016, over 600 people per 100,000 in the country experienced in-house incarceration in either a prison or jail (Kaeble \& Cowhig, 2018). While this number is the result of a trend shifting to a smaller percentage of the population incarcerated, this has only been a recent occurrence. From 1980 through 2005, the prison population was steadily increasing within the country, putting not only a stress on the criminal justice system, but the community at large. An increase in the capacity, or number, of prisons must necessarily follow an increase in number of individuals incarcerated. As of 2005, there were over 1,000 state and federal prisons within the United States, a $9 \%$ increase from the number in 2000. This increase in prisons was met nearly one-for-one with the increase in prisoners held in custody increasing by $10 \%$ over the same period (Stephan, 2008).

A recent study by Dippel and Poyker (2020) investigates the question of prison capacity and incarceration from a different angle. Namely, does an increase in capacity lead to higher rates of incarceration, or increased sentence lengths? ${ }^{1}$ Their results present a concerning finding, primarily within the private prison system. Large increases in prison capacity, as measured by private prison openings, and even small increases in bed availability are associated with harsher sentences for victims sentenced within a two-and-a-half month window following the increased capacities. This is concerning as the criminal justice system should be incarcerating individuals based on their danger to society, and not merely on the availability to house them. However, this finding was only present for private prisons, and not for publicly-run facilities.

\footnotetext{
${ }^{1}$ Cunningham and Kang (2018) do this in a less-direct way, using funding from a 1993 Texas initiative to invest in prison infrastructure.
} 
The econometric approach of the authors is strong, and allows for causal inference using contiguousborder court-pairs as a spatial discontinuity utilizing differences in capacity within counties from different states that border one another. However, it may be the case that public prisons could be more responsive to these changes in bed capacity, functioning at a more state-wide level than private prisons. The purpose of this paper is to further investigate these capacity changes in public prisons at a state-wide level, using prison openings in the state of Florida from 2004-2017.

When new prisons are constructed, their placement is endogenous, decided by the legislative body of the state. These prisons are usually constructed in rural, generally poorer, where these facilities could serve to stimulate the local economy and bring benefits that outweigh the costs. This can lead to competition among communities lobbying for the siting of the prison within their district. This development is largely due to the job offerings prisons can provide for local residents for places that have few alternatives for economic development (Carlson, 1991). This supposed benefit appears to be short-lived (Glasmeier \& Farrigan, 2007) and particularly impactful for those communities that were early to host these facilities (Eason, 2017). ${ }^{2}$ However, this placement can have pervasive effects on the wider criminal justice system. In Florida, prosecutors, judges, and even public defenders (McCannon, 2018) are elected public officials. This election mechanism may change the behavior of elected officials, especially if there is a potential of the prison shutting down or reducing the number of employees due to a lack of inmates.

This points to a larger discussion in the sentencing literature about electoral cycles. This literature has heavily focused on the actions of judges. At the most basic level, voters are generally poorly informed about the quality of judges, and therefore a single high-profile case could earn or lose a vote for the incumbent judge (A. Huber \& Gordon, 2004). Likely, voters will be more likely to be attention at the end of a term, than the beginning. Therefore, expected effects should be more pronounced as the election approaches. Berdejó and Yuchtman (2013) find just that, with sentences that are $10 \%$ harsher at the end of a term than at the beginning. This strategic behavior (as also demonstrated by D. Abrams, Galbiati, Henry, and Philippe (2019)) is sensitive to the presence and quality of challengers (M. G. Hall \& Bonneau, 2006; Gordon \& Huber, 2007). However, not all states elect judges, and within the states that do, results may not be consistent. In an evaluation of states that were studied previously, as well as a collection of new states, Dippel and Poyker (2019) find that the electoral cycles in criminal sentencing are not uniform across a variety of states.

However, there also exists a literature that focuses on the behavior of prosecutors when faced with electoral pressures. The discretion that judges are able to exert on the outcome of a case only follow the discretionary decisions of the prosecutor. Namely, if a prosecutor is able to plea bargain a case, the discretion of the judge in sentencing may be muted by an already agreed to sentencing structure from the prosecutor and defense team. The re-election concerns of prosecutors decreases the likelihood of plea bargaining (which typically results in shorter sentences) and increase the likelihood of taking a case to trial (Bandyopadhyay \& McCannon, 2014). This likely is a way the prosecutors can signal quality to voters (Bandyopadhyay \& McCannon, 2015). However, sentence lengths, and not conviction rates may be what drives the success of a prosecutor's career (Boylan, 2005). This is informative to the current study. Namely, if these prison openings serve as an additional measurement of salience to the voting community, it is expected that utility optimizing prosecutors will increase sentence lengths, potentially through plea bargaining, trials, or both.

\footnotetext{
${ }^{2}$ See also: (King, Mauer, \& Huling, 2003; Blankenship \& Yanarella, 2004; Besser \& Hanson, 2016)).
} 
This paper will not explicitly use elections as the mechanism, rather it directly relates to the emerging literature on the impact of extra-legal factors on sentencing decisions. In an ideal world, the only considerations for the sentencing or incarceration decision of a defendant would be the merits of a case. However, legal officials have been shown to be susceptible to extraneous forces. In particular, judges modify their sentencing decisions based on a multitude of extra-legal factors such as: defendant birthday (Chen \& Philippe, 2017), food breaks (Danziger et al., 2011), and unexpected outcomes of local football games (Eren \& Mocan, 2018). Additionally, prosecutors are not immune to behavioral shifts. Bonneau and McCannon (2019) investigate the impact of police officer deaths on the sentencing outcomes for defendants with cases already in process at the time of the death. The resulting salience of the death could increase the jury's likelihood of conviction. Prosecutors, aware of this potential, engaged in more aggressive plea bargaining tactics, leading to an increase in the sentences resulting from plea bargains.

These prisons do not only provide an economic advantage to those counties that house them, but they may also serve to reduce crime in the area. Consistent with Becker (1968), prisons may serve as a potential mechanism to increase the expected cost of undertaking criminal activity (Bedard \& Helland, 2004). Levitt (1996) empirically tests this hypothesis, and finds that the magnitude of the responsiveness to the salience of incarceration is double the previous estimates, or an increase of one prisoner is associated with a decrease in fifteen crimes per year. This possibility for a reduction in crime within a community, combined with the economic advantage of a new prison make these prison openings a salient event for residents of the community. Therefore, these may be events that influence the behavior of prosecutors and/or judges as voters may have a heightened awareness to the results of the criminal justice system over this period.

This is the finding of the current paper. Using all felonies processed in Florida from 2004-2017, there is an increase in the likelihood of incarceration by about 7-10\%. Breaking down the first year after a new prison is opened into three-month windows, this effect is concentrated within the first nine months after that prison begins accepting inmates. This effect is more pronounced in plea bargained cases, though it does exist at a lesser extent within the first three months for cases taken to trial.

The paper will proceed as follows. Section 2 introduces the criminal justice and prison systems in Florida. Section 3 describes the data used for the analysis. Section 4 describes the methodology. Section 5 presents results, and Section 6 considers alternative specifications for robustness and falsification. Lastly, Section 7 concludes and offers a discussion of potential policy implications.

\subsection{Florida's Criminal Justice System}

Florida is comprised of 67 counties, each of which houses its' own county court. These counties are then part of larger circuits, of which there are 20 within the state. Depending on the population of the counties in the circuit, they range from one county (such as the Eleventh Circuit - Miami-Dade), to seven $^{3}$ (Third Circuit). A map of the circuits and the counties that are within them is provided in Figure 3.1. Circuit courts are the primary courts for felony cases, the subject of this study. These circuits will vary in the number of sitting judges, prosecuting attorneys (assistant state attorneys) ${ }^{4}$,

\footnotetext{
${ }^{3}$ Columbia, Dixie, Hamilton, Lafayette, Madison, Suwannee, and Taylor Counties.

${ }^{4}$ One state attorney resides over one circuit and serves as the chief prosecuting attorney for that circuit. However, the number of assistant state attorneys (those who prosecute a majority of the cases) will vary based on the caseload.
} 
public defenders, and private law firms. Those on the side of the criminal justice system are elected, though by different means. Trial judges are popularly elected in non-partisan elections, while state attorneys are elected in partisan elections. In addition, Florida is one of only four states where public defenders are elected in popular elections (McCannon, 2018).

Figure 3.1: Florida Circuits

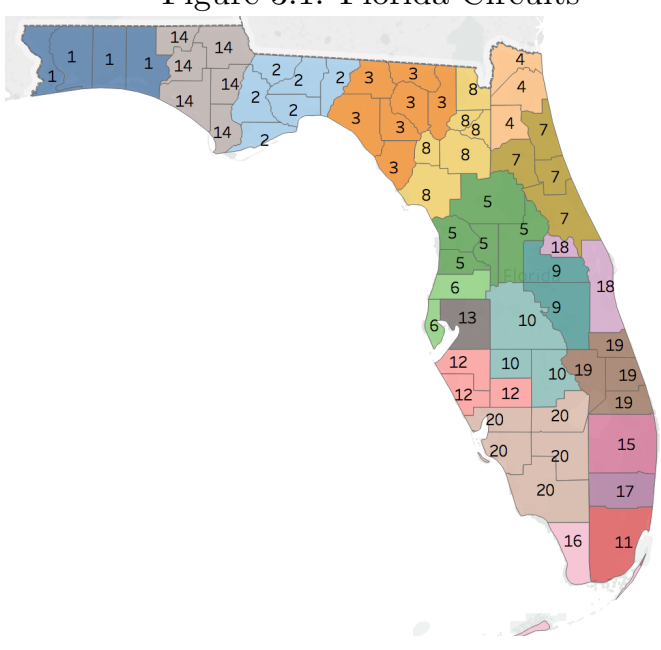

Florida currently has 148 correctional institutions, of which 50 are designated as major institutions and 17 are annexes to these major facilities (FLDOC, 2018). In addition, some of these facilities have undergone expansions throughout the last few decades, and some have ceased their operation. Private prisons are also present within the state, where they primarily operate as workrelease camps. Institutions under the jurisdiction of the Florida Department of Corrections (DOC) are grouped into four distinct regions that will be important to the methodology (see Figure 3.2). These facilities vary on the types of services they provide for inmates ${ }^{5}$, and only incarcerate felons whose sentence exceeds one year. The process by which these convicted felons are placed is formulaic, but not consistent in a sense that a defendant sentenced in one circuit may not be sentenced to a facility in the same circuit. Once sentenced, a defendant is sent to a reception center where they will remain for three to four weeks and participate in an intake process. During this intake process, criminal history, sentence length, seriousness of offenses, and other factors are taken into consideration. Based on these responses, the defendant will be transferred to the appropriate institution where they will serve out the remainder of their sentence.

For the purposes of this study, only major correctional institutions and their annexes are considered. These correctional facilities are prisons with razor wire, electronic detection systems, perimeter towers with armed guards, and officers patrolling in vehicles on the perimeter (FLDOC, 2018). Inmates assigned to these facilities do not live in cells, and instead are largely housed in large dormitories with bunk bends. These facilities host a multitude of security levels (most from minimum to close security) and house nearly $85 \%$ of Florida's prison population. Across the 74 total institutions considered to be broadly defined as correctional institutions ${ }^{6}$, there are over 81,000 inmates. $^{7}$

\footnotetext{
${ }^{5}$ These programs can be broadly grouped into: Academic, vocational, substance abuse, chaplain services, betterment, and re-entry programs. Most prisons have at least one service offered within each category, though it is not ubiquitous.

${ }^{6}$ This grouping includes correctional institutions, private correctional institutions, and annexes. Of these, six are female institutions (four correctional, one private, and one annex).

${ }^{7}$ There are 97,794 total inmates incarcerated in the state as of 2017.
} 


\subsection{Data}

Data from Florida's Office of the State Courts Administrator (OSCA) is utilized to evaluate the potential effect of a new prison on the likelihood a defendant faces incarceration in prison. This rich data set includes every charge for each docket that was processed between the years of 2004-2017. Additionally, it includes all information about each case including demographic characteristics of the defendant; county of arrest and prosecution; date of arrest, prosecution, and court appearance; as well as detailed information about the specific charges that were filed against the defendant. Though there is the possibility of multiple types of defense represented for a particular case within the data, defense counsel usually remains consistent. ${ }^{8}$ Importantly, incarceration is broken up into a tiered category that allows for potential falsification tests. Namely, the data denotes if an individual was sentenced to prison, jail, hospital, juvenile facility, or some other form of diversionary control. The variable of interest for this study will be incarceration specifically in prison.

For the purposes of this study, only cases where a defendant was charged with a felony at some point in the duration of their case are considered. ${ }^{9}$ This is due to a few reasons. Primarily, misdemeanor cases will not end up in prison. Only felony cases that have a sentence length of over one year make the defendant eligible for this type of incarceration in the state of Florida. Additionally, felonies have a wide variance in the severity of sentencing. Some third degree felonies may sentence an individual for a year or less. First degree felonies can be up to 25 years or carry a death sentence in Florida. This will allow us to exploit more variation in the sentences and reduce the cluster that occurs near zero.

After removing all non-felony cases, the data set is partitioned into two samples that will be used for the primary analysis. The first data set will retain cases, including those that were dismissed at some point. This is done to investigate the mechanism that adjusts the probability of incarceration. Next, the analysis will remove these dismissed cases and only consider those cases in which a guilty verdict was rendered. That is, any case that was fully dismissed, transferred, or otherwise disposed of without a guilty verdict is removed from this particular sample. Lastly, appellate cases must be removed from the data. While these appeals could provide an interesting perspective similar to McCannon (2013), investigating the potential over-zealousness of prosecutors, the process by which the appellate information is entered removes the initial case details. In other words, any information that existed on the initial charges is overwritten with the appellate information. This poses an issue with the completeness of the data. For example, if a docket initially had three charges that for which a defendant was found guilty, but only one is appealed, only the one appealed charge would appear in the data set.

The summary statistics for the full sample (including dismissed cases) is provided in Table 3.1. This sample of 1,833,766 observations has just over $20 \%$ of cases dismissed at some point along the criminal justice process. Combining this with the $78 \%$ plea bargaining average, it can easily be seen that trials make up a very small portion of the sample, only 1.5\%. Additionally within this case characteristics portion, two outcomes presented, though more are present in the data so these

\footnotetext{
${ }^{8}$ However, some charges may be adjudicated at different times. In this scenario, a defendant may have a court appointed attorney for the first set of charges in the stage prior to indictment, and then have a public defender represent them in court for some reason that is unspecified within the data. It may also be the case that a defendant changed their type of representation during the case.

${ }^{9}$ For example, it may be the case that a defendant is arrested for a misdemeanor charge, but upon reaching the desk of the prosecutor they change the charge to a felony due to a specific element that was overlooked by the arresting officers.
} 
Table 3.1: Summary Statistics - Including Dismissed Cases

\begin{tabular}{|c|c|c|c|c|}
\hline & Mean & St. Dev. & Min & $\operatorname{Max}$ \\
\hline \multicolumn{5}{|l|}{ Case Characteristics } \\
\hline Dismissed & 0.204 & 0.403 & 0 & 1 \\
\hline Prison & 0.278 & 0.448 & 0 & 1 \\
\hline Jail & 0.481 & 0.500 & 0 & 1 \\
\hline Highest Sentence & 14.780 & 39.046 & 0 & 1200 \\
\hline Plea Bargain & 0.781 & 0.414 & 0 & 1 \\
\hline Counts & 2.584 & 5.967 & 1 & 899 \\
\hline Habitual Offender & 0.008 & 0.086 & 0 & 1 \\
\hline Habitual Violent Offender & 0.001 & 0.030 & 0 & 1 \\
\hline Career Violent Offender & 0.000 & 0.007 & 0 & 1 \\
\hline \multicolumn{5}{|l|}{ Demographic Characteristics } \\
\hline Male & 0.797 & 0.402 & 0 & 1 \\
\hline Female & 0.202 & 0.401 & 0 & 1 \\
\hline White & 0.607 & 0.489 & 0 & 1 \\
\hline Black & 0.386 & 0.487 & 0 & 1 \\
\hline Asian & 0.002 & 0.047 & 0 & 1 \\
\hline Native & 0.001 & 0.027 & 0 & 1 \\
\hline Age at Arrest & 32.606 & 11.392 & 14 & 96 \\
\hline \multicolumn{5}{|l|}{ Counsel Type } \\
\hline Private & 0.222 & 0.416 & 0 & 1 \\
\hline Public & 0.545 & 0.498 & 0 & 1 \\
\hline Appointed & 0.049 & 0.216 & 0 & 1 \\
\hline Self & 0.128 & 0.334 & 0 & 1 \\
\hline Other & 0.098 & 0.297 & 0 & 1 \\
\hline
\end{tabular}

$\mathrm{N}=1,833,766$ for all variables. 
variables will not sum to one. The primary dependent variable in the analysis is labeled "Prison" and represents an individual that was sentenced to prison incarceration of any length for at least one of the charges in their docket. The proportion of cases that faced prison incarceration is just over $27 \%$, while those who are sentenced to lower-level jail sentences are at $48 \%$. Due to the nature of this sample, there will be individuals that experience no form of incarceration, but instead must adhere to probation or community service as their disciplinary consequence for a guilty verdict or plea. Finally, while there is no criminal history within the data, there are qualifiers that are presented as special sentencing provisions. Three categories are used as a proxy for criminal history. These three proxies are various levels of previous exposure to the criminal justice system. These are presented in increasing severity, with a habitual offender as the broadest category, while a career violent offender is the harshest classification. ${ }^{10}$ An indicator variable is created based on whether an individual was either sentenced, or adjudged, to fall in one of these categories for at least one of the charges within their docket.

Though the length of a prison sentence is not the primary concern of this study, the length of incarceration may provide some insight into the mechanism driving the results. Additionally, literature previously discussed has found that sentencing lengths may be the most salient to potential voters. Here, the sentence is presented in months. That is, the average sentence is just under 15 months. This variable is top-coded at 1200 months, with any sentence above this value grouped into the category of 100 years. This is done due to the inability to categorize differences in large sentences that may have been the result of error in data entry, and so as to reduce the upward bias in any regression utilizing this measurement.

The demographics of the sample are relatively straightforward. Traditional categories of racial classifications are present within the data with one exception. Defendants of white or Hispanic descent are grouped into the classification of "White." Therefore, if there are any differences between these two races, this study will be unable to properly control for them. Lastly, the average age at arrest is just over 32 years of age. There are individuals in the raw data that appear as younger than the reported minimum age. However, children under the age of 14 are unable to have their charges transferred to an adult court, and therefore the data are left-censored at this age. No such censoring was conducting for the upper bound of the age at arrest.

Finally, individuals in the United States have many options when it comes to defensive representation. A majority of defendants qualify for indigent defense, which will be carried out by either a public defender or a court appointed attorney. Public defenders are the most common type of representation in the data set, with over half of defendants utilizing this office. Private counsel is the second most frequent, with nearly a quarter of the data being represented by a private attorney. The rest of the data is split between individuals that had a court appointed attorney, some other type of representation, or represented themselves. There is no way to know what falls into this "other" category as it was provided in the raw data.

There may be a benefit in exploring the percentage of charges that are adjudicated guilty. However, with the focus of this study on the plea bargaining process, this would be endogenous to the identification strategy. That is, if the change in prosecutorial behavior functions through the preva-

\footnotetext{
${ }^{10} \mathrm{~A}$ description of the process for designation of these qualifiers can be found in Florida Criminal Code 775.084(3)(a). This is not the best measure for criminal history, but it is the only measure within the data that is available. There is full acknowledgement that this is likely going to be incomplete, as there is a potential for individuals who are sentenced or adjudged to be one of these categories may be missing this qualifier within the data.
} 
lence of charge bargaining following a new prison opening, the model would be unable to be correctly specified to capture this behavior. Sentences have the possibility of being served consecutively (one sentence ends, and another begins) or concurrently (all sentenced served at the same time). There is no designation within the data as to if the sentence was to be served consecutively or concurrently. Because of this, all sentences are treated as though they are served concurrently. This should not be an issue for the study however, unless the process by which a defendant serves their sentence varies systematically with the opening of a new prison.

Finally, the sentence variable used is constructed from the bounds applied to the sentence through the sentencing score-sheet. This score-sheet takes into account the information about the case, as well as criminal history to assign a lower bound and an upper bound to a sentence. In some cases, these bounds are equal. To construct the "Highest Sentence" variable, the upper bound of the sentence attached to the most severe charge within a docket is used. That is, only the bounds of the sentence for the charge that was most severe, as measured by felony degree, are used to construct the sentence measurement. ${ }^{11}$ From this, the upper bound of that sentence is taken for the highest sentence received by that defendant.

The Florida Department of Corrections (FDOC) keeps record of all prisons within the state and the year they opened. However, due to the daily nature of the crime data, a more refined data set on the opening date of prisons was collected using the Way Back Machine. Using this, each prison was searched within the prison population records of the FDOC website. The first month that the prison appeared with a non-zero population was used as the month of opening. To be careful, this may not be the official month the prison began accepting inmates. However, it is the best information that can be gathered to address a plausible opening date. During the period of study, eight new prisons opened. These prisons are listed in Table 3.2, and include seven male prisons, and one female prison. $^{12}$

Table 3.2: List of New Prison Openings

\begin{tabular}{lcccccc}
\hline Prison Name & Opening Date & County & \multicolumn{4}{c}{ Circuit Region Capacity Gender } \\
\hline Columbia Correctional Institution Annex & $09 / 2004$ & Columbia & 3 & 2 & 1,566 & Male \\
Franklin Correctional Institution & $07 / 2005$ & Franklin & 2 & 1 & 1,346 & Male \\
Santa Rosa Correctional Institution Annex & $03 / 2006$ & Santa Rosa & 1 & 1 & 1,478 & Male \\
Demilly Correctional Institution & $11 / 2008$ & Polk & 10 & 2 & 372 & Male \\
Suwannee Correctional Institution & $12 / 2009$ & Suwannee & 3 & 2 & 1,502 & Male \\
Suwannee Correctional Institution Annex & $09 / 2010$ & Suwannee & 3 & 2 & 1,346 & Male \\
Mayo Correctional Institution Annex & $1 / 2012$ & Lafayette & 3 & 2 & 1,345 & Male \\
Florida Women's Reception Center & $03 / 2012$ & Marion & 5 & 3 & 1,345 & Female \\
\hline
\end{tabular}

Each of these prisons houses over 1,300 inmates (with the exception of Demilly Correctional Institution) and are for adult offenders only. Consistent with the literature addressed earlier, these prisons are located in the more rural, northern portion of the state.

A map of each county within each circuit is provided in Figure 3.1. Within this figure, each

\footnotetext{
${ }^{11}$ For example, if a defendant was charged with a first degree felony, and a second degree felony, only the sentence received for the first degree felony would be considered. Additionally, it is possible that defendants have multiple charges within the same felony degree. In this case, the first charge to appear is considered to have the highest severity.

${ }^{12}$ The woman's prison is a reception center, which is primarily utilized for the initial intake of inmates following sentencing. Even though this prison houses general inmates as well, it will not be considered in the sample. Accessed at: http://www.dc.state.fl.us/ci/368.html
} 
number corresponds to the circuit, with county borders drawn in. New prisons are located primarily in the northern portion of the state, with one located centrally. Circuits 1, 2, 3, 5, and 10 experienced new prison construction in the period of this paper. The location of these prisons in more rural areas is important for an understanding of the crime rates potentially faced within each of these circuits. Glaeser and Sacerdote (1999) explains that potential differences in the crime rate disparity experienced between urban and rural areas is largely attributable to the higher benefit one can receive from committing crime in an urban setting, while also decreasing the expected costs associated with the crime as it is more difficult to find perpetrators in a denser setting. For the purposes of the analysis, the pool of potential criminals is less important, as the focus is on those individuals who are not only arrested, but are additionally convicted of crimes. Thus, the selection issue discussed in most crime studies should be minimized with the focus on these end of process criminals.

The following analysis hinges on the method by which defendants are sentenced to a particular prison. Within the criminal data, there is no way to follow a defendant from conviction to the prison in which they were incarcerated. ${ }^{13}$ This will potentially have a problematic effect on the results, as they not be capturing the individuals who were in fact sentenced to these facilities. However, this decision also lies outside of the purview of the judges, as their prison assignment is determined after assignment to a reception center. Judges and prosecutors do, however, retain discretion over the formal sentencing of defendants. Therefore, using information similar to that found in the available data, these officials make the determination of whether to sentence an individual to formal incarceration in prison, and the length of sentence they will receive. The lack of ability to track a defendant to their prison is an issue, but the following section describes an approach to approximate the prison location of defendants.

\subsection{Where are Prisoners Sentenced?}

Florida's prison system is divided into four prison regions depicted in Figure 3.2. Mapping the circuits of each prison to these regions shows that only regions 1, 2, and 3 received a new prison throughout 2004-2017. Therefore, there may be a different response in region 4 (southern portion of the state) than the others.

The methodology will be presented in two separate ways: A state-wide analysis, and a regional analysis that only considers those cases heard in regions 1, 2, or 3. However, the absence of a new prison in region 4 does not make this approach necessarily correct. To address the validity of this methodology, a data set of all prisoners that have been released since 1997 is collected from the Florida Department of Corrections. This data set does not provide the home address of the defendant when they were incarcerated, but it does provide the address to which the prisoner was released upon serving their sentence. This address is used as a proxy for their home address prior to incarceration, as it is assumed likely that many prisoners will be returning to the same address upon release. This address is then mapped to the county, circuit, and region it corresponds to. Additionally, the county in which the crime was committed is also included and utilized. This

\footnotetext{
${ }^{13}$ The FL DOC keeps an online database of all inmates at every facility within the state. These inmates are assigned a DOC Number, which is their number for as long as they are incarcerated on their sentence within the state. There is also information about the county-level docket number which can be used to cross-reference criminal records with the current prison population. The data used in this study includes the state docket number. Since this number differs from the county docket, inmates cannot be matched to their criminal case.
} 
Figure 3.2: Florida Department of Corrections Regions

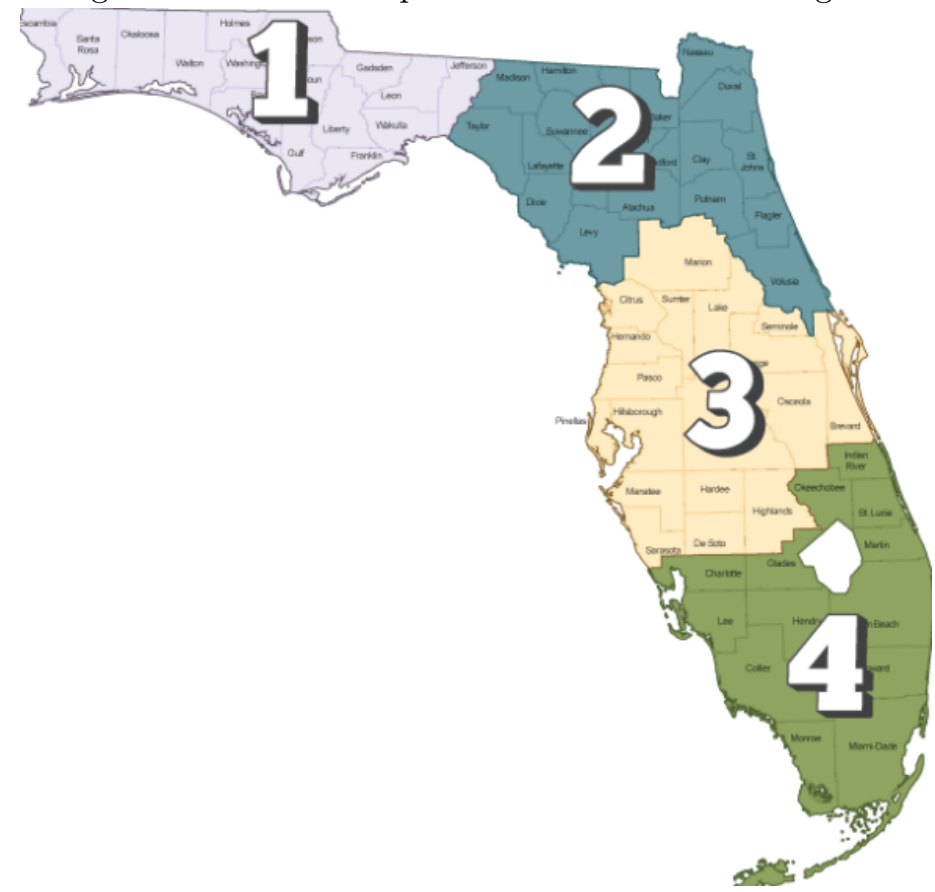

information is then combined with the location of the prison to uncover the percentage of inmates that have been released that are in the same county, circuit, or region as their home address and/or where they committed the crime.

Table 3.3: Home and Crime Locations

\begin{tabular}{lccc}
\hline & County & Circuit & Region \\
\hline County & $69.81 \%$ & - & - \\
Circuit & - & $74.65 \%$ & - \\
Region & - & - & $86.19 \%$ \\
\hline
\end{tabular}

This table presents the percentage of inmates who have crimes that occurred in the same location as their home address. Values will only occur on the diagonals, as these represent the matches between the home location and the crime location. Each value represents the percent of the total number of inmates for which the locations were equal at each level of aggregation. The total number of inmates is 271,004. The number of inmates with crimes occurring in the same county, circuit, and prison region as their home address are: 189,205; 202,294; 233,567, respectively.

Table 3.4: Home and Prison Locations

\begin{tabular}{lccc}
\hline & County & Circuit & Region \\
\hline County & $9.61 \%$ & - & - \\
Circuit & - & $18.63 \%$ & - \\
Region & - & - & $49.68 \%$ \\
\hline
\end{tabular}

This table presents the percentage of inmates who were incarcerated in the same location as their home address. Values will only occur on the diagonals, as these represent the matches between the home location and the prison location. Each value represents the percent of the total number of inmates for which the locations were equal at each level of aggregation. The total number of inmates is 271,004. The number of inmates with prisons located in the same county, circuit, and prison region as their home address are: 26,051; 50,000; 134,644, respectively.

Table 3.3 presents the percentage of inmates that committed the crime within the same county, circuit, or region as their home. It is no surprise that many prisoners committed their crimes 
Table 3.5: Crime and Prison Locations

\begin{tabular}{lccc}
\hline & County & Circuit & Region \\
\hline County & $9.43 \%$ & - & - \\
Circuit & - & $15.08 \%$ & - \\
Region & - & - & $45.96 \%$ \\
\hline
\end{tabular}

This table presents the percentage of inmates who were incarcerated in the same location as where they committed the crime they are being sentenced for. Values will only occur on the diagonals, as these represent the matches between the crime location and the prison location. Each value represents the percent of the total number of inmates for which the locations were equal at each level of aggregation. The total number of inmates is 271,004 . The number of inmates with prisons located in the same county, circuit, and prison region as where they committed the crime are: 25,$557 ; 40,807 ; 124,557$, respectively.

within the same county in which they live. With nearly $70 \%$ of inmates committing crimes within their counties, that number increases to $75 \%$ when comparing the circuit of residence to the circuit within which they committed their crime. Extending further to the broadest classification available, regions, it is found that over $86 \%$ of inmates committed a crime within the same region as their home. Therefore, it is uncommon for individuals to commit crimes outside of their home prison region, and therefore is likely that they will face a court appearance within the same region.

Table 3.4 is similar, but uses the home address and prison location at the county, circuit, and region level. Here, there is less than $10 \%$ of individuals that are sentenced to a prison within their same county. This makes sense, as not every county houses a prison. For those in counties without a prison, they are guaranteed to be sentenced in some other county. However, many circuits have prisons. In fact, some circuits have multiple prisons. Therefore, there is a near-doubling of the percentage of individuals that are sentenced within the same circuit in which they live. Finally, extending to the prison region, about half of all inmates are sentenced to a prison that is in the same region as the location in which they were released, which is used as a proxy for home address at the time of sentencing. Finally, Table 3.5 shows the percentages where the crime and prison location are in the same county, circuit, or region. These values are very similar to the ones presented earlier in Table 3.4. Importantly, a prison outside of the home region may actually be closer to their home. Additionally, just comparing their home address to the region they're sentenced in does not validate the strategy of separating the results regions 1, 2, and 3 from region 4.

To investigate this with the consideration of the location in which the inmate committed their crime, Table 3.6 considers the percentage of individuals sentenced in the same region as their home address based on the condition that the crime and home county, circuit, or region are equal. Additionally, it also considers the breakdown by the four regions for each category. The percentage presented in the second column for the top of each section (ex. Crime County $=$ Home County) is the same as the percentages found across the diagonals in Table 3.3. The last two columns of this table display the number and percentage of inmates that met the defining criteria and were sentenced to a prison within their region. As can be seen in this first section, individuals sentenced in regions 1,2, and 4 have the highest likelihood of being housed in a prison within their home and crime region. This makes sense as these regions are one the extremes of the state, while region 3 is in the middle of the state and therefore may be closer to a prison in one of the other regions as opposed to a prison within the same region. A similar finding is present when considering if the crime circuit is the same as the home circuit. However, when considering the broadest classification, regions 1 and 4 have the highest percentage. With region 1 representing the panhandle of the state, it makes 
sense that it would have the highest likelihood of sentencing an individual that committed a crime and lived in this area would be sentenced to a prison within this area, otherwise the costs to the DOC and the inmate would be increasingly high for transporting them to some other region. Here, with this consideration of each grouping of regions, over half of those that lived in region 4 were sentenced in region 4 . With the omission of consideration of the effect of region 4 on the results, an additional step to consider the interactions between the regions when it comes to sentencing is necessary. That is, a formal breakdown of each individual that lives in a particular region and the region of the prison they are sentenced to can potentially provide insight into the validity of this strategy.

Table 3.6: Percent Sentenced within Region

\begin{tabular}{lcccc}
\hline \hline & & \multicolumn{3}{c}{ Prison in Same Region } \\
\cline { 5 - 5 } & $\mathrm{N}$ & \% Obs. & $\mathrm{N}$ & $\%$ Obs. \\
\hline Crime County = Home County & 189,205 & $69.81 \%$ & 94,334 & $49.86 \%$ \\
Region 1 & 24,462 & $12.93 \%$ & 18,757 & $76.68 \%$ \\
Region 2 & 28,720 & $15.18 \%$ & 14,367 & $50.02 \%$ \\
Region 3 & 79,482 & $42.01 \%$ & 33,008 & $41.53 \%$ \\
Region 4 & 56,541 & $29.88 \%$ & 28,202 & $49.88 \%$ \\
Crime Circuit = Home Circuit & 202,294 & $74.65 \%$ & 101,452 & $50.15 \%$ \\
Region 1 & 28,627 & $14.15 \%$ & 21,999 & $76.85 \%$ \\
Region 2 & 31,608 & $15.62 \%$ & 15,753 & $49.84 \%$ \\
Region 3 & 83,959 & $41.50 \%$ & 34,890 & $41.56 \%$ \\
Region 4 & 58,100 & $28.72 \%$ & 28,810 & $49.59 \%$ \\
Crime Region = Home Region & 233,567 & $86.19 \%$ & 117,818 & $50.44 \%$ \\
Region 1 & 30,579 & $13.09 \%$ & 23,571 & $77.08 \%$ \\
Region 2 & 34,327 & $14.70 \%$ & 17,125 & $49.89 \%$ \\
Region 3 & 99,567 & $42.63 \%$ & 42,156 & $42.34 \%$ \\
Region 4 & 69,094 & $29.58 \%$ & 34,966 & $50.61 \%$ \\
\hline
\end{tabular}

Each row grouping sets the criteria for those that follow. This baseline of the row grouping only considers those inmates for which the condition that is bold and underlined is true. The total number of inmates is presented, as well as the percentage of all inmates this represents. Additionally, columns 3 and 4 present the number of people who were sentenced within the same region for which the condition is true. The percentage of inmates that were sentenced within the region is additionally provided. The rows below the bold and underlined groupings are for particular regions. That is, Region 1 below the first grouping is for only those individuals for which this is true and the location is within Region 1. Regions 1-4 are collectively exhaustive and mutually exclusive.

To do this, inmates are separated into mutually exclusive groups representing the region of their home address. Then, the location of their prison is aggregated to the region. These results are presented in Table 3.7. The region as defined in each row of the table is the home region of the defendant, while the columns represent the region of the prison in which they were sentenced. The total number of individuals is presented in the table, with the percentage of individuals from the row region sentenced to each column region is presented in brackets. For example those individuals with a home address in region 1 , and a prison location in region 1 is 23,571 . This makes up $77.08 \%$ of all individuals that had a home address in region 1. Therefore, the summation of the percentages in the bracket sum to 100 for each column. Additionally, the percentages along the diagonal are the same percentages that were presented in the final four values in the final column of Table 3.6. Continuing with using region 1 as an example, there are $10 \%$ of individuals that were from region 1 that were sentenced to a prison in region 2, $11 \%$ that were sentenced in region 3 , and only $1.5 \%$ that were sentenced to region 4 . The bottom row of this table adds up the total percentage of individuals that 
were sentenced to a prison within regions 1, 2, or 3. For regions 1, 2, and 3, all of these values exceed 95\%. Meanwhile, under $50 \%$ of the individuals from region 4 were sentenced to one of these three regions. When considering the state-wide analysis this suggests that there may be a muted effect from including those individuals in region 4 that appear to be unlikely to be sentenced to one of the new prisons, as they are unlikely to be sentenced in regions 1,2 , or 3 . With the knowledge that the prosecutor and judge have no control over the location of sentencing, it is likely that those officials within this region would understand that they their defendants are less likely to be sentenced to the new prison and therefore they may not have been adjusting their behavior to the same degree. Considering this from a different angle, adding up the percentage of individuals from regions 1, 2, or 3 that were sentenced in region 4 gives us just over $8 \%$. That is, just over $8 \%$ of individuals from these three regions get sentenced to a prison in region 4 .

Table 3.7: Home and Prison Region Percentages

\begin{tabular}{lcccc}
\hline \hline & \multicolumn{4}{c}{ Home Region } \\
\cline { 2 - 5 } & Region 1 & Region 2 & Region 3 & Region 4 \\
\hline Region 1 & 23,571 & 10,895 & 27,373 & 11,108 \\
& {$[77.08 \%]$} & {$[31.74 \%]$} & {$[27.49 \%]$} & {$[16.08 \%]$} \\
Region 2 & 3,135 & 17,125 & 25,475 & 11,748 \\
& {$[10.25 \%]$} & {$[49.89 \%]$} & {$[25.59 \%]$} & {$[17.00 \%]$} \\
Region 3 & 3,388 & 5,555 & 42,156 & 11,272 \\
& {$[11.08 \%]$} & {$[16.18 \%]$} & {$[42.34 \%]$} & {$[16.31 \%]$} \\
Region 4 & 485 & 752 & 4,563 & 34,966 \\
& {$[1.59 \%]$} & {$[2.19 \%]$} & {$[4.58 \%]$} & {$[50.61 \%]$} \\
\hline In Region's 1-3 & $98.41 \%$ & $97.81 \%$ & $95.42 \%$ & $49.39 \%$ \\
\hline
\end{tabular}

Home region is shown across the top, while prison region is represented across the side. The home region is used for individuals who committed a crime while in the same prison region they live in, for simplicity of analysis. Each value presents the total number of individuals from a home region (across the top) that were sentenced to a prison within one of the regions (across the side). The percentage of all individuals who were from that respective region and sentenced to the region across the side of the table is presented in brackets. The diagonal shows the values for those individuals who were sentenced to a prison within the same region that they reside, and committed a crime, in. Across the bottom is the total percentage of individuals who were from a particular region that were sentenced in Regions 1, 2, or 3. Regions 1-3 are the primary focus of this study, as they are the only regions for which a new prison was constructed during the sample period. The total number of individuals considered for this table was 233,567 , or $86.19 \%$ of all inmates.

Taking this into consideration, the fact that a majority of individuals commit a crime within their home regions, suggests that using the crime location present in the criminal data as a proxy for the home address of the defendant is reasonable. Combining this with the sentencing location, it is reasonable to highlight the effect of those individuals that committed a crime in regions 1,2 , or 3. This is because they are very likely to be sentenced to a prison in one of these regions, and these are the only regions within the sample that saw a new prison open its gates. It is likely that considering a state-wide effect will attenuate the results because it is unlikely that individuals within region 4 will be sentenced to the new prison in one of the other regions, while it is very likely that a defendant from one of those three regions will be sentenced within that group. 


\subsection{Methodology}

As mentioned in the previous section, two approaches to investigate the impact of a new prison on the likelihood of incarceration for a case heard within the first year following prison construction are used. First, the effect will be investigated at the state level. Next, only those cases that were heard within one of the regions that received a new prison throughout the sample are considered. These differences will be defined using the prison regions from the FDOC. Earlier, it was identified that all new prisons opened either in the northern or central portions of the state. Therefore, region 4 did not see a new prison open. Due to this and the distance from region 4 to where the new prisons were built, those individuals sentenced from region 4 may have a lower probability of being sentenced to the new prison. An investigation of inmate incarceration and home locations suggest that this probability is low. If the judges and prosecutors have these beliefs, their behavior may not change in the same way as those that have a higher probability of Both analyses use a Linear Probability Model (LPM). The state-wide equation is characterized by Equation 3.1. The subscripts represent an individual case, $i$, in county $c$, at time $t$. Time is measured at the month of year level.

$$
I_{i c t}=\beta_{0}+\sum_{q=1}^{4} \beta_{q} N_{i c t}+\gamma_{i c t}+\chi_{i t}+\delta_{i c}+\varepsilon_{i c t}
$$

$I_{i c t}$ is a binary variable that takes on the value of 1 if a particular defendant with a particular case was sentenced to serve their time in prison, and takes on the value of zero otherwise. Importantly, those cases that were sentenced to formal incarceration in the form of jail will take on the value of zero and be treated as a member of the control population. This specification makes sense, as the dockets under question are only felony dockets, which primarily end up serving time in prison, barring any plea bargaining that may occur and reduce the incarceration mechanism. In addition, any sentences that were not formal incarceration (i.e. probation or community service) will be assigned a value of zero.

$N_{i c t}$ is the variable of interest, with $\beta$ 's 1-4 representing the coefficients of interest. Since the first year after a prison is opened is disaggregated into three month windows, the persistence of the effects due to the opening can be tested. That is, if the salience of the new prison opening fades within the first year, or gets stronger as the year continues.

Specific controls for the individual and their case characteristics are captured in $\gamma_{i c t}$. These controls include race, gender, age, total counts, and the Florida criminal chapter of the most severe charge. Additionally, this includes controls for the type of counsel an individual received with their case. Lastly, county-by-year fixed effects are included in the model, represented by $\gamma$ and $\delta$ respectively. These will account for specific trends that are occurring within an individual county (for example, if one county tends to have a harsher criminal justice system than another) and in a specific year (to account for any adverse events that may be occurring on the macro level).

The primary specification, however, will account for spatial differences between defendants. That is, those defendants that were tried in the southern portion of the state, in which there were no new prisons, may be treated differently than those that were heard in a region that did have a prison.

$$
I_{i c t}=\beta_{0}+\alpha_{1} \text { Region } 123+\sum_{q=1}^{4} \beta_{q} N_{i c t}+\sum_{q=1}^{4} \theta_{q} N_{i c t} * \text { Region } 123+\gamma_{i c t}+\chi_{i t}+\delta_{i c}+\varepsilon_{i c t}
$$


This main analysis is a difference in difference specification, that will not remove those cases from region 4, but will instead highlight the spatial differences between the three regions that saw a new prison and region 4. This is represented by Equation 3.2. Here, an additional indicator variable (Region123) is added to the analysis and equal to 1 if the defendant's crime was committed in either region 1,2 , or 3 ; and zero if it was in region 4 . Additionally, the coefficients of interest change to $\sum_{q=1}^{4} \theta_{q}$. That is, these $\theta^{\prime}$ 's represent each three month window within the first year following a new prison opening for those cases that were heard within regions 1,2 , or 3 . In other words, they are the interaction term between the time and space variables. All other fixed effects remain the same as described for Equation 3.1.

Within these models, it is important to note that the decision to sentence a defendant to incarceration in prison may be related to unobservable factors. Of note, there is no identifier within the data set for criminal history, something that limits the analysis as there is no way to discern previous incarcerations or other potential attempts at levying a lighter sentence to an individual. In addition, there may be additional extralegal factors that influence the decision to incarcerate in prison as opposed to any other form, such as election season that are not controlled for in this specification. An additional control that would be worthwhile would be judge-level, as some judges may have a proclivity to harsher sentences, especially for specific crimes, which may be biasing the results if those judges are prominent in certain parts of the state than others. With these caveats, the above methods are the best attempt to answer the question at the outset of this paper.

\subsection{Results}

Initial results are run using a Linear Probability Model (LPM) as represented by Equation 3.1. These models allow a cursory look at how a binary variable is effected by an assortment of independent factors. While this is not the ideal specification, it was the one that was least computationally expensive while still providing the ability to run preliminary analysis. All models will present standard errors that are clustered at the county level, to control for within-group variation amongst counties that should be treated similarly due to the consistency of the officials, barring turnover from elections (Cameron \& Miller, 2015).

\subsubsection{Statewide Analysis}

Initial results are run at the statewide level and investigate the impact of a new prison opening in three month windows. That is to say, each three month window (referred to as quarters later) has it's own dummy variable equal to one if the case had a sentencing date that was within the specific window of that quarter.

Tables 3.8 and 3.9 present these initial results with the effect on the disposal type, and the incarceration outcome for each case, respectively. Table 3.8 shows that at the statewide level, there is no impact of a prison opening on the three broad methods by which a case can be disposed: Dismissal, plea bargaining, or an appearance at trial. This informs the analysis that, at least at the state-wide level, the composition of cases at each stage remains relatively constant. That is, there is no significant adjustment made in the charging decisions on behalf of the prosecutors office.

Moving beyond the decision of how to dispose of the case, the outcome of a conviction is then investigated. Importantly, results in Table 3.9 still include dismissals within the data. That is 
Table 3.8: Statewide Results - Disposal Type

\begin{tabular}{lccc}
\hline \hline Dependent Variable & Dismissed & Plea Bargain & Trial \\
\hline Q1 & 0.001 & -0.000 & -0.001 \\
& $(0.002)$ & $(0.003)$ & $(0.002)$ \\
Q2 & 0.000 & -0.000 & 0.000 \\
& $(0.003)$ & $(0.003)$ & $(0.001)$ \\
Q3 & -0.001 & 0.002 & -0.001 \\
& $(0.002)$ & $(0.003)$ & $(0.001)$ \\
Q4 & -0.000 & 0.001 & -0.001 \\
& $(0.002)$ & $(0.002)$ & $(0.001)$ \\
\hline Case Controls & $\checkmark$ & $\checkmark$ & $\checkmark$ \\
Demographic Controls & $\checkmark$ & $\checkmark$ & $\checkmark$ \\
Counsel Controls & $\checkmark$ & $\checkmark$ & $\checkmark$ \\
Time FE & $\checkmark$ & $\checkmark$ & $\checkmark$ \\
Location FE & $\checkmark$ & $\checkmark$ & $\checkmark$ \\
\hline$R^{2}$ & 0.097 & 0.088 & 0.038 \\
N & $1,833,766$ & $1,833,766$ & $1,833,766$ \\
\hline \hline
\end{tabular}

$p<0.1 *, p<0.05 * *, p<0.01 * * *$. Dependent variables are binary equal to one if a case was dismissed, plea bargained, or had any counts appear at trial, respectively. Q1, Q2, Q3, and Q4 represent the first year after a prison is opened, split into periods of three months. That is Q1 is equal to one for cases that were heard within the first three months of the prison opening, Q2 is for cases heard between three and six months following a prison opening, and so on. Case, demographic, and counsel controls are listed in Table 3.1. Time FE include fixed effects for the month of sentencing for potential seasonality in sentencing decisions, and the year of sentencing for yearly trends in the decision. Location FE control for the prison regions within Florida. To control for more granular fluctuations in the sentencing decisions, county fixed effects are also included in the model.

to say, there may be an attenuation on the coefficients presented in this table as cases that were dismissed are unlikely to have any formal sentence or incarceration associated with them. The first column in this table uses a dependent variable equal to one if any charge within a docket receives a formal incarceration in prison. There is an immediate increase in the likelihood of formal prison incarceration of $1.8 \%$ ( 0.5 percentage points) in the first three months following the prison opening. However, the significance of this result drops off outside of this first three month period, suggesting that the state-wide effect of a new prison opening is concentrated in the months immediately following the opening.

Shifting attention to the most common form of incarceration, the middle column represents those cases that had at least one charge sentenced to jail. The admittance of felony cases into jail is likely the result of a plea bargaining agreement, either directly through sentence bargaining, or through charge bargaining where the most serious crimes are dropped, or a felony charge is reduced to a misdemeanor. Therefore, this jail outcome serves as somewhat of a placebo test. However, the inclusion of jail also informs the analysis as to if there is any sort of substitution occurring between prison and jail in these periods following new prison construction. While no data exist for the opening of a new jail, if there is a negative effect using jail as the dependant variable, there may be suggestive evidence that the manipulation of charges that leads to those with at least one felony in their docket reduces in frequency when a new prison opens. This is suggested, though it does not occur within the same period as the increase seen for the prison variable. Therefore, a conclusion of the potential differential effects between prison and jail will be investigated further in later subsections. 
Table 3.9: Statewide Results - Case Outcome

\begin{tabular}{lccc}
\hline \hline Dependent Variable & Prison & Jail & Highest Sentence \\
\hline Q1 & $0.005^{* *}$ & -0.005 & 0.188 \\
& $(0.003)$ & $(0.005)$ & $(0.195)$ \\
Q2 & 0.002 & $-0.008^{* *}$ & 0.124 \\
& $(0.003)$ & $(0.003)$ & $(0.293)$ \\
Q3 & 0.001 & $-0.006^{*}$ & 0.058 \\
& $(0.003)$ & $(0.003)$ & $(0.231)$ \\
Q4 & -0.003 & 0.001 & -0.093 \\
& $(0.002)$ & $(0.004)$ & $(0.208)$ \\
\hline Case Controls & $\checkmark$ & $\checkmark$ & $\checkmark$ \\
Demographic Controls & $\checkmark$ & $\checkmark$ & $\checkmark$ \\
Counsel Controls & $\checkmark$ & $\checkmark$ & $\checkmark$ \\
Time FE & $\checkmark$ & $\checkmark$ & $\checkmark$ \\
Location FE & $\checkmark$ & $\checkmark$ & $\checkmark$ \\
\hline$R^{2}$ & 0.172 & 0.157 & 0.149 \\
$\mathrm{~N}$ & $1,833,766$ & $1,833,766$ & $1,833,766$ \\
\hline \hline
\end{tabular}

$p<0.1 *, p<0.05 * *, p<0.01 * * *$. Dependent variables are binary equal to one if a defendant was sentenced to incarceration in prison, or jail, respectively. The final column of the table uses the upper bound of the sentence attached to the most severe charge within for a docket. Q1, Q2, Q3, and Q4 represent the first year after a prison is opened, split into periods of three months. That is Q1 is equal to one for cases that were heard within the first three months of the prison opening, Q2 is for cases heard between three and six months following a prison opening, and so on. Case, demographic, and counsel controls are listed in Table 3.1. Time FE include fixed effects for the month of sentencing for potential seasonality in sentencing decisions, and the year of sentencing for yearly trends in the decision. Location FE control for the prison regions within Florida. To control for more granular fluctuations in the sentencing decisions, county fixed effects are also included in the model. 
Lastly, there may be reason to believe that the criminal justice system may provide either harsher or shorter sentences to defendants during this period. A couple of hypotheses exist. First, it could be the case that due to increased harshness in the type of incarceration, there is offsetting behavior in the sentencing length. Alternatively, it could be the case that prosecutors and judges double-down on harshness, and increase the sentence length on top of focusing on sending more defendants to prison. However, in this state-wide analysis, there is no effect on the sentence length.

These state-wide results are suggestive of a potential effect of a new prison opening on decisions made in the sentencing of defendants. There is an immediate increase in the likelihood an individual is sentenced to incarceration in prison, and a lagged effect for a decrease in the likelihood of incarceration in jail. However, as Table 3.2 shows, all of these new prisons open in prison regions 1, 2, or 3 , with no new prisons opening in region 4 in the Southern portion of the state.

\subsubsection{Regional Analysis}

With no prisons opening in region 4, there may be attenuation of the effect as these defendants are included within the grouping of periods following a new prison opening. In order to correct this problem, a difference-in-difference analysis is used to separate out the effect of these other three regions that did see a new prison constructed. As mentioned previously, these prison regions are largely used to keep individuals within a reasonable distance of the county they reside in. However, there is a fair amount of sharing between regions 1,2 , and 3 . This will be explored at a later point in this paper. However, this regional analysis provides a clearer picture of how prison openings may effect incarceration decisions in the immediate areas surrounding the new prison.

Table 3.10 presents the same results as Table 3.8, but with a difference-in-difference analysis using an indicator variable for if a case was heard within regions 1, 2, or 3. From this table, only the interaction term is reported. The results are presented in stark contrast to the lack of significance found in the state-wide analysis. Only taking into consideration the first column, which uses a binary variable for whether a case was dismissed, there is significance on all coefficients across the first year after a prison opens. These coefficients represent between an 8\% increase in months 10-12 after the opening, and $14 \%$ in months 7-9. This suggests that following a prison opening in one of these regions, there is a differential increase in the likelihood a case is dismissed for those dockets heard within the first year in one of these regions.

Considering instead the impact on plea bargaining in the second column, there is likely a substitution away from plea bargaining to dismissal for this group over these particular periods. The reduction in plea bargaining is nearly equal to the increase in dismissals that occur in each period, except for the first three months where there is no effect on plea bargaining. This is an unexpected result. It potentially points to a narrative that suggests that prosecutors are shifting their behavior to potentially allow them to consolidate resources to only pursue cases that could end in a felony conviction. If there was an effect on the likelihood of trial (column 3) then there could be suggestive evidence that prosecutors were shifting resources to better prepare for cases at trial as they have become more abundant. However, the lack of significance here suggests that prosecutors may

be focusing their attention on cases that have the potential for incarceration, that is more serious felonies, and dropping those cases that are less serious offenses.

The effect of the initial charging decisions does not provide additional insight into the mechanism through which an increase in prison incarceration may occur. Shifting attention to Table 3.11, there 
Table 3.10: Regional Results - Disposal Type

\begin{tabular}{lccc}
\hline \hline Dependent Variable & Dismissed & Plea Bargain & Trial \\
\hline Q1*Region13 & $0.021^{* * *}$ & -0.008 & -0.012 \\
& $(0.006)$ & $(0.013)$ & $(0.011)$ \\
Q2*Region13 & $0.026^{* * *}$ & $-0.024^{* * *}$ & -0.002 \\
& $(0.008)$ & $(0.008)$ & $(0.003)$ \\
Q3*Region13 & $0.029^{* * *}$ & $-0.033^{* * *}$ & -0.004 \\
& $(0.007)$ & $(0.007)$ & $(0.004)$ \\
Q4*Region13 & $0.016^{* * *}$ & $-0.025^{* * *}$ & -0.009 \\
& $(0.006)$ & $(0.009)$ & $(0.006)$ \\
\hline Case Controls & $\checkmark$ & $\checkmark$ & $\checkmark$ \\
Demographic Controls & $\checkmark$ & $\checkmark$ & $\checkmark$ \\
Counsel Controls & $\checkmark$ & $\checkmark$ & $\checkmark$ \\
Time FE & $\checkmark$ & $\checkmark$ & $\checkmark$ \\
Location FE & $\checkmark$ & $\checkmark$ & $\checkmark$ \\
\hline$R^{2}$ & 0.098 & 0.088 & 0.038 \\
$\mathrm{~N}$ & $1,833,766$ & $1,833,766$ & $1,833,766$ \\
\hline \hline
\end{tabular}

$p<0.1 *, p<0.05 * *, p<0.01 * * *$. Dependent variables are binary equal to one if a case was dismissed, plea bargained, or had any counts appear at trial, respectively. Q1, Q2, Q3, and Q4 represent the first year after a prison is opened, split into periods of three months. That is Q1 is equal to one for cases that were heard within the first three months of the prison opening, Q2 is for cases heard between three and six months following a prison opening, and so on. The interaction term within this table is the result of a difference-in-difference using the quarters and an indicator variable for whether the case was heard in a circuit that falls within regions 1,2 , or 3. Only the interaction term is presented hear for brevity. Case, demographic, and counsel controls are listed in Table 3.1. Time FE include fixed effects for the month of sentencing for potential seasonality in sentencing decisions, and the year of sentencing for yearly trends in the decision. Location FE control for the prison regions within Florida. To control for more granular fluctuations in the sentencing decisions, county fixed effects are also included in the model. 
is a strong increase in the likelihood of an individual in region 1, 2, or 3 being incarcerated if their case was heard within the first nine months following the opening of a prison. This effect reaches its peak of 11\% 4-6 months after the opening of a prison. This increase is not only statistically significant, but is economically significant as well. These results portray a scenario where individuals located near a new prison face a higher likelihood of being sentenced to that prison within the first nine months of it opening.

Table 3.11: Regional Results - Case Outcome

\begin{tabular}{lccc}
\hline \hline Dependent Variable & Prison & Jail & Highest Sentence \\
\hline Q1*Region13 & $0.022^{* * *}$ & 0.010 & $2.397^{* * *}$ \\
& $(0.007)$ & $(0.017)$ & $(0.541)$ \\
Q2*Region13 & $0.031^{* * *}$ & 0.004 & $1.986^{* * *}$ \\
& $(0.009)$ & $(0.021)$ & $(0.578)$ \\
Q3*Region13 & $0.027^{* *}$ & 0.004 & 0.928 \\
& $(0.011)$ & $(0.023)$ & $(0.690)$ \\
Q4*Region13 & 0.015 & -0.004 & 0.109 \\
& $(0.010)$ & $(0.016)$ & $(0.797)$ \\
\hline Case Controls & $\checkmark$ & $\checkmark$ & $\checkmark$ \\
Demographic Controls & $\checkmark$ & $\checkmark$ & $\checkmark$ \\
Counsel Controls & $\checkmark$ & $\checkmark$ & $\checkmark$ \\
Time FE & $\checkmark$ & $\checkmark$ & $\checkmark$ \\
Location FE & $\checkmark$ & $\checkmark$ & $\checkmark$ \\
\hline$R^{2}$ & 0.173 & 0.157 & 0.149 \\
$\mathrm{~N}$ & $1,833,766$ & $1,833,766$ & $1,833,766$ \\
\hline \hline
\end{tabular}

$p<0.1 *, p<0.05 * *, p<0.01 * * *$. Dependent variables are binary equal to one if a defendant was sentenced to incarceration in prison, or jail, respectively. The final column of the table uses the upper bound of the sentence attached to the most severe charge within for a docket. Q1, Q2, Q3, and Q4 represent the first year after a prison is opened, split into periods of three months. That is Q1 is equal to one for cases that were heard within the first three months of the prison opening, Q2 is for cases heard between three and six months following a prison opening, and so on. The interaction term within this table is the result of a difference-in-difference using the quarters and an indicator variable for whether the case was heard in a circuit that falls within regions 1,2 , or 3. Only the interaction term is presented hear for brevity. Case, demographic, and counsel controls are listed in Table 3.1. Time FE include fixed effects for the month of sentencing for potential seasonality in sentencing decisions, and the year of sentencing for yearly trends in the decision. Location FE control for the prison regions within Florida. To control for more granular fluctuations in the sentencing decisions, county fixed effects are also included in the model.

Shifting attention to the third column of the table, remember the hypotheses laid out in the statewide results subsection. Here, the behavior that is occurring in concert with these incarceration decisions can be given some clarity. First, it is worth mentioning that sentences in prison are commonly much longer than sentences in jail. Therefore, the increase in the likelihood of sentencing an individual to prison may account for a significant portion of the increase in the highest sentence length received for a defendant. However, the increase of over two months of additional sentence length found in the first three months following the opening of a prison is about a $14 \%$ increase. Disentangling the increase due to prison incarceration, and the increase due to the stacking of charges or the decrease in the willingness to negotiate on the length of the sentence is not able to be done for this study. However, it is important to recognize that this may be an additional channel through which these particular defendants are being adversely effected by the timing of their case.

Disaggregating the results found in Table 3.11 between trial and plea bargaining can reveal 
suggestive evidence regarding the mechanism through which these results are found. Table 3.12 presents the disaggregated difference-in-difference measurements for the sentencing variables of interest. Considering only the prison variable first, there is an initial increase in the likelihood of prison incarceration for both trial and plea outcomes. However, the effect for cases heard at trial is only concentrated in the immediate three months following the prison opening. However, throughout the remaining periods for the first year, there is no effect for cases heard at trial. This may be due to the noise present with such a small percentage of the data facing trial. However, turning attention to those cases that were plea bargained, there is a more persistent effect, even though the magnitude of the coefficient is smaller. The $23 \%$ increase in the likelihood of incarceration for cases heard in the first three months after a prison opening at trial is nearly double the largest increase seen for plea bargained cases. However, it appears that the persistence of the effect for plea bargained cases could suggest that the generosity of the plea bargaining offers from prosecutors is diminishing. Combining this with the information within the sentence column of that table, cases that are plea bargained within six months of a new prison opening in regions 1, 2, or 3 face increases in their sentences by about one and a half months (about 10\%). This appears to corroborate the hypothesis of the mechanism for the increase in prison incarcerations, namely, a decrease in the generosity of the plea offers for felony defendants.

Finally, the analysis can again address the question of the substitutability between jail and prison. Previously, results suggested there may be a reduction in the likelihood of a defendant facing incarceration in jail. However, in those earlier results, there was not a commensurate increase in the likelihood of prison incarceration during the same periods. This disaggregation may give some idea if there is a differential effect occurring. That is, are cases that face an increase in prison incarceration through the plea bargaining process facing adverse effects of the prison opening, where they would have otherwise been sentenced to jail. However, as can be seen from the second column in Table 3.12, there is no significance on any of the coefficients for the jail column. Combining this information with the inconsistent results found previously, it is likely that there is not a high percentage of substitutablility between prison and jail, even in the case of new prison construction. ${ }^{14}$ Put differently, it may be supposed that these new prisons were built to deal with capacity concerns. Due to these capacity issues, there may be some defendants that were eligible for prison sentences that were instead sentenced to jail because they were low-level felonies. Under this hypothesis, it would be reasonable to find that there was an increase in prison sentences and a decrease in jail sentences as these individuals were sentenced to the correct institution. However, this is not found. Therefore, even if these prisons were built due to capacity concerns, it does not seem to be adversely displacing jail sentences, at least not in a way that is statistically powerful enough to cut through the noise of this measurement.

These results relate to the previous literature on extralegal influences in judicial outcomes (Danziger et al., 2011; Eren \& Mocan, 2018; Chen \& Philippe, 2017; McCannon, 2013; Bandyopadhyay \& McCannon, 2014). This result points to a potentially disturbing reality within the criminal justice system. The criminal justice system is incarcerating more individuals because there are more places to house them. The question of whether or not these convicted defendants have

\footnotetext{
${ }^{14}$ Cunningham and Kang (2018) investigate a change in legislation in Texas, and suggests that there may be an increase in incarceration due to a decrease in the probability of a prisoner receiving parole. Due to the nature of the data, this interesting margin is unable to explored, so the dimension of prison vs. jail is used in an attempt to address a similar, but certainly different, question.
} 
Table 3.12: Regional Results - Case Outcome by Disposal Type

\begin{tabular}{|c|c|c|c|}
\hline Dependent Variable & Prison & Jail & Highest Sentence \\
\hline \multirow[t]{2}{*}{ Q1*Region13*Trial } & $0.064^{* *}$ & -0.008 & 8.020 \\
\hline & $(0.032)$ & $(0.020)$ & $(9.356)$ \\
\hline \multirow[t]{2}{*}{ Q2* Region $13^{*}$ Trial } & 0.061 & 0.008 & 5.207 \\
\hline & $(0.041)$ & $(0.023)$ & $(10.243)$ \\
\hline \multirow[t]{2}{*}{ Q3*Region13*Trial } & 0.059 & 0.015 & 4.116 \\
\hline & $(0.040)$ & $(0.024)$ & $(10.553)$ \\
\hline \multirow[t]{2}{*}{ Q4*Region $13^{*}$ Trial } & 0.042 & -0.008 & 2.845 \\
\hline & $(0.033)$ & $(0.019)$ & $(7.438)$ \\
\hline \multirow[t]{2}{*}{ Q1*Region $13^{*}$ Plea } & $0.026^{* *}$ & -0.001 & $1.566^{* * *}$ \\
\hline & $(0.011)$ & $(0.021)$ & $(0.480)$ \\
\hline \multirow[t]{2}{*}{ Q2*Region $13 *$ Plea } & $0.035^{* *}$ & -0.008 & $1.337^{* *}$ \\
\hline & $(0.015)$ & $(0.029)$ & $(0.647)$ \\
\hline \multirow[t]{2}{*}{ Q3*Region $13 *$ Plea } & $0.032^{* *}$ & -0.009 & 0.448 \\
\hline & $(0.015)$ & $(0.029)$ & $(0.725)$ \\
\hline \multirow[t]{2}{*}{ Q4*Region $13^{*}$ Plea } & 0.020 & -0.010 & -0.219 \\
\hline & $(0.013)$ & $(0.022)$ & $(0.783)$ \\
\hline Case Controls & $\checkmark$ & $\sqrt{ }$ & $\checkmark$ \\
\hline Demographic Controls & $\checkmark$ & $\sqrt{ }$ & $\checkmark$ \\
\hline Counsel Controls & $\sqrt{ }$ & $\checkmark$ & $\checkmark$ \\
\hline Time FE & $\sqrt{ }$ & $\checkmark$ & $\checkmark$ \\
\hline Location FE & $\checkmark$ & $\checkmark$ & $\checkmark$ \\
\hline$R^{2}$ & 0.173 & 0.157 & 0.149 \\
\hline $\mathrm{N}$ & $1,833,766$ & $1,833,766$ & $1,833,766$ \\
\hline
\end{tabular}

$p<0.1 *, p<0.05 * *, p<0.01 * * *$. Dependent variables are binary equal to one if a defendant was sentenced to incarceration in prison, or jail, respectively. The final column of the table uses the upper bound of the sentence attached to the most severe charge within for a docket. Q1, Q2, Q3, and Q4 represent the first year after a prison is opened, split into periods of three months. That is Q1 is equal to one for cases that were heard within the first three months of the prison opening, Q2 is for cases heard between three and six months following a prison opening, and so on. The interaction term within this table is the result of a difference-in-difference using the quarters and an indicator variable for whether the case was heard in a circuit that falls within regions 1,2 , or 3. Additionally, this DiD is disaggregated into the contribution from plea bargained and trial cases, respectively. Only the interaction term is presented hear for brevity. Case, demographic, and counsel controls are listed in Table 3.1. Time FE include fixed effects for the month of sentencing for potential seasonality in sentencing decisions, and the year of sentencing for yearly trends in the decision. Location FE control for the prison regions within Florida. To control for more granular fluctuations in the sentencing decisions, county fixed effects are also included in the model. 
a different probability of re-offending when they are released than those who were heard prior to the new prison opening is a question left for future research to consider. However, the main results presented rely on the differential effect occurring in the prison regions that received at least one new prison. The logic behind this strategy was related to that these regions are likely to sentence individuals from their own region to this prison, and since region 4 is isolated in the southern portion of the state, it seems unlikely that they will be transferring their inmates to the Northern portion of the state.

\subsubsection{Removing Dismissed Cases}

So far, the analysis has been concerned with all cases that have at least one felony present at some point throughout the life of the case. This data set also included dismissed cases. However, dismissed cases will always cause a downward bias on the coefficient of interest, as those who have cases dismissed are unlikely to be sentenced to prison. Therefore, while those results are important when considering the universe of cases at the time, it is also useful to only consider those cases that had at least one charge reach a guilty verdict. Doing so reduces the sample to just over 1.45 million dockets. This subsection will recreate tables from the previous section using this refined data set. Summary statistics for this sub-sample can be found in Table 3.13 .

\begin{tabular}{lcccc}
\multicolumn{5}{c}{ Table 3.13: Summary Statistics - w/o Dismissed } \\
\hline \multicolumn{1}{c}{ Mean } & St. Dev. & Min & Max \\
\hline Case Characteristics & & & & \\
Prison & 0.347 & 0.476 & 0 & 1 \\
Jail & 0.542 & 0.498 & 0 & 1 \\
Highest Sentence & 18.265 & 42.761 & 0 & 1200 \\
Plea Bargain & 0.981 & 0.137 & 0 & 1 \\
Counts & 2.653 & 6.023 & 1 & 899 \\
Habitual Offender & 0.009 & 0.096 & 0 & 1 \\
Habitual Violent Offender & 0.001 & 0.033 & 0 & 1 \\
Career Violent Offender & 0.000 & 0.008 & 0 & 1 \\
& & & & \\
Demographic Characteristics & & & & \\
Male & 0.823 & 0.382 & 0 & 1 \\
Female & 0.176 & 0.381 & 0 & 1 \\
White & 0.591 & 0.492 & 0 & 1 \\
Black & 0.403 & 0.490 & 0 & 1 \\
Asian & 0.002 & 0.042 & 0 & 1 \\
Native & 0.001 & 0.0264 & 0 & 1 \\
Age at Arrest & 33.114 & 11.250 & 14 & 95 \\
& & & & \\
Counsel Type & & & & \\
Private & 0.208 & 0.406 & 0 & 1 \\
Public & 0.560 & 0.496 & 0 & 1 \\
Appointed & 0.053 & 0.223 & 0 & 1 \\
Self & 0.132 & 0.338 & 0 & 1 \\
Other & 0.093 & 0.290 & 0 & 1 \\
\hline \hline for all variables. & & & &
\end{tabular}

The analysis once again begins with a statewide analysis of the impact on the case outcome in 
Table 3.14. This table focuses on the decision to send a defendant to prison or jail, and the sentence they receive. Using the same three month periods following a prison opening as before, there is once again only an increase in the likelihood of prison incarceration in the first three months immediately following the opening of the prison. This increase, however, is only about $2 \%$ of the mean of this variable. Therefore, it is a modest increase. Once again, no periods after these first three months are significant for the likelihood of incarceration. However, considering the jail incarceration decisions, there is, again, a decrease for months 4-6. Lastly, at the state-wide level there does not appear to

be any difference in the sentence received by any of these defendants that were sentenced within the first year after a prison opens.

However, moving into the regional difference-in-difference as before, focusing only on regions 1,2 , and 3 presents a different set of results. Namely, the increase in the likelihood of prison incarceration increases for months 1-9 after a new prison opens. Also, there is upwards of a 5-fold increase in the magnitude of the coefficients. These results are $7.7 \%$ in the first three months, and then increase to over $10 \%$ for months $4-6$. The increase in the third quarter after the prison opens is also around that $10 \%$ figure. Therefore, there is an increase in the likelihood of incarceration when considering both the data set with dismissed cases, and the one without. However, there is no finding of an effect on the likelihood of incarceration in jail, making any argument about substituting away from jail into prison difficult. Lastly, increases in the sentence received by these defendants are found. These increases are upwards of $16 \%$ for the cases heard in regions 1, 2, or 3 within the first three months after a prison opens. However, it is important to once again investigate if these increases in the likelihood of prison incarceration and the increase in sentences is a result of decisions made at trial or an increase in the harshness of plea bargaining offers accepted.

To analyze this result, each difference-in-difference coefficient is disaggregated by trial and plea in Table 3.16. Once again, there appears to be a concentration in the plea bargaining process, though there is an effect in the incarceration decision for those at trial. While the magnitude of the increase in the likelihood of incarceration is smaller for those cases that were plea bargained, it appears to have a more persistent effect in the plea bargaining institution. Also, when considering the effect on sentences, it does appear that the prison construction is materializing into harsher plea bargaining offers that are agreed to, which is likely due to an increase in the harshness of the minimum offer the prosecutor is willing to accept.

\subsection{Discussion}

The analysis here buttresses the analysis in Dippel and Poyker (2020). Those authors find that there is an increase in the sentence lengths for defendants following an increase in capacity at private prisons. This paper asks the question in a slightly different way, considering effects across an entire state for public prisons. Additionally, by disaggregating the result into groups of behavior at trial and the behavior of prosecutors during the plea bargaining process, the role of prosecutors in the changing sentencing habits can be evaluated directly. Results suggest that prosecutors may be offering harsher plea bargaining agreements, that land more defendants in prison. At the most basic level, the argument for these results relates to the election mechanism found in previous studies. However, it is argued that these prison openings are a salient event to potential voters, and elected prosecutors (and judges) may view it as their responsibility to their communities to make sure these 
Table 3.14: Statewide Results - Case Outcome w/o Dismissed

\begin{tabular}{lccc}
\hline \hline Dependent Variable & Prison & Jail & Highest Sentence \\
\hline Q1 & $0.007^{* *}$ & -0.006 & 0.156 \\
Q2 & $(0.003)$ & $(0.005)$ & $(0.229)$ \\
& 0.002 & $-0.009^{* *}$ & 0.156 \\
Q3 & $(0.004)$ & $(0.004)$ & $(0.343)$ \\
& 0.001 & -0.007 & 0.023 \\
Q4 & $(0.004)$ & $(0.004)$ & $(0.272)$ \\
& -0.004 & 0.001 & -0.154 \\
Case Controls & $(0.003)$ & $(0.004)$ & $(0.254)$ \\
Demographic Controls & $\boldsymbol{V}$ & $\boldsymbol{V}$ & $\boldsymbol{\checkmark}$ \\
Counsel Controls & $\boldsymbol{V}$ & $\boldsymbol{V}$ & $\boldsymbol{\checkmark}$ \\
Time FE & $\boldsymbol{V}$ & $\boldsymbol{V}$ & $\boldsymbol{V}$ \\
Location FE & $\boldsymbol{V}$ & $\boldsymbol{V}$ & $\boldsymbol{V}$ \\
\hline$R^{2}$ & 0.105 & 0.121 & 0.114 \\
$\mathrm{~N}$ & $1,459,852$ & $1,459,852$ & $1,459,852$ \\
\hline \hline
\end{tabular}

$p<0.1 *, p<0.05 * *, p<0.01 * * *$. Dependent variables are binary equal to one if a defendant was sentenced to incarceration in prison, or jail, respectively. The final column of the table uses the upper bound of the sentence attached to the most severe charge within for a docket. Q1, Q2, Q3, and Q4 represent the first year after a prison is opened, split into periods of three months. That is Q1 is equal to one for cases that were heard within the first three months of the prison opening, Q2 is for cases heard between three and six months following a prison opening, and so on. Case, demographic, and counsel controls are listed in Table 3.1. Time FE include fixed effects for the month of sentencing for potential seasonality in sentencing decisions, and the year of sentencing for yearly trends in the decision. Location FE control for the prison regions within Florida. To control for more granular fluctuations in the sentencing decisions, county fixed effects are also included in the model. 
Table 3.15: Regional Results - Case Outcome w/o Dismissed

\begin{tabular}{lccc}
\hline \hline Dependent Variable & Prison & Jail & Highest Sentence \\
\hline Q1*Region13 & $0.027^{* * *}$ & 0.007 & $3.016^{* * *}$ \\
& $(0.009)$ & $(0.016)$ & $(0.658)$ \\
Q2*Region13 & $0.037^{* * *}$ & 0.002 & $2.509^{* * *}$ \\
& $(0.012)$ & $(0.022)$ & $(0.708)$ \\
Q3*Region13 & $0.032^{* *}$ & 0.004 & 1.148 \\
& $(0.014)$ & $(0.025)$ & $(0.875)$ \\
Q4*Region13 & 0.018 & -0.004 & 0.082 \\
& $(0.012)$ & $(0.018)$ & $(1.019)$ \\
\hline Case Controls & $\checkmark$ & $\checkmark$ & $\checkmark$ \\
Demographic Controls & $\checkmark$ & $\checkmark$ & $\checkmark$ \\
Counsel Controls & $\checkmark$ & $\checkmark$ & $\checkmark$ \\
Time FE & $\checkmark$ & $\checkmark$ & $\checkmark$ \\
Location FE & $\checkmark$ & $\checkmark$ & $\checkmark$ \\
\hline$R^{2}$ & 0.107 & 0.123 & 0.135 \\
$\mathrm{~N}$ & $1,459,852$ & $1,459,852$ & $1,459,852$ \\
\hline \hline
\end{tabular}

$p<0.1 *, p<0.05 * *, p<0.01 * * *$. Dependent variables are binary equal to one if a defendant was sentenced to incarceration in prison, or jail, respectively. The final column of the table uses the upper bound of the sentence attached to the most severe charge within for a docket. Q1, Q2, Q3, and Q4 represent the first year after a prison is opened, split into periods of three months. That is Q1 is equal to one for cases that were heard within the first three months of the prison opening, Q2 is for cases heard between three and six months following a prison opening, and so on. The interaction term within this table is the result of a difference-in-difference using the quarters and an indicator variable for whether the case was heard in a circuit that falls within regions 1,2 , or 3. Only the interaction term is presented hear for brevity. Case, demographic, and counsel controls are listed in Table 3.1. Time FE include fixed effects for the month of sentencing for potential seasonality in sentencing decisions, and the year of sentencing for yearly trends in the decision. Location FE control for the prison regions within Florida. To control for more granular fluctuations in the sentencing decisions, county fixed effects are also included in the model. 
Table 3.16: Regional Results - Case Outcome by Disposal Type w/o Dismissed

\begin{tabular}{|c|c|c|c|}
\hline Dependent Variable & Prison & Jail & Highest Sentence \\
\hline Q1*Region13*Trial & $\begin{array}{l}0.066^{* *} \\
(0.030)\end{array}$ & $\begin{array}{l}-0.001 \\
(0.017)\end{array}$ & $\begin{array}{c}9.531 \\
(9.535)\end{array}$ \\
\hline Q2*Region13*Trial & $\begin{array}{l}0.066^{*} \\
(0.039)\end{array}$ & $\begin{array}{c}0.010 \\
(0.020)\end{array}$ & $\begin{array}{c}6.462 \\
(10.202)\end{array}$ \\
\hline Q3*Region13*Trial & $\begin{array}{l}0.062^{*} \\
(0.036)\end{array}$ & $\begin{array}{c}0.024 \\
(0.019)\end{array}$ & $\begin{array}{c}4.593 \\
(10.325)\end{array}$ \\
\hline Q4*Region13*Trial & $\begin{array}{c}0.043 \\
(0.031)\end{array}$ & $\begin{array}{l}-0.008 \\
(0.015)\end{array}$ & $\begin{array}{c}3.170 \\
(7.193)\end{array}$ \\
\hline Q1*Region13*Plea & $\begin{array}{c}0.027^{* * *} \\
(0.009)\end{array}$ & $\begin{array}{c}0.007 \\
(0.016)\end{array}$ & $\begin{array}{c}2.891^{* * *} \\
(0.593)\end{array}$ \\
\hline Q2*Region $13 *$ Plea & $\begin{array}{c}0.037^{* * *} \\
(0.012)\end{array}$ & $\begin{array}{c}0.002 \\
(0.023)\end{array}$ & $\begin{array}{c}2.442^{* * *} \\
(0.767)\end{array}$ \\
\hline Q3*Region13*Plea & $\begin{array}{l}0.032^{* *} \\
(0.015)\end{array}$ & $\begin{array}{c}0.004 \\
(0.025)\end{array}$ & $\begin{array}{l}1.097 \\
(0.928)\end{array}$ \\
\hline Q4*Region $13 *$ Plea & $\begin{array}{c}0.018 \\
(0.013)\end{array}$ & $\begin{array}{l}-0.004 \\
(0.018)\end{array}$ & $\begin{array}{c}0.004 \\
(1.065)\end{array}$ \\
\hline Case Controls & $\checkmark$ & $\checkmark$ & $\checkmark$ \\
\hline Demographic Controls & $\checkmark$ & $\checkmark$ & $\checkmark$ \\
\hline Counsel Controls & $\checkmark$ & $\checkmark$ & $\checkmark$ \\
\hline Time FE & $\checkmark$ & $\checkmark$ & $\checkmark$ \\
\hline Location FE & $\checkmark$ & $\checkmark$ & $\checkmark$ \\
\hline $\begin{array}{l}R^{2} \\
\mathrm{~N}\end{array}$ & $\begin{array}{c}0.107 \\
1,459,852\end{array}$ & $\begin{array}{c}0.123 \\
1,459,852\end{array}$ & $\begin{array}{c}0.135 \\
1,459,852\end{array}$ \\
\hline
\end{tabular}

$p<0.1 *, p<0.05 * *, p<0.01 * * *$. Dependent variables are binary equal to one if a defendant was sentenced to incarceration in prison, or jail, respectively. The final column of the table uses the upper bound of the sentence attached to the most severe charge within for a docket. Q1, Q2, Q3, and Q4 represent the first year after a prison is opened, split into periods of three months. That is Q1 is equal to one for cases that were heard within the first three months of the prison opening, Q2 is for cases heard between three and six months following a prison opening, and so on. The interaction term within this table is the result of a difference-in-difference using the quarters and an indicator variable for whether the case was heard in a circuit that falls within regions 1,2 , or 3. Additionally, this DiD is disaggregated into the contribution from plea bargained and trial cases, respectively. Only the interaction term is presented hear for brevity. Case, demographic, and counsel controls are listed in Table 3.1. Time FE include fixed effects for the month of sentencing for potential seasonality in sentencing decisions, and the year of sentencing for yearly trends in the decision. Location FE control for the prison regions within Florida. To control for more granular fluctuations in the sentencing decisions, county fixed effects are also included in the model. 
prisons reach capacity. In this sense, it may be more related to the budding literature on extralegal factors influencing the criminal justice system (Danziger et al., 2011; Eren \& Mocan, 2018; Chen \& Philippe, 2017).

Through multiple specifications including different periods for which the new prison may be effecting existing cases, and account for spatial variation, it is found that defendants experience a $7-10 \%$ higher likelihood of facing formal incarceration in prison. This effect is more pronounced when focusing on the areas of Florida that are more likely to sentence a defendant to one of the regions in which a new prison was constructed. An investigation into the substitutability of prison and jail does not produce confident estimates that these individuals that were previously receiving jail sentences are now receiving prison sentences. While there have been many reforms on sentence length through sentencing guidelines, actors within the criminal justice system still experience ample discretion when it comes to the conviction and incarceration a defendant experiences. One concern is that judges may have the ability to choose which facility a defendant serves their incarceration, since this information does not exist within the data. However, judges within the state of Florida have no control over the facility, and it is instead decided by the reception center the defendant visits upon conviction.

Lastly, a consideration has been made that judges and prosecutors may be offering a reduced sentence to these individuals that are now being sentenced to prison incarceration. However, that is not found to be the case. At the state-wide level, there is no effect on the highest sentence a defendant received. However, the difference-in-difference analysis, finds that for those individuals in the regions most likely to be affected by the new prison opening they see increases of their sentences exceeding 14\%. Justifying the methodology of the analysis, an investigation of the release addresses, crime location, and prison location was conducted on all inmates released from a Florida prison since 1997. These results suggest justification for the refinement of the locations investigated, with over $95 \%$ of defendants for regions 1,2 , or 3 facing incarceration in one of those three regions, while only $8 \%$ of all defendants from any of those regions seeing incarceration in the southern fourth region.

When considering the implications of this research, it is important to remember that there are unobservables that may also be influencing incarceration decisions, such as criminal history, that are not present within the data used for this analysis. While attempts were made to control for some measure of criminal history, it certainly does not fully capture it accurately. Additionally, there is no knowledge of where a particular defendant was sentenced, and they are unable to be linked to the prisoner data set used in the final subsection. However, with these caveats, the results suggest that the efforts to increase prisons may put pressure on the actors in the criminal justice system that have some control over the size of the prison population. This paper should be viewed as suggestive evidence in support of a potentially wider-spread effect of prison capacity than what was found in Dippel and Poyker (2020). Future work to test the narrative presented for the cause of this effect should focus on states in which officials of some areas are elected, while others are appointed. 


\section{References}

Abrams, D., Galbiati, R., Henry, E., \& Philippe, A. (2019). Electoral Sentencing Cycles.

Abrams, D. S. (2011). Is Pleading Really a Bargain? Journal of Empirical Legal Studies, 8, 200-221.

Agan, A., Freedman, M., \& Owens, E. (2017). Is Your Lawyer a Lemon? Incentives and Selection in the Public Provision of Criminal Defense. Review of Economics and Statistics, 1-51.

A. Huber, G., \& Gordon, S. C. (2004). Accountability and Coercion: Is Justice Blind When it Runs for Office? American Journal of Political Science, 48(2), 247-263.

Albonetti, C. A. (1997). Sentencing Under the Federal Sentencing Guidelines: Effects of Defendant Characteristics, Guilty Pleas, and Departures on Sentence Outcomes for Drug Offenses, 19911992. Law and Society Review, 789-822.

Baker, S., \& Mezzetti, C. (2001). Prosecutorial Resources, Plea Bargaining, and the Decision to go to Trial. Journal of Law, Economics, and Organization, 17(1), 149-167.

Bandyopadhyay, S., \& McCannon, B. C. (2014). The Effect of the Election of Prosecutors on Criminal Trials. Public Choice, 161(1-2), 141-156.

Bandyopadhyay, S., \& McCannon, B. C. (2015). Prosecutorial Retention: Signaling by Trial. Journal of Public Economic Theory, 17(2), 219-256.

Bar-Gill, O., \& Gazal Ayal, O. (2006). Plea Bargains Only for the Guilty. The Journal of Law and Economics, 49(1), 353-364.

Bebchuk, L. A. (1984). Litigation and Settlement Under Imperfect Information. The RAND Journal of Economics, 404-415.

Becker, G. (1968). Crime and Punishment: An Economic Approach. The Journal of Political Economy, 169, 176-177.

Bedard, K., \& Helland, E. (2004). The Location of Women's Prisons and the Deterrence Effect of "Harder" Time. International Review of Law and Economics, 24(2), 147-167.

Bell, B., Jaitman, L., \& Machin, S. (2014). Crime Deterrence: Evidence from the London 2011 Riots. The Economic Journal, 124(576), 480-506.

Bellemare, M. F., \& Wichman, C. J. (2020). Elasticities and the Inverse Hyperbolic Sine Transformation. Oxford Bulletin of Economics and Statistics, 82(1), 50-61.

Berdejó, C., \& Yuchtman, N. (2013). Crime, Punishment, and Politics: An Analysis of Political Cycles in Criminal Sentencing. Review of Economics and Statistics, 95(3), 741-756.

Bernasco, W., \& van Dijke, R. (2020). Do Offenders Avoid Offending Near home? A Systematic Review of the Buffer Zone Hypothesis. Crime Science, 9, 1-10.

Besser, T. L., \& Hanson, M. M. (2016). Development of Last Resort: The Impact of New State Prisons on Small Town Economies in the United States. Community Economic Development, 
73.

Bibas, S. (2004). Plea Bargaining Outside the Shadow of Trial. Harvard Law Review, 2463-2547.

Bindler, A., \& Hjalmarsson, R. (2018). How Punishment Severity Affects Jury Verdicts: Evidence from Two Natural Experiments. American Economic Journal: Economic Policy, 10(4), 3678.

Bjerk, D. (2007). Guilt Shall Not Escape or Innocence Suffer? The Limits of Plea Bargaining When Defendant Guilt is Uncertain. American Law and Economics Review, 9(2), 305-329.

Blankenship, S. E., \& Yanarella, E. J. (2004). Prison Recruitment as a Policy Tool of Local Economic Development: A Critical Evaluation. Contemporary Justice Review, 7(2), 183-198.

Bonneau, D., \& McCannon, B. C. (2019). Bargaining in the Shadow of the Trial? Deaths of Law Enforcement Officials and the Plea Bargaining Process. Working Paper.

Bowers, K. J., \& Johnson, S. D. (2003). Measuring the Geographical Displacement and Diffusion of Benefit Effects of Crime Prevention Activity. Journal of Quantitative Criminology, 19(3), $275-301$.

Boylan, R. T. (2005). What do Prosecutors Maximize? Evidence from the Careers of US Attorneys. American Law and Economics Review, 7(2), 379-402.

Boylan, R. T. (2012). The Effect of Punishment Severity on Plea Bargaining. The Journal of Law and Economics, 55(3), 565-591.

Breen, P. D. (2011). The Trial Penalty and Jury Sentencing: A Study of Air Force Courts-Martial. Journal of Empirical Legal Studies, 8(1), 206-235.

Burbidge, J. B., Magee, L., \& Robb, A. L. (1988). Alternative Transformations to Handle Extreme Values of the Dependent Variable. Journal of the American Statistical Association, 83(401), $123-127$.

Bushway, S. D., Owens, E. G., \& Piehl, A. M. (2012). Sentencing Guidelines and Judicial Discretion: Quasi-Experimental Evidence from Human Calculation Errors. Journal of Empirical Legal Studies, 9(2), 291-319.

Bushway, S. D., \& Redlich, A. D. (2012). Is Plea Bargaining in the "Shadow of the Trial" a Mirage? Journal of Quantitative Criminology, 28(3), 437-454.

Bushway, S. D., Redlich, A. D., \& Norris, R. J. (2014). An Explicit Test of Plea Bargaining in the "Shadow of the Trial". Criminology, 52(4), 723-754.

Cameron, A. C., \& Miller, D. L. (2015). A Practitioner's Guide to Cluster-Robust Inference. Journal of Human Resources, 50(2), 317-372.

Carlson, K. A. (1991). What Happens and What Counts: Resident Assessments of Prison Impacts on Their Communities. Humboldt Journal of Social Relations, 17(1/2), 211-237.

Chen, D. L., Moskowitz, T. J., \& Shue, K. (2016). Decision Making Under the Gambler's Fallacy: Evidence from Asylum Judges, Loan Officers, and Baseball Umpires. The Quarterly Journal of Economics, 131(3), 1181-1242.

Chen, D. L., \& Philippe, A. (2017). Clash of Norms Judicial Leniency on Defendant Birthdays. Institute for Advanced Study in Toulouse/Toulouse School of Economics.

Cheng, C., \& Long, W. (2018). Improving Police Services: Evidence From the French Quarter Task Force. Journal of Public Economics, 164, 1-18.

Circo, G., \& McGarrell, E. (2020). Estimating the Impact of an Integrated CCTV Program on Crime. Journal of Experimental Criminology, 1-22. 
Cooter, R., Marks, S., \& Mnookin, R. (1982). Bargaining in the Shadow of the Law: A Testable Model of Strategic Behavior. The Journal of Legal Studies, 11(2), 225-251.

Cragg, J. G. (1971). Some Statistical Models for Limited Dependent Variables with Application to the Demand for Durable Goods. Econometrica: Journal of the Econometric Society, 829-844.

Cui, L., \& Walsh, R. (2015). Foreclosure, Vacancy and Crime. Journal of Urban Economics, 87, $72-84$.

Cunningham, S., \& Kang, S. (2018). Incapacitating Drug Users: Evidence from Prison Construction. Working Paper.

Danziger, S., Levav, J., \& Avnaim-Pesso, L. (2011). Extraneous Factors in Judicial Decisions. Proceedings of the National Academy of Sciences, 108(17), 6889-6892.

Daughety, A. F., \& Reinganum, J. F. (2018). Evidence Suppression by Prosecutors: Violations of the Brady Rule. The Journal of Law, Economics, and Organization, 34(3), 475-510.

Deck, C. A., \& Farmer, A. (2007). Bargaining Over an Uncertain Value: Arbitration Mechanisms Compared. The Journal of Law, Economics, \& Organization, $23(3), 547-579$.

Dippel, C., \& Poyker, M. (2019). How Common are Electoral Cycles in Criminal Sentencing? NBER Working Paper 25716.

Dippel, C., \& Poyker, M. (2020). Do Private Prisons Affect Criminal Sentencing? NBER Working Paper 25715.

Di Tella, R., \& Schargrodsky, E. (2004). Do Police Reduce Crime? Estimates Using the Allocation of Police Forces After a Terrorist Attack. American Economic Review, 94 (1), 115-133.

Dobbie, W., Goldin, J., \& Yang, C. S. (2018). The Effects of Pretrial Detention on Conviction, Future Crime, and Employment: Evidence from Randomly Assigned Judges. American Economic Review, 108(2), 201-40.

Draca, M., Machin, S., \& Witt, R. (2011). Panic on the Streets of London: Police, Crime, and the July 2005 Terror Attacks. American Economic Review, 101(5), 2157-81.

Eason, J. M. (2017). Prisons as Panacea or Pariah? The Countervailing Consequences of the Prison Boom on the Political Economy of Rural Towns. Social Sciences, 6(1), 7.

Eren, O., \& Mocan, N. (2018). Emotional Judges and Unlucky Juveniles. American Economic Journal: Applied Economics, 10(3), 171-205.

Farmer, A., \& Pecorino, P. (1994). Pretrial Negotiations with Asymmetric Information on Risk Preferences. International Review of Law and Economics, 14 (3), 273-281.

Farmer, A., \& Pecorino, P. (2002). Pretrial Bargaining with Self-Serving Bias and Asymmetric Information. Journal of Economic Behavior \&3 Organization, 48(2), 163-176.

Farmer, A., \& Pecorino, P. (2010). Pretrial Bargaining with Asymmetric Information: Unilateral Versus Bilateral Payoff Relevance. Southern Economic Journal, 77(2), 369-384.

FLDOC. (2018). Annual Report. Accessed at: http://www.dc.state.fl.us/pub/annual/1617/FDC $C_{A} R 2016-$ 17.pdf.

Gay, G. D., Grace, M. F., Kale, J. R., \& Noe, T. H. (1989). Noisy Juries and the Choice of Trial Mode in a Sequential Signalling game: Theory and Evidence. The Rand Journal of Economics, $196-213$.

Glaeser, E. L., \& Sacerdote, B. (1999). Why is There More Crime in Cities? Journal of political economy, 107(S6), S225-S258.

Glasmeier, A. K., \& Farrigan, T. (2007). The Economic Impacts of the Prison Development Boom 
on Persistently Poor Rural Places. International Regional Science Review, 30(3), 274-299.

Goodman-Bacon, A. (2018). Difference-in-Differences with Variation in Treatment Timing. NBER Working Paper 25018.

Gordon, S. C., \& Huber, G. (2007). The Effect of Electoral Competitiveness on Incumbent Behavior. Quarterly Journal of Political Science, 2(2), 107-138.

Gould, J. P. (1973). The Economics of Legal Conflicts. The Journal of Legal Studies, 2(2), 279-300.

Grossman, G. M., \& Katz, M. L. (1983). Plea Bargaining and Social Welfare. The American Economic Review, 73(4), 749-757.

Hall, D. B. (2000). Zero-Inflated Poisson and Binomial Regression with Random Effects: A Case Study. Biometrics, 56(4), 1030-1039.

Hall, M. G., \& Bonneau, C. W. (2006). Does Quality matter? Challengers in State Supreme Court Elections. American Journal of Political Science, 50(1), 20-33.

Helland, E., \& Tabarrok, A. (2003). Race, poverty, and American Tort Awards: Evidence from Three Data Sets. The journal of legal studies, 32(1), 27-58.

Kaeble, D., \& Cowhig, M. (2018). Correctional Populations in the United States, 2016. Bureau of Justice Statistics.

King, R. S., Mauer, M., \& Huling, T. (2003). Big Prisons, Small Towns: Prison Economics in Rural America. Sentencing Project Washington, DC.

Klick, J., \& Tabarrok, A. (2005). Using Terror Alert Levels to Estimate the Effect of Police on Crime. The Journal of Law and Economics, 48(1), 267-279.

Koper, C. S. (1995). Just Enough Police Presence: Reducing Crime and Disorderly Behavior by Optimizing Patrol Time in Crime Hot Spots. Justice Quarterly, 12(4), 649-672.

LaCasse, C., \& Payne, A. A. (1999). Federal Sentencing Guidelines and Mandatory Minimum Sentences: Do Defendants Bargain in the Shadow of the Judge? The Journal of Law and Economics, 42(S1), 245-270.

Lambert, D. (1992). Zero-Inflated Poisson Regression, with an Application to Defects in Manufacturing. Technometrics, 34(1), 1-14.

Landes, W. M. (1971). An Economic Analysis of the Courts. The Journal of Law and Economics, $14(1), 61-107$.

Levitt, S. D. (1996). The Effect of Prison Population Size on Crime Rates: Evidence from Prison Overcrowding Litigation. The quarterly journal of economics, 111(2), 319-351.

Lim, C. S., \& Snyder Jr, J. M. (2015). Is More Information Always Better? Party Cues and Candidate Quality in US Judicial Elections. Journal of public Economics, 128, 107-123.

Lim, C. S., Snyder Jr, J. M., \& Strömberg, D. (2015). The Judge, the Politician, and the Press: Newspaper Coverage and Criminal Sentencing Across Electoral Systems. American Economic Journal: Applied Economics, 7(4), 103-35.

Lin, M.-J. (2009). More Police, Less Crime: Evidence From US State Data. International Review of Law and Economics, 29(2), 73-80.

Linden, L., \& Rockoff, J. E. (2008). Estimates of the Impact of Crime Risk on Property Values from Megan's Laws. American Economic Review, 98(3), 1103-27.

Marselli, R., McCannon, B. C., \& Vannini, M. (2015). Bargaining in the Shadow of Arbitration. Journal of Economic Behavior $\&$ Organization, 117, 356-368. 
McCannon, B. C. (2013). Prosecutor Elections, Mistakes, and Appeals. Journal of Empirical Legal Studies, 10(4), 696-714.

McCannon, B. C. (2018). Debundling Accountability: Prosecutor and Public Defender Elections in Florida. Working Paper.

McCannon, B. C. (2019). Prosecutors and Plea Bargains. In V. A. Edkins \& A. D. Redlich (Eds.), A System of Pleas: Social Science's Contributions to the Real Legal System (pp. 56-79). Oxford University Press New York, NY.

McMillen, D., Sarmiento-Barbieri, I., \& Singh, R. (2019). Do More Eyes on the Street Reduce Crime? Evidence from Chicago's Safe Passage Program. Journal of Urban Economics, 110, $1-25$.

Mnookin, R. H., \& Kornhauser, L. (1979). Bargaining in the Shadow of the Law: The Case of Divorce. The Yale Law Journal, 88(5), 950-997.

Mustard, D. B. (2001). Racial, Ethnic, and Gender Disparities in Sentencing: Evidence from the US Federal Courts. The Journal of Law and Economics, 44(1), 285-314.

Philippe, A., \& Ouss, A. (2018). "no Hatred or Malice, Fear or Affection": Media and Sentencing. Journal of Political Economy, 126(5), 2134-2178.

Piza, E. L., Welsh, B. C., Farrington, D. P., \& Thomas, A. L. (2019). Cctv Surveillance for Crime Prevention: A 40-year Systematic Review with Meta-Analysis. Criminology 83 Public Policy, 18(1), 135-159.

Posner, R. A. (1973). An Economic Approach to Legal Procedure and Judicial Administration. The Journal of Legal Studies, 2(2), 399-458.

Priest, G. L., \& Klein, B. (1984). The Selection of Disputes for Litigation. The Journal of Legal Studies, 13(1), 1-55.

Project, D. C. T. (2019). A Critical Summary of Detroit's Project Green Light and its Greater Context (Tech. Rep.).

Ratcliffe, J. H., \& Breen, C. (2011). Crime Diffusion and Displacement: Measuring the Side Effects of Police Operations. The Professional Geographer, 63(2), 230-243.

Rehavi, M. M., \& Starr, S. B. (2014). Racial Disparity in Federal Criminal Sentences. Journal of Political Economy, 122(6), 1320-1354.

Reinganum, J. F. (1988). Plea Bargaining and Prosecutorial Discretion. The American Economic Review, 713-728.

Reinganum, J. F. (2000). Sentencing Guidelines, Judicial Discretion, and Plea Bargaining. The RAND Journal of Economics, 62-81.

Reinganum, J. F., \& Wilde, L. L. (1986). Settlement, Litigation, and the Allocation of Litigation Costs. The RAND Journal of Economics, 557-566.

Roach, M. A. (2014). Indigent Defense Counsel, Attorney Quality, and Defendant Outcomes. American Law and Economics Review, 16(2), 577-619.

Rosenfeld, R., Deckard, M. J., \& Blackburn, E. (2014). The Effects of Directed Patrol and SelfInitiated Enforcement on Firearm Violence: A Randomized Controlled Study of Hot Spot Policing. Criminology, 52(3), 428-449.

Shavell, S. (1982). Suit, Settlement, and Trial: A Theoretical Analysis Under Alternative Methods for the Allocation of Legal Costs. The Journal of Legal Studies, 11(1), 55-81.

Silveira, B. S. (2017). Bargaining with Asymmetric Information: An Empirical Study of Plea 
Negotiations. Econometrica, 85(2), 419-452.

Starr, S. B. (2015). Estimating Gender Disparities in Federal Criminal Cases. American Law and Economics Review, 17(1), 127-159.

Stephan, J. J. (2008). Census of State and Federal Correctional Facilities, 2005. Bureau of Justice Statistics.

Stevenson, M. T. (2018). Distortion of Justice: How the Inability to Pay Bail Affects Case Outcomes. The Journal of Law, Economics, and Organization, 34(4), 511-542.

Waples, S., Gill, M., \& Fisher, P. (2009). Does CCTV Displace Crime? Criminology \& Criminal Justice, 9(2), 207-224.

Weisburd, S. (2016). Police Presence, Rapid Response Rates, and Crime Prevention. Review of Economics and Statistics, 1-45.

Welsh, B. C., \& Farrington, D. P. (2009). Public Area CCTV and Crime Prevention: An Updated Systematic Review and Meta-Analysis. Justice Quarterly, 26(4), 716-745.

Yang, D. (2008). Can Enforcement Backfire? Crime Displacement in the Context of Customs Reform in the Philippines. The Review of Economics and Statistics, 90(1), 1-14. 